\title{
IMAGINING 9/11: \\ BLOCKBUSTER HOLLYWOOD CINEMA \\ AS CULTURAL VIOLENCE
}

FROM 1996-2003

BY

BRADY HAMMOND

\begin{abstract}
A thesis
submitted to the Victoria University of

Wellington in fulfilment of the requirements for

the degree of Doctor of Philosophy
\end{abstract}

Victoria University of Wellington

(2011) 



\section{Abstract}

This thesis explores the relationship between blockbuster cinematic violence and its historical context in the period surrounding the events of September 11, 2001. It charts the trajectory of violence by showing that screen violence in successful blockbuster cinema responds to historical developments. Violence in this thesis is defined according to the tripartite definition of violence articulated by peace studies theorist Johan Galtung. In order to analyse the historical positioning of the violence in the blockbusters being analysed, tripartite violence has been fused with the diagnostic critique of cultural theorist Douglas Kellner, which "uses history to read texts and texts to read history" (Media 116). By synthesising the two theoretical frameworks in this way, the diagnostic critique becomes violencecalibrated, and can be readily deployed to discern the ways in which blockbuster screen violence engages with the historical context of the text. The texts analysed represent the top grossing film from each year from 1996 to 2003, a period selected for its political relationship to 9/11. The eight films analysed are: Independence Day, Titanic, Saving Private Ryan, Star Wars: Episode I- The Phantom Menace, Dr. Seuss' How the Grinch Stole Christmas, Harry Potter and the Sorcerer's Stone, Spider-Man, and The Lord of the Rings: Return of the King. This thesis shows that the films from the pre-9/11 period articulate a clear "dream" of a world that is defined in binary terms with a good Self in opposition to an evil Other that is always external. The trends found in the violent dreams begin to shift with The Grinch as the relationship between the Self and Other changes, but the transformation does not fully manifest itself until the post-9/11 period when the films are marked by paranoia stemming from the repeated appearance of an Other than can pass as the Self, and ultimately a Self that behaves like the Other. While the violence that is found in the pre-9/11 films "dreams" of the Bush response to $9 / 11$, the post-9/11 films ultimate envision a future that the War on Terror could not deliver. In the end, this thesis will develop a methodology that can be used to explore blockbuster cinematic violence in terms of the nuances that exist between the three types of violence Galtung articulates: direct, structural, and cultural. 



\section{Acknowledgements}

I am pleased to have this opportunity to thank everybody who has contributed to this thesis. To begin, I would like to thank my supervisors, Russell Campbell, Tim Groves, Liz Watkins, and especially Sean Redmond, who has provided invaluable guidance and advice throughout the dissertation process. I would also like to thank those who have helped me procure funding for this work through letters of reference and overall support, particularly Paula M. Cohen, Marnie Reed, and Suzie Young. I must also acknowledge the support of the Postgraduate Film Research Group at Victoria University of Wellington and other academics in the Wellington area, who have provided me with crucial feedback on this work. Along those lines, I would also like to thank Jan Morris for her continual overseas feedback as well as her proofreading assistance. Additionally I would like to thank my family for their multi-faceted support of this work and my career in general.

Lastly, I would like to thank Hollywood for making movies I love to hate and hate to love. 



\section{CONTENTS}

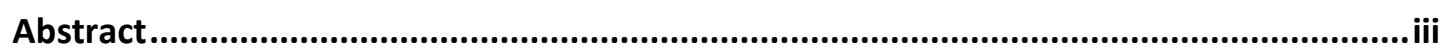

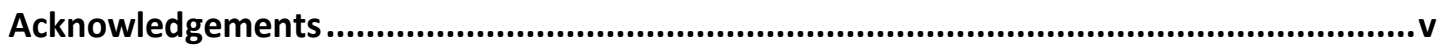

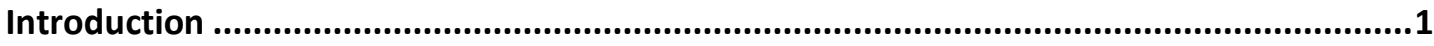

Chapter One: Patriotism Reborn: Independence Day (1996) ...............................................33

Post-War Blues: Identity Crisis in the United States .....................................................35

Flag Waving on the Moon: Patriotic Imagery in Independence Day ................................38

Technologies of Difference: Mapping Self and Other through technology......................41

The American Self: Structural Peace and Violence in Independence Day ........................45

Aliens and Arabs after 9/11: The Dreams of Independence Day .....................................52

Chapter Two: Adrift with the American Dream: Titanic (1997) ........................................57

Recession, Victory, and Resurgence: The US Economic Self in the 1990s.........................59

The American Way: Titanic and the American Dream .................................................64

Below the Surface: The Self and Other in Titanic …..................................................... 70

Shining in the Boiler Room: Whiteness on Titanic ..................................................... 74

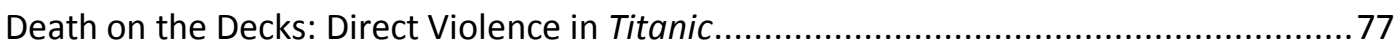

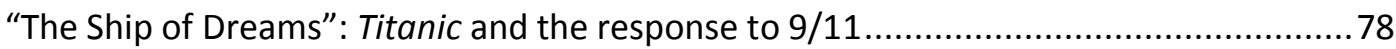

Chapter Three: Fighting the Good War Again: Saving Private Ryan (1998).......................83

Nation Without Other: The Post-Cold War US …............................................................ 85

The Mythic Self of the United States: American History in Saving Private Ryan ................89

The White Man's War: Ethnicity in Saving Private Ryan ..................................................93

The Secondary Other: Positioning the Jewish People in Saving Private Ryan ....................98

Mechanical Death: Technology and Direct Violence in Saving Private Ryan ..................102

A New Good War: Saving Private Ryan after 9/11 ..................................................106

Chapter Four:

Having Faith in Myth: Star Wars: Episode I - The Phantom Menace (1999)...................111

Crisis of Faith: Millennial Religion in the United States ...............................................113

"May the Force Be with You": The Religious Self in The Phantom Menace ....................117

Mythic Divisions: Defining the Self and Other in The Phantom Menace ........................125

Intergalactic Stereotypes: Race and The Phantom Menace ….....................................130

Faith and Terrorism: Fighting The Phantom Menace after 9/11 ................................135 
Chapter Five: Insidious Acceptance in the New Millennium

Dr. Seuss' How the Grinch Stole Christmas (2000)....................................................... 139

Religion and Family in the Millennial United States ................................................. 142

"Where is Christmas": Faith and Materialism in The Grinch ....................................... 145

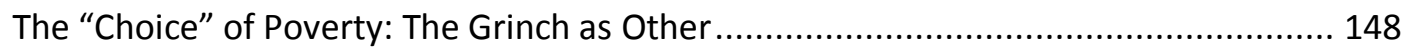

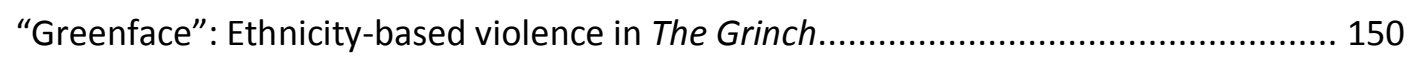

Taming as Conversion: Structural Violence in The Grinch ......................................... 157

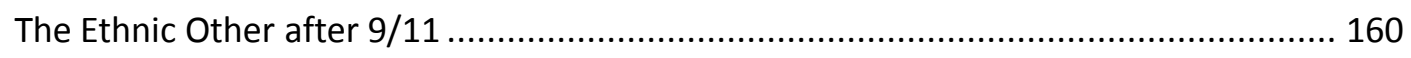

Chapter Six: A Paranoid Turn for a New Crusade

Harry Potter and the Sorcerer's Stone (2001)............................................................. 163

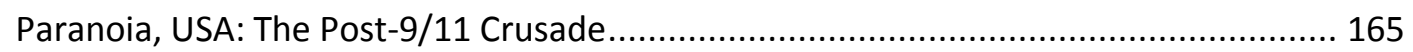

Mythic Beginnings: The Violence of Plot in The Sorcerer's Stone ................................ 170

The False Villain: Structural violence in The Sorcerer's Stone ...................................... 174

The Unilateral Wizard: The Bush Doctrine and The Sorcerer's Stone ............................ 181

Chapter Seven: Atoning for Sins Past: Spider-Man (2002) ............................................... 185

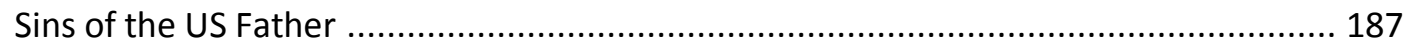

Old Glory: Patriotism, Self, and Other in Spider-Man ............................................. 191

Eternal Vigilance: Spider-Man, Atonement, and Presidential Doctrines ....................... 198

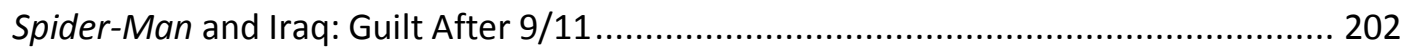

Chapter Eight: The Failure of the King

The Lord of the Rings: The Return of the King (2003) ...................................................... 207

Pax Americana: Planning for a New World Order .................................................... 210

Becoming like "them": Heroes, Villains, and the Self and Other ................................. 215

"The Days of the Kings": Structural Violence as victory in The Return of the King ......... 220

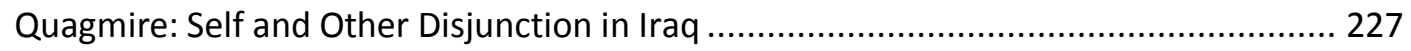

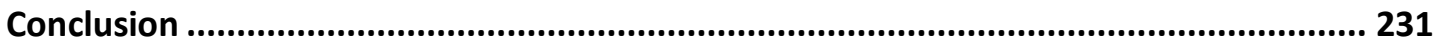

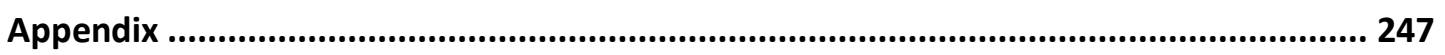

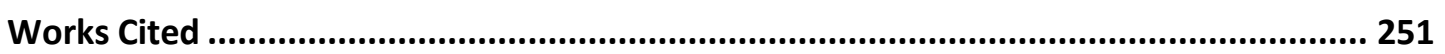

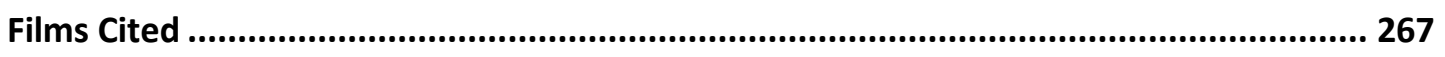




\section{List of Illustrations}

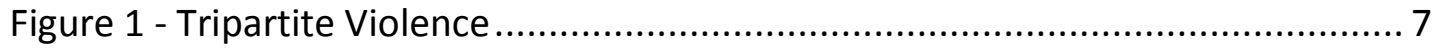

Figure 2 - The Strata of Violence ................................................................. 8

Figure 3 - The dominance of the United States in the opening of Independence Day

Figure 4 - Spano (Margaret Colin) visually dominating male aides in Independence

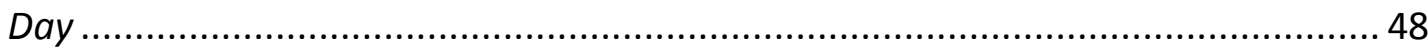

Figure 5 - The luminous white elite set apart from the darker masses in Titanic .... 65

Figure 6 - The white Rose embarking on the American Dream in Titanic ................ 76

Figure 7 - Production and setting of Saving Private Ryan in relation to Victory

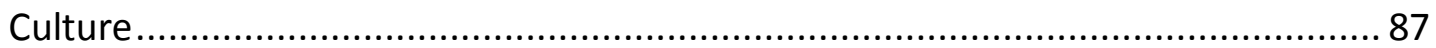

Figure 8 - The opening and closing image of Saving Private Ryan ......................... 91

Figure 9 - The Self, Other, and Secondary Other of Saving Private Ryan ................ 101

Figure 10 - The Nazi techno-human killing American soldiers in Saving Private Ryan

Figure 11 - The Self, Other, and Secondary Other in the Iraq Invasion .................. 108

Figure 12 - The post-Cold War fragmentation of the religious Self in the United

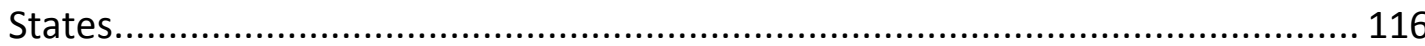

Figure 13 - Belief and Narrative Importance in relation to the Self/Other binary.. 121

Figure 14 - The Secondary Other in The Phantom Menace ................................. 123

Figure 15 - Stereotype reactivated with Binks stealing "chicken" in The Phantom

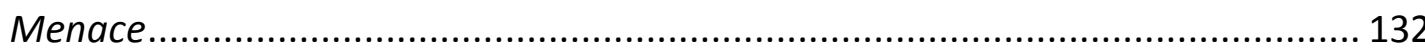

Figure 16 - Fighting stereotypes with direct violence in The Phantom Menace..... 134

Figure 17 - Superficial normalisation of the Grinch through redecoration of his cave

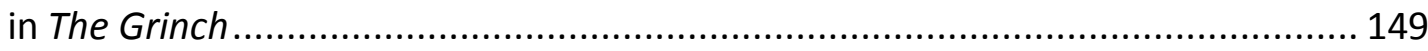

Figure 18 - The sexualised Martha May in The Grinch ....................................... 154

Figure 19 - The Grinch throwing himself before the law, and the Self in The Grinch 159

Figure 20 - Severus Snape under suspicion in The Sorcerer's Stone ..................... 173

Figure 21 - Quirinus Quirrell, the actual villain of The Sorcerer's Stone ................. 178

Figure 22 - New glory and Old Glory: the final moments of Spider-Man ............... 193

Figure 23 - The techno-terror of Spider-Man ..................................................... 196

Figure 24 - Main characters on Self/Other spectrum........................................ 219

Figure 25 - Main characters on Hero/Villain spectrum ........................................ 220

Figure 26 - "The Days of the King" in Return of the King .................................... 221

Figure 27 - The White Rider in battle in Return of the King ................................ 224

Figure 28 - Frodo darkened as corruption nears in Return of the King ................... 226

Figure 29 - Tripartite Violence redux ................................................................. 235 


\section{List of Tables}

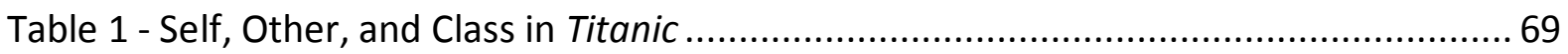

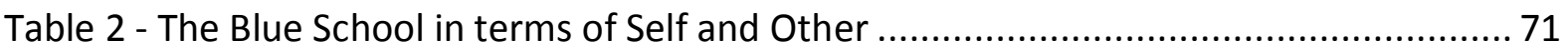

Table 3 - Humans and Aliens sorted in Good/Bad alignments....................................... 127

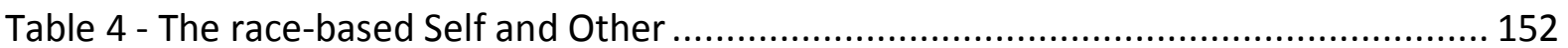

Table 5- Traits of the Grinch as Rejected Other versus the Grinch as Accepted Other ....... 158

Table 6 - Division of Proppian character spheres along Self/Other boundary ................... 172

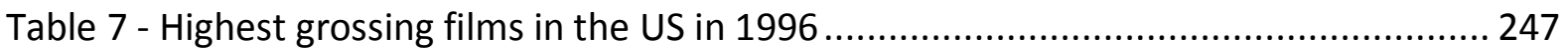

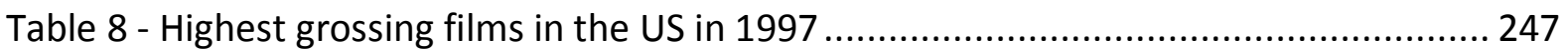

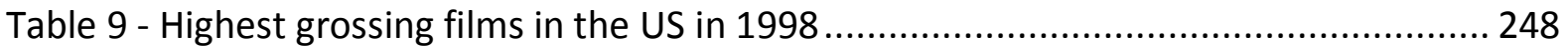

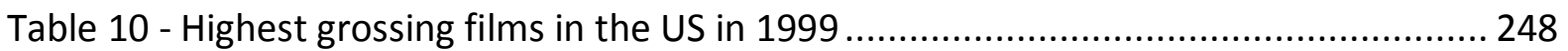

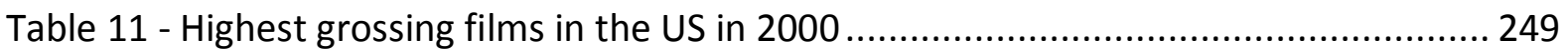

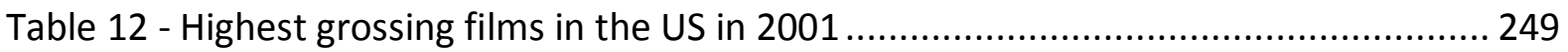

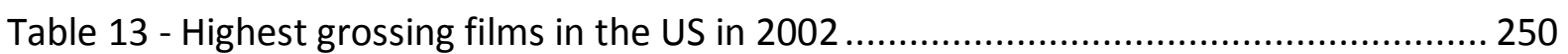

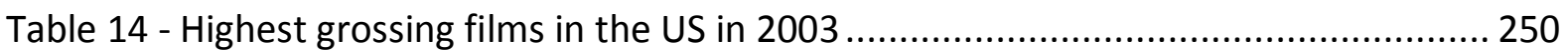




\section{Introduction}

\section{Wishing for "A New Day of Infamy"}

On the evening of September 11, 2001, homes across the United States were bathed in a phantasmagorical glow as people watched the continual coverage of the terrorist attacks that had occurred that morning. The attacks themselves - the hijacking of four commercial airliners, three of which were then intentionally crashed into iconic buildings in New York City and Washington, D.C. - brought the nation to a standstill. On that day, on television, on the radio, on the Internet, and in print, images and sounds of the planes striking the World Trade Center towers in New York City were presented again and again; all regular programming was cancelled. The only footage that rivalled the initial attacks in terms of airtime was that of the twin towers, with smoke billowing across the skyline, ultimately collapsing again and again. These images and the nearly endless media attention and analysis that accompanied it seemed to signal the vulnerability of the United States, but did so in a way that made it seem entirely unpredictable; the attacks seemed to come out of nowhere.

In the days after the attacks of September 11, 2001, newspapers across the United States were emblazoned with headlines that spoke of the shock that resonated throughout the nation. Newsday, for instance, bore the headline "America Attacked" ("Extra” n. pag.), whilst The San Francisco Chronicle read "War Against America" ("War" n. pag.), and wrote about "gut-punch effect on this country's sense of security" ("War" n. pag.). The shock evident in US headlines and stories stemmed largely from the fact that the attacks were not committed abroad, but on US soil. For decades the wars of the United States were external. Although images of those wars could be seen across all media, the familiar forms of the US military and its soldiers were dislocated geographically; the locales were always foreignthe Middle East, Latin America, Africa, Europe, Asia and more. The shock of September 11 came from the collapse of that safe distance. The backdrop of war was suddenly the hallowed New York City skyline with the absence of the twin towers standing as a testament to the wound the nation suffered in the attack. 
In the days and months following September 11, 2001, many discussed how the attacks of that day could not have been foreseen. On September 12, 2001, for instance, The Boston Globe bore a headline reading "A New Day of Infamy" (Zukoff \& Brellis), linking 9/11 to the attack on Pearl Harbor in World War II. President George W. Bush reinforced the point on September 20, 2001, when he referred to the events of $9 / 11$ as "surprise attacks" ("Transcript" n. pag.). A similarly forceful statement regarding the surprising nature of the attacks came over a year later on October 1, 2002, when Paul Wolfowitz, the Deputy Secretary of Defense, made the following remarks:

"Although September $11^{\text {th }}$ has taken its place alongside December 7th as a date that will live in infamy, the larger lesson we may draw from these attacks, remains unchanged and clear: we must be prepared for surprise-from wherever it may appear and however it may threaten" (n. pag.).

However, as many, such as Chalmers Johnson and Noam Chomsky (Hegemony), have subsequently shown, a review of American foreign policy suggests an event such as 9/11 was not only possible, but was quite probable-the spectre of US foreign policy inevitably returning to home soil. Such authors argue that the attacks were not as surprising as they seemed. For some, such as Bill Schaffer and Jean Baudrillard, the visual imagery of the attacks was not unfamiliar either.

In the immediate wake of 9/11, Bill Schaffer suggested that the experience of watching the disaster was "like a movie" (n.pag.) linking the destruction of the attacks to countless cinematic antecedents ranging from First Blood to Charlie's Angels. Schaffer even draws direct connections between the falling towers and the collapsing buildings that populate so many blockbuster films. He takes these parallels further, though, when he suggests that

"It seems very possible that the shape of the act itself, if not the desire to commit it, may have been inspired at least partly by such conspicuously destructive, internationally distributed American films as Independence Day, and Fight Club" (n. pag.). 
This "video causality" (n.pag.), as Shaffer refers to it, points to the fact that film violence potentially had a part to play in terrorists formulating the attacks in the first place. In that way, Schaffer suggests that Hollywood can be seen as having indirectly foreseen the events of 9/11 through its rampant destruction of urban landscapes, even if it did not cause them outright. It is the images of the collapsed cityscapes, however, that theorist Jean Baudrillard draws together in his formulation of a more provocative connection between cinema and 9/11.

Writing about the attacks of 9/11, Baudrillard argues that before $9 / 11$, the American system was reaching a state of omnipotence. The closer it came to this supreme state, the more its death was desired by the world, including its own population. For him, "the increase in the power of power heightens the will to destroy it" (6-7), and the "The West, in the position of God (divine omnipotence and absolute moral legitimacy), has become suicidal, and declared war on itself" (7). Thus, even though he, as a French writer, observes that "we can say that they did it, but we wished for it" (emphasis in original) (5), the fact that he inscribes it within the matrix of suicide suggests that the United States "wished for" its own demise. Returning to images of cities destroyed, Baudrillard supports his point by drawing on the disaster films of the 1990s, writing that "the countless disaster movies bear witness to this fantasy" (7) suggesting that in those films are dreams of the destruction that arrived on September 11, 2001. Yet by building upon the work of Baudrillard and looking at the wishes found in the larger body of films that draw upon the aesthetic of blockbuster American cinema, which all the disaster films Baudrillard alludes to do, the details of the connections between US cinema from that period and 9/11 are revealed to be far more nuanced than a simple wish for (suicidal) destruction. This can be seen in an examination of the central conflicts found in blockbuster American cinema, which pit good versus evil; the Self is positioned against the Other. It is in the ways that this opposition is constructed that the wishes of the films can be found. Thus, while Baudrillard develops the concept of the "spirit of terrorism," as he calls it, this thesis will look instead at the ways in which inflections of the Self/Other binary in films preceding and following 9/11 wished not just for destruction, but for the return of an heroic identity for the 
United States itself, an identity which had vanished in the wake of the Cold War. In order to chart this relationship, the Self and Other will be examined in much greater detail, and this will be accomplished through an analysis of the violence that exists between them. This will necessarily involve using a comprehensive definition of violence that extends beyond the physical.

Accordingly, this thesis sets out to achieve two tasks. The first is to analyse the violence in blockbuster cinema surrounding $9 / 11$ to see how it articulates wishes and anxieties from both the pre- and post-9/11 periods. Specifically, it will use an expanded definition of violence articulated by peace studies theorist Johan Galtung to explore the ways in which the violence of blockbuster cinema, both leading up to and following $9 / 11$, functioned to legitimise the violence inherent in the response articulated by the Bush administration. Following the definition of violence Galtung creates, this analysis will necessarily involve different types of violence, both visible and invisible. It is important to note, however, that this process will not suggest causality between media representations of violence and acts of violence. Instead, this analysis will show how a major act of real-world violence-the attacks of 9/11-harmonised with the wishes and dreams articulated in blockbuster cinematic violence that preceded it. At the same time, though, the analysis will show how the response to $9 / 11$ ultimately diverged from the dreams spelled out by violence in post-9/11 blockbuster cinema. Building upon this, the second task this thesis will accomplish is the establishment of a methodology that permits the elucidation of the relationship between blockbuster cinema, violence as defined by Galtung, and historical context. Otherwise stated, this thesis will develop a method that permits blockbuster cinema to serve as a type of barometer that can be utilised to gauge the violence that is sanctioned in blockbuster cinema at a larger cultural level. The first task, then, serves as a case study of sorts for the second. The first will be explored in the main body of the thesis, while the second will be implicitly developed throughout, and overtly in the Conclusion. To begin to understand how the thesis will accomplish this work, it is necessary to first define violence, and for that, a broader understanding of the ways in which violence has previously been treated in various disciplines is needed. 


\section{Defining Violence}

The traditional understanding of violence is that it is a physical phenomenon. Violence is often understood as the domain of the fist fight or open warfare, but that understanding of violence excludes a number of important factors. For instance, prejudice and violence frequently accompany one another, yet prejudice itself usually falls outside the definition of violence. For this thesis, a definition of violence is needed that not only links those two in an explicit fashion, but also clearly defines both, and so moves away from theories that frame it as a physical phenomenon, or that address it implicitly as part of larger treatises. This can be seen in the works of both Machiavelli and Hobbes, whose writings heavily engage with violence, but rarely, if ever, explore it on its own. What engagement with violence there is, however, treats it as a physical concept through either interpersonal conflict or large-scale warfare. As violence became a discrete object of study, its depth was slowly probed, and the notion of it as a solely physical act began to diminish. This can be seen in the distinct shift towards direct engagement with violence in the twentieth century with authors such as Walter Benjamin and Hannah Arendt who entered into a dialogue with previous authors. Arendt, for instance, responded to previous writing by authors such as Georg Wilhelm Friedrich Hegel, who saw violence legitimised by "social station" (80), Karl Marx, who Bhikhu Parekh observes has two positions on violence, one from the "moral or conventional point of view, and regrets it," and one "from the historical or species point of view, and fully approves of it," (113), and Frantz Fanon, whose positions Jean-Paul Sartre summed up in the preface to Wretched of the Earth, "In the first days of the revolt you must kill" (233). From this dialogue, Arendt was able to explore violence more fully as an individual subject. Her investigation supplemented violence with a variety of other concepts such as power and force, and showed that a discrete study of violence revealed a multi-facted, multi-layered concept that could not be easily explained or simply defined. Research in other disciplines has yielded similar findings.

In the field of psychology, for instance, while violence is often seen as a physical action, it is frequently paired with the concept of aggression, which spans non- 
physical actions and threats. Curt R. Bartol and Anne M. Bartol, for example, use psychology in criminological settings to describe violence as "destructive physical aggression intentionally directed at harming other persons or things" (emphasis in original) (146) with aggression defined as "behaviour perpetrated or attempted with the intention of harming another individual physically or psychologically (as opposed to socially) or to destroy an object" (emphasis in original) (145). Although violence is physical here, it is part of a larger matrix of harm.

In the field of peace studies, a definition of violence has been developed by Galtung that expands the nature of violence. It incorporates elements that Arendt introduces, such as power and force, and positions them within a much more robust formulation that simultaneously focuses on violence at multiple levels of society, essentially theorising violence into macro- and micro-levels ("Cultural"; Peace). For Galtung, this definition of violence provides a lens through which one can view the world; relationships of violence and peace connect everything. It is the definition of violence offered by Galtung that will form one of the key methodological elements of this thesis, and will necessarily need to be explored in much greater detail.

For Galtung, violence is a tripartite structure. As shown in Figure 1 (Peace), violence is divided into three types: direct, structural, and cultural. The three function as a dynamic set, with each vertex of the triangle feeding into the other two such that cultural violence informs direct and structural violence while direct violence can shape structural and cultural violence. What is more, Galtung argues that the absence of one or two points of the triangle but the presence of the remainder will result in the remanifestation of the absent forms of violence. As he terms it, "violence breeds violence" (Peace 7). Thus, if structural violence is present, but direct and cultural violence are absent, the structures of violence will ultimately reproduce direct and cultural violence. The triangle, though, reflects the argument that Galtung makes which is that violence, which he generally defines as "harming and/or hurting" (Peace 2), is not simply a matter of physical actions. 


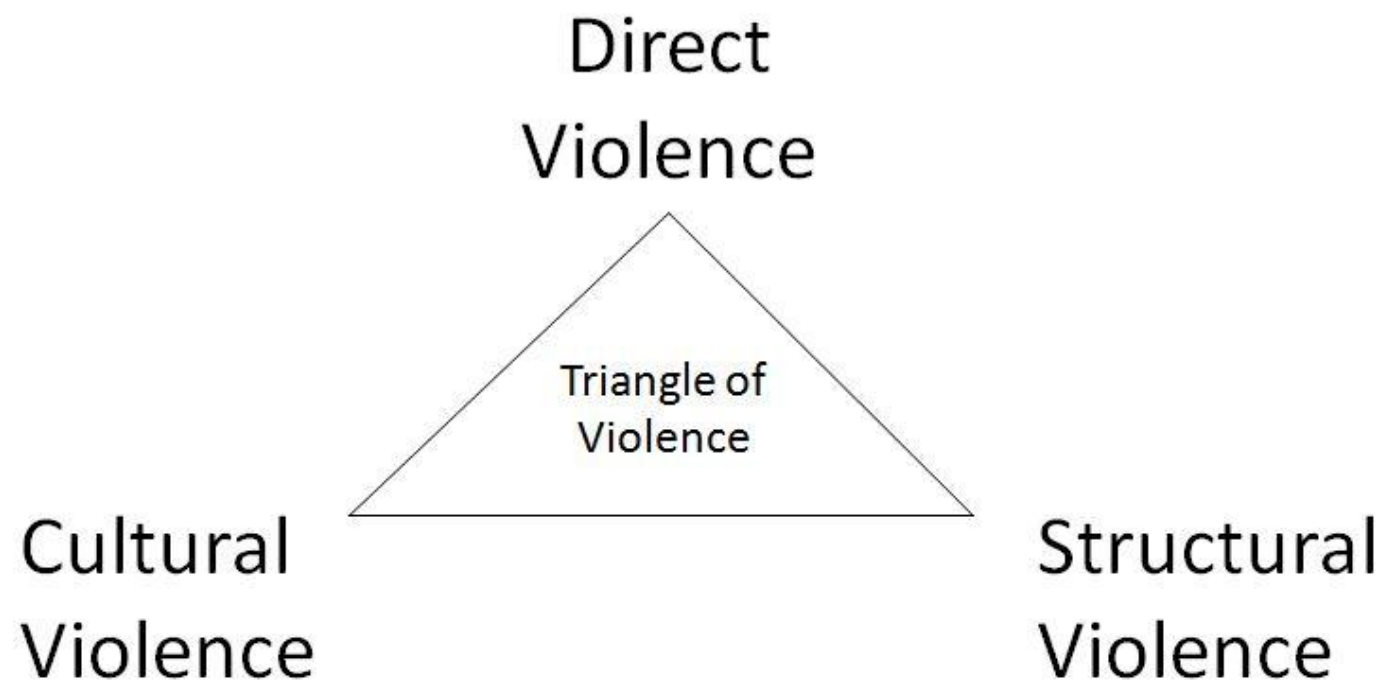

Figure 1 - Tripartite Violence

Direct violence is violence which transpires between what Galtung calls a "sender" or "actor" who intentionally directs violence at a receiver or receivers. So if a person physically strikes another, it would be direct violence. If there is no direct relationship between the sender and receiver, then it is indirect or structural violence, terms which Galtung uses synonymously. Structural violence "comes from the social structure itself" (Peace 2), and describes constructs which privilege some at the expense of others, such as racism or sexism. In this thesis, this violence will largely be explored in depictions of ethnicity, class, and gender. Lastly, cultural violence is "symbolic" violence "in religion and ideology, in language and art, in science and law, in media and education" that functions "to legitimize direct and structural violence" (Peace 2). A religious crusade, for instance, legitimises discrimination against a certain group (structural violence) which in turn legitimises physical attacks and war (direct violence). Violence, then, becomes the actions of one against another, directly or indirectly. Otherwise stated, violence is predicated upon the creation of a Self in opposition to an Other. To understand the relationship between the two, it is useful to consider another construction of violence that Galtung presents to accompany the triangle of violence, which is a "violence strata image" ("Cultural" 294), shown in Figure 2. 


\section{Strata of Violence}

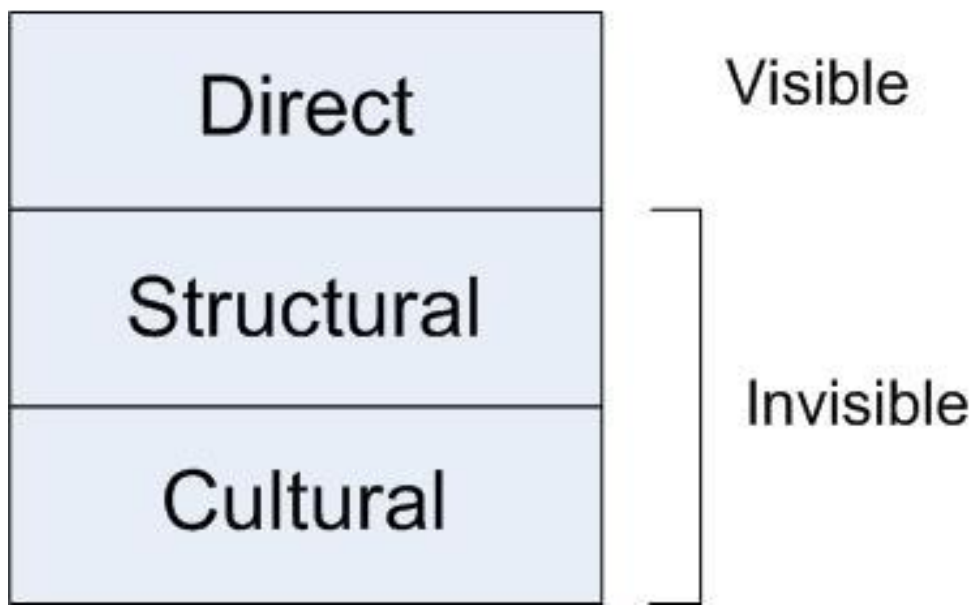

Figure 2 - The Strata of Violence

At the bottom of this image is cultural violence, "a substratum from which the other two can derive their nutrients" ("Cultural" 294). Above that is a stratum of structural violence where "patterns of exploitation are building up, wearing out, or torn down, with the protective accompaniment of penetration-segmentation preventing consciousness formation, and fragmentation-marginalisation preventing organization against exploitation and repression" ("Cultural" 294). Lastly, the highest stratum is direct violence which is plainly evident "to the unguided eye and to barefoot empiricism" ("Cultural" 294-295). As Galtung notes, "a causal flow from cultural via structural to direct violence can be identified" ("Cultural" 295). Borrowing from Hans Reudi Weber, he expands, writing:

"The culture preaches, teaches, admonishes, eggs on, and dulls us into seeing exploitation and/or repression as normal and natural, or into not seeing them (particularly not exploitation) at all. Then come the eruptions, the efforts to use direct violence to get out of the structural iron cage, and counter-violence to keep the cage intact" (“Cultural" 294).

In terms of Self and Other, structural and cultural violence essentially reinforce the separation of the two, while they both ultimately inform more immediate interactions between them in the form of direct violence. In looking at film, this 
thesis will primarily be dealing with "invisible" cultural violence, but it will focus on representations of all three types of violence in the films. Although other theorists have developed models of violence very similar to that which Galtung articulates, they are not as useful in this analysis as they are not as methodologically reproducible, and focus less on violence embedded within cultural artefacts.

Slavoj Žiżek, for instance, constructed a framework of violence that closely resembles that of Galtung. As with the tripartite form of violence Galtung defines, Žiżek extends violence beyond physicality, and separates it in binary terms such that there is subjective and objective violence (1-7). For him, subjective violence is violence that is visible while objective violence is invisible, and can be either symbolic or systemic. As he expounds upon this definition, it is clear that subjective violence correlates to direct violence while objective violence encompasses structural and cultural violence through its two subcategories. However, unlike Galtung, Ẑiziek approaches the subject in a less scientific fashion, which does allow him to shift between media representations of violence and real world violence with ease-a considerable strength-but the reasoning behind those transitions is not always clear. The result is an inconsistent methodological framework. More importantly, his analysis of the categories of violence he delineates does not develop symbolic violence as fully as it does other forms of violence. This is partially because his use of the term derives from the work of Pierre Bourdieu, who defines the term as "the gentle, invisible violence, which is never recognized as such, and is not so much undergone as chosen" (192). Interestingly, this is one of the forms of violence that Baudrillard discusses in relation to 9/11 (22). In a comparative analysis of Galtung and Bourdieu, Peter Imbusch observes the similarities between cultural violence and symbolic violence, but notes that while the former "is aimed at making other forms of violence appear just-or at least not unjust-and thus making them acceptable for society" (25), the latter is "the violence embodied in concepts, language, and systems of symbols aimed at obscuring, veiling and glossing over unspoken conditions of rule" (25). Thus while cultural violence has strong connections to other forms of violence, symbolic violence is viewed as an alternative to physical violence. As Bourdieu notes, 
"Gentle, hidden exploitation is the form taken by man's exploitation of man whenever overt, brutal exploitation is impossible" (192). Since this is an analysis of the culturally violence blockbuster cinema before and after $9 / 11$, it will necessarily connect that violence with both structural and direct violence, a connection that would not be present were symbolic violence to be used on its own.

Of course, this connection to the work of Bourdieu can easily be extended to the work of Louis Althusser on the ideological state apparatus and the repressive state apparatus, the latter of which he argues "functions by violence" (79), which can in turn be connected to later theories of violence which build on those concepts. While it is important to consider the various trajectories that can be traced from this discussion of Galtung and violence, it is important to not deviate too far from tripartite violence as it is that definition of violence which forms the key structural component of this thesis in its exploration of representations of blockbuster cinematic violence. Thus while Althusser builds upon Bourdieu, the concept of the state apparatuses is not useful in the present analysis. That having been said, a closer examination of cultural violence, as Galtung defines it, does bring it into direct engagement with other theorists that must be considered.

\section{Violence and Power}

To discuss the dimensions within which cultural violence works, Galtung suggests that "a concept broader than violence, and also broader than peace" (Peace 2) is needed, and argues that "Power is that concept" (emphasis in original) (Peace 2). For him, power, which he also refers to as discourse, can exist as one of four types: "cultural, economic, military, and political" (emphasis in original) (Peace 2). Galtung is clear that each of these "realms" affects the other three. He argues, though, that

"single acts of direct violence come out of structures of political decisions and economic transactions; and the latter cause each other. But underneath it all lurks culture; legitimizing some structures and acts, delegitimizing others" (Peace 2) 
Following that logic, while this thesis will be exploring representations of violence in all four dimensions, the grounding of the analysis in the cultural artefacts of cinema places it, at a meta-level, firmly within the cultural realm. Such a focus can help to address the ways in which culture makes violence of any type appear to be legitimate. However, the larger discussion that must be addressed at this point is the fact that Galtung sees violence as being subsumed within power.

As noted above, Arendt established connections between power and violence. For her,

"Power corresponds to the human ability not just to act but to act in concert. Power is never the property of an individual; it belongs to a group and remains in existence only so long as the group keeps together" (44)

While there are certainly some parallels to the work of Galtung here in that his definition of violence largely focuses on power relations, his precise use of that concept is more closely aligned with the work of Michel Foucault. In fact, because of the many parallels between the works of Foucault and Galtung, a discussion of Foucault is necessary here.

Despite the different lexicons Foucault and Galtung utilise, it is clear that what both write about with regard to power is dispersed mechanisms which are not located in any one central body. For Foucault, power "brings into play relations between individuals (or between groups)" ("The Subject" 337). Accordingly, it describes and permits the ways in which one acts towards another (or an Other) ("The Subject" 344). As he observes, "a relationship of confrontation reaches its term, its final moment (and the victory of one of the two adversaries) when stable mechanisms replace the free play of antagonistic reactions" ("The Subject" 346-347). Thus, "For a relationship of confrontation, from the moment it is not a struggle to the death, the fixing of a power relationship becomes a target" ("The Subject" 347). Galtung addresses the same concept, but by locating it within his tripartite definition of violence. 
For instance, in discussing slavery, Galtung notes that:

"Africans are captured, forced across the Atlantic to work as slaves; millions are killed in the process - in Africa, on board, in the Americas. This massive direct violence seeps down and sediments as massive structural violence, with whites as the master topdogs and blacks as the slave underdogs, producing and reproducing massive cultural violence with racist ideas everywhere. After some time, direct violence is forgotten, slavery is forgotten, and only two labels show up, pale enough for college textbooks: 'discrimination' for massive structural violence and 'prejudice' for massive cultural violence" ("Cultural" 295).

Thus while violence in Foucauldian terms would correspond to direct violence, power correlates to cultural and structural violence, as it is within those domains that discourse is formed. Given the broader similarities, though, it is unsurprising that Galtung, along with Richard C. Vincent, uses a definition of discourse-"a construct that accommodates thoughts" (US Glasnost 99)-that seems to largely derive from the work of Foucault.

For Foucault, discourse is formed through statements which themselves do not carry meaning, but function to produce meaning. When patterns of meaning emerge, dispersed, so to speak, across various sites, a "system of dispersion" emerges. Of this, Foucault remarks that

"Whenever one can describe, between a number of statements, such a system of dispersion, whenever, between objects, types of statement, concepts, or thematic choices, one can define a regularity (an order, correlations, positions and functionings, transformations), we will say, for the sake of convenience, that we are dealing with a discursive formation" (Archaeology 41)."

A discursive formation, then, is essentially a collection of discourses that, in a way, define the production of truth ("Truth" 119); for Foucault, this is related to power. 
It is important because in terms of tripartite violence, an analysis of cultural violence-assessing cinematic texts in terms of their representations of violence-is essentially the same as an elucidation of their power structures, in the Foucauldian sense. It is useful here to consider the notion of bio-power developed by Foucault and extended by Giorgio Agamben.

For Foucault, bio-power refers to "the administration of bodies and the calculated management of life" (History 140). While his observation that bio-power replaced the "old power of death" (History 139) indicates that bio-power could function in much the same way as the three types of violence Galtung identifies, the work by Agamben both extends and moves away from the more comprehensive definition of violence elucidated by Galtung. For Agamben, bio-power describes the essential politicisation of "bare life." As Agamben argues, 'it can even be said that the production of a biopolitical body is the original activity of sovereign power,' (Homo 6). Yet in this formulation of bio-power in relation to the sovereign, Agamben situates it within, to draw on Galtung, the political. Thus two impediments arise with regard to the use of the works of both Foucault and Agamben in this thesis. The first, particularly with regard to Agamben, is that his thinking analyses the political rather than the cultural. While they are intertwined with one another, the focus Agamben places on the political makes his methodology considerably less useful for an analysis of cultural artefacts. The second relates more directly to Foucault and can be seen in the writing of Galtung and Vincent, who deviate from the work of Foucault is when they suggest that a more complete study of discourse would involve real-world contexts (US Glasnost 136). ${ }^{1}$ Again, Agamben does offer such real-world contextual analysis, as he showed in his application of his theories of homo sacer and "bare life" to the policies of the Bush Administration, observing that they produced "a legally unnamable and unclassifiable being" (State 3). However, while Galtung and Vincent offer a medium between Foucault and Agamben-a discourse analysis that can focus on cultural discourses in addition to political-it is not tailored to specifically examine violence in entertainment media such as film. Since the aim of this thesis is to examine the violence in blockbuster

\footnotetext{
${ }^{1}$ For more on the way in which Galtung and Vincent define discourse, see US Glasnost.
} 
films as it relates to the historical moment of the films, it is useful to consider here the ways in which screen violence has previously been analysed with regard to history.

\section{Screen Violence and History}

For this thesis, a methodological framework is needed that engages with history and either uses the more robust definition of violence Galtung articulates or is able to accommodate his work. In many traditional studies of screen violence, historical connections are made, but they are frequently predicated upon violence as a physical phenomenon. This is often a good thing, though, as some of the most useful studies of screen violence focus predominantly on the term as a physical concept, despite their vastly different approaches to the subject. For instance, J. David Slocum, in his insightful analysis of film violence and its connection to New Hollywood and the historical moment of "the Sixties" ("The Film" 15-17), reaches his conclusions using a definition of film violence that sees it as "images of bodily harm, pain and death, and the deployment of rough or injurious physical force" ("The Film" 28). Similarly, in a thorough study that draws connections between violence and narrative, Nick Brown et al define film violence as "an interpersonal, aggressive physical act that impacts another character, committed by a human agent in the course of a conflict" (352). This emphasis on the physical is even seen in more personal approaches to the subject, such as the one conducted by Vivian Sobchack, where she observes that film violence in the 1970 s

\footnotetext{
"literally satisfied an intensified cultural desire for 'close-up' knowledge about the material fragility of bodies, but also-and more important-made increasingly senseless violence in the 'civil' sphere sensible and meaningful by stylizing and aestheticizing it" (“The Violent" 119).
}

While she somewhat revises her opinion in her afterword to the original article ("The Violent" 124), her discussion of violence remains grounded in the physical act of harm. Even studies which specifically focus on the historical period this thesis examines-9/11-look at physical violence, as is the case with the excellent analysis 
of screen violence Gabrielle Murray has conducted which shows how images of torture in film relate to post-9/11 events such as the Abu Ghraib scandal (3-4). James Kendrick observes that screen violence research has also focused on the aesthetic dimensions of violence, with Stephen Prince being a key figure here as he created a relationship between "stylistic and behavioral components of film violence" (33). For Prince, though, it is "graphic violence" - direct violence-which remains his focus (1-4). While studies such as these provide diverse insights into the relationship between direct violence and history, they do not engage with all the types of violence that Galtung identifies and the Self/Other relationships they articulate. Some studies, do, however, probe beyond direct violence.

In constructing a history of screen violence research, James Kendrick observes that many definitions of violence are quite broad (8-10). For instance, Kendrick notes of the Cultural Indicators project developed by George Gerbner, Larry Gross, Marilyn Jackson-Beeck, Suzanne Jeffries-Fox and Nancy Signorielli that it "has used the broadest of definitions" for violence (Kendrick 9). In one of the most recent iterations of the project, the authors define violence as "a social relationship" (5) although they still tie this directly a more physical notion of "hurting or killing" (5). Kendrick also draws attention to the fact that Slocum defines violence in a complex fashion in other writing (9-10). In the Introduction to Violence and American Cinema, Slocum equates violence with harm, and even introduces the concept of structural violence ("Introduction" 2). Ultimately, though, his discussion of violence does not fully integrate concepts that resemble those found in the work of Galtung. Despite the delicate probing of the boundaries of violence that Kendrick conducts, arguing that violence is very much a negotiated social construct, he ultimately engages with violence as a physical concept (6-13). Thus, while these explorations of screen violence establish valuable connections between history and representations of violence, they are either immersed in the study of direct violence or bound by it. The result is that such methodological frameworks do not mesh with the aims of this thesis. Conversely, studies which introduce more expansive definitions of violence often focus less on the historical implications. 
For instance Albert Bandura approaches violence in media using a definition that appears to incorporate wider concepts, such as aggression, a concept largely developed in the field of psychology which represents violence that does not manifest itself as physical force (2-3). Similarly, Dale Kunkel et al., have attempted to situate physical violence within a larger contextual framework, writing that "each act should be considered as part of an ongoing exchange between characters, and each exchange must also be situated within the larger setting of the program as a whole" (288). What studies such as these do is establish connections between viewers and the onscreen representations of violence. What is missing is a larger historical context. While there is some resemblance to the aim of this thesis, the frequent privileging of violence at the macro level is at odds with the micro/macro approach of this work. There have been some studies that focus more on that double-tiered approach, but they have been conducted outside the realm of media studies. For instance, The End of Victory Culture by Tom Engelhardt and Gunfighter Nation by Richard Slotkin both extensively look at the way culture and violence in the United States interact. However, since their focuses are primarily on history and society, they do not explore media texts as incisively as other studies which take those texts as their primary object of study. Thus while films feature prominently in some of their discussions, their approach to the films, which are engaging, are again not sufficient for this thesis.

\section{Incorporating the Diagnostic Critique}

A methodological framework is needed that can explore blockbuster cinematic violence in terms of history, and history in terms of blockbuster cinematic violence. While violence is not the focus of his work, Douglas Kellner has developed what he terms the diagnostic critique. He asserts that it "uses history to read texts and texts to read history" (Media 116). To accomplish this, Kellner draws on the work of sociologist Robert Wuthnow and the three categories he developed to conduct discourse analysis: social horizon, discursive field, and figural action (12-14).

For Wuthnow, these terms are strongly connected to ideology, which he sees as "an identifiable constellation of discourse that in fact stands in some degree of 
articulation with its social context" (16). At the same time, though, he observes that "it is that aspect of discourse that pertains in some special way to its social surroundings" (16). While not directly connected with discourse or discursive formations as defined by Foucault, the parallels are clear. Returning to the three terms, then, social horizon "refers to features of the real, experienced social context in which ideology is produced, selected, and institutionalised" (12); discursive field "refers to a symbolic space or structure within the ideology itself" (13); and figural action "refers to representative behaviours, modes of thinking, or characters that occupy space within a discursive field and are defined by the structural features of that field" (14).

Kellner adapts these categories directly to media analysis, including the reading of film texts, noting that the diagnostic critique

"[utilises] the categories of social horizon, discursive field, and figural action to describe some of the ways that cultural texts transcode and articulate social images, discourses, and conditions and in turn operate within their social field" (Media 104).

Perhaps most importantly, the diagnostic critique permits an examination of the ways in which cultural artefacts articulate neither a hegemonic nor a counterhegemonic position, but exist instead as a site of struggle between the two oppositional sides. Directing his critique of an individual cinematic text, such as Poltergeist, he connects the film with anxieties active in the United States at the time the film was released, class concerns and gender issues in that particular case. The diagnostic critique, then, "uses history and social theory to analyze cultural texts and uses cultural texts in turn to illuminate historical trends, conflicts, possibilities, and anxieties" (Media 125). This offers a level of engagement with historical context not found in the previously discussed analyses of screen violence. The problem remains, though, that while the historical context of the texts can be discerned via the critique, it is not calibrated to analyse violence.

To that end, the diagnostic critique will be fused with the work of Galtung, particularly his concept of tripartite violence. This will be accomplished by 
refocusing the categories Kellner adapts from Wuthnow so that violence is the primary object of study. In so doing, the diagnostic critique becomes violencecalibrated so that the critique is placed firmly on cinematic violence and its relationship to the historical context of the films. Additionally, the synthesis of the diagnostic critique with tripartite violence will permit the elucidation of the ideological discourses with which the various types of violence engage. This fusion will result in a more accurate gauge of the relationships between violence in blockbuster cinema and the historical violence of $9 / 11$, ultimately serving as a novel methodology which can be utilised to study blockbuster screen violence and its historical context.

Returning to Baudrillard, then, the use of the modified diagnostic critique will permit an articulation of the wishes and dreams of these films. For instance, if the film exhibits strong structures of violence which privilege patriarchal authority, that finding will be read within the context of the historical trajectory both leading up to and following the events of $9 / 11$. However, given the dramatic historical shifts those events catalysed, the analyses of films from different periods will aid in constructing an historical trajectory. It is important to note, however, that Kellner designed his process to explore popular media texts. While blockbuster cinema, the area of inquiry for this thesis, is popular media, it is a very particular type of popular media. To that end, additional considerations need to be made regarding how the violence-calibrated diagnostic critique will be modified even further to ensure that it is even better suited to look at blockbuster cinema.

\section{Blockbuster Cinema and the Modified Diagnostic Critique}

In deploying his diagnostic critique, Kellner intentionally selected texts that had been successful in the marketplace. One reason for this is that, as he notes, "popular media culture taps into existing fears, hopes, fantasies, and other concerns of the day" (Media 105). For instance, in a diagnostic critique of The XFiles, Kellner connects the popular television show with prevalent socio-cultural issues at the time, such as paranoia ("The X-Files" 205). As that example shows, however, Kellner is focused on a much broader set of texts ranging from cinema to 
television to music. Given the focus on blockbuster film in this thesis, it is useful to supplement the work of Kellner with a more cinema-specific approach. This can be found in the work of Mike Chopra-Gant.

In his exploration of popular film in post-World War II America, Chopra-Gant states his objective as creating

"an account that privileges neither the films nor the materials used to establish a cultural context for those films, but rather sees both the movies and the wider cultural context as being involved in a dialogic, discursive relationship and which sees in the dialogue between these different cultural artifacts an expression of the cultural climate in the early postwar period of the United States" (12).

In outlining his approach to the films he is analysing, Chopra-Gant discusses how previous analyses of film noir have treated it as representative of their era despite the fact that they only comprised a small number of the total films produced during that period. In short, film noir is often thought to represent all of Hollywood, and indeed the underbelly of American culture, during the post-war period when in fact it can be argued it did not (Chopra-Gant 16). Viewed that way, it is a case of synecdoche and, as Chopra-Gant notes,

"the idea of zeitgeist as the spirit of the age demands a unanimity that is inconsistent with the fragmentation and contradiction that characterised American society and culture during the early postwar years" (emphasis in original) (11).

By studying films which better reflect the tastes of the audiences of the time, then, Chopra-Gant suggests that a more accurate sense of culture and society can be gleaned. Again, this is not to argue that all audiences respond to each film in the same way, but instead to suggest that popular cinema better captures "the spirit of the age," so to speak, and can help to compensate for smaller sample sizes. The solution that Chopra-Gant offers is to focus on popular films as determined by their 
performance at the box office. The goal of this selection is "to obtain an objective set of movies which was very clearly not chosen by me for the films' consistency with any preconceived notions [he] held about the movies and culture of the period" (12). Thus, a selection of films which would better reflect the broader trends in society would be one that is composed of the most popular films from a particular historical period. Since the historical period of this thesis surrounds $9 / 11$, it is important to consider the fact that the films which dominated the box offices during that time were blockbusters. However, there is not a consensus on the precise definition of a blockbuster.

For instance, while Justin Wyatt roughly defines the blockbuster as a film which has "a pre-sold property....within a traditional film genre, usually supported by bankable stars (operating within their particular genre) and director" (78), Julian Stringer suggests a much more nebulous concept of the blockbuster. He states that the blockbuster "has no essential characteristics" (10), and aligns it with an idea rather than a specific type of film. Additionally, citing a discussion of film noir by James Naremore, Stringer describes the blockbuster as "a loose, evolving system of claims and counterclaims" (3). At the core of that evolution is box-office revenues.

Along those lines, Geoff King sees the blockbuster format "as part of an effort to create a much wider audience for certain films" and observes that "[gaining] the resonance of a broader cultural event" ("Spectacle" 9) is the ultimate goal. To accomplish this, King contends that studios producing blockbusters utilize market research to identify key issues that will appeal to the viewers that do not often view movies theatrically. In short, the blockbuster is intentionally positioned as a cultural phenomenon. It is unsurprising, then, to find that some blockbusters are hits while others are not since predicting the interests of any culture is intensely imperfect. However, with the benefit of hindsight, it is possible to determine which films truly were cultural events by considering the fact that only a select few number of films earned phenomenal amounts of money. To successfully analyse these films and their violence, then, avenues of exploration are needed that can reliably provide access to the deeper issues of the films, particularly with regard to the representations of violence. Accordingly, it is useful to look for similarities 
between blockbusters. While this might seems at odds with the claim made by Stringer regarding the lack of "essential characteristics" (10), the identification of similarities does not necessarily imply that the parallels are essential to the blockbuster. To that end, a starting point is provided by Star Wars, one of the films that arguably launched the age of the blockbuster.

When it was released, the success of Star Wars was so overwhelming that it immediately became the focal point for numerous imitators who wanted to reproduce its formula for success. While this led to a revival of the science fiction genre, it also led to a stronger focus on certain narrative structures. This was due to the fact that the director of Star Wars, George Lucas, openly acknowledged the influence the work of mythologist Joseph Campbell had on the film, particularly with regard to the "hero's journey." While that journey can certainly be found throughout numerous films that are not blockbusters, its simplicity lent itself well to a form that was slowly emphasising its spectacular elements while potentially reducing the complexity of the narratives. Along those lines, one way to supplement the diagnostic critique to better analyse the relationship between the Self and Other in blockbuster cinema would be through the work on narratology.

The importance of the Self/Other binary to constructions of cultural violence, and in particular the branches of narratology that focus on character functions and their relationships are most useful here. For example, the work of Vladimir Propp on folktales is particularly useful as it analyses the narratives in terms of a hero (the Self) and a villain (the Other). This closely parallels the formulation of cultural violence that Galtung establishes, since that definition is heavily predicated upon a Chosen/Unchosen binary, which indeed manifests itself as Self and Other ("Cultural" 297). Given the similarities, the work of Propp lends itself well to an analysis of the violence in blockbuster cinema. Thus by supplementing the modified diagnostic critique with it, the ways in which the villain is made the acceptable target of violence can be better understood. However, the specific categories identified by Propp do not always sufficiently capture the diverse representations of violence in the film. Specifically, the consideration for the ways in which non-human elements reinforce the violence in the films is sometimes 
minimal. To that end, an additional framework is needed that accounts for the ideological implications found outside of the characters and their functions. For that purpose, the work of Roland Barthes on myth will be utilised as well.

For Barthes, myth is a second order sign. While the first order involves signs which encompass the signified and the signifier-the word flag represents the literal image of a flag - the second order positions the first order sign as a signifier and couples it with a signified meaning-the flag, as Barthes argues, becomes a sign of the nation, with the image effectively privileging France over all others (116). This is the level of myth. Given the way Barthes discusses how myths essentially reinforce certain cultural standards, it bears a strong resemblance to the paradigm of cultural violence established by Galtung. Specifically, myth functions to legitimise ideological positions which may contain within them certain discriminatory or prejudicial positions, as the example above about the flag shows. This is essentially the same function of cultural violence, but Galtung approaches it in a way that presents it within a clearer Self/Other paradigm. Therefore, by mobilising the concept of myth in a way that augments the diagnostic critique, particularly with regard to the historical contexts being discussed, the deeper meanings of the representations of violence being examined can be understood, and indeed the connections between elements of the films that might not seem to be connected to violence, but are, can be analysed as well. While each theory will not necessarily be applied to each film, their incorporation into the diagnostic critique forms an essential toolkit that will enable an application of the violencecalibrated diagnostic critique that is more finely tuned to the subtleties of tripartite violence and blockbuster cinema at the turn of the millennium. The result will be a more precise analysis of violence that permits even deeper connections to be made with the geopolitical situation that preceded and followed 9/11. Of course, to do so a better understanding of that time period needs to be explored in order to determine the precise scope of this thesis. 


\section{The End of the War}

During the Cold War, the world was divided by the United States and the Soviet Union, two superpowers. Accordingly, a binary relationship existed wherein allegiances could be categorised in terms of us or them. Of course both sides saw themselves as "us" and the other as "them." In 1991 the Soviet Union collapsed. The decades-long struggle which shaped the binary relationship gave way to a world with only one superpower. However, in the escalation of arms and military spending during the Reagan years, despite the fact that the objective was victory, there seemed to be no actual plan for the peace that would presumably follow. This was made clear by the disappearance of the Soviet Other. The result was that the identity of the United States came into question. As Engelhardt argues, the nation was effectively lost (The End $\mathrm{x}$ ). Engelhardt, whose work will heavily inform the reading of history used in this thesis, argues that this was largely due to the collapse of what he calls "victory culture," which will be explored in greater detail in Chapter One. However, the result of the Soviet absence was an identity crisis in the United States wherein the position of the US in the world was no longer clear. This crisis seemed to cause an upswing in violence in the domestic United States. This was not necessarily the case, though. Instead the apparent rise in violence was likely due to the fact that fears of foreign threats often no longer muted the violence that occurred in the domestic sphere of the nation. Of course even during the Cold War inequalities could not always be contained and eruptions of direct violence resulted, as the development of the Civil Rights movement showed, but in general, the threat to survival presented by the Soviet Union effectively trumped violence which was less dire. Accordingly, structures of violence which had been secondary to the Soviet threat became prominent in the post-Cold War United States; they were elevated to primary concerns. Among the concerns that were most pervasive in that period were those that involved class-, gender-, and ethnicity-based structural violence. In each case, the inequalities and prejudices manifested themselves at the national level, sometimes even as outbursts of direct violence. 
For instance, in 1992, months after the collapse of the Soviet Union, the verdict in the high-profile trial of Los Angeles Police Department officers accused of assault and excessive force against Rodney King was released, and the officers were all found not-guilty. The implications of this verdict exacerbated racial tensions in Los Angeles and resulted in riots that lasted nearly a week. Although the riots were an isolated incident in terms of large-scale direct violence, the structures of violence they erupted from are indicative of systemic issues. What the rising visibility of that violence suggested was that the United States was possibly fragmenting; there was no longer a fully cohering national Self.

In 1994, Robert Kaplan controversially argued that the post-Cold War world was one of imminent anarchy. The United States, he contended, could not survive in this increasingly chaotic geo-political system. The "nation-state" was falling apart, and it could be seen, he argued, in signs such as "racial polarity, educational dysfunction, [and] social fragmentation of so many kinds" (76). Again, the binary world-US/Soviet-functioned to force disparate groups together: one was either part of the Self or the Other. The disappearance of that geopolitical formation thus produced multiple identity crises in the US. At one level, the fragmentation resulted in the shifting identities of individual groups as new identities were negotiated. Drawing again on the LA riots, it was clear that groups which were subjected to ethnic discrimination lashed out against an oppressive system in an attempt to alter prejudicial conditions. Although the riots were unique to the nation during that period, the changing domestic dynamics were not.

For example, during the confirmation hearings when Clarence Thomas was nominated to be a Supreme Court Justice, one of his former employees, Anita Hill, testified regarding allegations that Thomas had sexually harassed her. Although Thomas was ultimately confirmed as a Justice, the high-profile nature of the hearings promoted awareness of gender politics in the United States that had previously been overlooked. At the same time as the hearings, third wave feminism was coming into its own as gender became another site of identity negotiation. In discussing both race and gender, bell hooks argues that both "can be used as screens to deflect attention away from the harsh realities class politics exposes" (7). 
She treats the three terms - race, gender, and class-as "interlocking" (7), and observes that it is "impossible to talk meaningfully about ending racism without talking about class" (7). Following that logic, it would also be impossible to talk meaningfully about ending sexism without talking about both class and race. Accordingly, it is worth considering class as another site of identity negotiation in the 1990s. This is particularly evident in the developments which took place during the Reagan era as the economic landscape changed dramatically. As Thomas Byrne Edsall argued, the middle class was essentially disappearing. hooks suggests, though, that class is a less visible issue because it is often subsumed within debates surrounding race and gender (7-8). That does not, however, diminish the importance of class identity and its negotiation in the United States in the wake of the Cold War.

The way in which Kaplan positions such identity negotiations as fragmentations suggests an underlying violence. Specifically, the crises emerge from the destabilisation of the status quo. If rights for the lower classes, women, and nonwhite ethnicities are viewed as dangerous or threatening, it can be inferred that the status quo privileges upper class, white males. Part of the larger identity crisis, then, was that the new president, Bill Clinton, did not adhere to the traditional concept of leadership that Ronald Reagan had reforged in the 1980s (Jeffords 90).

Bill Clinton was elected to office on a fairly liberal platform, and did not project himself as a father figure, as Reagan and George H.W. Bush had done (Jeffords 90). What is more, Hillary Clinton, his wife, was given an active position in the White House, being tasked with health care reform. These changes were indicative of an attempt to move away from the past, but they did not last. His policies moved towards centre, and Hillary Clinton, after the failure of her health care initiative, played a subdued role in the administration. The most important aspect of this shift was the more overt display of the Clinton Doctrine, which essentially advocated military action and intervention "where our values and our interests are at stake, and where we can make a difference" (Clinton, "Remarks" n.pag.). This was most clearly evidenced in the US participation in the Kosovo War in the form of the Yugoslavia bombing. The identity crisis persisted, however, after the election of 
George W. Bush in 2000, although the Bush Doctrine clearly suggested the changes to come. Even so, it was not until September 11, 2001, that things radically changed.

After the events of September 11, 2001, the United States, via the Bush administration, had an enemy again. The vaguely defined terrorists became an Other to the national Self. As noted above, the links to Pearl Harbor evoked images of a noble struggle against an evil Other, and the identity crisis of the United States seemed to abate. It is unsurprising that this movement was paired with the refiguration of Bush as a white, patriarchal figure. Interestingly, the construction of his image positioned him as a person from the lower class, but he was in fact from an elite family. Despite such inconsistencies, the positioning of Bush as leader during the post-9/11 period seemed to avert the crisis. During that time, the United States invaded both Afghanistan and Iraq, and was positioning itself for a third war against Iran. However, with no end in sight for the first two wars, public support began to falter by 2004, and, in the 2006 mid-term election, Democrats in the United States took control of both the House of Representatives and the Senate. This ultimately led to the election of Barack Obama in 2008. Based on these events, the 2003 failure of the Bush administration to accomplish the mission in Iraq marks a clear end to the initial phase of the US response to 9/11, an end underscored by the inability of the Bush administration to gain support for an invasion of Iran.

For this thesis, $9 / 11$ is a critical point of inquiry because of the far reaching changes it caused not just to the United States, but the world. What is more, those changes were immediate. Since one of the primary tasks of this work is to determine if there is indeed a relationship between cinematic violence and history (again, not a relationship of causality), a focus on the time period around 9/11 will provide a powerful historical moment to observe. By focusing on the pre-9/11 and post-9/11 periods, not only can the patterns of the relationship between screen violence and its historical moment be established, but so too can the aftermath. In this way, the dreams of violence can be seen in relation to a dramatic historical shift. To that end, the historical period under investigation in this thesis will span the pre- and 
post-9/11 period, with $9 / 11$ serving as the obvious point of demarcation between the two. The first period will span from 1996 to September 11, 2001, and has been selected since it encompasses both the application of the Clinton Doctrine and the formation of the Bush Doctrine. The second spans from September 11, 2001, to the end of 2003, and includes the development and full deployment of the Bush Doctrine via the US military. Thus, blockbuster films from 1996 to 2003 will be analysed using the violence-calibrated diagnostic critique.

\section{Selection and Analysis}

The films examined in this thesis will be the single highest grossing films from each year in the range of study-1996 to 2003. This is following the logic of both Kellner (Media) and Chopra-Gant who view popular media and cinema respectively as more in touch with the times in which they were produced. What is more, by selecting the highest grossing films, it will ensure that the films are those which have been popular enough to garner repeat viewings at the cinema. This is in keeping with the rationale of Barbara Klinger, who observes, "when a film becomes a blockbuster, a larger part of its success is generated by audience members who return to see it again in theatres" (135). Thus, the films selected earned their high grosses by resonating with audiences. The films to be analysed are as follows: Independence Day (1996), Titanic (1997), Saving Private Ryan (1998), Star Wars: Episode I - The Phantom Menace (1999), Dr. Seuss' How the Grinch Stole Christmas (2000), Harry Potter and the Sorcerer's Stone (2001), Spider-Man (2002), Lord of the Rings: Return of the King (2003). ${ }^{2}$ Each of these films was the highest grossing film in the year of its release. ${ }^{3}$ This does not necessarily mean that each film earned its entire gross during that calendar year.

For instance, Titanic premiered on December 19, 1997. It earned just over 600 million USD during its domestic theatrical run, but of that amount, only 124 million USD was earned in December, with the rest being earned in 1998. Accordingly,

\footnotetext{
${ }^{2}$ Although the original title of the film and the book from which Harry Potter and the Sorcerer's Stone was adapted is Harry Potter and the Philosopher's Stone, this chapter deals with the American release so the American title-The Sorcerer's Stone-will be used.

${ }^{3}$ All box office figures from Box Office Mojo. See Appendix for the precise grosses.
} 
there is some overlap in terms of years and gross. It is also worth mentioning that some of the second highest-grossing films made nearly as much money as the highest-grossing films. While very often these close second films are directly represented by their sequels in this thesis-The Lord of the Rings: The Fellowship of the Ring is not analysed, but the third film in the series, The Return of the King, isthey also frequently represent other trends or related themes. In 1998, for instance, Saving Private Ryan earned only 15 million USD more than Armageddon. However, the latter film is not only an overtly patriotic film, evoking themes similar to Saving Private Ryan, but it is also a disaster film, representing the last major hit of the 1990s disaster film cycle of which Independence Day and Titanic, films analysed in Chapters One and Two respectively, were a part. Lastly, it must be noted that two of the films, Titanic and Saving Private Ryan deal with actual historical events. While the focus of this thesis is partially on history, it is the historical moment of the film itself that is of relevance here rather than that of the narrative. In other words, the historical sinking of the Titanic is not important here, but its presentation in the late-1990s is. That is not to say the historical aspects will not be considered as indeed the mythical implications of any historical events in the films are important, but they will not be the focus of the analysis. With those points considered, the films selected still represent the peaks of blockbuster cinematic popularity from 1996 to 2003.

Since the diagnostic critique is designed to use history to read texts and vice versa, each chapter will necessarily provide more historical information, suggesting the ways in which history and the anxieties the films respond to developed alongside one another or, to build on Baudrillard, how the films wished the events of $9 / 11$ and its aftermath. Additionally, drawing on the various supplementary tools outlined above, the analysis will reveal the dynamic natures of the Self and Other with the goal of showing how the wishes articulated through them developed alongside the historical contexts of the pre- and post-9/11 eras.

The trajectory will be established in Chapter One with an examination of Independence Day. Analysing the construction of myth in the film, this chapter will investigate the ways in which violence is established as a conflict between a 
patriotic Self and an external (literally alien) Other. Drawing on both Engelhardt and Barthes, history will be read against that binary, and it will be made clear that the violence of the film offers audiences exactly what was missing in the United States at that time which was a national Self united. This presentation of an alien Other parallels developments against Arabs and Muslims in the post-9/11 United States, legitimising their overt marginalisation.

Chapter Two will show how in Titanic the binary Self/Other paradigm found in Independence Day is reproduced in an historical rather than fantastic setting. This is accomplished by pairing Galtung with Barthes, and by aligning the Self with a mythic construction of the United States-one which relies upon the American dream - while the Other remains external and is linked with the violence, largely inequalities, of the Edwardian era. This chapter will then conclude by showing that the regression into a mythic historical past where a clear national Self dominated served as a counterpoint to the fragmentation of the 1990s. By re-establishing a binary world-Self/Other-in the post-9/11 period that resembled that of the Cold War period, the response to 9/11 effectively regressed to a historical Self and Other relationship as well.

In Chapter Three, the threads of the first two chapters will be brought together in an analysis of Saving Private Ryan. It will be shown using the work of Barthes and numerous scholars that in this film, the patriotic militarism of Independence Day is fused with the historical glory of the mythic United States to create an idealised US Self which is placed in opposition to a clear external Other, the Nazi army. Additionally, the chapter will focus on how a secondary Other is created, which is an Other to both the US and the Nazis, that enables the US to be more heroically positioned; violence becomes even more justified as a result. In terms of historic context, the film came out at a point when interest in World War II was high, suggesting that the film addresses anxieties felt by many viewers surrounding the prowess of the nation, a point supported by the lack of any noble military endeavours which united the nation during that period. The post-9/11 period revitalised the use of the military for noble purposes while at the same time reconstructed a binary notion of Self and Other. 
The analysis in Chapter Four will focus on The Phantom Menace with particular attention to the way in which it maintains a Self/Other binary in terms of religious belief. This will necessarily draw upon the work of Vladimir Propp. As before, the Other is external despite the suggestion of change in the title. Situated contextually, this binary figures into the approaching millennium and draws on many of the anxieties active at that time, particularly the fear that religion was slowly vanishing. The redefinition of the Self in terms of religion was a key rhetorical tactic used in the post-9/11 period when constructing the national Self, particularly when considering the figure of Bush.

Chapter Five will look at The Grinch, which is the first film that deviates from the trajectory of violence established in the films thus far. While there is still a Self/Other binary, the film ultimately resolves with the Other joining the Self. This is still a movement suffused with violence, particularly in terms of ethnicity-based stereotypes, but it suggests that some form of conflict resolution between the Self and the Other exists that does not rely on direct violence. In short, it represents a potential shift away from the violence-suffused conflict resolution that dominated in the previous films. Despite this shift, the film does still heavily rely upon traditional ethnic stereotypes, only permitting the Other to join the Self in a position of subservience. To that end, the work of Galtung will be used along with that of Donald Bogle, who has written extensively on stereotypes in film. The fact that these prejudices persist even in a movie that is apparently peaceful suggests that it still informs the stereotypes of the post-9/11 United States which identified the Other using the same stereotypes as a way of distinguishing between Self and Other.

Chapter Six will look at the first post-9/11 film in this thesis, and will take the concept of the movement of the Other introduced in the previous chapter and develop it further with The Sorcerer's Stone. However, while The Grinch made some effort to resolve conflicts using peace rather than violence, The Sorcerer's Stone takes that movement and reintegrates it into a framework which is grounded in violence. Thus, the fact that the Other could be part of the Self is not a sign of subservience, but a threat that must be violently dealt with. Accordingly, the 
analysis in this chapter, using the work of Propp, will focus on the way in which the narrative structure of the film creates a pervasive atmosphere of paranoia that is predicated upon violence. In addition, though, the film still marks the Other through the deployment of multiple structures of violence which draw on stereotypical depictions of Others. By reframing the shift in the Self and the Other into a paranoid context, the film manages to participate in the rhetoric of the nascent War on Terror by essentially drawing on the fears of the era, and the anxieties promoted by the mental state engendered by a "crusade" (Carroll 24-25).

In Chapter Seven, Spider-Man will be analysed. Although the film still shows the Other hiding within the Self, the paranoia of The Sorcerer's Stone is largely supplanted by dramatic irony. This transition effectively allows the film to broaden its engagement with other issues, specifically an exploration of power and responsibility. While this exploration permits the film to perpetuate the separation of the Self and the Other, it also allows the film to dream of a noble struggle against the Other in which the Self is able to metaphorically atone for failing to protect members of the Self. While that positioning will be articulated largely through the work of Galtung, it will then be connected to the Clinton and Bush Doctrines, showing how the film articulates anxieties active during the post-9/11 period that enhance the threat level of the Other, making the need for an empowered and proactively violent Self urgent.

The final chapter, Chapter Eight, will explore The Return of the King. The focus here will be the final phase in the violent repositioning of the Self and the Other in the post-9/11 period. While the film still endorses the standard tropes of violence seen in the previous two films, it takes the movement of the Self and Other to its terminal moment. Specifically the analysis, working with both Galtung and Propp, will explore the new dimension the relationship takes with the Self becoming like the Other in terms of its deployment of violence. Although there is never a true crossover where the boundaries between the Self and the Other cease, this movement suggests a new sense of approval in terms of behaviour the Self can utilise while still remaining part of the Self. However, the film reduces the complexity of these changes to such a degree that as the real-world corollaries 
emerged in the post-"Mission Accomplished" phase of the Iraq invasion, particularly in the Abu Ghraib prison scandal, the dreams of the film could not be realised. This was largely due to the fact that the film showed the transgression of the Self leading to an immediate era of peace. This formulation will be connected with the idea of the Pax Americana, and its inability to bring the War on Terror to a clear and concise conclusion, ultimately resulting in the ebbing of support for the adventurism instigated by $9 / 11$.

This thesis will continually examine the trajectory of violence in blockbuster films from 1996 to 2003 and will situate it historically. This will be accomplished by drawing on the diagnostic critique developed by Kellner and fusing it with the concept of tripartite violence articulated by Galtung. This modified critique will then be supplemented with tools to more fully engage with tripartite violence. In so doing, this work will explore the relationship between blockbuster cinematic violence and the historical moment of $9 / 11$, ultimately reaching the conclusion that blockbuster cinema is cultural violence, a point which will be explored further in the conclusion. Thus, by better understanding the ways in which the violence of these films is situated historically, the violence of history itself can be better understood. Returning to the claim made by Baudrillard in relation to $9 / 11$ that "they did it, but we wished for it" (5), this thesis is not simply looking at the wishes evident in the violence of blockbuster cinema before and after $9 / 11$, but it is looking at its dreams, and in so doing it will develop a critical approach to blockbuster cinematic violence. 


\section{Chapter One}

\section{Patriotism Reborn: Independence Day (1996)}

In the wake of the dissolution of the Soviet Union in 1991, the United States found itself at a loss. Despite its victory in the Cold War, the US was a nation which had defined itself for decades against the Soviet Other. In the 1990s, though, the US emerged as the sole superpower in the world. The result was that it no longer had an Other against which to define its Self. Accordingly, the United States experienced a post-Cold War identity crisis wherein it sought to find a new identity in the pre-millennial world. This search is evident in the disaster film cycle that erupted in the United States during the 1990s.

Disaster films were not new to Hollywood in the 1990s. In the 1970s, for instance, numerous films were released which showed the destruction of the United States in various ways, often by way of natural disasters. Comparing the new cycle of disaster films to the previous cycle, Stephen Keane observed that the new films "have the effect of bringing existing social and political themes to light, issues independent of pure zeitgeist and characteristic of the 1990s as a whole" (64); they address "national and international concerns" (64) in ways not seen in previous disaster films. Geoff King takes ideas such as those further, connecting them directly to the changes in the geo-political landscape during that time, observing that the 1990s disaster films made manifest the anxieties over the "instability and uncertainty" ( Spectacular 154) of the era. While many of these films, such as Twister and Armageddon, present natural disasters, the highest-grossing film of 1996, Independence Day, positioned its protagonists against a clear, corporeal Other. In fact at first glance Independence Day, with its spectacular space battles and extraterrestrial Others as foes, appears to be a science fiction film rather than a disaster film. However, as Susan Sontag notes of the original science fiction invasion films in the 1950s, they are concerned "with the aesthetics of destruction" (44), and indeed the feature set-piece of the film is the mass destruction of New York City, Los Angeles, and Washington, D.C. This connection to previous science 
fiction films is explicitly noted in the promotional materials for the film, but the core of the film was also said to include "the disaster films of the Seventies" (Twentieth Century Fox 3) as well as "the war movies of the Forties" (Twentieth Century Fox 3). Despite the futuristic nature of the plot-an alien invasion-Independence Day is a film very much grounded in a militaristic past.

It is my contention that the violence in Independence Day functions to resolve the post-Cold War identity crisis experienced by the United States. This is because it recreates a Self/Other binary which returns the US audience to a pre-Vietnam War era of "unabashed patriotism" (Twentieth Century Fox 3) so as to evoke a mythic image of the United States as a worldwide protector, an image that would ultimately be revived in the post-9/11 era. My analysis will begin by examining the state of the US Self in the mid-1990s, focusing on the concept of "victory culture" that Tom Engelhardt defined. I will show how politically there did appear to be a significantly diminished presence of "victory culture." However, I will argue that the cultural demand for it remained high, as evidenced from the very beginning of Independence Day. My analysis of the film will start, then, by focusing on the ways in which it attempts to recuperate patriotism and, via patriotism, the US military. Specifically, I will discuss how the film draws on older conventions and genres in Hollywood cinema in ways that reposition the viewer both in and before the Cold War in a mythic United States. For this I will draw upon the work of Roland Barthes. With the viewer repositioned, I will examine how the Self and the Other within the film are constructed beginning with the ways that technology is used to define the Self as human and the Other as inhuman. While this creates a clear distinction between Self and Other, it is a distinction which is supported by multiple structures of violence. Accordingly, my analysis will continue by showing how the heroic Self is predicated upon multiple inequalities, particularly sexism. Drawing on the concept of "dreaming" the attacks of 9/11 that Jean Baudrillard suggests, my analysis will conclude by showing how the film did not dream of the destruction of the United States, but rather of the resilience of the nation and its securing of power. It is that dream which can be seen in the way that the Bush administration responded to the attacks of 9/11. Specifically, the Bush administration reconnected 
the post-9/11 United States with its mythic past, resurrecting notions of Self and Other grounded in an era of "victory culture." What is more, like the film, this new national Self claimed to be about the unification of the United States, but that unity elided rather than addressed the numerous structures of violence that seemed to underpin domestic US politics in the 1990s. Ultimately, what Independence Day dreams of is a Self united by internal structures of violence, and it is that manner of Self which the Bush administration sought to create in the post-9/11 period.

\section{Post-War Blues: Identity Crisis in the United States}

At the end of the Cold War, the United States was a Self alone. With decades of struggling against the Soviet Other, it was ill-prepared for peacetime. As Engelhardt writes, "The United States also stood alone and enemy-less and seemingly confused in a world of midget bad guys" $(x)$. One aspect of this seemed to be that the United States was looking inward, rather than outward, for an Other. In his apocalyptically titled article, The Coming Anarchy, Robert Kaplan said that the United States in the nineties was under threat by long standing domestic issues such as "racial polarity, educational dysfunction, social fragmentation of many and various kinds" (76), all reflecting structures of violence pervasive throughout the United States. He predicted that "As Washington's influence wanes, and with it the traditional symbols of American patriotism, North Americans will take psychological refuge in their insulated communities and cultures" (76). In short, without an external Other, the Self seemed like it would break apart. This process is similar to the one Johan Galtung describes in his theories surrounding state systems.

In articulating his concept of states, Galtung identifies five types of states: dissociative, associative, confederal, federal, and unitary. ${ }^{4}$ He then assesses each of these systems in terms of their "peace-building capacity inside" and their "peacethreatening capacity to the outside" (Peace 65), concluding that the dissociative system - an anarchic state-has the lowest levels of both while the unitary system has the highest potential for both. While the truly unified system would be something akin to a nation-state, by defining its national Self against the Soviet

\footnotetext{
${ }^{4}$ For the complete discussion of the five state systems, see Galtung Peace Part I, Chapter Five.
} 
Other, the Cold War era United States managed to approach to those levels as it was a federal system. Accordingly, the capacity for violence against that Otherpeace-threatening, as Galtung terms it-was high (Peace 65). As the Cold War evidences, that capacity was realised more often with structural violence than with direct violence. With no super-power Other against which to direct that violence, the internal peace-building capacity of the United States seemed to go unrealised, as seen in the increasingly fragmented nature of the United States that Kaplan observed. As such, it is reasonable to conclude that the national Self was increasingly a series of insular Selves that saw different groups within the United States as Other. This meant that race-based structures of violence, for instance, which had always been part of the United States, were focused on more directly by the public and as the issues of violence which drove them were addressed, the sense of a unified national self decreased. Otherwise stated, the larger identity crisis that the nation experienced drew attention to domestic crises it fuelled. One reason for the collapse of the national Self that precipitated this crisis is put forward by Engelhardt with his notion of "victory culture."

For Engelhardt, victory culture is very closely tied to what he calls "the American war story" (5). This story was "an inclusive saga of expanding liberties and rights that started in a vast, fertile, nearly empty land whose native inhabitants more or less faded away after that first Thanksgiving" (4). He suggests links towards such concepts as manifest destiny, and notes:

"If occasional wrongs were committed or mistakes made, these were correctable; if unfreedom existed within America's borders, it was only so that-as with slavery-it might be wiped away forever" (4).

Accordingly, victory culture is the mentality embraced by the United States wherein "war was invariably portrayed as a series of reactive incidents rather than organized and invasive campaigns" (4), and "victory, when it came, was guaranteed to bathe all preceding American acts in a purifying glow" (4). Drawing on the work of Roland Barthes, then, "victory culture" does not rely upon historical fact, but instead upon 
myth. As Barthes writes, a key trait of myth is the "privation of history" (151). He notes that, "Myth deprives the object of which it speaks of all History" (151). ${ }^{5}$ In fact, it would seem that historical fact is antithetical to victory culture. This is apparent in the argument Engelhardt makes that "between 1945 and 1975, victory culture ended in America" (10). He bases this on the fact the horrors of dropping the atomic bombs on Japan and the fighting in Vietnam did not adhere to the narrative of the American war story. Thus, after World War II, he argues, the culture of the United States "was not one of triumph, but one of triumphalist despair" (9) as the threat of nuclear catastrophe and the Cold War defied the war story. As he observes:
"Triumphalist despair proved a unique and unstable mix. Without the possibility of total victory, without the ballast of the war story, 'freedom' came unanchored as the 'freest country on earth' presided over a 'Free World,' many of whose members from Franco's Spain to Diem's Vietnam embodied unfreedom" (10).

He concludes by observing that young people were "horrified by a war fought in freedom's name that had the look of an atrocity" (10). Recontextualising this within terms of violence, then, "victory culture" ended because the Self came to resemble the Other. As noted, this is due to the mythic conceptions of both Self and Other which came into increasing conflict with the reality of the situation. To borrow the language of Barthes, the history of the object could not be entirely shut out since it was being broadcast nightly on US televisions. The result was that the mythic construction of the United States that fuelled victory culture could not be sustained. Accordingly, victory culture retreated and took along with it the image of the US military as heroic.

While there were certainly films which celebrated the Cold War binary between the United States Self and the Soviet Other after the Vietnam War-Rambo: First Blood, Part II and Top Gun being two key examples - there was a distinct national attitude towards war which positioned it as a negative. This response has generally been

\footnotetext{
${ }^{5}$ Barthes uses the term "history" here in a Marxist sense. For more see Barthes 151.
} 
labelled the Vietnam Syndrome and is described by Douglas Kellner as "the shame concerning the loss of the war and overcoming the reluctance to again use U.S. military power" (Media 28). Its pervasiveness has even been acknowledged by the United States government. For example, when the Persian Gulf War ended in 1991, George H.W. Bush, speaking to the American Legislative Exchange Council stated, "It's a proud day for America. And, by God, we've kicked the Vietnam syndrome once and for all" (n.pag.). While his re-election bid in 1992 failed for numerous reasons, the fact that the victory in the Persian Gulf was not enough to secure a political win showed that neither the military nor patriotism had been recuperated in the mind of the public. It is likely, then, that events such as these led Kaplan to predict the increasing fragmentation of the United States and the fading of "traditional symbols of American patriotism" (76). Again, though, as films like Top Gun and Rambo: First Blood, Part I/ showed, the mythic "American war story" of a noble Self in opposition to an evil Other was still in demand in some sites, and in 1996 this was nowhere more evident than in Independence Day. Despite being set in an alternate present, the film exists largely as a pastiche of mythic national pasts, specifically pasts immersed in "victory culture."

\section{Flag Waving on the Moon: Patriotic Imagery in Independence Day}

Independence Day has a Classical Hollywood three act structure which follows the three days of an alien invasion. The aliens arrive on July 2 , they launch an attack on much of the world and its population on July 3 , attempting to eradicate all human life, and on July 4, the American Independence Day, they are instead themselves destroyed by humanity. While the formulaic structure of the film certainly evokes a traditional quality, the film does not hesitate in making its patriotic intentions excessively clear. The opening shot of the movie presents an American flag on the surface of the moon, shown in Figure 3. 


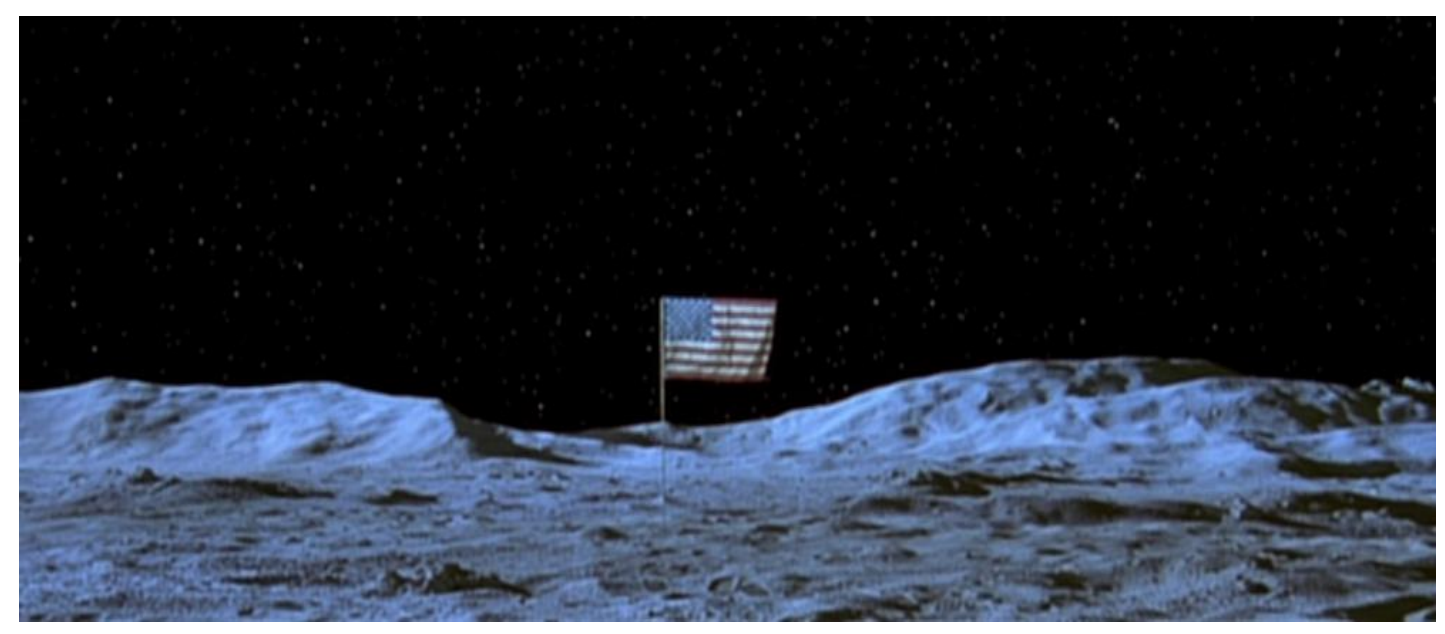

Figure 3-The dominance of the United States in the opening of Independence Day

The mythic nature of the flag is discussed by Barthes, who, argued that even if the flag is only implied to be part of the image, it still is a mythic sign that represents the nation itself (116). The image of the flag in this case, then, points toward the pinnacle of American ingenuity and its iconic call to being a 'frontier' nation. The myth of America is reinforced in the subsequent shot, which shows the plaque left on the lunar surface by the Apollo 11 mission, focusing on one sentence in particular: "We came in peace for all mankind." In terms of Self, this focus establishes the mission of the United States as one of peace, effectively eliding a history of violence which manifested itself domestically and abroad. What is more, by focusing on the idea of the United States as representatives of "mankind," something the film extensively reiterates, the notion of the United States envelops the idea of humanity; the United States is humanity. It is the Self of the world. However, the accomplishments of the United States are not solely symbolic cloth and metal plaques, as the next shot shows the footprints left on the moon by the US astronauts. Jan Mair sees this brief sequence as "[identifying] the instrumentalities inherent in American cultural production-liberation, freedom, democracy-the peak of human civilization" (36). While the flag can be read as a symbol of direct violence, a fact underscored by a brief shot of a statue memorializing the raising of the flag on Iwo Jima, it is a reading which omits the historical context of the imagery since the numerous dead soldiers that contributed to that moment are absent from the memorial. Considering the historical moment 
highlighted by these open lunar shots, the sequence also frames the United States as a benevolent and peaceful nation, specifically through its connection to the American moon landing of 1969.

What makes the highlighting of the moon landing so important is that it positions the viewer to identify not with a United States embroiled in the Vietnam War or even suffering a post-Vietnam identity crisis, but with a United States which was at the apex of its achievements. The importance of the lunar moment was established in 1962 in the vision laid out by President John F. Kennedy who said:

"For the eyes of the world now look into space, to the moon and to the planets beyond, and we have vowed that we shall not see it governed by a hostile flag of conquest, but by a banner of freedom and peace. We have vowed that we shall not see space filled with weapons of mass destruction, but with instruments of knowledge and understanding" (n. pag.).

Read this way, the lunar imagery at the start of Independence Day directly responds to the anxiety over the "instability and uncertainty" King refers to in the post-Cold War 1990s by relocating the viewer to the Cold War era of the 1960s (Spectacular 154). While this was still an era where the United States faced, as Engelhardt labelled it, "an enemy too diffuse to be comfortably located beyond national borders" (6), the film rectifies this by its use of an Other external to humanity, space aliens.

Unlike the Other of the Cold War, the alien Other of Independence Day lacks any humanity. It has eyes and appendages, but it has tentacles and a differently shaped body. Through such extreme physical differences, then, the film is able to maintain a distinct separation between Self and Other. This differentiation precisely evokes the work of Sontag who, writing about the original cycle of invasion films in the 1950s and 1960s, argues that the films are based on an "extreme moral simplification" (45) in which the enemies are "beings excluded from the category of human" (45). Given that Independence Day is attempting to recreate, among other genres, the alien invasion genre of the 1950s, the assessment Sontag makes of the 
earlier invasion films applies to Independence Day as well. As for the function of the alien Other, Ziauddin Sardar, writing about alien characters in general, suggests that "Aliens demonstrate what is not human to better exemplify that which is human" (6). Sardar, though, goes further, noting that

"Difference and otherness are the essence of aliens for only then can they stiffen the sense of self and self-defence that completes the chain of science fiction as normative genre" (6).

In short, the aliens foster a sense of unity in those positioned against them, creating a binary conflict. While normally those unified would be humanity in general, in Independence Day the United States is humanity. Before the nuances of the Self can be examined, particularly the ways in which gender-based structural violence is mobilised within it, the distinction between Self and Other must be better understood, and it is through technology that the film most clearly articulates that difference.

\section{Technologies of Difference: Mapping Self and Other through technology}

At one level, Independence Day is a battle of technology. On one side is the dutiful military technology of the United States Self, poised to defend the nation. On the other is that of the futuristic aliens which is foreign in its appearance, but familiar in its effects-an uncanny presence. Galtung describes technology as a reflection of a culture and its predilections towards peace and violence (Civilization n.pag.). The positions of both human and alien technology are shown in their arrival during the previously discussed close up of human boot pints on the moon. These footprints are linked with a sense of "knowledge and understanding," to quote Kennedy (n. pag.), which present the US Self as benevolent, while the arrival of the aliens by way of intense vibrations which erase the prints indicates the pervasive violence, direct and structural, associated with the aliens and their technology. The violence of that technology can be seen throughout the film in the gratuitous displays or their technology ranging from the scenes of urban destruction due to the "massive phalanx of fire" (Twentieth Century Fox 20) to sequences of aerial combat. It is 
important to note, though, that in all of these displays it is the technology of the aliens, and not the aliens themselves, which is visible as the technology conceals the bodies within. Even when it seems an alien is finally revealed it turns out to be a bio-mechanical body suit which shrouds the being within even further. This sheath of technology that envelops the aliens evokes the notion Sontag advances about technological artefacts being the "sources of power" (45) in invasion films. By contrast, the technology of the US Self displays rather than conceals the human element.

The human technology exhibited in the film - nuclear weapons, computer viruses, fighter jets-undoubtedly reflects a violent culture, but the film focuses instead on the fact that this technology, unlike the alien technology, requires explicit human control to function. This focus is established in the opening sequence with the focus on the Eagle Lunar Module. The Eagle exists in the film only as a harmless monument to American ingenuity since without its human operators that is all it can be; it is functionally useless on its own. While this technology could easily be read as a manifestation of the Cold War struggle making it a symbol of the constant threat of mutually assured nuclear destruction, its functionality is underscored in the film by the visual linking with the Apollo 11 plaque. The plaque operates as what Sontag would call "a certificate of utility" (45) because it marks the technology as tame, thereby detracting from the potentially negative reading of the resulting violence. The only times the humans use technology is when it is explicitly under control. This is the case in the numerous flying scenes where fighter jets engage in aerial combat with the alien craft. However, rather than adhering to the argument made by Mark Jancovich of the original invasion films from the 1950s, "that rather than legitimating Fordism and its application of scientific-technical rationality to the management of American life, these texts often criticised this system by directly associating the alien with it" (26), the "scientific technical rationality" of Independence Day is coupled with American exceptionalism. Thus while there are many shots of airborne acrobatics, the film continually brings the viewer inside the 
canopies of the US jets to see the pilots. ${ }^{6}$ What is more, the audio track is filled with the voices of the US men and women in the sky. The result is a technophilic position because the technology serves the needs of the people using it to protect the Self, while simultaneously allowing some people to stand out. Of course that protection is contingent upon the fact that the human technology is just as deadly as the alien technology.

Halfway through the film this is made very clear when the president is faced with the decision to deploy nuclear weapons over Houston in an attempt to destroy one of the alien ships hovering over the city. For the Self, then, the question of deploying this destructive technology is not questioning the technology itself, but instead the morality of its use. Accordingly, one of the primary heroes of the film, President Thomas J. Whitmore (Bill Pullman), resists launching the missiles as there could be survivors in the city. He is ultimately swayed to use them, but the fact that he resisted at all suggests a unity of Self-the United States, through its president, must protect itself or it will cease to be. This decision, of course, gains extra ideological importance given the importance of Houston to the lunar missions that landed humans on the moon. By authorising the use of weapons and destroying Houston, it is suggested that the US must forge a new history, one that ultimately elevates humanity above its technology rather than subsuming it. In this way, the film also articulates technophobia.

Scott Bukatman sees a fear of dehumanisation at the root of technophobia. When technology can transform a human into something inhuman, as the cavalier use of nuclear weapons would, it is a transformation to be feared (2-5). Thus the massdestruction of cities via alien technology seen in the first act of the film is a display of inhuman technology. This disregard for human life is made explicit later in the film when a captured alien is asked by the president, "What do you want us to do," and the alien simply responds, "Die." In that moment, then, the alien has shown that it has become indistinguishable from its technology-all it can do is mechanically destroy. The technophobia of the film also resembles that which is

\footnotetext{
${ }^{6}$ See Jeffords, especially Chapter Five, for a detailed analysis of the hardy body in action films as it relates to technology. For a critical race reading of this sequence, see Kakoudaki 128.
} 
articulated by Michael Ryan and Douglas Kellner who, discussing fantasy films, situate it within a conservative context. For them, the transformative technology puts "'natural' social arrangements" (245) in peril because it threatens to destabilise the status quo. Interestingly, since Ryan and Kellner view the status quo as a system of inequalities, such as patriarchal authority, what Galtung would call structural violence, technology which threatens that status quo would challenge those structures of violence potentially ushering in structural peace. Of course, as the alien technology of Independence Day shows, it may also usher in an era of even more extravagant violence.

The fact that technology is viewed through the double paradigm of phobia and philia is unsurprising, though, given the historical context of the period. Specifically, the mid-1990s were a period of promise and caution with technology. In 1996, the Internet was gaining increasing notice as the World Wide Web rose to prominence, promising a new electronic frontier. At the same time, however, millennial anxieties became focused on the threats posed by technology, such as the Y2K bug, a computer error which would reset the dates on computers at the turn of the millennium, a flaw which many theorised would result in the end of Western civilization. Independence Day draws on both these hopes and fears with the hopeful technologies aligned with the Self and the fearful ones relegated to the Other. There are some overlaps in technology at the start of the film, though, as the United States is over-reliant on its technology. This is clear in the way that the aliens use the satellite technology that the United States is shown to be dependent on against the US. This technological reliance ultimately facilitates the destruction of all the major cities of the world. At the end of the film, the reversion to more "human" forms of communication is exemplified by the fact that worldwide repulsion and destruction of the aliens is made possible by Morse code transmissions, technology that requires constant human intervention. The film, of course, cannot escape entirely from its position as a blockbuster, though, as the heroes achieve victory large in part due to the destruction of the alien mothership through the use of an Apple MacBook, which is featured prominently in the story. While this reflects the industrial concerns of the blockbuster and the importance of 
product placement, it does not negate the stance on technology the film articulates since even though the technology was cutting edge at the time the film was released, it is still subordinate to the user.

Ultimately, the distinction the film makes between the technologies of the Self and Other hinges upon structural violence. When the aliens arrive, their immediate action is to attempt to destroy humanity. The only way for this position to be justified for them is if they have established such a steep Self/Other gradient that privileges themselves in relation to all others, a key component of nationalism according to Galtung; they are the only species that matters. While Galtung largely grounds his theories in human relations, what the aliens exhibit would be an extreme form of nation-based violence, "speciesism," rather than nationalism (Cultural 298). The extremity of it authorises not just a structure of violence which elevates them, but it does so in a way that legitimises direct violence at the level of genocide, which is made possible with their technology. Conversely humanity attempts to communicate with the aliens, sending out a greeting craft aptly named the Welcome Wagon. The Welcome Wagon is a sign of structural peace, one that indicates humanity does not picture itself above or below any other species. The aliens, however, destroy it without provocation, an event which integrates the spurning of the metaphoric open hand into the concept of "victory culture." Humanity, again represented by the United States, is shown to be peaceful until the destruction of the Welcome Wagon and, subsequently, their cities. Like the mythic United States of victory culture, the US of the film, a victim of an unprovoked assault, wages war against the aliens as a reactive measure rather than as a premeditated assault. The result is a just war with American heroes leading the way.

\section{The American Self: Structural Peace and Violence in Independence Day}

In keeping with the generic traditions of both the disaster film and the combat film, Independence Day has multiple heroes. The four primary heroes are the war veteran-cum-president; a fighter pilot, Captain Steve Hiller (Will Smith); a computer genius, David Levinson (Jeff Goldblum); and an alcoholic Vietnam veteran, Russell 
Casse (Randy Quaid). Despite the military similarities between three of them, these heroes are intended to represent a cross-section of America, albeit a limited one. As with other disaster films, the concept seems to be one of adversity bringing diverse people together, and that notion of equality-structural peace-can be seen in the ways in which these characters interact with one another, particularly Hiller and Levinson, a black character and a Jewish character respectively.

In the climactic battle of the film, Hiller and Levinson fly a captured alien craft into space to plant a virus on the alien mothership. While this is a standard act of heroism, the ethnicity of the two characters adds an extra dimension to the sequence. Specifically, as Michael Rogin argues, they contribute to the larger agenda of the film which is to dramatise the mending of relations between African American and Jewish communities in the United States (45-50). This is, of course, a response to the perceived rift between the two groups. However, at a larger level the attempt the film makes to reconcile these groups is reflective of a larger effort at reforming the nation. Borrowing again from Kaplan, the suggested clashing between Jewish and African American communities reflects the fragmentation of the larger national Self into "insulated communities and cultures" (76). Indeed the film shows, through Hiller and Levinson, that when united under the banner of the nation, the pieces of the Self can indeed be reformed into a single whole. In terms of these two characters, then, a structure of peace emerges. However, a broader examination of social factors reveals that the film actually constructs the Self from structures of violence, even in its depiction of apparent racial harmony.

Of the main characters, three are not ethnically white. In addition to Hiller and Levinson, there is the partner of Hiller, Jasmine Dubrow (Vivica A. Fox), who is black. Yet these characters bear only superficial markings of their ethnicities; they could be played by actors of any race or ethnic heritage. This could simply be a reflection of the fact that, as Sontag contends of the original invasion films, characters were often weakly developed (45). Additionally, it could be a sign of a post-race America where ethnicity is a non-factor, suggesting a structure of peace rather than a race-based structure of violence. However, the casting of Will Smith points towards a conscientious engagement with race in the United States. That 
engagement, though, does not confront deeper race-oriented issues, a fact that Amy Taubin argues is the reason Will Smith was cast in the film, as his role on the television show The Fresh Prince of Bel Air positions him as "the only African American actor in Hollywood guaranteed to be nonthreatening to a white middleclass audience" (6-8). This is a contention echoed by Despina Kakoudaki who suggests that "The alignment of the white male hero with the black male hero enables the reaffirmation of a patriarchal bond, which is used to reestablish white supremacy" (127). The fact that the representations of race as well as class relations in the United States which could potentially threaten a white-middle class audience, are absent in the film-or reappropriated, as when one white pilot quotes Jesse Jackson - supports those arguments. However, both Taubin and Kakoudaki point towards further structures of violence by way of integrating issues of class and gender into their arguments. This integration supports the arguments of bell hooks, about class, gender, and race being "interlocking" concepts (7). Accordingly, it is useful to further examine the ways in which the film articulates notions of class and race as well.

In terms of class, the film presents another (limited) cross-section of America. On one end is the first family - the president, first lady, and their daughter. On the other are characters like Dubrow, who works as a stripper to support her son, and the Casse family, who live in a mobile home, which is used as a sign to represent their lower socio-economic standing. While this positioning of certain characters along various class lines could serve as a commentary on the class struggles in the United States during the mid-1990s, particularly by presenting an ensemble of characters from different classes who are forced to come together, the ultimate resolution of the film does not engage with the class disparities that started the film in any way, nor does it suggest they have been resolved. In fact in the final moments of the film, the poverty-stricken Casse sacrifices his own life to save humanity while Hiller and Levinson await approval from the president for their own heroic acts. Thus, the class-based hierarchy remains in place. Since it privileges the president over all others, it is a structure of violence. However, the most overt structure of violence in the film remains that which is tied to gender. 


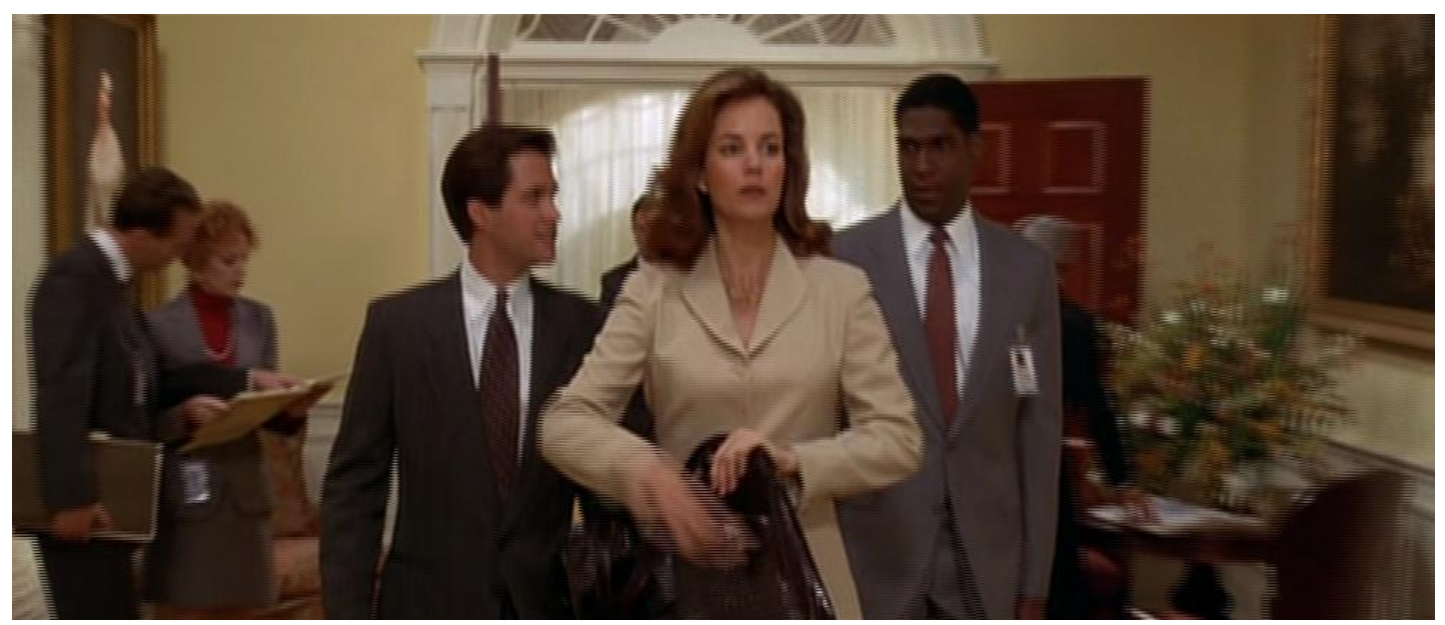

Figure 4 - Spano (Margaret Colin) visually dominating male aides in Independence

Day

At the outset of the film, there appears to be gender equity. This is most apparent in the presentations of the first lady, Marilyn Whitmore (Mary McDonnell), and the White House Communications Director, Constance Spano (Margaret Colin). Both women are shown in positions of power and authority such as when Spano is seen giving orders to two men who are following her and are periodically obscured by her figure, as shown in Figure 4. Although both women are, in a sense, bound to the president, being his wife and handler respectively, it is not a binding that operates within traditional notions of patriarchal order. For instance, Marilyn Whitmore is seen as an independent woman and politician working on her own agenda. The fact that women are presented in this opening as the equals, and sometimes even superiors, to men, points towards a society which has moved outside the boundaries of traditional patriarchal leadership, a movement which would suggest that it is indeed a structurally peaceful society in terms of gender. However, these elements do not function in that fashion due to the ways in which the film draws on the negative treatment of Hillary Clinton in the media by making Marilyn Whitmore her clear proxy.

Hillary Clinton was assailed in the media during the 1992 presidential campaign, specifically due to her gender. Karlyn Kohrs Campbell notes that Clinton has the "dubious distinction of being the first presidential candidate's wife to be the focus of a major opposition strategy" (qtd. in Mattina 424). That strategy focused on 
comments Clinton made which appeared belittling to women in traditional gender roles, such as housewives. Lisa M. Burns details how the media continued to put Clinton in a negative light once she was the first lady, specifically with regard to her efforts to reform health care in ways that present her as "boundary-violating" (141) because she was not acting like a traditional first lady. Having the character of Marilyn Whitmore parallel Hillary Clinton by violating boundaries is not a negative thing in and of itself. Again, Whitmore, like Clinton, expands the role of women in a traditionally patriarchal society by challenging the structural violence of patriarchal gender roles by acting as an individual, Whitmore by working on an undeveloped political agenda, and Clinton through her attempts at health care reform. This makes both women images of a potential structural peace.

However, the negativity comes from the fact that the expansion of her role as first lady is contrasted with images of her husband, the president, and their daughter, alone and unhappy. At one level the personal aspirations of the first lady appear to bring her happiness and, on a larger level, represent steps towards a society of gender-based equality rather than inequality. However, the fact that the potentially positive elements are immediately contrasted with images of the hurt family unit and the injured masculinity of the president elevates both masculinity and patriarchy above independent identities for women. In short, the challenge to patriarchy via empowered women is framed as negative, thereby reinforcing the gender-based structural violence of a patriarchal system. This is also an interesting revision to the notion of dehumanization Sontag describes.

Writing about technology, Sontag observes that the dehumanization found in the original invasion films is a source of anxiety as well as an ideal to which one should aspire (48). As discussed above, the technological elements in the film adhere to this formulation. In other ways, though, the film shows that humanization, specifically the humanization of women, is a threat. In this way, the gender politics of Independence Day address the anxieties surrounding the destabilisation of patriarchal order in the 1990s. These anxieties are seen in three of the four main families as Levinson and Spano are a divorced couple; Casse is an absent father without a wife; and the president seems to simply wander around the White House 
ineffectually. However, because the scale of the conflict is taken to such a catastrophic extreme, the threat of the humanization of women is also amplified so that it jeopardizes more than just family structures.

Teresa Santerre Hobby argues that Independence Day blames the women who exist outside of the traditional patriarchal system for the suffering humanity must endure throughout the narrative. She asserts that the death toll of the film is only as high as it is because of Spano, who "[refused] to listen to her estranged husband about the countdown and the inevitability of the attack" (52). Read this way, the liberated women in Independence Day are dangerous because they threaten to destroy humanity itself. However this misogyny results in the reversion to the “'natural' social arrangements" Ryan and Kellner (245) discuss as it is only after the female characters in the film are removed from all positions of power that humanity is able to achieve victory over the aliens. Thus the Self is divided between men and women where men are privileged above women. This is reinforced by a theme of conservative heteronormativity throughout the film.

In Independence Day, when the first act reaches its climax and massive direct violence is meted out by the alien weaponry, those who do not conform to traditional heterosexual couplings, specifically monogamous marriage, are eliminated. Thus, despite the claims of the filmmakers that any character could die at any moment (Twentieth Century Fox 3), the only two named characters who die in the initial holocaust are Marty Gilbert (Harvey Fierstein) and Tiffany (Kiersten Warren). Marty is clearly coded as homosexual, one of the negative comic relief stereotypes the film contains, and Tiffany is an exotic dancer like Jasmine, who again is one of the heroines of the film. However, while Jasmine openly states that she is only working as a dancer to support her family, framing her as a mother figure, there is no similar explanation as to why Tiffany holds the position, an absence which positions her as an unfit mother figure. In addition to these deaths, Jimmy Barnes (Harry Connick Jr.), the best friend of Hiller, dies in an early retaliatory attack. As Rogin argues, in one of the few scenes Jimmy is in before his 
death he is coded as sexually ambiguous if not openly homosexual (65). ${ }^{7}$ The first lady, although a wife and mother, is established both in the film and through connections to Hillary Clinton as incapable of being rehabilitated into the patriarchal order, and eventually dies from wounds suffered in the initial invasion, a death which Mair reminds "serves to galvanise our WASP president into acting" (45) further underscoring the patriarchal structures of violence. Lastly, Casse, an alcoholic and absent father, redeems himself in his final sacrifice, metaphorically atoning for his failure to be a proper father. Interestingly, Casse accomplishes this in suicidal fashion using an aircraft, an act which holds a parallel with the 9/11 attack, but also, as Rogin notes, in a fashion which carries with it strong homosexual undertones (69). The dominant reading of this sequence, though, ignores those undertones, focusing instead on the masculine heroism of the act as it is shown to be the way he finally regains the respect of his children.

At the end of the film, then, the Self that has persevered is one rife with structural violence. It is a strongly patriarchal system which has no room for those who do not adhere to its hierarchical order. Additionally, while men are privileged, those who belong to higher socio-economic classes are more esteemed than those who do not. While there is some apparent ethnic diversity, the prominence of the nation means that the individual, along with any ethnic heritage, is secondary. It is necessary to remember that even though the film sanctions this violence by normalising it, the larger goal of this articulation of the Self is to create a unified entity against which it positions the alien Other. Accordingly, the Self of Independence Day ultimately forms a state system that Galtung would describe as Unitary since it shows a very high internal capacity for peace-building, and a very high external capacity for peace-threatening (Peace 65). This is the mythic version of the United States, and it is primarily that national identity which is found in the dreams the film presents.

\footnotetext{
${ }^{7}$ For a more complete analysis of the homosexual themes in the film specifically as they relate to AIDS, see Rogin Chapter Five.
} 


\section{Aliens and Arabs after 9/11: The Dreams of Independence Day}

In the mid-1990s, the precise nature of the US Self was in question. The concept of "victory culture" that had once been integral to its identity was no longer in favour. Thus, the policies of the Clinton administration, which in 1994 alone involved a near military intervention in Haiti and troubled negotiations involving nuclear regulations with North Korea, were met with sharp criticism. Whether the criticism was aimed at the policies or Clinton himself is debatable, but the result was that Clinton shifted his policies more towards centre. Additionally, multiple acts of domestic terrorism, including the 1993 bombing of the World Trade Centers and the 1995 Oklahoma City bombing, raised questions about the security of the United States. These apparent instabilities seemed to give credence to the apocalyptic predictions made by those such as Kaplan (1994) who saw the United States on an imminent path toward destruction. However, the absence of "victory culture" in the political arena did not indicate it was gone from the United States entirely. As the above analysis of the film shows, tenets of victory culture not only did not go away with the Cold War, but they were in high demand in the public consciousness.

Discussing the disaster films of the 1990s, Jean Baudrillard described them as indicative of a larger phenomenon in the world. For him, the popularity of these films represented a mass envisioning of the demise of the United States before it reached "perfection or omnipotence" (7); the ruined cityscapes revealed the (hidden) ire towards the capitalist system. At the same time, though, he views these dreams as suicidal, suggesting that the United States itself is chief among those wishing for its demise. Of the 9/11 attacks, then, the remark that Baudrillard makes, "they did it, but we wished for it" (emphasis in original) (5), can be read in a larger suicidal context, suggesting that "we" is also the United States. In other words, the terrorists who attacked the United States on September 11, 2001, simply performed a deed for which the people of the United States had been wishing. However, the idea of the suicidal drive of the United States fails to see the larger picture. Specifically, the physical spaces in these films were destroyed, but the principles which built them not only survived, but are reinvigorated. This is true of many disaster films from the 1990s, such as Twister or Volcano, where Self- 
specifically the United States -is brought together through adversity against nature as Other. However, in Independence Day where the Other is corporeal and must be actively destroyed rather than just subdued, it serves the additional purpose of showcasing the military might of the United States. As Mair remarks of the aliens in Independence Day, they allow for the display of "the impregnability of American supremacy and its rightful leadership of the globe" (34). In other words, what Independence Day offers the viewer is a wish fulfilment fantasy where the United States uses its apparent destruction by a super-powered Other as a means of redefining a unified Self that exists in a binary Self/Other situation. The steepness of the Self/Other gradient imbues the Self with purpose: destroying the Other. Thus Independence Day shows a resolution to the post-Cold War identity crisis through regression to a pre-Vietnam Cold War-style conflict that erupts, at last, into a hot war. This dream was realised in the response of the Bush administration to attacks of $9 / 11$.

In the rhetoric George W. Bush used in the immediate post-9/11 period, it was clear not only that Bush was defining the United States as a unified Self against an enemy Other, but that he was doing so in a way that evoked a mythic United States. For instance, on September 20, 2001, in an address to a joint session of the United States Congress, Bush said, "They [the terrorist groups] hate our freedoms-our freedom of religion, our freedom of speech, our freedom to vote and assemble and disagree with each other" ("Address" n. pag.). This definition of the United States works both to define the Self and the Other with the Self of the United States becoming mythic. Absent from that definition are the domestic tensions that were prevalent throughout its history. Also elided are the domestic developments in the 1990s, where the lack of an external Other saw the fragmentation of the national Self. Such an elision points towards structural violence. Of course, if the Self is the mythic supporter of freedom in those remarks, the Other becomes the mythic opposition to Freedom. Again, the historical impetuses for the attacks, "blowback" for instance, are not acknowledged in any way by the definition Bush articulates of the Self and Other. For both cases, the comments Bush made serve another purpose, which is to connect the post-millennial Self and Other with the heroes and 
villains of World War II in the period before the atomic bomb, which is to say in the period of victory culture. This is accomplished by the fact that the list Bush presented not only evokes the tenets of the Founding Fathers by way of the Bill of Rights, it also points towards the Four Freedoms which were articulated by Roosevelt during the Second World War. This twin reference rhetorically positioned the United States as a benevolent nation being victimized by forces of oppression, and, in so doing, did not resolve any structures of violence, but, like Independence Day, drew the focus away from them. The result was solidification of a Self in opposition to the terrorist Other that healed the "instability and uncertainty" (King, Spectacular 154) of the 1990s. Like the film, though, the response to 9/11 did not actively address the structures of violence which were prevalent in the United States at that time. Unlike the film, though, which defined the Other as a (literally) alien species, the $9 / 11$ response relocated that definition onto human races, specifically Arabs, presenting them as inhuman. This is evident in further remarks made by Bush such as his reference to the War on Terror as a "crusade" ("Remarks" n. pag.), a statement which will be explored in much greater detail in subsequent chapters. Returning again to the notion of state articulated by Galtung, then, the response to $9 / 11$ aimed to create a Unitary-style system wherein the population of the United States was bound beneath its president, and sought to destroy the foreign Other. As the approval ratings for Bush evidence, the initial reception by the American people was very high, earning him an approval of over $90 \%$ in the immediate wake of the events of $9 / 11$. However, as time passed this approval rating dropped substantially.

Ultimately, then, Independence Day is a film that presents a standard Self/Other binary. This relationship is key to the concept of victory culture that Engelhardt advances, but it was a relationship which was absent in the wake of the Cold War. During the 1990s, instead of an external Other, the structures of violence within the United States made apparent the internal Others, resulting in an apparent fragmentation of the Self. The dream of Independence Day is not one which sees the United States destroyed for its position of potential dominance, but instead is one which validates that power by creating an enemy Other to fill the void left by 
the dissolution of the Soviet Union in 1991. After the attacks of 9/11, the response of the Bush administration made this dream a reality as the US Self was redefined in opposition to the Other of terrorism. Like Independence Day, which drew on conventions from World War II films, the response to $9 / 11$ made allusions to World War II- "the good war" - in an effort to frame the War on Terror as another noble cause. For both the film and the $9 / 11$ response, however, it was a redefinition of Self that seemingly solved the fragmentation of the 1990s, but ultimately addressed none of the underlying issues. 


\section{Chapter Two}

\section{Adrift with the American Dream: Titanic (1997)}

In 1997, still in the throes of a major identity crisis in addition to the numerous smaller crises it engendered, the United States found itself on an economic upswing. Despite beginning the decade in a recession, the US underwent an extended period of growth in the latter part of the decade. With the economy in such good stead, it is unsurprising that the American Dream found its way again into political rhetoric. During his second inaugural address in 1997, President Clinton made the follow statement:

"May those generations whose faces we cannot yet see, whose names we may never know, say of us here that we led our beloved land into a new century with the American Dream alive for all her children; with the American promise of a more perfect union a reality for all her people; with America's bright flame of freedom spreading throughout all the world" (“Inaugural” n. pag.).

For Clinton, the American Dream was a dream "that one day America would rise up and treat all its citizens as equals before the law and in the heart" ("Inaugural" n. pag.). However, at the same time it was a dream of material equality and economic mobility. New technologies, such as the World Wide Web, opened up new avenues of potential success. It was during this time that companies such as Amazon.com and eBay rose to prominence. While the reactivation of the American Dream seemed to suggest a resolution to the identity crisis of the United States, the crisis itself was not resolved. Instead the anxieties surrounding the identity of the nation, coupled with other anxieties such as those relating to the impending millennium, manifested themselves in cultural artefacts. One such set of artefacts are the films which comprised the disaster film cycle that emerged in the mid-1990s.

As discussed in the previous chapter, the disaster films became a major force in Hollywood during this time. Given the advances in special effects technologies, it is 
unsurprising that these films emphasised destruction, often showcasing it in spectacular detail. This is not, however, simply a matter of enhanced special effects. As Stephen Keane observes, comparing the 1990s films to a cycle of disaster films in the 1970s, "the stakes are generally much higher in the 1990s disaster cycle" as the disaster often threatens the planet itself (74). Of course the planet is frequently represented by the United States, as in Independence Day. While the increased peril could certainly be connected with apocalyptic anxieties tied to the millennium, Keane cautions that treating them solely in that way as it "ignores not only industrial imperatives but also further, ideological readings that can be brought to bear on them" (74). By considering these films within the context of the political developments in the post-Cold War United States, approaches to the texts which elucidate the violence they contain can be developed in much greater detail. To that end, the most successful of the disaster films, Titanic, which was also the most successful US film in history until the release of Avatar over a decade later, speaks to the identity crisis in the United States and it does so by addressing the concept of class, specifically class mobility.

In this chapter I will argue that Titanic "dreams" a resolution to the identity crisis of the United States by reactivating mythic notions of the American Dream. In so doing, it perpetuates structures of violence by effacing inequities entirely and replacing them with visions of structural peace. Further, it is my contention that the response to $9 / 11$ carried out by the Bush administration brings the dream of Titanic to fruition by mobilising a similar rhetoric. The first portion of my analysis will focus on the economic situation in the United States during the 1990s, directly connecting it to the work of Johan Galtung who labels the US as a Blue School economy (Peace 149). By establishing that connection, I will show how the Self/Other paradigm established during the Cold War between the United States and a Soviet Other worked to align the United States entirely with the free market principles of the Blue School. The post-Cold War identity crisis in conjunction with increased wealth disparity threatened that definition of the Self, ultimately leading to a need for either a new national identity or a revitalisation of the old one. I will next argue that what Titanic provided audiences with was exactly that revitalisation 
of Self, which, drawing on the work of Roland Barthes, I will suggest was accomplished through its articulation of a mythic America founded on the American Dream, which itself is a myth. The Self/Other relationship the film articulates, then, is one that hinges upon support, or lack of support, for the American Dream. I will then show not only how the Self is overtly aligned with the structural peace the mythic American Dream brings, but also how it is implicitly connected with the structures of violence that inform the myth. This section will show the ways in which the Self is thus based upon both gender- and ethnicity-based violence. However, I will argue that because these structures of violence are both rendered invisible by the film and externalised onto an Other, the Self is able to retain an innocence that validates its own deployment of violence against the Other, albeit in a struggle to survive. I will then connect this analysis of the violence in the film to the response of the Bush administration to the events of 9/11. It is my ultimate contention that by drawing upon similar mythic notions of the United States which emphasised structural peace and concealed structural violence, the response to 9/11 saw the dreams articulated in Titanic brought to fruition where a peaceful US Self was violated by a violent Other.

\section{Recession, Victory, and Resurgence: The US Economic Self in the 1990s}

At a cultural and political level, the Cold War was framed as an ideological conflict. On one side was the democracy of the United States and on the other the communism of the Soviet Union. These ideologies of course informed the economics of each superpower such that the free market economy became an integral part of how the United States defined the Self, with socialist principles enmeshed with the concept of the Other. In 1987, after a dramatic drop in the stock market, the United States economy fell into a recession. Despite some signs of an early recovery, the US economy languished and it took far longer to regroup than anticipated. Coupled with the financial rise of Japan, the position of the United States as a dominant economic super-power seemed threatened on multiple fronts. The threat, though, was cut short by the sudden collapse of the Soviet Union during that period with the United States technically "winning" the 
Cold War. The victory seemed to validate the socio-economic ideology of the United States and the capitalist system. Thus, despite the faltering US economy, the free market principles that the US defined as Self throughout the Cold War remained firmly in place and continued to thrive throughout the 1990s as the economy eventually revived and grew. To relate this political, and indeed economic, development to the definition of Self and Other, it is useful to consider the articulation of the US and Soviet models by Johan Galtung.

For Galtung, the term "economy" refers to "the organization of nature-productionconsumption cycles" (Peace 139). To understand how an individual society structures its economy, Galtung approaches it via the "economic cycle" which he sees as involving a range of societal elements including "factors of production" and "relations of production" (Peace 139). Each culture, then, makes certain choices which define its economy along six spectra. Galtung identifies these as individualism and collectivism, verticality and horizontality, monetization and specificity, processing and 'naturity,' and expansion and stability (Peace 139). ${ }^{8}$ Certain configurations form the foundation of what Galtung calls "schools" of economics, and he roughly categorises the US and Soviet economies into what he labels Blue and Red Schools respectively. The Blue School is grounded in Smithism, while the Red School is a socialist model. Galtung does not see either economic model as being necessarily bound to the development of their respective nations, but the economics and history are certainly enmeshed. It is worth further clarifying, as Galtung does, that "the Red system is not based on Marxism," but was instead "developed by improvisation, challenging Blue assumptions on crucial points" (Peace 144). Thus a binary is created between "Market and Capital" and "State and Power," representing the US and Soviet Union in turn. Galtung contrasts the two within the six spectra mentioned above, suggesting that the Blue School privileges the individual based on merit while the Red School functions based on leadership dictates with no substantive consideration of popular opinion. ${ }^{9}$

\footnotetext{
${ }^{8}$ See Galtung Peace, especially pages $139-141$ for a more detailed explanation of these spectra.

${ }^{9}$ For a more detailed account of how Galtung defines these and other economic schools, see Galtung Peace, Part III.
} 
In terms of cultural violence, then, the United States identified the tenets of the Blue School-the meritorious individual-as key components of the Self while those of the Red School-the stereotyped drone worker-were relegated to the Other. Films such as Red Dawn and Top Gun capture the Reagan-era bias of an insidious Soviet Other in opposition to a noble US Self, making them prime examples of cultural violence. The Soviet Union, of course, utilised the opposite definition of Self and Other. The fact that the US economy began to recover after 1992 and indeed entered one of the largest periods of sustained growth in US history bolstered this ideological definition of Self and Other. This is particularly important since it was concurrent with the post-Cold War identity crisis that the United States experienced. The free market ideology became a key element of the 1990s US Self, exemplified at the end of the decade by the dot-com boom, where fortunes were seemingly made overnight on the new electronic frontier.

Of course, as Galtung contends, ideology is one of the key domains of cultural violence, and in this case the ideological system that grew out of the economic policy became conflated with national identity, producing an American ideology which resembled that of a nation-state (Cultural 298-299). In defining itself as the victor of the Cold War, the connections between capitalism and nation were reinforced. These connections point to the fact that inherent in this economicallygrounded Self was potential violence, especially given the way that Galtung frames the nation-state as an inherently violent entity. The nation-state ideology, however, is not the only source of ideology-based violence. Galtung also argues that any economic school, including the Blue School, carries with it certain "sideeffects" which he labels "externalities" (Peace 154); these effects will primarily be at the structural rather than the cultural level, although they can certainly be validated in cultural artefacts. It is important to note, though, that these effects are not necessarily negative as they could reinforce structural peace rather than structural violence. For instance, the Green School Galtung describes is based upon "civil society and dialogue" and makes meeting needs a higher priority than wealth accumulation (Peace 146). Since it essentially encourages social equity, "externalities" of the system would produce structural peace. It is also worth 
pointing to the fact that Galtung acknowledges his approach towards the investigation of these externalities uses definitions which are potentially problematic. However, it is those issues which form the foundation of his exploration and he uses them to investigate the complex interrelationships between the economic externalities. ${ }^{10}$

Since the side-effects can be both positive and negative, Galtung takes a similar approach to his analysis of the externalities of the Blue School, noting that at the individual level freedom is possible, but so is repression. Along those lines, within a social sphere, equity is paired with exploitation, solidarity with fragmentation, participation with marginalisation, and so on. Again, what these externalities represent is the potential for any economic system to both promote and restrict social equalities. However, as Galtung notes, "mainstream economics discourse makes much of what happens around economic activities opaque by excluding many dimensions from serious consideration" (Peace 154)-and those dimensions include the side-effects he delineates. It is unsurprising, though, that mainstream analysts would not give detailed assessments of potential inequities discussed since effacing them maintains and supports a status quo. By identifying the Self in terms of the Blue School model, something which was done both explicitly and implicitly in the United States, the nation defined its Self in terms of pre-existing, idealistic structures of peace, and also with structures of violence which, by definition, supported and concealed societal inequities. By hiding, or eliding, the negative aspects of the free market economy, the Self came to be defined in terms of mythic concepts like American Exceptionalism and, perhaps even more pervasively, the American Dream. These ideas, and others like them, will be discussed in detail below, but it is important here to acknowledge that they came to embody the American Self as the United States grew and developed in the period under investigation. However, due to the mythic nature of the concepts being examined, they do not reflect historical conditions in full. Accordingly, they do not substantively engage with the negative externalities that Galtung mentions such as fragmentation or marginalisation-structures of violence. By concealing this

\footnotetext{
${ }^{10}$ See Galtung Peace, part III, especially section 3 for more.
} 
violence through omission, the representation of the American Self ultimately reinforces it.

Thomas Byrne Edsall has discussed the shift in the domestic economic and political situations in the United States in the late twentieth century. According to him, the economic statistics from the 1980s reflected the fact that "economic and political power are flowing from the middle class to the affluent" (n. pag.), a movement which points towards potential inequities. This wealth disparity continued to exist throughout the 1990s. As William Domhoff shows, through his use of work by economist Edward N. Wolff, from 1981 to 1998 the share of wealth held by the bottom $99 \%$ fell from $75.2 \%$ to $61.9 \%$ and the share of wealth held by the top $1 \%$ rose from $24.8 \%$ to $38.1 \%$ (n. pag.). More importantly, although the changes in these statistics span two decades, the more detailed numbers Domhoff presents show that the wealth concentration by class remained fairly constant throughout the 1990s (n. pag.). The purpose of presenting these statistics here is not to suggest that they serve as evidence of structural violence. Instead, it is to illustrate two key points. The first is that the wealth disparity in the United States, as shown in the statistics above, increased substantially at the end of twentieth century. The second is that this increasing disparity of wealth points to the fact that class mobility was limited in the United States during the 1990s. Both of these are important because they point towards a potential conflict with the US identity which was predicated heavily on the idea of the American Dream. While the decrease in economic mobility did not kill the American Dream, it did make it seemingly more difficult to achieve. What is more, the fact that the dream was tied so closely to the identity of the United States, which was in crisis, caused it to be questioned as well. This questioning manifested itself at the cultural level, as exhibited in Titanic. However, Titanic does not question the viability of the dream, nor does it reassert it. Instead, the film takes the dream and rebuilds it in a mythic fashion, effectively revitalising it entirely. This is accomplished by the creation of a representation of the United States based solely on the dreams of those travelling to it. The result is that the film presented late-1990s audiences with a view of America that was dramatically different from the nation as it existed at that time. 
In the film, the viewer is relocated to a period where the American Dream was a novel concept, and abilities and merit were the most important qualities an individual could have. In Titanic, viewers are positioned in a period where the American Dream was alive and well. To understand how the film does that, it is useful to first look at the dream itself.

\section{The American Way: Titanic and the American Dream}

For Galtung, class is a concept that exists as part of a larger network of ideas. As he defines it, it is integrated into a framework which involves both state and race. These broad categories are then broken down further into ten "fault lines" where humanity and nature intersect with one another (Peace 60). Those points are human/non-human, gender, generation, race, class, nation, countries, "and the three edges in the state-civil society-capital triangle, in social and world space" (Peace 60). When there is a unitary system, such as a single-class society, he contends that internal peace-building capacity will be high as will external peacethreatening capacity, which is to say violence. Conversely, if there is a multisystem, such as a multi-class system, then internal violence will be high as "stratification" increases (66) and levels of external violence will vary.

The American Dream was first defined by James Truslow Adams in his seminal volume The Epic of America, as "that dream of a land in which life should be better and richer and fuller for every man, with opportunity for each according to his ability or achievement" (404). This definition establishes the United States as a meritocracy where success is seemingly only connected to personal ability. The implication is that if somebody has the ability, nothing is out of their reach. However, since this dream is predicated on class mobility, it necessarily exists within a multi-class system. As Galtung predicts, this will promote stratification, something which is evident in a few ways, even in the words Adams uses in his definition. For instance, his language is gendered. So while it is clear that "every man" might achieve the American Dream, it is unclear that women in the United States can expect the same thing. Given the structures of violence in US culture that privilege men over women, structures prevalent both at the time Truslow was 
writing and in the contemporary period, it is likely the definition stands as an embodiment of these structures. The American Dream of a merit-based system is one that, even at its codification, privileged certain groups over others, thereby reinforcing structures of violence in addition to creating a stratified class system. In other words, the definition itself reinforces social inequities, which is at odds with the very concept of a meritocracy. Titanic is like this original definition of the American Dream: there are progressive elements in it, but ultimately the cinematic language it uses to define the American Dream, and by extension the America Self, is language that reinforces rather than condemns structural violence.

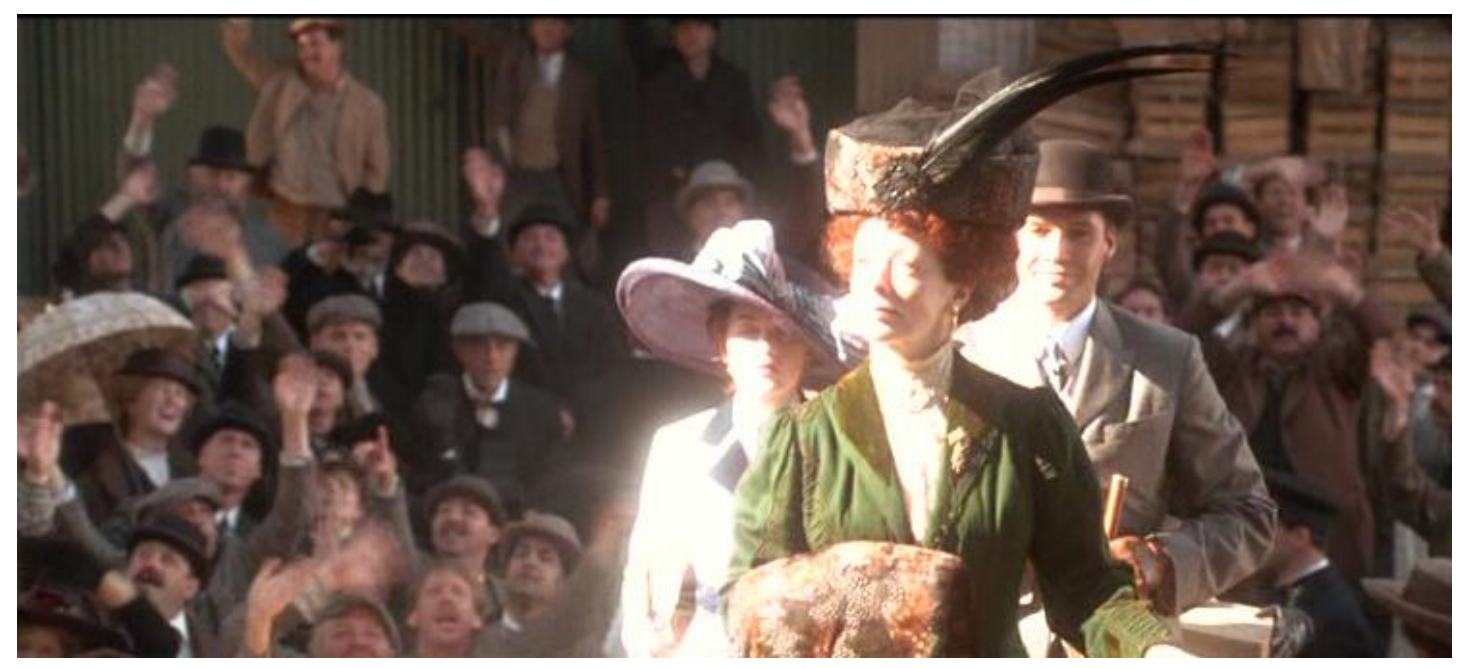

Figure 5 - The luminous white elite set apart from the darker masses in Titanic

Titanic is ostensibly concerned with class. From the first shots of the boat in port with passengers clamouring to board it, there are very intentional distinctions drawn between the wealthy and the poor. The ultra-rich are ostentatiously dressed and set apart from both the masses and the environment while the poor blend together both with each other and with the grimier locales. For instance, Rose DeWitt Bukater (Kate Winslet) is first shown arriving at the Titanic with attendants and masses of luggage. She is wearing an oversized hat and an extravagant dress. The area the wealthy enter into is visually demarcated from the domain of the poor; they are figures apart from the crowd, as shown in Figure 5 where a bright white light "spots" them. Rose then ascends a platform reserved for the wealthy passengers, literally elevating her above the masses of people below. This of 
course works in tandem with the star image of Kate Winslet. Conversely, Jack Dawson (Leonardo DiCaprio) is first shown in a small bar gambling for his passage. The bar is in poor repair, and he is surrounded by unkempt sailors. While his handsomeness sets him apart from the others-something Sean Redmond connects with his star image which is "heavenly white and blonde-ish" (200)-his simple clothing grounds him in the scene.

Interestingly, the film does not develop the middle class in any way, which perhaps can be read as a concern over the disappearance of the middle class in America that many have observed. However, it is more likely that this is due to the fact that the binary structure between the rich and the poor makes for a clearer narrative. In fact, the magnification of the conflict between these two classes has led some, such as David L. Lubin, to describe the film as telling an "upstairs/downstairs" (17) story, in reference to the British television drama, Upstairs, Downstairs, which followed the lives of people living in an Edwardian-era London townhouse, specifically the wealthy owners and the poor servants. This comparison is all the more apt given the fact that Titanic engages with Edwardian England and its class politics.

The RMS Titanic is shown in the film to be a physical manifestation of Edwardian era politics. The upper decks which house the wealthy are physically separated from the lower decks and the steerage passengers. However, since the Titanic sank at the end of the Edwardian era-some mark the event as the actual end of the era rather than World War I-the story itself shows the conflict between the old system and the new, with the new represented by the United States and the American Dream. In terms of violence, the old value system and the new are the Other and the Self respectively. The conflict takes shape in the romance between Rose and Jack, in which Rose must choose between being a society girl whose wealthy lifestyle is guaranteed-thereby becoming part of the Other-or giving it all up and relying only on her natural abilities - thus aligning with the Self. Ultimately she chooses the latter and in so doing becomes a symbol of the American Dream. However, the fact that she renounces her privileged life to essentially test herself in the "melting pot" of the United States says much about the Self/Other paradigm constructed by the film. 
J. Emmett Winn observes of the film that "the upper class are overwhelmingly depicted as malevolent; and the underclass, as virtuous" (109). While this does sum up many of the characters, it overlooks some important elements that need to be qualified, specifically that neither the upper nor the lower classes are homogeneously "malevolent" or "virtuous." For example, the "unsinkable" Molly Brown (Kathy Bates) is a character in the film based on an historical person. She was ostensibly living the American Dream, having risen from poverty to wealth during her lifetime. Even though the wealth gained her access to the upper class, the people in that class did not accept her; in the film much is made of the fact that she is "new money." Her position as a member of the upper class does not situate her as the Other because the money has been earned rather than inherited. Accordingly she does not privilege her social position more than her position as a member of humanity. This is clear when Jack is afforded a chance to attend a dinner in the first class dining area and she furnishes him with the appropriate attire. That he is able to successfully blend into the culture raises issues regarding class and "passing." The inverse of Molly Brown can be seen in the character of Spicer Lovejoy (David Warner), the personal valet of Caledon "Cal" Hockley (Billy Zane), the man Rose is to marry. Although he is a member of the underclass, the "downstairs" as it were, he is only ever seen working to carry out the orders of Cal; his motivations never appear to be connected to class mobility. He has accepted his position as underclass, and based upon his antagonistic actions towards Rose and Jack for their violation of the strict Edwardian social structures, he becomes a villain despite the fact that he belongs to the underclass. The characters of Molly Brown and Spicer Lovejoy, then, stand as evidence that the film does not construct Self and Other, as Winn suggests, according to class affiliation. Instead the film articulates them in relation to the American Dream of merit-based class mobility. Specifically, the Other of the film is comprised of the particular characters within both the upper class and underclass who wish to maintain the rigid class structures that formed the foundation of Edwardian values. The two primary antagonists of the film, Cal Hockley and Ruth DeWitt Bukater (Frances Fisher), exemplify this position of the Other. 
Cal explicitly advocates the preservation of a strict class system in the United States. This is clear when he gives Rose a priceless diamond called the Heart of the Ocean, telling her that "It's for royalty. And we are royalty." With the ship sailing to the United States, his remark acts as a foreboding comment on the imposition of Edwardian values on the American Dream. It is clear that Cal believes that the upstairs and downstairs, so to speak, should be permanent social institutions, and that the United States needs a class system. This ideology is reinforced throughout the film by his repeated and vehement objections to the lower-class Jack being permitted on the upper decks. The class mentality is also a part of Ruth: she has arranged for Rose to marry Cal as a way of maintaining the position of her family in society since her deceased husband lost all of their money. The fact that she is forcing Rose into the marriage is not-so-subtly underscored in a scene where she roughly laces Rose into a corset as Rose objects to the marriage saying that it is "unfair." It is worth noting, though, that Ruth responds by saying, "Of course it's unfair. We're women. Our choices are never easy." So while the sequence does emphasise the position of Ruth as Other due to her adherence to Edwardian code at all costs, it also suggests that gender is as much a factor as class. This again evokes the writing of bell hooks and the "interlocking" elements of class, gender, and race (7)-the latter of which will be discussed further below. While the clear gender discrimination does present the larger plight of Ruth, who is indeed a victim of structural violence, she remains an Other in the film because she places personal privilege over the ideals of a meritocracy. The Self, of course, is represented by the characters who believe in the prospects of America.

While the Self of the film is ultimately embodied by Rose, who survives the sinking of the Titanic and goes on to live the American dream, she adopts her worldview from Jack. Jack is depicted as a figure that is able to transgress class boundaries because he wholeheartedly believes in the American Dream. For him, there is no boundary he cannot cross if he so wishes. He adapts to each situation as he confronts it and relies upon his natural abilities to pull him through. This is clear in the already discussed dinner sequence where he successfully passes as a member of the upper class, but it is also seen in the larger context of his relationship with 
Rose. He wants to be with Rose and ultimately he is. However the scenes in which Jack essentially lives the American dream are those in which Jack gets Rose to transgress the boundaries with him. For instance, at one point he brings Rose to the lower decks where the steerage passengers are having a raucous celebration. Unlike Jack who only passes as a wealthy passenger while on the upper decks, Rose, it is suggested, is able to become a steerage passenger. Despite her obviously upper class attire, the passengers on the lower decks do not care about her position since by being there, it is understood, she acknowledges equity between classes. This willing downward movement of Rose, and of course her ultimate commitment to that movement after the ship sinks, positions her as part of the Self, of which a more detailed representation is found in Table 1 which categorises the main characters in the film. What the diagram makes clear is the fact that class status does not determine alignment in terms of Self and Other, evidenced by the fact that members of the upper and lower classes are defined as both Self and Other.

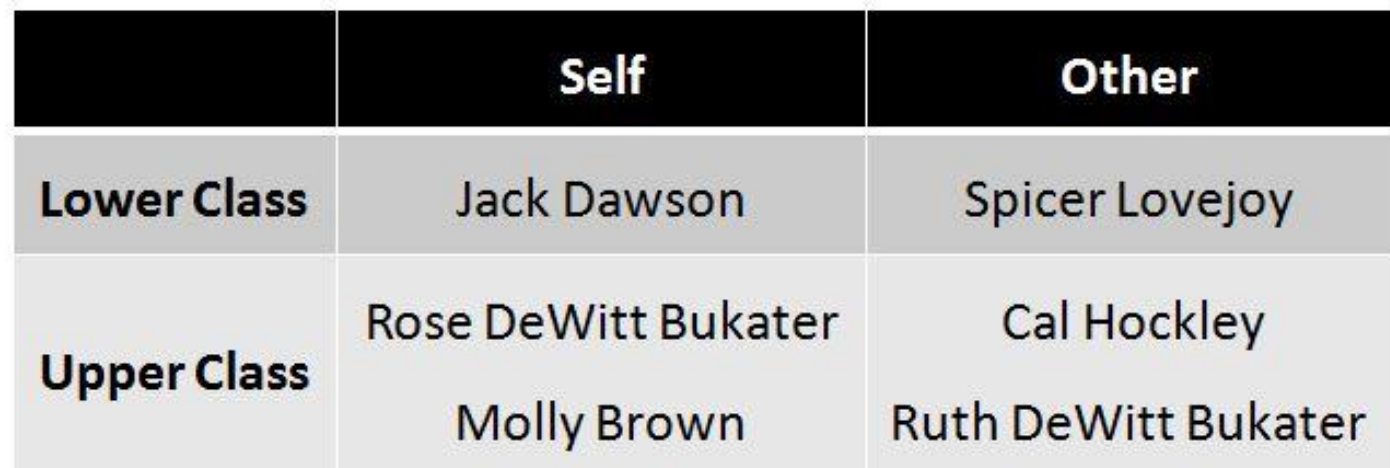

Table 1 - Self and Other overriding class affiliations in Titanic

While the Self/Other binary of the film is not strictly built around class divisions, this does not entirely invalidate the observations made by Winn regarding the differences between the wealthy and the poor (109). For instance, as is shown during the party on the lower deck, the steerage passengers have an unbridled lust for life, and despite their rough appearance, their acceptance of Rose does indeed position them as almost universally "virtuous," as Winn claims. All of this is perhaps best explained in the fact that for them the Titanic, as is stated in the film, was "the 
ship of dreams." This sentiment is also echoed in the production materials for the film which state that, "the passengers in third-class were emigrants travelling with all they owned, leaving behind all they knew and heading to America flush with the hope of a new life and greater fortunes" ("Handbook," 22). Interestingly, despite the fact that the steerage passengers have been shown to be multi-ethnic, the representations here present them largely as stereotypically Irish, a representation which suggests a structure of violence. In fact, the construction of a mythic America in the film, particularly with regard to the principles of the economic schools discussed earlier, contributes to the articulation of multiple structures of violence.

\section{Below the Surface: The Self and Other in Titanic}

Based on the above analysis of the Self/Other paradigm, it would appear that the film is devoutly opposed to the imposition of class structures which create social inequities, and indeed it is. However, the opposition between the Self and Other in the film frames the class structures of the Edwardian era as a relic of the old world, and an old economic model. While there certainly are some differences in the way Cal and Jack approach business, they both ultimately represent the Blue School of economics which elevates private ownership, material wealth, and, as Galtung notes, "no stop sign" (Peace 142) in terms of expansion. The Blue School elements are clearly seen in the characters of both Cal and Jack.

For instance, Cal is a wealthy heir whose family is in the steel industry. While he is framed as arrogant and unsympathetic towards the lower classes, his connection to steel evokes the history of Andrew Carnegie, who immigrated to the United States, worked as a factory worker, and rose to become one of the wealthiest men in history. In short, he is one of the great examples of the American Dream. Despite that connection, Cal is positioned as inheriting his wealth instead of earning it. Jack, on the other hand, creates his own luck and forges his own destiny. This is clearest in the dinner sequence where the opulence stands in stark contrast to his humble beginning, underscoring the fact that he can rise to material heights. In so doing, of course, he validates the American Dream. In fact, it is because Cal opposes this 
mobility that he becomes a villain in the film. His opposition to the lower classes, however, effectively conceals the fact that his material wealth is underpinned by the same principles that support Jack, which again are those of the Blue School.

When discussing the externalities of the Blue School, Galtung divides them into the positive and the negative (Peace 156). These are categorised into six spaces, which are nature, human, social, world, time, and culture. The positive are pathways to peace while the negative lead to violence. Reading the side effects of the Blue School in terms of the construction of the Self and Other in Titanic reveals a sharp division between the two. Specifically, the Self and Other in the film do not represent separate economic schools, as the United States and Soviet Union did. Instead they are the positive and negative aspects of the Blue School respectively, as shown in Table 2.

\begin{tabular}{|c|c|c|}
\hline & Self & Other \\
\hline Nature & Diversity, Symbiosis & Depletion, Pollution \\
\hline Human & $\begin{array}{l}\text { Well-being, Challenge, } \\
\text { Identity }\end{array}$ & $\begin{array}{l}\text { Misery, Monotony, } \\
\text { Alienation }\end{array}$ \\
\hline Social & Horizontality, Solidarity & Verticality, Individualism \\
\hline World & Horizontality, Solidarity & Verticality, Nationalism \\
\hline Time & Reproducibility & Degradation \\
\hline Culture & Holism, Idealism & Atomism, Materialism \\
\hline
\end{tabular}

Table 2 - The Blue School in terms of Self and Other (adapted from Galtung Peace 160)

In that diagram, the Self is clearly aligned with the positive aspects, such as Identity and Idealism, the latter being a key element of the American dream. What is more, all of these qualities would be associated with peace building rather than violence. As for violence, as the chart shows, it is associated entirely with the Other as concepts such as Alienation and Degradation are the tactics used by the upper class against the steerage passengers in the film. It is worth noting, though, that the positive and negative qualities of the Blue School economy exhibited in the film are not located in a single sphere, with the film representing all, including Nature to 
some degree. The result is that the Self in the film is an idealised version of the Blue School. Since the Self is so firmly identified with the American Dream, that too becomes idealised; the steerage passengers are seemingly guaranteed to have wonderful lives when they reach America despite the scheming of the elite Other. The point is that the intentionally skewed nature of the Self produces a mythic version of the American dream, a sanitisation that is itself a form of violence.

It is useful here to draw again on the work of Roland Barthes on myth. In defining myth, Barthes observes that it is "a kind of ideal servant: it prepares all things, brings them, lays them out, the master arrives, it silently disappears: all that is left for one to do is to enjoy this beautiful object without wondering where it comes from" (151). What Titanic presents is an entirely decontextualised version of the American dream where seemingly anything is possible. For instance, at the end of the film after Rose arrives in the United States, she effectively denounces her heritage and is left with nothing, yet as the contemporary sequences in the film show, she has lived a life full of everything she had ever hoped to have, save for Jack of course. The contention is that the United States welcomed all immigrants equally and did not discriminate against anybody. If somebody wanted to have something and was willing to work to achieve it, then nothing would stand in his or her way. What this mythic version of America effectively elides are the numerous structures of violence present in American culture that would have prevented such dreams from becoming reality such as sexism and racism. Without that historical context, though, the structures of violence become elided, and what remains are the positive elements only. Thus, while Titanic does concern itself with class-based structural violence, it does so only at the most superficial level; there is no active development of the underlying causes of inequity, namely the violence associated with the practices of the Blue School. Instead what the film explores is how the different classes view issues such as gender. This makes sense since hooks not only observes that class, race and gender are related elements, but argues that both race and gender are frequently used "as screens to deflect attention away from the harsh realities class politics exposes" (7). Accordingly, the film mobilises gender as 
a way of deflecting attention away from the deeper issues of class-based structural violence.

For the upper class, the movie posits, women are expected to behave in a very specific way, abiding by the patriarchal rules of the culture; Molly Brown is not accepted since she challenges this in many ways. The lower class, however, shows that women are able to drink and carouse along with the men. Additionally, the women in steerage, as is evident in the repeated shots throughout the film of an Irish mother (Jenette Goldstein) trying to save her children, have a much closer relationship with their children. This becomes all the more evident when contrasted with the corset scene where it is binding rather than protection that links mother and child. Of course the corset also suggests the additional layer of direct violence-the bodily confinement-that accompanies the gender-based structural violence of the film. The point, though, is that the film does not treat sexism as a form of violence found in both Edwardian and American culture, but instead is one relegated to the characters that support the old ways rather than the new. This elision implies that such violence is absent from the United States. Of course the US it refers to is a dehistoricised, mythic one. Returning to the externalities of the Blue School, then, the mythic America permits well-being, challenge, and identity while the enemy of that myth seeks to institute misery, monotony, and alienation. Interestingly, this view is reinforced in the film in the way it critiques the lack of reverence paid to the Titanic by professional scavengers in the contemporary framing sequences, particularly the character of Brock Lovett (Bill Paxton).

When Lovett is first encountered, he is delivering a speech about the emotional power of Titanic. His words are immediately revealed to be an act, though, as he is simply searching for wealth, again a sign of Blue School materialism. What is worth noting, however, is that Lovett is characterised by a very overt sense of stereotypical masculinity. He smoke cigars, curses, and is above all determined to succeed. Contrasted with the more effeminate masculinity of the primary hero, Jack, which Lubin discusses repeatedly in his book on the film, the film does seem to mount a challenge towards traditional male gender roles as well. That having 
been said, the film also reinforces the concept of the heroic death of the man, a subtle condoning of the privileges accorded to masculinity. Thus, despite the fact that the film suggests the need for a different type of masculinity, and even for a change in traditional gender roles, it ultimately presents Rose, and all the women, as existing in a world dominated by patriarchal authority, something reinforced by the final shot of the film. In that shot, Rose returns to Titanic-in a dream or in death, it is unclear-and is reunited not only with Jack, but with all of the structural violence between the Self and the Other, as represented by the dead passengers of the ship perpetually bound to their identities aboard the Edwardian ship. Given the high level of gender-based violence and following from hooks, it is important also to consider, then, how the articulation of Self and Other here inform ethnicity-based violence.

\section{Shining in the Boiler Room: Whiteness on Titanic}

According to the myth of the American Dream, anybody in the United States can rise beyond their beginnings if they possess ability. This, of course, presents a severely restricted view of the United States. What is more, it highlights the positive externalities of the Blue School, such as diversity and well-being, while concealing the negative. One way this elision occurs in the film is through the depiction of race. At first, the film appears to deal with race only by omission. While there were non-white passengers on the Titanic who are briefly seen in the film - a Chinese passenger, for instance, is visible as Jack makes his way to his cabin -the film does not focus on them. This lack of focus is problematic in and of itself, but the bigger issue in the film is its depiction of whiteness. Specifically, the absence of racial diversity is compensated for by a repositioning of race-based discourses along a spectrum of whiteness. ${ }^{11}$

Both Sean Redmond and K.J. Donnelly situate the ethnic discourses in the film around the Irish passengers on the ship. Redmond, for instance, notes that among the ways Jack is marked as an "Other" is his identification as a bohemian as well as

\footnotetext{
${ }^{11}$ For a more developed discussion of the development of a spectrum of whiteness, particularly as it relates to physical appearance of women, see Gilman 221, for his discussion of the painting The Babylonian Marriage Market by Edwin Long, as well as Chapter Three.
} 
his association with the Irish (200-201). This is an observation which situates the "dark" Irish on one end of the spectrum in opposition to the hyper-white upper class. Donnelly makes a similar assertion, writing that "Titanic's 'Irishness' works as a signifier of difference" (212). In short, structures of violence which might normally revolve around different skin colours are instead mapped onto different ethnicities of characters that could in other contexts be viewed as being a homogeneous group. The processes of othering both Redmond and Donnelly discuss clearly mark Jack, and more so the steerage passengers, as ethnically different, especially with regard to Cal and the upper class. Following from the discussion above, then, the Self of the film is associated with the less pure whites in the film. However, it is very important to emphasise that this association does not mean they are identified as belonging to the same area of the spectrum of whiteness. To understand this connection, it is useful to consider Rose.

Rose is the ideological anchor of the film. She is the narrator for much of the film, and what the audience sees is almost entirely through her eyes. As discussed, when first seen she is old, but living a seemingly happy life. When she begins her story of Titanic she is wealthy and pristinely white. As the narrative progresses, she begins to associate with those at the other end of the spectrum of whiteness, but she herself remains pure in her own whiteness, the embodiment of idealised female whiteness. This is most apparent in the sequence where Rose and Jack run through the engine room. Earlier in the film the coal shovelers on the ship were juxtaposed with the bridge of the ship-the working poor versus the working elite-and the filth of the coal room, bathed in blackness, was shown in opposition to the brightness of the bridge. When Rose enters the coal room, at a narrative level she is able to completely transgress the boundaries of the ship suggesting she belongs there, but at the visual level her luminous white gown is contrasted with the blackness of the room. Similarly when she arrives in port at the end of the film, her whiteness is emphasised by the lights on her face in a way that resembles the use of lighting Richard Dyer argues is key to the construction of whiteness in women. He writes that, "Idealised white women are bathed in and permeated by 
light. It streams through them and falls on to them from above. In short, they glow" (122), and indeed Rose does "glow" in this scene, as shown in Figure 6.

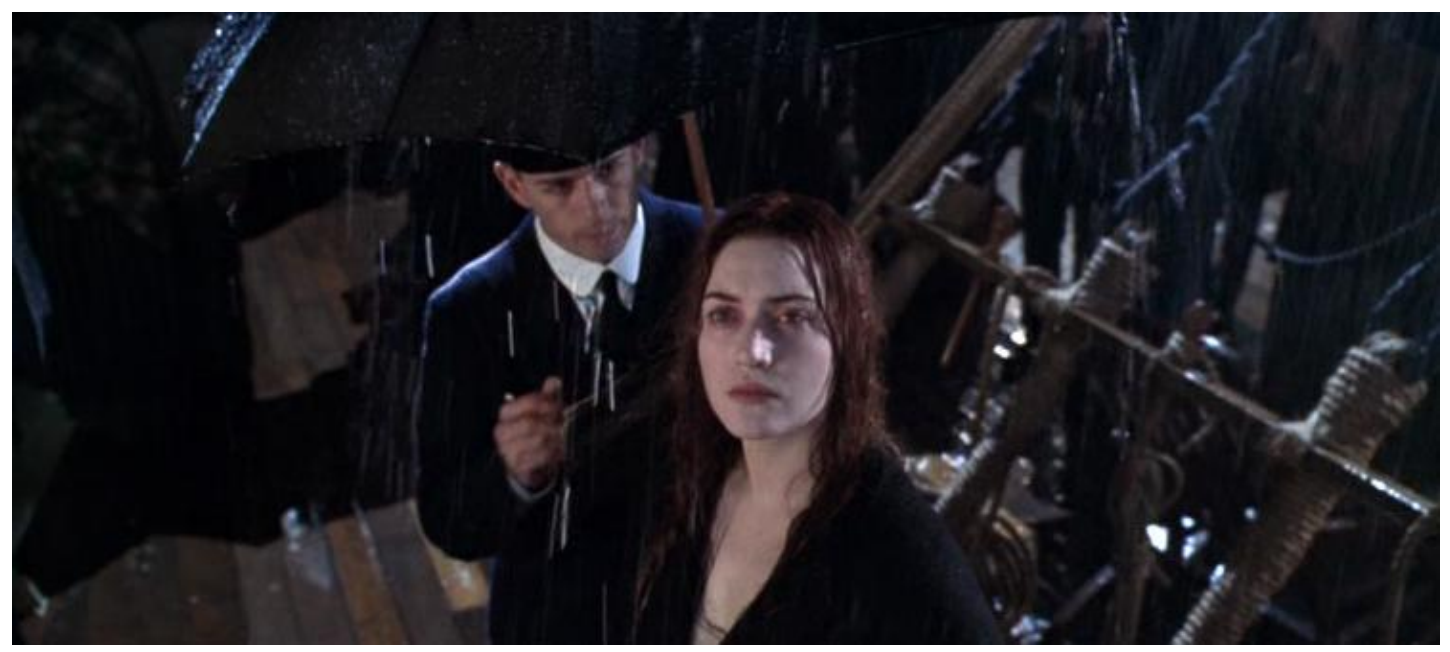

Figure 6 - The white Rose embarking on the American Dream in Titanic

Given the fact that the film presents Rose as a figure who is aligned with the impure end of the whiteness spectrum, her continual framing as idealised whiteness reveals that to be an appropriation of the Other, and not a true identification with it. Thus despite dancing with the Irish, and choosing to stay behind with the poor steerage passengers, Rose remains the paragon of white beauty. Nonetheless, the film uses Rose to suggest that race-based structures of violence are not present in the United States. This is clearest in the sequence which shows that even though Rose arrived in the United States poor and alone, she was able to realise her own American Dream as seen in the presentation of multiple photographs showing her living an unbridled life. In other words, by grafting racial Otherness onto a white female character and having the character succeed, the film suggests that there is no gender- or ethnicity-based structural violence. Of course by effacing this structural violence, the film ultimately reinforces the very violence it suggests is absent. Yet while structural violence informs direct violence, it is only the overt representations of structures of violence, specifically gender and class, which inform the direct violence of the film. 


\section{Death on the Decks: Direct Violence in Titanic}

Titanic is a film filled with death. Over 1500 passengers died when the ship sank and the film attempts to show them all including the conditions which caused them. While there are some wealthy passengers who die, Thomas Andrews (Victor Gerber), the shipbuilder being one of them, the direct violence of the film largely targets the lower classes. Due to the construction of the Self and the Other, this means that direct violence is primarily directed against the Self. This is clearest in the containment procedures enacted by the crew during the sinking which privileged the wealthy over the poor.

When the ship is sinking, the steerage passengers, including Jack and Rose, are locked below deck. The film shows them begging to be freed, but the crew refuses. In terms of structural violence, this would be an instance of the Other restricting the needs of the Self, particularly those relating to what Galtung terms identity, well-being, and freedom (Cultural 292). While the marginalisation and segmentation of the steerage passengers was clear before the ship began to sink, the fact that it does sink elevates the structural violence to direct violence as survival is at stake. By keeping the steerage passengers locked below decks, the crew are essentially sentencing them to death. Faced with such a dire situation, the steerage passengers resort to physical violence. In this way, the film condemns the violence committed against the Self, but condones the violence committed against the Other. This is made even clearer in a scene later in the film where First Officer William Murdoch (Ewan Stewart) fires a gun at a poor passenger attempting to get onto a lifeboat. The passenger dies almost immediately and Murdoch, realising what he has done, shoots himself in the head. In short, the First Officer is a working class person. Being a First Officer on Titanic, however, aligns him with an Edwardian system that privileges the wealthy over the poor, or in this case, the greed over humanity. Accordingly, realising that he has aligned himself with an inhuman system, Murdoch "resigns" by killing himself as his crime of disregarding the Self cannot be atoned. The sanctioned and condemned direct violence, then, raises two points. The first is that if the Self is sufficiently imperilled by an Other, then direct violence is legitimised. The second is the notion that when such 
retaliatory violence is coupled with the violence of the Other, the result will be the manifestation of self-destroying direct violence. This point is reiterated later in the film when the fate of Cal is revealed to be suicide after the Wall Street crash in 1929 , but it is most forcefully underscored by the sinking of the ship itself.

At one level, the ship is an inanimate object and the disaster of the film, though the result of human labour, is essentially natural. However, since the ship itself is a microcosm of the Edwardian Era and its attending structures of violence, the sinking of the ship and the mass death of the Self can be read much the same as the violence above, which is to say as structural violence becoming direct violence. Accordingly, the deaths that punctuate the last act of the film can be read as murders. This reading is echoed in the direct violence perpetrated against Jack and Rose. Specifically, once the ship begins to sink, both Cal and Lovejoy target Jack with direct violence and, eventually, Rose as well. Initially this is in the form of physical restraint where Jack is handcuffed below deck, and, interestingly, Rose must deploy direct violence in the form of a fire axe to free him. Ultimately, however, both Cal and Lovejoy pursue Jack and Rose with a firearm. At that point in the film, the violence deployed against Jack and Rose is less a question of suppressing the underclass and more a matter of vengeance for deposing, as it were, the upper class. Thus when the ship finally sinks, the wealthy passengers have largely been preserved, save for those who the film deems "noble," Andrews again being one, while the poor are dealt a final blow of direct violence from the Edwardian Era, being cast into the frigid waters. This violence is given a personal edge and tied directly to the feature Self of the film by focusing on Jack and Rose in the water. Since Jack embodies the American Dream, his death at the end of the film suggests that the Edwardian Era, or more broadly, an Other, is assaulting that dream. That the dream survives this devastating assault in the icy waters of the North Atlantic ultimately shows it is a dream of resiliency as much as it is a dream of success, and indeed this privileging of American myth is exactly what the post-9/11 United States used to define itself.

\footnotetext{
"The Ship of Dreams": Titanic and the response to 9/11
} 
Throughout the 1990s, American identity waned and a post-Cold War identity crisis ensued. As discussed above, one of the potential themes which resonated for the audience of Titanic was the redefinition of American identity through the revitalisation of the American Dream. In so doing it emphasised the positive aspects of the dream, such as social equity and a merit-based society, elements which ostensibly advocate for a structural peace. The negative elements, including wealth disparity and discrimination, issues which similar to those Kaplan argues fuelled the increasing fragmentation of the United States in the 1990s, thus became associated with the Other (76). In a similar fashion, even before the attacks on September 11, 2001, Bush cultivated a political persona that situated him as a man of the people. This is clearest in his continued reinforcement of his cowboy image, one that can be directly traced to the very same persona Jeffords identifies with Ronald Reagan while he was president. For Reagan, Jeffords observes that this was that of a macho man "chopping wood at his ranch, riding horses, [and] standing tall at the presidential podium" (25). However, Erik Baard of The Village Voice observes, the cowboy Bush is quite far from the actual "cowboy code" (n. pag.). His comparison between Bush and the mythic image of the cowboy goes a long way in debunking the notion that Bush is a true cowboy, but it does not address the deeper issue, which is that the reality of the situation is not what is of primary importance (n. pag.). Just as Titanic presented an image of America which elided historical and contemporary fact with regard to the violence in the United States, so too did the presentation of Bush as a resilient cowboy. This image, however, was not a passive construction; it actively informed the policies of the Bush administration, specifically the Bush Doctrine.

The key tenet of the Bush Doctrine, as defined by Charles Krauthammer, is that the United States is the sole super-power in the world and it is deserving of the title and willing to act accordingly (n. pag.). While a more detailed analysis of the Bush Doctrine will be conducted in Chapter Seven, the salient point here is that, as Walter Lafeber notes, the doctrine drew heavily on the notion of American Exceptionalism (558). Lafeber specifically refers to the speech Bush delivered on September 20, 2001, where he asked other nations to "join us" (553). Lafeber 
argues that the particular wording of this speech resulted not in an open dialogue with allies, but in an indication "that U.S. strategies were not open for debate" (553), something that would later define the unilateralism of the Bush Doctrine. Further, Lafeber contends that the foreign policy deployed by the Bush Administration amid uniform public support was not one that really was contingent upon approval from anybody (554). In other words, by creating the image of Bush as a man having risen from the people of the United States, the fact that he had no connection to the people of the United States became less important because his status seemed to reflect the support of the people. This positioning was bolstered by the fact that the cowboy president image Bush cultivated accentuated the positive aspects of the United States - those embodied in the American Dream. This was particularly the case given the fact that, despite his privileged upbringing in the northeast United States which ultimately saw him attending Yale University, Bush affected an image of a man who had adopted the principles of the American Dream as his own. It was as if he had renounced his name to become a lowly Texas rancher who had then risen to become governor of Texas and the president of the United States. This idea of Bush as a self-made man despite his family connections holds clear parallels with Rose in Titanic, but it also resonates with the myth of the United States as a classless society. Even so, in the pre-9/11 period this image was criticised by some such as USA Today writer Laurence McQuillan, as it gave "the impression that he's not in charge" (n. pag.). What is more, it made it seem as if Bush was inattentive toward the domestic issues which fuelled the US identity crisis. What his persona was missing, however, was an Other. In the period after the events of 9/11, with terrorists shaped as the new Other, that same persona was lauded. This was because the response to $9 / 11$ escalated the concerns surrounding the survival of the United States to such a level that it ultimately managed to have myths attached to nation elide the fragmented America of the 1990s. To better understand how this relates to Titanic, it is useful to return to the notion proposed by Baudrillard that the disaster films of the 1990s were an instance of "wishing" 9/11 and the end of an American empire (5). 
As Baudrillard argues, the popularity of the 1990s disaster films articulated a desire on the part of the audience to see the United States fall. Specifically, he claims, they make evident "the impulse to reject any system growing all the stronger as it approaches perfection or omnipotence" (7). Titanic, though, equates "perfection or omnipotence" with Edwardian England, the Other, thus positioning the US Self as the location of resistance against such power. In fact, in the reading Baudrillard conducts of the destruction of the World Trade Center buildings, he observes that "When the two towers collapsed, you had the impression that they were responding to the suicide of the suicide-planes with their own suicides" (7), it recalls the sinking of the ship itself, suicidally sinking into the ocean as if it was aware of its own violence against humanity. However, as the above analysis of the violence in the film shows, the resistant US Self is one that conceals the fact that it ultimately supports structures of violence which create inequities similar to those that are used as rationale behind the vilification of the Other. This does not suggest that the United States of the film is nearing "perfection or omnipotence," though, since Titanic asserts the resiliency of the United States, particularly in its ideals. Thus when Bush argued for a retaliation against the terrorist attacks, he utilised rhetoric which fore-grounded the ways in which the United States was a structurally peaceful nation. For that argumentation to work, though, the contemporary history of the United States could not be considered. Accordingly, the policies of the United States in the Middle East in the twentieth century could not be fully taken into account. Those that did, such as Chalmers Johnson, argued that the attacks on 9/11 were the result of "blowback," essentially response to the US foreign policy (vii-xvii). Read that way, it is the Other and not the US Self which is the victim. As with Titanic, then, rather than revealing the structures of violence (both domestic and foreign) which permeated the fabric of the nation, the rhetoric of the Bush administration effectively highlighted the mythic structural peace of the United States - namely the Four Freedoms. Accordingly, the dream of Titanic, where the anxieties that plagued a fragmented US Self could be assuaged by a return to a mythical period of hope, was realised by the response to the attacks of 9/11. What is more, the underside of that dream was brought to fruition as well, where the status quo and its attending structures of violence are not just 
preserved, but externalised onto an Other, against whom the deployment of direct violence became legitimate. Titanic dreamed of a resolution to the post-Cold War identity crisis that faced the United States, one which revived a mythic America without having to address any of the causes of the strife, and the response to 9/11 carried out by the Bush administration realised that dream. 


\section{Chapter Three}

\section{Fighting the Good War Again:}

\section{Saving Private Ryan (1998)}

In 1998, the identity crisis the United States faced in the wake of the Cold War intensified. It was in that year that President Bill Clinton was embroiled in a sex scandal for which he was impeached. Although approval ratings for Clinton remained high throughout the scandal, the ordeal underscored the fact that the nation was no longer defining its national Self against an external Other, but was instead focusing on internal disputes. This fragmentation was precisely what Robert Kaplan had predicted would happen as the nation drifted further away from the identity it had during the Cold War (76). This search for identity was exacerbated by anxieties surrounding the approaching millennium as well, with apocalyptic fears mounting. The future offered people no certainty. It is unsurprising, then, that many looked toward the past for hope. While this connects with the idea of nostalgia articulated by Fredric Jameson ("Postmodernism" 18), which will be discussed in greater detail in Chapter Five, it is more useful here to examine the precise way in which World War II reappeared in popular US culture at the end of the twentieth century.

The late-1990s in the United States marked a period of renewed interest in both World War II and its veterans. Guy Westwell notes that this "renewal" can be seen across media, particularly in the publishing industry which had a major success in 1997 with Citizen Soldiers: The U.S. Army from the Normandy Beaches to the Bulge to the Surrender of Germany, June 7, 1944 - May 7, 1945 by Stephen Ambrose (84$86,98-99)$. The book focused on the struggles of individual Gls rather than on the broad trends of the war. The result was a reframing of the conflict that worked to highlight the ways in which individual contributions were made by soldiers out of a sense of duty to the nation regardless of the walk of life from which they came. In 1998, the wave of interest in World War II crested with the release of Saving Private 
Ryan which drew heavily on this newer image of the citizen duty-bound to the national Self, and reluctantly, but ably, deploying direct violence in the war effort. The film earned over 216 million USD domestically, making it the highest grossing film of 1998. As with most blockbusters, though, despite a veneer of novelty, the film did not greatly diverge from its cinematic forebears.

Jeanine Basinger asserts that Saving Private Ryan is a very generic combat film, which has much in common with other war films such as Beach Red and The Sands of Iwo Jima ("Translating" n. pag.). ${ }^{12}$ However, she also claims that arguments which suggest the film has a "new and different purpose" when compared to previous war films merit further attention. She specifically writes that this is because Saving Private Ryan, like other combat films throughout cinematic history, is a response to the historical conditions of its time. Going further, Basinger then poses the question, "What has reactivated the combat genre?" ("Translating" n. pag.) She offers a variety of explanations including anxieties surrounding the millennium, but she does not commit to a single theory. Instead, she sums up the historical importance of the film for contemporary audiences, writing:

"Spielberg's true accomplishment is that he has used familiar genre elements for a new purpose, putting them together in a brilliantly visualized movie that causes Americans to take the war seriously again" ("Translating" n. pag.).

It is my contention that the combat genre is "reactivated" by Saving Private Ryan as a way to address the post-Cold War identity crisis, specifically the concerns brought about by domestic anxieties surrounding the fragmentation of the US Self as well as the approaching millennium. Accordingly, my analysis in this chapter will show the ways in which the film articulates Self based upon traditional forms of masculinity while at the same time incorporates multiple structures of violence. I will begin by looking at the identity of the United States in the post-Cold War period, specifically the way in which the concepts of nationalism and "victory culture," articulated by Johan Galtung ("Cultural") and Tom Engelhardt respectively, no longer formed the

\footnotetext{
${ }^{12}$ For more examples supporting these points, see Basinger "Translating."
} 
foundation of the US Self, as they had during previous historical periods. I will then discuss how Saving Private Ryan mobilises both concepts to construct a Self that is predicated upon patriotism. Drawing on the work of Roland Barthes, however, I suggest that the Self the film presents is based upon a mythic version of the United States, and, by decontextualising the conflict of World War II, effectively incorporates multiple forms of structural violence including racism and sexism. As my analysis will show, the racism was necessary for the elevation of the Self and ultimately in positioning it against the Other. I will also show how these concepts are reinforced by the deployment of direct violence and technology in the film. I will connect that analysis to the response to the attacks of September 11, 2001, showing the ways in which the Bush administration brought into being the Self that the film dreamed of, including its attending violence. Lastly I will show how the Bush administration attempted to present a unified national Self which seemed to address the pre-9/11 anxieties surrounding the structural violence in the United States, but, in fact, did not.

\section{Nation Without Other: The Post-Cold War US}

The end of the Cold War dealt a major blow to the national psyche of the United States. Engelhardt describes the reaction to the collapse of the Soviet Union as one of "befuddlement and paralysis" (x). This can be explained by the fact that during the Cold War the United States relied heavily upon the rhetoric of nationalism which is predicated upon a Self/Other binary. As argued previously, with the collapse of the Soviet Union there was no longer an Other against which to define the national Self. Although the US engaged in multiple military interventions throughout the 1990s, they existed outside the framework of a Self-Other binary; the United States was the sole super-power and there were no suitable opponents to frame as Other. Without an Other, nationalism as an ideology cannot function.

Johan Galtung describes nationalism as ideologically informed cultural violence which is "rooted in the figure of the Chosen People and justified through religion or ideology" ("Cultural" 298). There are often religious overtones in the definition of the United States as a nation of Chosen People-the notion of the United States as 
the "City upon a Hill" is a prime example-but nationalism in the United States is also often predicated on the ideology of a more secular version of American Exceptionalism. ${ }^{13}$ During the Cold War, this often factored into the self promotion of the United States as it served as a perfect point of contrast with the Soviet Union whose citizens were easily framed as the Unchosen People due to their dramatically different ideology. Jim A. Kuypers observes that the "Cold War metanarrative permeated every aspect of U.S. foreign policy decisions" and "involved the general American cultural perception of the Soviets as bad or evil, as opposed to the United States, which was identified with being good or moral" (emphasis in original) (2). Kuypers grounds these statements in the work of Robert L. Ivie, who argues that the enemies of the United States are traditionally vilified through the use of "images of savagery," and shows how Lyndon Johnson positioned the Vietnam War as one of defence against "forces of violence"" rather than as an aggressive manoeuvre by the United States (279). This meshes well with the idea of "victory culture" put forth by Engelhardt in Chapter One, as the direct violence of the United States remains reactive. Thus, the Cold War fostered a domestic sense of nationalism wherein the civilised United States was defined in opposition to savage Soviet Russia. Galtung warns, though, that when nationalism is combined with "steep Self-Other gradients, and statism with the right, even the duty to exercise ultimate power" ("Cultural" 299) the result is the "ideology of the nation-state" ("Cultural" 299). While the diversity of the United States, ethnic and otherwise, throughout the Cold War shows that it was a country which existed as more than a nation-state, as Galtung defines it here, events such as the Second Red Scare and the Civil Rights struggle demonstrate that the United States does have a history that often intersects with the "steep Self-Other gradients" to which Galtung refers, perhaps indicative of a desire for the uniformity of the culture of a nation-state.

Without the Soviet Union the Self-Other relationship broke down in the 1990s as there was no suitable external Other for the United States to position itself against. The United States was the sole superpower, a fact that Engelhardt suggests led to a

\footnotetext{
${ }^{13}$ For more on the religious aspect of the Chosen People in the work of Galtung, see Peace Chapter Four.
} 
state of confusion (x). Basinger observes that some films, such as Starship Troopers (1997), made use of alien villains to fill the gap of the Other, but Saving Private Ryan responded to the post-Cold War anxieties more directly with the resurrection of a human villain in the form of the Nazis ("Translating" n. pag.). During the Cold War, the on-screen Soviets served as a consistent external entity, a cinematic bogeyman as it were; they were the de facto Other. No matter what the US Self did, the Soviet Other opposed it. However, the collapse of the Soviet Union diminished their screen villain status as they were revealed to be virtual hollow men. What made the Nazis a successful replacement Other was largely the memory of the Holocaust. Accordingly, the historical relationship between the Nazis and the United States allowed them to easily fill the gap left by the collapse of the Soviet Union in the nationalist ideology of the United States. At the same time, however, it permitted a return to a time before both the Vietnam War and the atomic bombing of Hiroshima and Nagasaki, events which Engelhardt claims led to the American disillusionment with warfare and the end of what he refers to as "victory culture" (3-15). This transition is represented in Figure 7 where the contrast between the time of production and the time of the story itself are shown, with the narrative being located before the atomic bombing of Japan. This, of course, refers to the World War II sequences of the film since the film is essentially an extended flashback sequence, which will be discussed below.

\section{Victory Culture \\ Decline of Victory Culture}

$\mid$
Narrative of
Saving Private Ryan

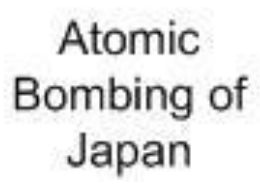

\section{Production of Saving Private}

Figure 7 - Production and setting of Saving Private Ryan in relation to Victory Culture 
Again, Engelhardt (4-5) views victory culture as part of an all-encompassing narrative that validated the military adventurism of the United States by having the goal-a mythically ideal nation-justify the means - violence of all types. In short, the history of the United States was continually sanitised to present it as a nation working to achieve a structural peace that would live up to the founding ideal of equality. This sanitisation was made manifest in the fact that, as Engelhardt suggests (4-5), the violence that did erupt was framed as an incursion against the US rather than the US acting as an instigator. ${ }^{14}$ Even a cursory examination of US history reveals ideological initiatives such as Manifest Destiny which show that military interventions were not "reactive," but actually were, as Engelhardt claims, "organized and invasive campaigns" (4). However, the attempt to legitimise those campaigns rhetorically suggests the presence of both cultural and structural violence which ultimately legitimises the direct violence of the interventions. This is also the case for World War II. The historical memory of US involvement in the war often suggests the United States acted solely as a protector of the persecuted Jews, and it is with this version of history that Saving Private Ryan largely deals. The result is that the film permits a return to an historical period of moral certainty where direct violence was ostensibly deployed to protect people and was therefore morally justified. While that appropriation of the Holocaust is problematic, as will be explored below, the relevant point to the current discussion is that the return is a selective one.

Commenting on the idea of memory that permeates Saving Private Ryan, John Bodnar remarks that "as Spielberg remembers, he also forgets" (806). This is because, for Bodnar, the representation of history in the film has very little to do with the historical United States. As he points out, the "Forties' calls to patriotic sacrifice were contingent on assurances of a more democratic society and world" (806), specifically citing the Four Freedoms, which were the list of four freedoms Franklin Roosevelt expounded upon in the 1941 State of the Union Address; the

\footnotetext{
${ }^{14}$ For a more detailed discussion of victory culture, particularly with regard to 9/11, see Engelhardt, especially the Introduction and Chapter One.
} 
freedoms were the freedom of speech and worship, and the freedom from want and fear. For many, then, the war effort was very much about equality. Bodnar also argues that the films made during that period, such as the Why We Fight series, articulated the war as a means of building a United States with "more social justice and individual freedom" (806). Of course, implicit in these calls is the fact that the United States was not a harmonious entity and that domestic structures of violence fostered inequalities along many lines including ethnicity and gender. Yet in Saving Private Ryan, there is no developed sense of domestic unease or tension. As will be discussed in more detail below, the men in the film do question the mission, but they do not question the Self of the United States. This historical elision is a process of sanitation, something Galtung regards as a type of cultural violence ("Cultural" 299). This is because, through omission, it conceals structures of violence, such as racism. So when Spielberg defines the Self of the United States by way of forgetting, as Bodnar argues (806), it results in Saving Private Ryan losing the democratic consciousness that Bodnar sees as being a hallmark of the forties. The film, he writes, focuses on "the moral individual in heroism and in pain at the expense of the moral or democratic community" (807). Thus, as Marouf Hasian Jr. contends, the film intentionally capitalised on nostalgia and sought to produce an "idealized past" (342) which replaced the moral ambiguity of modernity with clear cut morality from the past. In other words, the violence of sanitisation is deployed to strip the conflict in Saving Private Ryan of its historical context which in turn informs the violence of nationalism and the post-Cold War Self. What emerges from this process of decontextualisation is a United States Self which is not historical, but mythical.

\section{The Mythic Self of the United States: American History in Saving Private Ryan}

As discussed previously, Barthes sees myth as antithetical to history; for myth to function, it must remove the historical elements from an object (151). So although Saving Private Ryan shows World War II in graphic detail, it does not focus on the historical context or implications of the war, simply on the broad binary of the war: the United States against the Nazis with the US as Self and the Nazis as Other. This 
binary is often placed within the context of direct violence. While the Nazis are linked in the film to the Holocaust, even the Holocaust, to some extent, loses its historical meaning. This is evident in the way that the film only indirectly references it, and relies on the audience to fill in the details. For instance, in one scene the US soldier marked as Jewish, Private Mellish (Adam Goldberg) shouts "Juden" at German prisoners while holding up his Star of David necklace. Since none of the characters explicitly mention the Holocaust in this scene, the film relies on the memory of the audience to make the link between the Jewish icon and the defeated Nazis. In this way, Schindler's List becomes an important companion piece to this film, helping to shape the memory of the Holocaust. Yet by treating the Holocaust so indirectly, instead of as an historical event, it is reduced to its constituent violence-a steep Self-Other gradient that prompted the direct violence of attempted genocide. The result is that the Holocaust is not an historical event in the film, but instead functions as a sign of ultimate evil and extreme direct violence-attempted genocide-which allows the Nazis to easily become the Other to not only the mythic United States but the contemporary United States as well.

This historical displacement mythicises the Nazis and allows them to become viable as contemporary villains against whom the post-Cold War United States can define itself as a nation. In short, the decontextualised Saving Private Ryan allows the late-1990s United States to enter into a vicarious relationship with the mythic United States where there is a Self-Other relationship with the mythic Nazis. The lack of any historical grounding to this relationship further evokes Barthes, particularly his argument that myth presents an object, but obfuscates the origins of the object, and indeed effaces the historical context entirely (151). By deploying violence, direct and structural, against the pure evil of the mythic Nazis, the United States, though tarnished in reality as evidenced by the Vietnam Syndrome, is able to become mythic - what Barthes would refer to as a "beautiful object" (151)-and the violence of nationalism is able to function once again. Of course this is predicated upon the notion that the United States is not "beautiful" to begin with, an assumption that the film reinforces at the outset. 


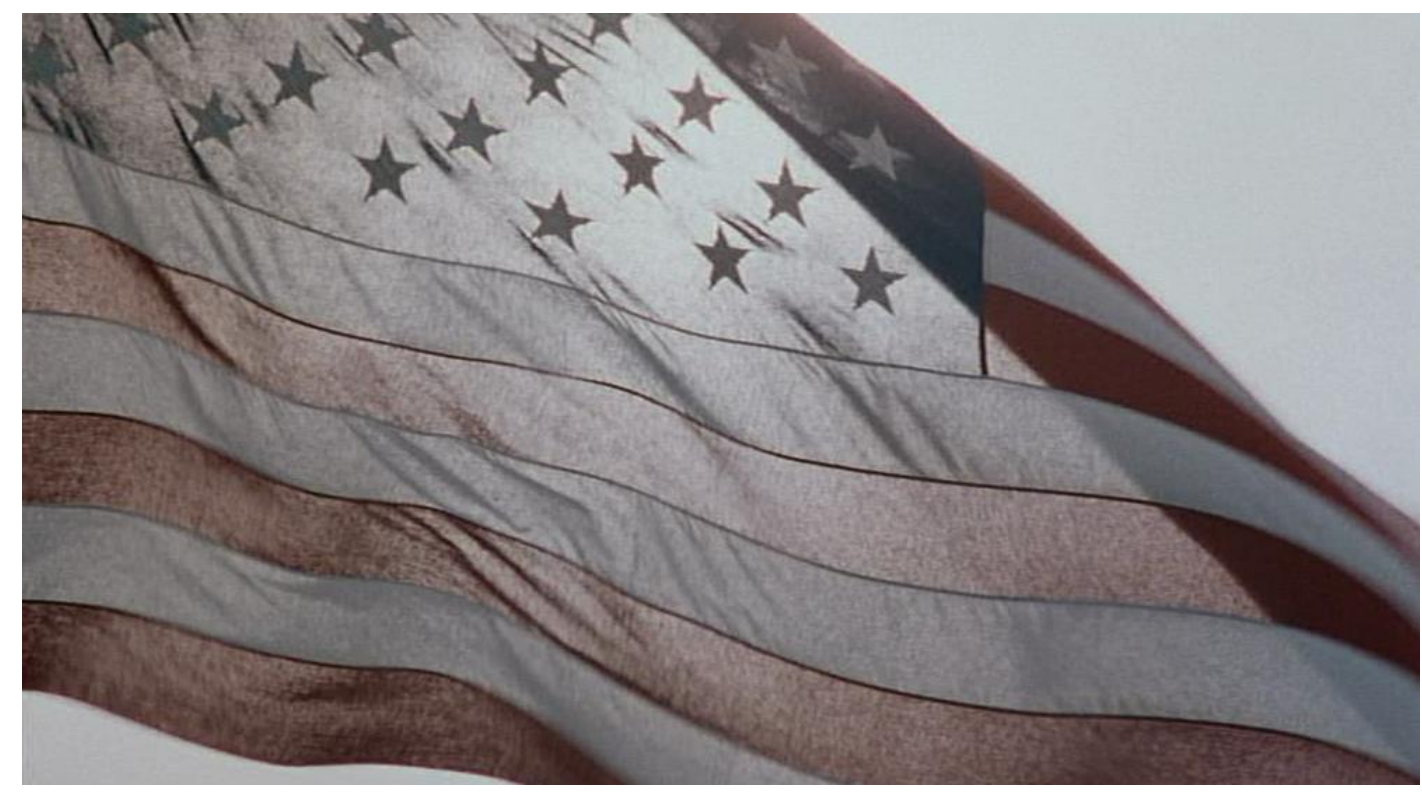

Figure 8 - The opening and closing image of Saving Private Ryan

The opening shot of the film features an American flag waving in the wind with the sun shining behind and through it, as shown in Figure 8. This positioning of the sun behind the flag results in a faded image with desaturated colours. The flag, of course, is a meaningful image in many ways. As discussed earlier, Barthes saw veneration of the flag as a blanket approval of the represented nation and its policies (116). Westwell, however, observes that in this shot "the weathered material and washed out cinematography suggest that the American flag postVietnam is still a relatively problematic signifier" (89). Thus, in the post-Cold War era, the flag of the United States can be read as sign of guilt rather than pride due to the fact that, as discussed above, American identity itself is still problematic in the post-Vietnam era. A. Susan Owen reads the flag in a similar way, but also sees it as an attempt at recuperation, as the flag is one of many "previously disabled icons of national identity lost to the [Vietnam] syndrome (the flag, honorable military service, military history, war in the service of democracy)...[moved] forward to diegetic and visual prominence in the story" (261). The flag at the beginning of the film, then, enhances the mythic nature of the United States and reinforces the importance of the mythic binary the film depicts between the United States Self and the Other of Nazi Germany. It is worth noting, here, that this image parallels the opening shot of Independence Day where the flag on the moon is shown to be 
under threat by an alien menace. Owen comments directly on the display of the flag in Saving Private Ryan, arguing that the film fulfils the function of a jeremiad "[offering] viewing audiences a 'way home' to mythic America” (250).

Read within the paradigm of a jeremiad, the film amounts to a direct critique of the millennial United States for failing to maintain the Self-Other binary that defined the World War II generation. Interestingly, this generation has come to be known as "the greatest generation" in contemporary times, a term which originated in the book of the same name by Tom Brokaw. That book served as a memorial to the disappearing generation that Brokaw described as "the greatest generation any society has ever produced" ( $x x x)$, and helps to further articulate the mythic past of the United States. However, because that generation was slowly fading in the late90 s, the film articulates a need to remember it. As Owen puts it, through certain characters the film articulates a "fear of forgetting a unified national purpose, paid for in blood and absolved through noble outcome" (emphasis in original) (261). The result is not just that the film functions as a jeremiad, but that it reemphasises the importance of nationalism. Beyond the opening shot, the film, of course, does not directly engage with the nuances of the waning of nationalism in the United States such as the end of the Cold War and the array of domestic tensions in late-90s America. Again the mythic nature of the film results in an elision of those elements since they would challenge the unified nature of the national Self. As Owen argues, the film articulates its sense of unity by foregrounding icons of nationalism such as the flag (261). The overwhelming success of the film shows that this recuperation of national icons and the structural violence they entail-primarily nationalismwas something that many people desired. This of course directly contradicts the arguments made by some, such as Kaplan, who claims that "the traditional symbols of American patriotism" (76) would wane in the 1990s, a sign of the increasing fragmentation of the United States. Despite the fact that his prediction did not come to pass, the destruction of symbols of America is something which deserves closer scrutiny, especially given the continued assault on the US soldiers in the film. In a mirror of the opening, the last image of the film is of the same desaturated and weathered flag still waving in the wind. Frank Tomasulo contends the bookending 
of these shots "suggest that the United States is the alpha and omega, the be-all and end-all, of human civilization" (118). The implicit message is that the United States, despite the horrors of war, remains; it has endured the violence, direct and structural and has emerged all the stronger for it. This message is underscored in framing sequences of the film that show the aged Ryan (Harrison Young) visiting the Normandy graveyard with his family. These sequences follow and precede the first and last shots of the flag respectively. Juxtaposed in such a way with the flag, the family becomes the embodiment of the Chosen People and the Self as it is they who precede the violence of the film and remain after it as well. They are the descendants of myth. The absence of direct violence in these scenes contrasts greatly with the rest of the film as even when physical force is not explicitly on display in the World War II sequences, the scarred landscapes serve as a constant reminder of that violence. The effect is that the framing sequences, particularly the final one, emphasise the peaceful time the Chosen now live in due to the sacrifices of direct violence made by the soldiers. However, the veneer of direct and structural peace in these sequences conceals the fact that the identification of the Chosen People in the film relies upon distinct structures of violence.

\section{The White Man's War: Ethnicity in Saving Private Ryan}

From the opening scene to the end of the film, Saving Private Ryan is a film which is bathed in whiteness. The Ryan family members at the beginning of the film, for instance, are over-powering in their whiteness, a fact which is accentuated by the bright lighting of the scene. ${ }^{15}$ The uniform ethnicity on display at the start functions to identify the Self as white while the Other, absent here, must be non-white. However, since the Ryan family are essentially proxies of the United Statesunderscored by the visual link between them and the mythic flag-their homogeneity is not brought into question. The film does not suggest there is anything amiss with the lack of non-white ethnicities. One reason for this might simply be that the filmmakers wanted to ensure that the image of the United States remained harmonious at the end of the film, but this would be problematic since

\footnotetext{
${ }^{15}$ For more on the relationship between light and whiteness, see Dyer White, Chapter 3.
} 
that harmony comes at the cost of collapsing the diverse United States into a single ethnic identity. As Catherine Gunther Kodat argues, through these sequences, particularly when they transition from the World War II Ryan to the aged Ryan, the film "attempts to pass itself off as a 'color-blind' re-birth of a nation" (89). Again, the absence of engagement with these issues despite their presence in the film amounts to an ethnicity-based structure of violence which causes the film to implicitly condone racism. This is not isolated to the framing sequences either, as the entire film presents whiteness as the standard.

As defined by Basinger, an integral element of the combat film genre is the group of men on a mission (The World 73-74). ${ }^{16}$ Basinger notes that "the group of men is a mixture of unrelated types, with varying ethnic and socioeconomic backgrounds" (The World 74). Additionally, within this group "minority figures are always represented: black, Hispanic, Indian, and even Orientals" (The World 74). By contrast, the group of men in Saving Private Ryan depicts none of the minorities listed by Basinger. Instead, the group has an Italian-American soldier as well as a Jewish soldier. While both of these ethnically marked soldiers add to the diversity of the squad, Private Mellish is as Peter Ehrenhaus notes, entirely assimilated and "embodies the ideals of American masculinity" (326), meaning that the ethnic diversity of the group does not compromise the larger identification of the soldiers with the United States as Self. While the segregated nature of the United States army during World War II could historically explain the homogeneity of the group, as Gerald Early observes, the contributions made by African American soldiers, for instance, have already been depicted in films such as Red Ball Express (n. pag.). Thus it is a significant omission that Saving Private Ryan shows no non-white characters even outside of the core group of characters. What is more, it is an omission which suggests the presence of structural violence through which whiteness becomes privileged by the absence of other ethnicities. Yet even without that omission, a closer reading of the ethnicities of the soldiers shows that

\footnotetext{
${ }^{16}$ See Basinger The World, especially pages $73-82$, for a more complete definition of the combat genre.
} 
the apparent homogeneity is nonexistent as there are marked differences between certain soldiers, particularly the ethnic and non-ethnic whites.

In discussing the painting The Babylonian Marriage Market by Edwin Long, which depicts maidens being auctioned for marriage, Sander L. Gilman observes that the women are sold "in order of comeliness" (221), and that the painting translates this into a continuum of whiteness where the most attractive girl has the whitest appearance and features while the least bears "Negroid features" (221). A similar continuum of whiteness can be seen in Saving Private Ryan, which positions the Italian-American, PFC Caparzo (Vin Diesel), and the Jewish Mellish in opposition to the purer whiteness of characters such as Captain Miller (Tom Hanks), and especially the all-American Private Ryan (Matt Damon). This conclusion is supported by the fact that at the end of the main flashback, which is the last sequence seen dealing with World War II, the only characters who have survived are Ryan, PFC Reiben (Edward Burns), and Technician Fifth Grade Upham (Jeremy Davies), none of whom are ethnically marked in the film. Interestingly, despite the fact that Ryan is an Irish name, a group which has traditionally been posited as less white, the film still presents the family as the pinnacle of whiteness. The implied message is that even though the ethnically marked characters are white and presumably equal, it is they who must die to ensure the survival of the unmarked characters. The massive display of direct violence that dominates the first act of the film, literally bathing the camera in blood, can be read as a winnowing, which ultimately purifies the US Self.

In this way, the US Self of the film parallels that of the historic Nazis and their attempt at ethnic cleansing. In the film, though, what makes the Nazis Other is that they threaten whiteness in addition to the non-white (or less white) US ethnicities. In that way, they hold a position in a spectrum of whiteness which has gone too far. They want to eliminate even Private Ryan. By comparison, of course, the structures of violence that support the US Self and its own prejudice are diminished. This is aided by the film itself since it operates on a central binary of nationalism that does not call into question or even recognise that structures of violence which privilege whiteness are present; this implicitly condones them. As briefly noted above, there 
are multiple points at which the leadership of the group is questioned, but at no time is this internal strife suggested to stem from ethnicity-based structural violence. As a result, the Self is aligned with unmarked whiteness throughout the film. Given the fact that the Nazis are the villains of the film, this creates logical and ideological contradictions.

As mentioned above, one of the primary ways in which the Nazis are positioned as Other in the film is through their connection to the Holocaust. Again this is not the historic Holocaust, but a mythic version. Thus the agenda of genocide is reduced to individual acts of direct violence which illustrate the fact that the Nazis have created such a steep Self-Other gradient that direct violence becomes a legitimate course of action for them to take against both the Jewish Other against which they define themselves and those who would attempt to stop them, namely the US Self. The multiple references throughout the film to the Holocaust, primarily situated around Private Mellish, reinforce this connection. It is this desire for genocide due to an ethnicity-based structure of violence which makes the Nazis the villains of the film. This structure of violence conflicts with the primary tenets of the United States, particularly the mythic United States, that "all men are created equal." Thus, because the Nazis are attempting to restrict the freedom of the Jews through both structural and direct violence, direct violence against the Nazis is legitimised; the aggressor, the film suggests, must be stopped. Yet even as the film exhibits contradictory positions on ethnicity, it also articulates further structures of violence, particularly in the ways it characterises male and female characters.

The fact that Saving Private Ryan focuses almost solely on the male experience of fighting in World War II is enough to suggest a gender-based structure of violence exists in the film. This extends beyond, however, the articulation of a traditional masculinity associated with mastery of direct violence. It also encompasses the characterisation of female characters in the film as subservient to males. This structural violence is primarily informed by the gender roles of the film as the women are either secretaries or wives and mothers. In both instances they lack true agency in film. For instance, one scene shows secretaries, all women, in an office typing up letters when one of them realises that three of the four Ryan 
brothers have been killed in the beach landings on D-Day. While this moment could elevate the female characters to a role of narrative significance, all they do in the film is bring the information to the attention of their male superiors in the office and then disappear from the film entirely. This elides the historical fact that women were active in capacities beyond secretarial work during the war. The film does not limit this violence to the past, however, as the framing sequences also reinforce gender roles by way of the most prominent female character in the film, Old Mrs. Ryan (Kathleen Byron).

Hillary Harris observes that in these framing sequences, Mrs. Ryan is consistently positioned between the family and the father (194). By positioning Mrs. Ryan in this way, she argues, "White Woman literally embodies both a meditation on and a mediation between the white patriarch and his life's meanings, as those meanings are stored in the family he was apparently saved to reproduce" (194). The linkage here between ethnicity and gender is unsurprising since, again following from bell hooks, they are "interlocking" elements (7). These sequences in Saving Private Ryan, though, show that it is the role of the wife to validate the patriarchy. This is clearest at the end of the film when the old Ryan speaks to the grave of Miller, saying that he hopes he has lived up to the final words of Miller, which were "Earn this...earn it." "This" and "it," as suggested by these sequences, is leadership over a family, which is of course a proxy for the United States. Thus, when the wife joins Ryan and he asks her to, "Tell me I've led a good life. Tell me I'm a good man," her immediate affirmation validates the position of white male over all others. In essence, it condones both race- and gender-based structural violence. As Harris argues, this scene makes it clear that

"the individualized American white patriarch-as well as his reproduction-is the deserved beneficiary of the combined sacrifices of lives, materials, and nations as represented by the cemetery at Normandy" (195).

Otherwise stated, these sequences identify the white male as the ideal American Self. Yet these structures of violence do not yet inform the direct violence of the 
film. For instance, the fact that Mrs. Ryan is subservient to Old Ryan bolsters his position as Self, but it does not explain how the film legitimises the direct violence deployed by the US Self against the Nazi Other. For that, it is necessary to look more closely at the relationship between the Self and Other.

\section{The Secondary Other: Positioning the Jewish People in Saving Private Ryan}

The conflict between the US Self and the Nazi Other is unusual, particularly in terms of the films already analysed, because this particular Self-Other relationship did not begin with the Other assaulting the Self. While the film presents its first act as a scene of unbridled direct violence deployed by the Other against the Self, the memory of World War II suggests an earlier beginning, specifically when the Nazis attempted to exterminate the Jews. For that attempted genocide to become legitimised in Nazi culture, ethnicity-based structural violence needed to reach such a point that the Jewish Other was regarded as inhuman by the Nazi Self. The fact that Saving Private Ryan utilises similar ethnicity-based structures of violence to define its Self problematises the relationship between the US Self and the Jewish characters, both on and off screen, but that seemingly contradictory structure of violence is ultimately necessary in defining the Self-Other binary between the US Self and the Nazi Other in the film. Accordingly, the lack of an initial conflict of direct violence between the Other and the Self necessitated a deeper motivation, which is provided for both parties by the Jewish Other. This is because the assault on the Jewish Other by the Nazis is recontextualised within an American context as an assault against its principle tenets, namely "life, liberty, and the pursuit of happiness." However, despite the fact that the United States in the film is implicitly fighting for the survival of the Jewish people, it is suggested that the Jewish people are unable to save themselves. This is primarily seen in the figure of Private Mellish.

Through the repeated and overt identification of Private Mellish as Jewish despite his previously noted "assimilation," he becomes intimately linked with the Holocaust. As Ehrenhaus remarks, "Mellish is the vehicle through which viewers can engage the Holocaust and participate in construction of its memory as an 
American phenomenon" (emphasis in original) (325). Ehrenhaus emphasises that the Holocaust of the film is not a crisis for Jewish people, but it is a crisis of involvement for the United States as evidenced by Mellish, particularly through his death (325). When he is killed, it is by a Nazi who was previously a prisoner of the American soldiers. The Nazi, nicknamed Steamboat Willie (Joerg Stadler), was released earlier in the film rather than executed. The murder of Mellish by Willie occurs in a secluded building within the battlefield. After a brief exchange of gunfire, the two become locked in a hand-to-hand struggle with a Hitler Youth knife introduced after the beach landing. Willie ultimately positions himself on top of Mellish and quietly drives the knife into his chest; Mellish futilely resists the much stronger man. In this moment the film seems to posit that the Jewish people were not strong enough to resist the Nazi Other. At the same time, though, neither are they strong enough to survive the war so that they can be part of the mythic United States. Of course while the murder transpires, Upham is next door, failing to intervene, and becoming an accomplice in the death of Mellish through is inaction. ${ }^{17}$

Ehrenhaus and others have read this as an explicit re-enactment of the Holocaust with the Nazis privately and silently killing the Jewish Other while the United States passively allows it (325-328). Critics have also read this scene in terms of its homoerotic undertones, suggesting a further structure of violence in the film, which is normative heterosexuality. Regardless, at the end of the scene, Mellish is dead and Upham, who is demonstrably weaker than Mellish throughout the film, survives. It is worth noting, however, that Upham, although cowardice prevents him from saving Mellish, redeems himself by killing Willie at the conclusion of the battle. At that time, however, he also lets other Nazi soldiers go. This act serves the double purpose of validating the humanity displayed in the earlier release of Willie-an important act in reinforcing the Self status of the United States-while at the same time underscoring the punishment accorded to those who were directly involved in the Holocaust versus those who were part of the war effort. Since Willie

\footnotetext{
${ }^{17}$ For close reading of this scene in terms of the parallels with the Holocaust, see Ehrenhaus 326 328.
} 
killed Mellish, an act Ehrenhaus again sees as metaphoric involvement (325-328), he is killed while the other German soldiers are released. However, the salient point of this discussion remains the fact that Upham ultimately survives while Mellish dies, a difference that suggests division between Mellish and Upham or, more broadly, the US Self and the Jewish Other.

Mellish, who is a proxy for the Jewish people, has no control over his life. He obeys all orders given to him by Captain Miller, and at the moment of his death he is entirely powerless. He can either be saved by Upham or be killed by Willie, which is to say his life is in the hands of the United States Self and the Nazi Other. His lack of agency reframes the conflict such that the apparently contradictory structures of violence which define the primary Self and the Other relationship, position the Jewish people as an Other to both the Nazis and the United States. The heroes achieve their status because they can save somebody who is otherwise helpless, and the villains because they can kill somebody who cannot defend themselves. What both sides need is a mythic victim and it is the Jewish people that Saving Private Ryan puts in that role even as it aligns them with the United States. This evokes the words used by Ehrenhaus when describing Mellish, whom he called "the mortally endangered Jew" (325). The ethnicity-based structures of violence which condone racism by Othering the Jewish people are used by the film to legitimise violence against the Nazi Other. Of course the Nazis are Others since they have already defined the Jewish people as Other. What emerges is a denial of agency for the Jewish people through Self-Other relationships as depicted in Figure 9. 


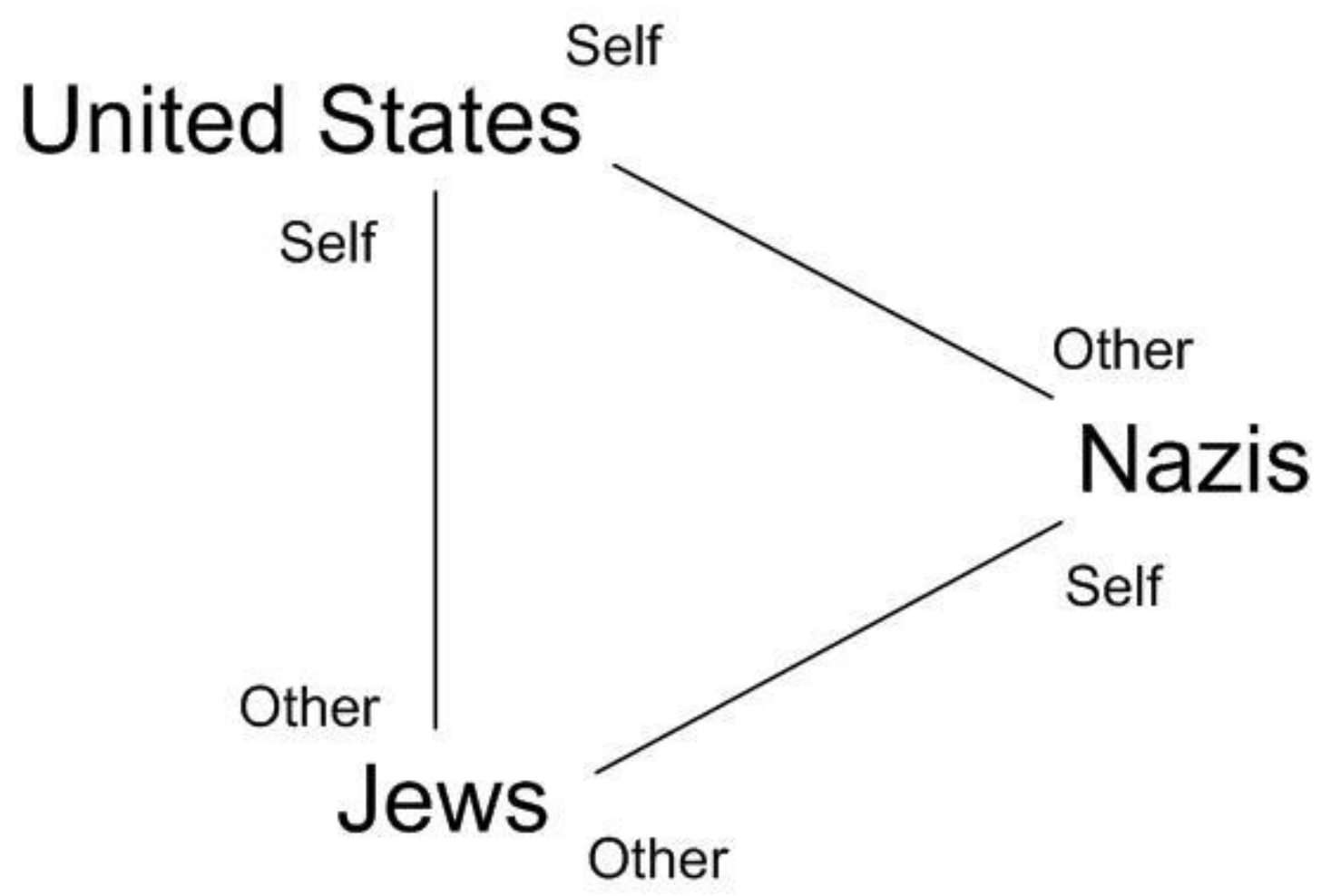

Figure 9 - The Self, Other, and Secondary Other of Saving Private Ryan

Of course the assumption of the diagram, and indeed the film, is that the United States is defined as Self. Without that assumption, any vertex of the triangle could be selected as Self to both of the others. However with that assumption, the Nazis are both a Self in relation to the Jews and an Other in relation to the United States, while the United States is a Self in all regards leaving the Jews always to be Others. Thus while the United States is a double Self, the Jews are a double Other. Another important aspect of this chart to note is that the enemy, the Nazis, are entirely external to the United States. While it is true that some of the men question the mission, they do not do so in any way that identifies them as Nazis. For instance, the most contentious moment between the US troops is when they argue about whether or not to execute Willie. One side claims that he is a Nazi and should be killed while the other states that he is a human and should not. The debate, then, is apparently between nationalism and peace, and at no point do the US soldiers discuss the matter in terms of ethnicity. The result is that even in the moment of the greatest discord, the US soldiers remain distinct from the Nazis in terms of their regard for humanity despite their unacknowledged similarities. This is an important 
distinction since, as will be discussed in Chapters Six, Seven, and Eight, the historical trajectory sees a shift toward an internal enemy in the post-9/11 period. For now, though, the external enemy is important to note because it is vital in establishing another key aspect of the larger Self-Other binary, that of humanity.

\section{Mechanical Death: Technology and Direct Violence in Saving Private Ryan}

As mentioned earlier with the work of Ivie, one of the key approaches to defining enemies of the United States has been to cast them as savage (279), and that is exactly what Saving Private Ryan does. This is particularly clear when the Nazi Other in the film is contrasted with the United States. The US will deploy direct violence, but only to stop an aggressor. The initial beach landing sequence does not establish its context, instead relying upon cultural memory of the mythic war wherein the United States responded to the aggressions of the Nazi Other. Drawing on these same myths, the Nazis are shown to have no regard for human life. Not only do they mercilessly kill the US soldiers at the beginning of the film, but they slowly kill all of the members of the group going to save Ryan. What is more, as is seen in the death of Mellish, the Nazis practically enjoy killing. This contrast is established in the first act during the beach landing. The first shot of the soldiers in the sequence is a close up of the trembling hand of Captain Miller (Tom Hanks) as he shakily drinks from his canteen. This involuntary gesture is a motif throughout the film, which serves as a constant reminder not only of his vulnerability as a human being, but of his humanity, and by extension that of the United States. The shot then pulls back from a close up on Miller to reveal the other soldiers in the landing craft. One, Sergeant Horvath (Tom Sizemore), is putting chewing tobacco in his mouth. Two other soldiers, both nameless, vomit. Miller and Horvath then discuss their landing strategies and a series of close ups on the faces of the soldiers with them conveys an array of human emotions - fear, dedication, resignation, panic, and faith. These shots all clearly show the reluctance of the soldiers to participate in armed combat. These are not the actions of men who love violence, the film suggests here. These are men who resist direct violence. The implication is that the Self of the film - the United States-is not an aggressor. Similar to the 
ideas Engelhardt (4-5) proposes regarding the "American war story," the US is only reacting to violence, not initiating it, a position which strengthens the notion that the US and its soldiers depicted in the film are mythic. This is underscored by the fact that their motivation is the protection of a secondary Other, the Jewish people. As already discussed, the motivations for American involvement in World War II were diverse and extensively connected to domestic politics, but the ultimate connection to the Holocaust elides those connections. Again, as Ehrenhaus argues, the memory of the event is "Americanised" (328-332). Importantly, this elision, structurally violent though it is, is never actively engaged with by the film. The result is an unquestioned portrayal of the American soldiers as having the utmost regard for all human life. This, of course, is contrasted with the Nazis who are almost always characterised as non-human entities, a positioning achieved largely through the representation of technology.

The first shot of a Nazi soldier occurs just after the US soldiers arrive at Omaha Beach. After seeing the US soldiers reduced to blood and flesh by machine gun fire, the perspective switches to the inside of one of the bunkers on the beach so that the perpetrators of the horrific direct violence are seen. From this interior perspective, the beach is shown clearly, but because it is properly exposed, the bunker is reduced to murkiness. All that can be seen are dark silhouettes of soldiers firing machine guns at the small figures on the beach, as shown in Figure 10. This alone is enough to establish the Nazis as villains since the gruesome deaths of the frightened US soldiers on the beach have already been shown, but the film does more to remove the humanity of the Nazis. Specifically, the Nazi silhouettes themselves make it difficult to distinguish between the soldier and the weapon. Instead there is a unified image that is part human, but also part weapon. Tomasulo remarks on the style of these images, noting that it "preserves their anonymity, prevents any identification with their predicament, and leaves them faceless automatons, no more human than their weapons" (119). The negative linkage between the Nazis and technology not only removes their humanity but enmeshes them with violence. They have not taken up arms, but are weapons themselves. The two cannot be separated. The technophobic position here echoes 
the ones articulated by Michael Ryan and Douglas Kellner and Scott Bukatman in Chapter One, which see technology as a threat to the natural-and therefore "correct"-order, as well as a dehumanising threat respectively (Camera 245, Terminal 2-4). Both of those theories can easily be applied to the technology of the Nazi Other in Saving Private Ryan. While this might seem to be contradicted in the figure of Willie who initially appears as an unarmed soldier begging for his life, he returns for the final battle in Ramelle as the killer of both Mellish and Miller. The first killing sees Willie using a knife. That action is given additional ideological importance since Willie is revealed to be a member of the Nazi SS. For the second killing, Willie uses a rifle. Although he is still recognisable, these views of him during the battle serve to not only underscore his deceptive nature, but also his (not-yet-complete) reintegration into the technological matrix that drives the Nazis of the film.

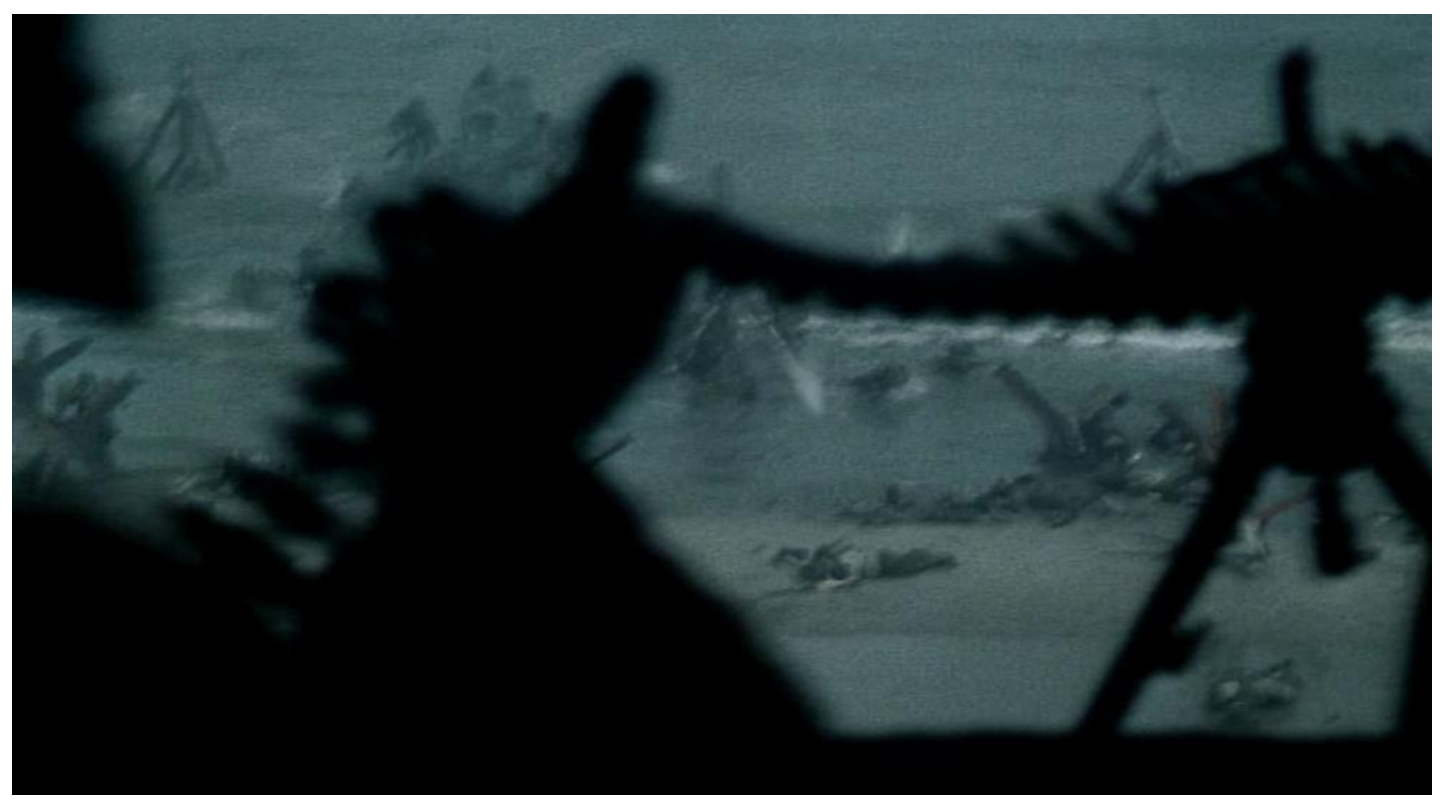

Figure 10 - The Nazi techno-human killing American soldiers in Saving Private Ryan

As mentioned in the previous chapters, anxieties surrounding technology were becoming stronger with the approach of the millennium. As the fervour surrounding the $\mathrm{Y} 2 \mathrm{~K}$ bug evidences, fears were largely situated around the idea of technology getting out of control and destroying humanity. The integration of weapons technology with the Nazis manifests this fear quite clearly, particularly 
given the fact that the US soldiers in the film are killed by this force en masse. While the US soldiers absolutely rely on technology, their use of it always shows either the technology mastered, but with reverence for its power, or unmastered such that its threat to humanity is clearly visible. In both cases, the technology humanises those who utilise it. For instance, Private Jackson (Barry Pepper), the sharpshooter for the main group of US soldiers, treats his gun like an extension of his body. He rarely misses a shot yet is almost always shown reciting scripture while using the gun. Thus his expertise is not associated with the technology itself, but with his faith, a subtle addition which adds further ideological implications to the notion of the Chosen People, fixing it in Christian ideology, something which the US response to $9 / 11$ also did. Apart from the constant threat of being killed by Nazi arms, the threat of technology is most visible in the final battle where the US strategy relies upon makeshift explosives called sticky bombs. While the bombs eventually work to destroy their targets, they also function imperfectly with one prematurely detonating and annihilating the soldier holding it. Interestingly, the bloody death is regarded by the film as a tragic sacrifice, but a heroic one nonetheless. This further enmeshes masculinity with direct violence. It is also worth noting that despite the military nature of the target, the soldier has essentially become a suicide bomber. The salient point, however, remains that this depiction of technology reinforces the human binary which separates the United States-Self-from the Nazis-Other-in a way that makes the dangers of technology eminently clear. In fact, this disdain for technology is even briefly glimpsed in the framing sequences when Ryan's son (Rob Freeman) is given an admonishing look by the others for filming the return to the graveyard, an act which the other characters indicate cheapens the ritual. Of course this contradicts the message of the film as the film itself functions, in the words of Michael Hammond, as "a celluloid memorial" (69). Ultimately, then, the film establishes a Self-Other binary wherein the Self is defined by its display of humanity in the face of an inhuman Other. In the film the representations of technology make the gradient between the two even steeper, but it is structural violence that ultimately brings the two into conflict. 


\section{A New Good War: Saving Private Ryan after 9/11}

In early 1998, stories began to be published about President Clinton having inappropriate sexual conduct with an intern. By the end of the year, with the story confirmed, Clinton was impeached. While acquitted of the perjury charges against him, the ordeal underscored the fact that the identity crisis the US faced was ongoing. This was exacerbated by the fact that Clinton did not adhere to the traditional notions of noble masculinity espoused by President Ronald Reagan during his terms as president. As Susan Jeffords observes of the "Reagan Revolution":

\footnotetext{
"It was a revolution whose success pivoted on the ability of Ronald Reagan and his administration to portray themselves successfully as distinctively masculine, not merely as men but as decisive, tough, aggressive, strong, and domineering men" (11).
}

What Reagan, and Bush to a lesser extent, offered the nation was a father figure. As Jeffords notes, the election of Clinton was a sign of change, particularly in terms of masculinity (23). She also notes that "the Clinton/Gore ticket negated any expectations for a presidential/vice-presidential father/son relationship by emphasizing their shared youthfulness" (90). Even when running for office, then, Clinton diverged greatly from the Reagan model; he was not a father for the nation. While his approval ratings remained high during the impeachment, they seemed not to engender a sense of national Self. In fact, they underscored the divisiveness of the process, with many perceiving the impeachment to be a political manoeuvre by Republican politicians. In short, it revealed further fragmentation of the Self. This is certainly not to indicate that the nation was united under Reagan, as there was considerable dissent during his tenure. Instead it is to suggest that what Reagan succeeded in doing was creating a national Self, driven by tenets of traditional masculinity, which was founded on diametric opposition to the Soviet Other. It is of a return to not only this Self-Other relationship, but of its World War II progenitor that Saving Private Ryan dreams. 
As noted in previous chapters, Baudrillard views the attacks of $9 / 11$ not only of a worldwide wish for the "omnipotent" United States to be stopped before it reaches supreme power, but also as the suicidal wishes of the people living within the increasingly powerful United States made manifest (7). While Baudrillard specifically makes this point in regard to the 1990s disaster films, his argument could be transposed to the bodies of the American soldiers, which are vigorously dispatched throughout the film, reduced to blood and pulp. Yet even as the film shows the American body being destroyed, like the American spirit in Titanic, Saving Private Ryan shows that body persisting. Most importantly, it is locked in a struggle against an evil Other which, unlike the previous two films analysed, is persecuting a secondary Other. The United States had to intervene, the film suggests, so as to ensure that people the world over share the same liberties as citizens of the United States. This position is what the film dreams and it is a dream which was realised by the response to $9 / 11$ of the Bush administration, especially in the Bush Doctrine.

Before 9/11, Charles Krauthammer identified three key principles of the Bush Doctrine. For him, they were that the United States acts as enforcer of the peace, maintainer of the peace, and extender of the peace (n. pag.). Otherwise stated, the United States, being the sole superpower, must act unilaterally to ensure that the world adheres to its concept of "peace," which is one which privileges the United States exclusively, making it an explicit structure of violence. However, the supposed benevolence of these actions served to distract from that underlying violence. In addition, the foreign nature of the Other directed the attention of the nation away from the domestic spheres and the anxieties surrounding the structures of violence which were brought to the fore during the identity crisis of the 1990s. Thus the dream articulated by Saving Private Ryan of a foreign conflict which seemingly made domestic conflicts irrelevant was brought to fruition. However, the dreamed Self of the film was riddled with structures of violence it sought to conceal. In the same way, the post-9/11 national Self articulated by the Bush administration was plagued by structures of violence. This can be seen in the rearticulation of Reagan-era masculinity that Bush affected. For instance, in 2001 
Bush remarked that he wanted Osama bin Laden "dead or alive" ("Guard" n. pag.), evoking the image of a lawman from a Western. What is more, the Other was not limited to bin Laden, but was extended to include an "axis of evil" which included North Korea, Iran, and Iraq. It was specifically the latter, Iraq, which provided the Self with a secondary Other. This relationship was made clear on March $19^{\text {th }}, 2003$, when President Bush addressed the United States to inform its citizens that the United States was indeed pre-emptively invading Iraq. In that speech he said that, "American and coalition forces are in the early stages of military operations to disarm Iraq, to free its people and to defend the world from grave danger" ("President Bush's" n. pag.). In this statement the relationship seen in Saving Private Ryan between the United States, the Nazis, and the Jewish people is replicated between the US, Saddam loyalists, and the Iraqi people, as shown in Figure 11.

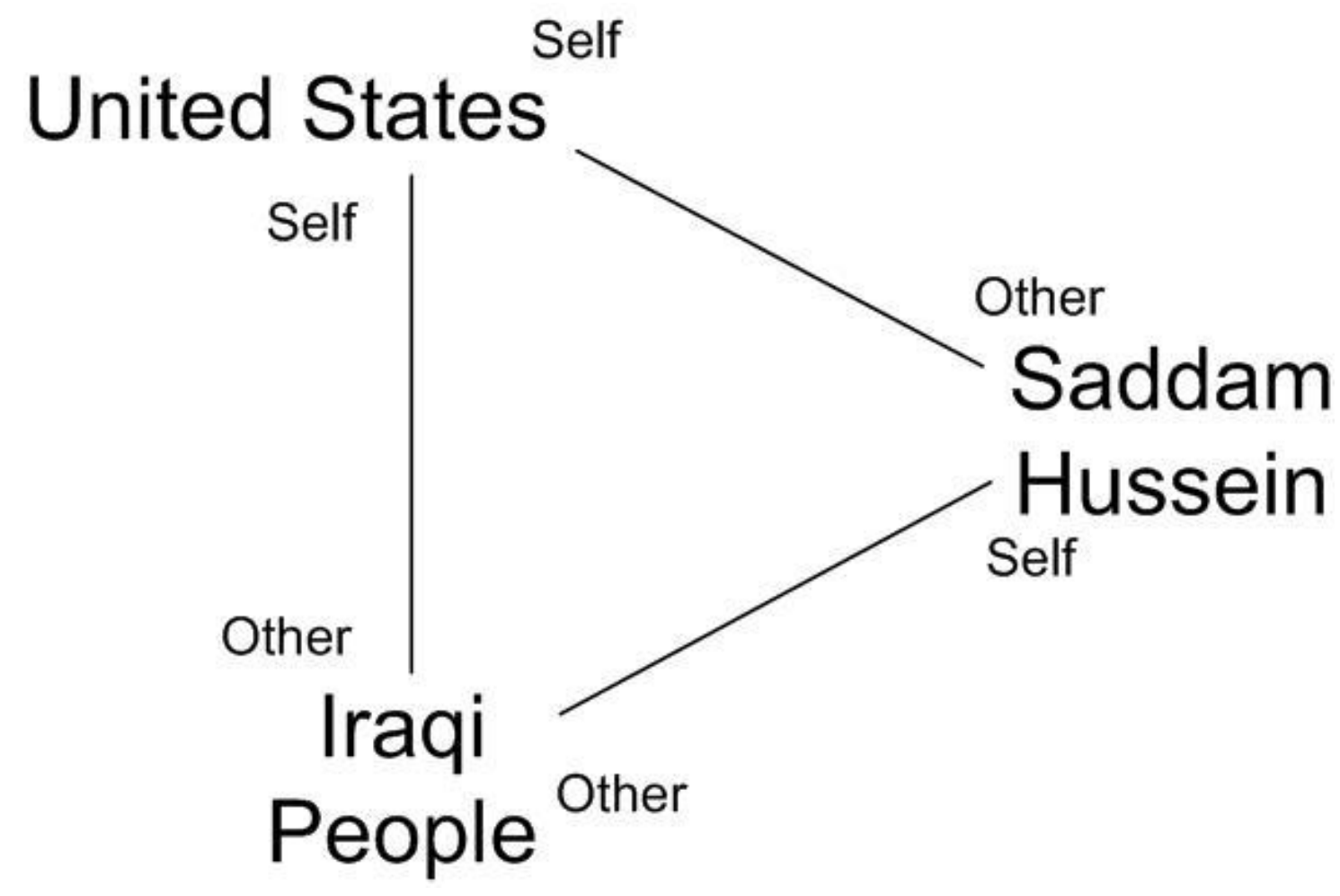

Figure 11 - The Self, Other, and Secondary Other in the Iraq Invasion

Thus, in framing their response to $9 / 11$, the Bush administration positioned alQaeda and subsequently Iraq as enemies which were equivalent to both the Nazis 
and the Soviets. Then it framed the military intervention as one designed to curtail the hostilities of this new Other against a secondary Other. In that way, the United States aimed to become a noble Self again, one grounded in the dream of the resurrection of a mythic American tradition predicated on direct violence. Of course, as discussed above, it was also one which was grounded in multiple structures of violence - sexism and racism - and indeed those structures of violence were present in the articulation of the post-9/11 Self. This is clear in the fact that the secondary Other was identified as the Iraqi people, a non-white population, but also in the stories that emerged from the Iraq invasion itself such as the supposed rescue of Private Jessica Lynch. In the end, the dreams and nightmares articulated by the violent construction of the Self and Other in Saving Private Ryan were realised by the Bush administration in its response to the attacks of September 11, 2001. 


\section{Chapter Four \\ Having Faith in Myth:}

Star Wars: Episode I - The Phantom Menace

(1999)

Near the beginning of the latter half of the twentieth century, there was a perceived move away from formal religious practices in the United States. For instance, C. Kirk Hadaway et al suggest that church attendance dropped sharply during this period (742-743). These findings are in keeping with trends identified by Caplow et al who observed that "many indicators of religious activity manifest decline in the late 1960s and early 1970s" (279). However, this apparent religious crisis prompted a revival in the US which manifested itself with a push for more active participation in religion or, as Caplow et al note, "a reversal of the downward trend" (279). This was evident in the late-1970s and early-1980s when a variety of political groups, such as the Moral Majority, founded in 1979, were on the rise. Their vocal condemnation of the lack of religion in US society was heard by many as a clarion call for a return to traditional religious practices. In the late-1990s, these calls intensified as major events in the US transpired which seemed to show a nation without morality, such as the Clinton sex scandal and the school shooting that took place at Columbine High School in Littleton, Colorado. Yet despite the apparent decline of formal religion, some argue that other religious outlets emerged during this time.

In 1997, author Orson Scott Card argued that, “...we Americans, despite all appearances, have not abandoned religion. We've merely changed its name" ( $n$. pag.). Card was specifically referring to the Star Wars films, which were rereleased as Special Editions in that same year. For Card, the films respond to "the innate human need for some religion, for a Deep Story that gives meaning to suffering and makes sense of the randomness of life" (n. pag.). This "religion" is primarily 
represented in the film through the main source of mystical power in the saga, a pervasive life-energy called the Force. As director George Lucas himself has stated, the Star Wars films "[take] all the issues that religion represents and [try] to distil them down into a more modern and easily accessible construct" (n. pag.). Similarly, Lucas claims that he wanted to encourage "more a belief in a God than a belief in any particular religious system" (n. pag.). In this way the films responded to the shift away from formal religion and provided a mythological religion - a "Deep Story" - with which its viewers are able to connect. In 1999, the religion of the original films was brought back to cinemas with the long-awaited prequel to the original trilogy, Star Wars: Episode I - The Phantom Menace, which became the highest domestic grosser of the year.

The narrative of The Phantom Menace is grounded by its relation to a mystical divinity featured in the original trilogy, called the Force. In the film the concepts of the Force are expanded, refined, and focused on in a way that caters to the fans of the mythology and centralises it within the narrative. Importantly, this development allows the film to present a world where religion is not solely a result of belief because the religion of the film, the Force, is a tangible entity; there are numerous instances in the narrative of the Force actually existing. However, the interest in the religion of The Phantom Menace is not solely due to a void left by the shift from formal religion in the twentieth century. Given the historical context of the film as a pre-millennial artefact, it is necessary to consider the religion of the film as it relates to the eschatological concerns of the period. Specifically, it is useful to consider how it mobilises religious concepts to define the Self and Other, and the ways in which that deployment articulates structures of violence.

It is my contention that The Phantom Menace responds to the anxieties active in US society at the time of its release by articulating a Self/Other Binary that is grounded in religious belief. However, rather than dramatising the conflicts between separate religions, it presents a world with a single religion, relocating the differentiating elements of Self and Other onto other concepts based on a morality constructed by the film. This relocation effectively conceals the structures of violence that dominate the film. Further, the stability of the religious solution 
offered by the film mirrors those ultimately brought to bear on the United States by the response of the Bush administration to the events of 9/11. My analysis will begin by showing the ways in which millennial anxieties fused with religious concerns to exacerbate the post-Cold War identity crisis in the United States. Additionally, I will discuss how those elements contributed to the fragmentation of the US Self. I will then look at how the articulation of Self and Other in The Phantom Menace addresses those anxieties. Specifically I will show how the Self and Other are not based on religious beliefs, but belief itself in conjunction with moral action. With the Self and Other thus defined, I will next explore the ways in which the binary is undermined by multiple structures of violence, particularly those informing racism. With the positive and negative aspects of the Self and Other articulated, I will then establish connections between the response to 9/11 and The Phantom Menace. Specifically, I will suggest that the religion-based Self/Other binary the film "dreams" is realised by the Bush administration. I will close by arguing that these parallels also reflect the concealed structures of violence found within the film. Thus the film dreams of both the positives and negatives of the post-9/11 era.

\section{Crisis of Faith: Millennial Religion in the United States}

At the end of the twentieth century, religion in the United States often became conflated with the anxieties surrounding the approaching millennium, particularly in terms of apocalyptic thinking. As Daniel Wojcik highlights, these apocalyptic undercurrents were found in the beliefs and behaviours of both secular and religious groups within the United States, and represent a long tradition of apocalyptic thought in the country (6). Along those lines, he notes that during the Cold War the Soviet Union played a key role in apocalyptic scenarios, but that the fears surrounding the USSR have segued into more contemporary conspiratorial beliefs surrounding the First Gulf War and the perceived threat of Islam. For instance, Wojcik observes that a number of eschatological writers have drawn connections between the First Gulf War and biblical prophecy (156-158). What prophetic beliefs such as those reflect, he argues, "is a complete loss of faith in 
government and dominant social institutions... [they also] reveal the depth of despair and alienation that exists among many Americans" (173). In short, anxieties at the millennium indicate a fragmentation in American society much like the already discussed predictions made by Robert Kaplan which were embodied in such events as the LA riots. While much of what Kaplan says is relevant here, the most noteworthy suggestion he makes is that people of the United States would retreat into "insulate communities and cultures" (76) as the fragmentation of the nation continued. Otherwise stated, as the large scale identity crisis exacerbated the numerous crises, groups in the United States would no longer be defined according to a single national Self, but instead as a series of isolated-and much smallerSelves. With the millennium approaching and fostering a rise in eschatological beliefs, this fragmentation often occurred along the fault lines between various religions, such that each system of belief became a veritable Self in opposition to all others. As Nancy A. Schaefer observes, the focal point of this apocalyptic fragmentation for many was the Y2K bug (85-86).

The $\mathrm{Y} 2 \mathrm{~K}$ bug was a computer programming error in which dates were electronically stored using two rather than four digits. At the turn of the millennium, then, computers would revert to 1900 rather than 2000 , causing a host of potentially catastrophic issues. History has shown that the bug was either patched or minor in its effects, but as Schaefer notes of the pre-millennial period, "some associated $\mathrm{Y} 2 \mathrm{~K}$ with biblical prophecies about apocalypse, forecasting widespread havoc, the breakdown of society, even the collapse of the government, implying that the 'crisis' could accelerate the advent of Christ's return" (86). Thus, the Y2K bug was incorporated into eschatological belief systems and became what Schaefer calls an "endtime sign" (85). While these contentions are open to technophobic readings, which will be investigated further below, what is relevant to the religious crisis in the United States at the turn of the millennium is how these fears of the apocalypse shaped the understanding of Self and Other in the post-Cold War era.

The apocalyptic fears prompted by the $\mathrm{Y} 2 \mathrm{~K}$ bug did not cause the religious rupture that many have observed in the United States to heal, but instead promoted a further fragmentation which caused visible effects even within religious groups, as 
can be seen in the actions taken by prominent religious figures. For instance, Schaefer notes that Jerry Falwell, a prominent Southern Baptist, encouraged his "followers to collect provisions and arm themselves" (86), words which essentially advocated the isolationism that, as mentioned above, Kaplan predicted earlier in the decade (76). Though such examples as that are common, it is important to note, as Schaefer does, that while some Christian leaders made such statements, the sentiment was by no means universal in those communities, nor was it limited just to Christian cultures (86). As Schaefer remarks, "computer programmers and corporate executives" also saw the $\mathrm{Y} 2 \mathrm{~K}$ bug as a source of major anxiety (86). However, since The Phantom Menace is overtly concerned with religion, it is useful to understand the ways in which sense of Self and Other in the United States, which Johan Galtung labels "the most Christian nation on Earth" ("Cultural" 298), is influenced by religious, specifically Christian, thinking. Galtung argues that this is unsurprising given the fact religion is one of the major domains that sustains cultural violence.

Since Judeo-Christian-Islamic thinking that is prevalent in US culture, there is a pervasive notion of a single god that exists outside of the individual. Galtung views this perception of divinity as a potential source of danger because it could cause "some people [to] be seen as closer to that God than others" ("Cultural" 296). Thus when a particular religious deity chooses one group, it automatically creates a binary division between those who are chosen and those who are not. Galtung suggests that this symmetry manifests itself in the God/Satan binary. For many religions, including Christianity, the Chosen People are the believers and the Unchosen People are the non-believers. Of course this division is treated differently by various religions, but it is not uncommon for structural violence based on such beliefs to lead to direct violence. For instance, in World War II the Jews were systematically Othered by the Nazi party on account of both their religion and their ethnicity. This process involved the deployment of an increasing number of structures of violence which threatened the basic needs of the Jewish people. Ultimately the structures of violence reached such a level that the Jewish people were no longer regarded as human, and direct violence in the form of attempted 
genocide became sanctioned by the Nazi party. Thus, a group which is perhaps initially only discriminated against may eventually be met with physical violence. However, because of the large-scale fragmentation of the Self in the Post-Cold War United States, which included religious groups, the notion of a single Chosen People also fractured. The result was that instead of a macro-Self defined by one or more religions, the millennial anxieties engendered the development of micro-Selves which made the Other even more threatening as it now included former aspects of the self, effectively splitting the subjectivity of the Self. This is shown in Figure 12 with Christianity as an example, although any religious or ideology group could be substituted.
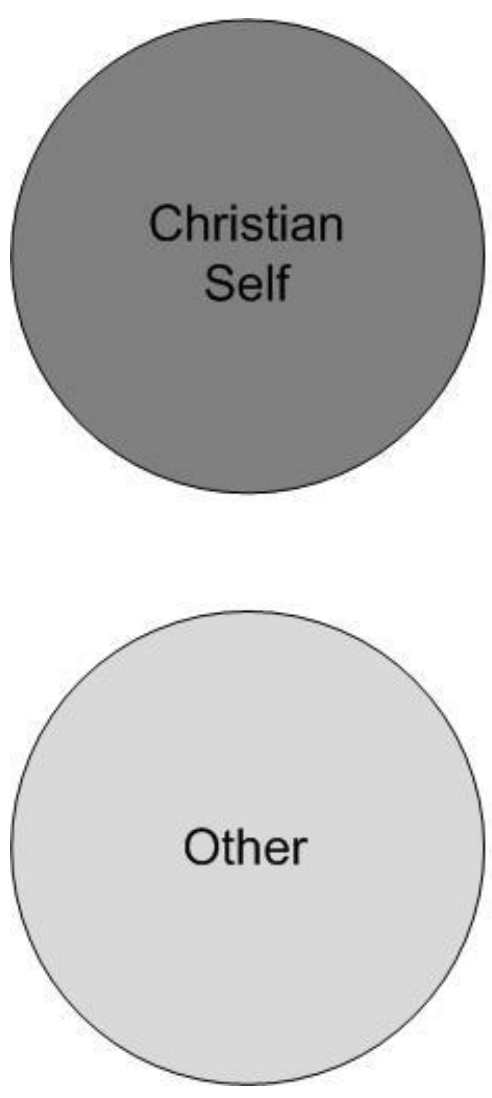

Figure 12 - The post-Cold War fragmentation of the religious Self in the United States

In the diagram, the larger Christian Self has been reduced to a smaller individual Self with elements that were previously part of that Self now regarded as Others along with those populations that were already seen as Other. While this 
redefinition of the Self is certainly not bound to religion-ethnicity-based structural violence, for instance, might have some groups retreat into homogeneous racial groupings - the important aspect of the Self with regard to The Phantom Menace is the religion itself. Returning to the concept of nostalgia, what the film offers is a world not defined by a multitude of oppositional faiths, but by a single denomination which, as in the original Star Wars films, fuses multiple belief systems in a way that seemingly heals the religion-based divides in pre-millennial US culture, effectively reconfiguring the shattered micro-Selves into a macro-Self by placing them in opposition to a single evil Other.

\section{"May the Force Be with You": The Religious Self in The Phantom Menace}

At its core, The Phantom Menace is a film about religion. As mentioned earlier, the central system of belief in the film, the Force, exists as an amalgamation of multiple real-world corollaries. Accordingly it fuses belief systems which have very different Self/Other binaries, specifically Judeo-Christian-Islamic beliefs and Eastern beliefs, religious structures that have static and fluid conceptions of good and evil respectively. At a conceptual level, combining religions can potentially result in peace if structurally violent concepts are selected against. For instance, if the tenets of Jainism, which encourage direct peace in all aspects of life, were fused with any other major religion, the result could be the absence of direct violence, possibly even structural violence, in religions which define a Chosen People and an Unchosen People.

However, given the vast number of subtle variables in each major worldview, or cosmology as Galtung labels it, unforeseen outcomes are very probable when attempting to effect change in such a complex system (Peace 238). Thus, while a combination of religions could accentuate the peaceful aspects of each - "Thou shalt not kill," for instance-there is an equal propensity for such a combination to elevate the elements of structural violence found in many religions, as evidenced by the Crusades and the Spanish Inquisition. What is important here, though, is that while the religious foundations are important, so too are the ways in which they come together. By analysing the presence of the Western and Eastern religious 
elements in the film, it becomes clear that although the combination of religions initially appears to assuage anxieties surrounding religion in the millennial United States-possibly suggesting a structural peace - the structures of violence inherent in the component religions are preserved and work together to articulate further structures of violence, including racism and sexism. To understand how this is the case, it is necessary to first look at the component religions of the film, beginning with the Judeo-Christian-Islam traces.

In terms of violence as defined by Johan Galtung, Judaism, Christianity, and Islam have similar Self/Other binaries in that each defines a Chosen People and an Unchosen People (“Cultural” 296-298). For these religions, though, Galtung differentiates between an external transcendental god and an internal immanent deity ("Cultural" 296), with the former shaping what he refers to as a "hard Judaism-Christianity-Islam" ("Cultural" 297) where a strict hierarchy is established which privileges certain groups as Chosen over others. Galtung also notes, however, that softer versions of those religions emerge when they incorporate an immanent rather than transcendental god. Although there is no deity in the Star Wars films, the Force functions as a divine power. As characters in the previous films remark, the Force exists within all living things, making it very similar to the immanent concept of god that Galtung discusses. In fact, as described in The Phantom Menace, micro-organisms called midi-chlorians reside in all people and connect them to the Force. In this sense, the divinity in the film is literally immanent. Certain aspects of the film, though, link the force specifically to Christianity.

For instance, while John C. McDowell acknowledges the Eastern qualities found in both the film and the concept of the Force itself, he identifies elements of Christian iconography in the film such as the "devilish-looking Darth Maul" and "the virgin birth image used of Anakin" (21). While the virgin birth is strongly connected to Christianity, it is worth mention that in an article by Jim Windolf in Vanity Fair, he quotes Lucas as saying that the birth was something he drew from the work of Joseph Campbell, the prominent mythologist, rather than the New Testament, saying "I don't want to get into specific terms of labelling things to make it one 
religion or another, but, basically, that's one of the foundations of the hero's journey" (117). Even so, his intent does not preclude a Christian reading of the virgin birth and the messianic overtones of the film. The importance of these Christian connections, though, is twofold. First, by establishing such clear corollaries between the Force and Christianity, the film effectively provides a location for domestic audiences to see their anxieties regarding the crisis of (Christian) faith played out on screen. The other reason the Christian connections are important is because the immanent nature of religion they articulate contributes to the definition of a very specific Self/Other binary. Although Galtung does not directly analyse immanent religions in a way that enables a clear elucidation of that particular Self/Other binary, an examination of his discussion on transcendental religion provides important information which can be used to infer what the Self/Other binary would be ("Cultural" 296-298).

As mentioned above, Galtung sees transcendental religion operating within a Manichean binary which identifies a Chosen People and an Unchosen People ("Cultural" 296). For the faithful, the Chosen are the Self and the Unchosen become the Other. Yet while Galtung says that this division can be found in both transcendental and immanent religions, he adds that "an immanent concept of god as residing inside us would make any such dichotomy an act against god" ("Cultural" 297). In other words, if everybody has access to the divine, then nobody can be closer to it, thus problematising the division between Self and Other in religious terms. In Star Wars, this is of course complicated by the fact that some characters in the film have more midi-chlorians within them than others do, effectively bringing them closer to the divine, but the film avoids getting locked into that strict binary by incorporating elements of Eastern religions.

Walter [Ritoku] Robinson cites the pervasive presence of the Force in "all living things" as an example of the ways in which it resembles the Eastern concept of $c h^{\prime} i$, which some religions believe is the energy that flows through all life (29). As he notes, "The philosophy of the Force is thus best understood by way of understanding the nature of ch'i and the wisdom of Zen" (29). He specifically refers to the search in The Phantom Menace for a messiah who, as is said in the movie, 
will "bring balance to the Force." Although the notion of a saviour clearly evokes Judeo-Christian-Islamic beliefs, Robinson focuses instead on how the concept of balance parallels Taoist notions of good and evil, showing that the ideas themselves exist in relation to one another rather than as universal absolutes (32). In terms of violence, the notion of balance evokes the idea of peace articulated by Galtung where all people are treated equally, without social inequity, which is to say without structural violence.

Kevin J Wetmore Jr. expands upon the connections the film has to Eastern religions, arguing that the lack of a concrete good/evil binary is antithetical to Christianity. He writes,

"Spiritual evil in the West is ultimately subservient to the divine principle, and the divine principle itself contains no inherent evil or dark side. It would seem, then, that if the Force consists of both light and dark sides, and neither is ultimately ascendant over the other, then real world religions that embrace duality are more echoed by the concept than Western monotheism" (82).

In that way, the Judeo-Christian-Islamic tenets that are key to much Western thought are insufficient for the religion of the film. Thus because the religious construct of the film draws on these Eastern elements, it does not truly reproduce a Manichean binary of Good and Evil. This is not to say that within the religion itself there are not clear distinctions between what a good character is and what a bad character is, it simply is not a factor of faith. As Figure 13 shows, however, faith is a key factor in determining the narrative importance of the Self and Other. Those who are more closely aligned to the Self exhibit a stronger believe in the Force and, additionally, gain more narrative importance. However, this also holds true for characters defined as the Other, which is shown in the v-shaped line in the diagram. Interestingly, those characters that either display no belief or simply casually believe are largely positioned as neutral. Thus, the more faithful a person is to the religion, the more forceful their alignment with Self and Other. This is not to say, 
however, that no other characters in the universe of the film believe, simply that for those presented in the film, this diagram holds true.

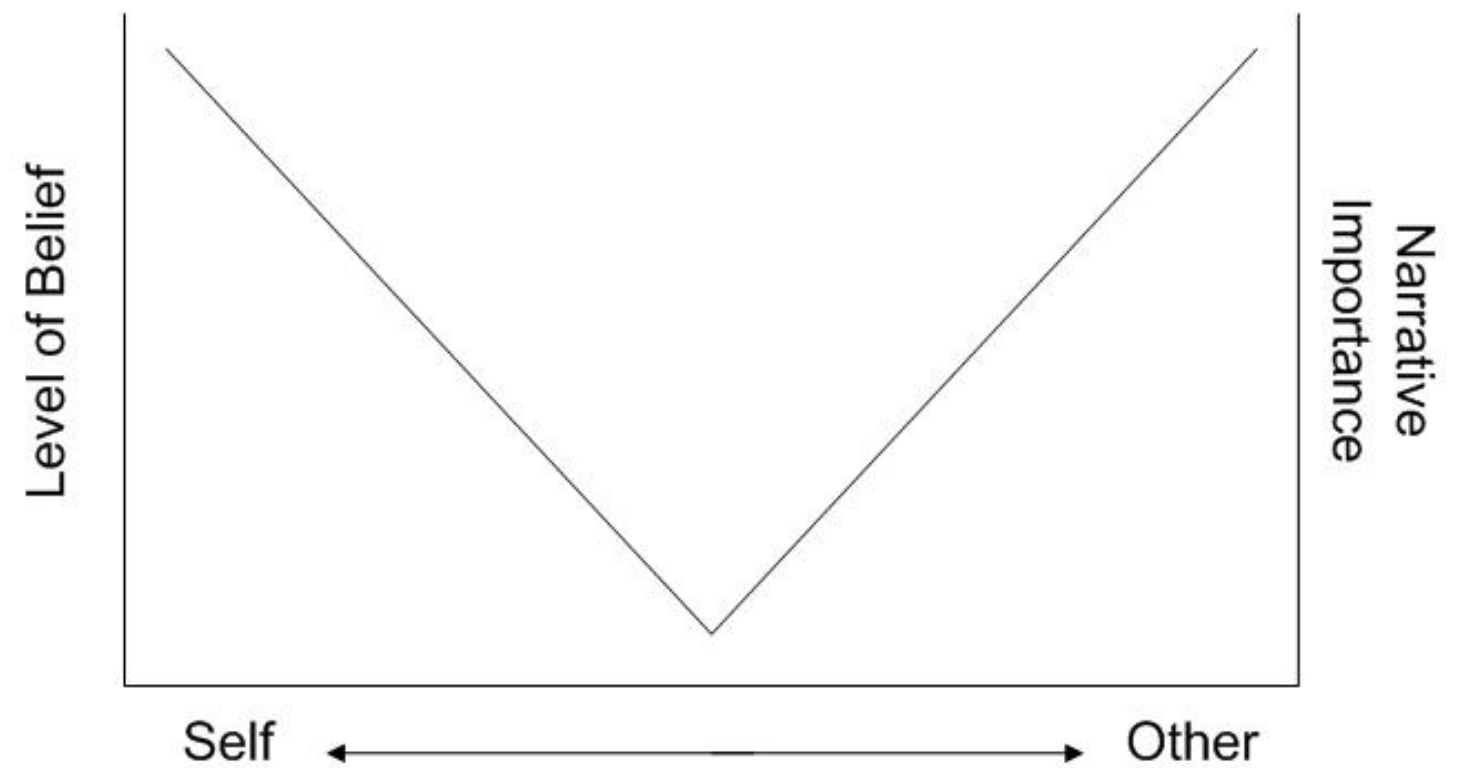

Figure 13 - Belief and Narrative Importance in relation to the Self/Other binary

It might seem like this matrix of relationships would reinforce the proximity to the god quality identified by Galtung ("Cultural" 297), making some people more Chosen than others. This would certainly seem to be supported by the introduction of midi-chlorians in the film since the identification of Anakin Skywalker (Jake Lloyd) as the "Chosen One" is due to having so many in his cells. Interestingly, this discovery is made via a blood test, suggesting the bodily fluids of Anakin have a sanctity which again alludes to the figure of the Christian messiah, but it is also important in terms of the concept of lineage, which, if privileged, can ultimately be tied to structurally violent concepts such as ethnic purity. However, the claim that it is an innate holiness which identifies the heroic from the non-heroic characters is weakened by the positioning of Queen Amidala (Natalie Portman), who has no ability to control the Force, but performs as a hero. The fact that Amidala devoutly believes in the Force, the same as the Jedi, again suggests that it is not proximity to the divine that defines the good characters, but is instead explicit belief in the divine. The quality of belief, however, cannot be used to distinguish between good 
and evil. Instead, what determines which side of the spectrum one is on is a sense of morality.

The heroes and the villains of the film represent two approaches to the Force. One, the light side, uses the Force to attempt to help people, for good. As is seen at the beginning of the film, the Jedi, who are on the light side, are called upon to arbitrate in a trade dispute, a role which positions them as advocates of social equity, aligning them with elements of structural peace. The other approach to the Force, the dark side, uses the Force for personal gain, for evil. In this way the adherents of the dark side become icons of structural and direct violence as they privilege themselves over all others, and do so in ways that threaten the survival needs of any who oppose them. For the dark Jedi, then, the trade dispute is a way to gain political power, but only through the attempted extermination of all life on a planet. Thus the dark side followers diminish the importance of the inhabitants of the planet as living beings, essentially exhibiting both racism and speciesism. The light side faction, campaigning for social equity, opposes the structural violence which legitimises the deployment of mass direct violence by the villains with direct violence of their own. The result is a Self/Other relationship which, like that in Saving Private Ryan, depends heavily on a group that is neither Self nor Other, but is under threat from the Other and thus needs to be protected by the Self. Although there is a racial component to the way in which this secondary Other is defined in Saving Private Ryan, the corresponding group in The Phantom Menace is defined by way of religion; they are the people who do not believe as fully in the Force as others do. A key example of this is the leader of the Gungans, one of the alien races in the film. The leader acknowledges the Jedi as powerful, but does not exhibit proper reverence for them. Ultimately, he is swayed by their powers. In this way, the film articulates a division between the faithful and the unfaithful, which elevates the former to both Self and Other while the latter is never more than Other. This relationship parallels the one in Saving Private Ryan between the US Soldiers, the Nazis, and the Jews, as evidenced by Figure 14. Here, though, instead of the US Self, the Self is comprised of the good heroes who are faithful. The Other, the one that is attempting to commit genocide, is defined by the evil 
villains who are also faithful. Lastly, the secondary Other is made up of the characters that are good, but are not true believers in the Force. Thus, the Gungan army, which performs heroically in the final act of the film, is prevented from truly being part of the Self since they do not fully believe in the power of the Force. The one partial exception is Jar Jar Binks (Ahmed Best), who believes and is elevated above his Gungan compatriots even though he is not fully integrated into the Self. The importance of this division along religious lines is of particular importance when considering the historical anxieties surrounding religion in the pre-millennial United States.

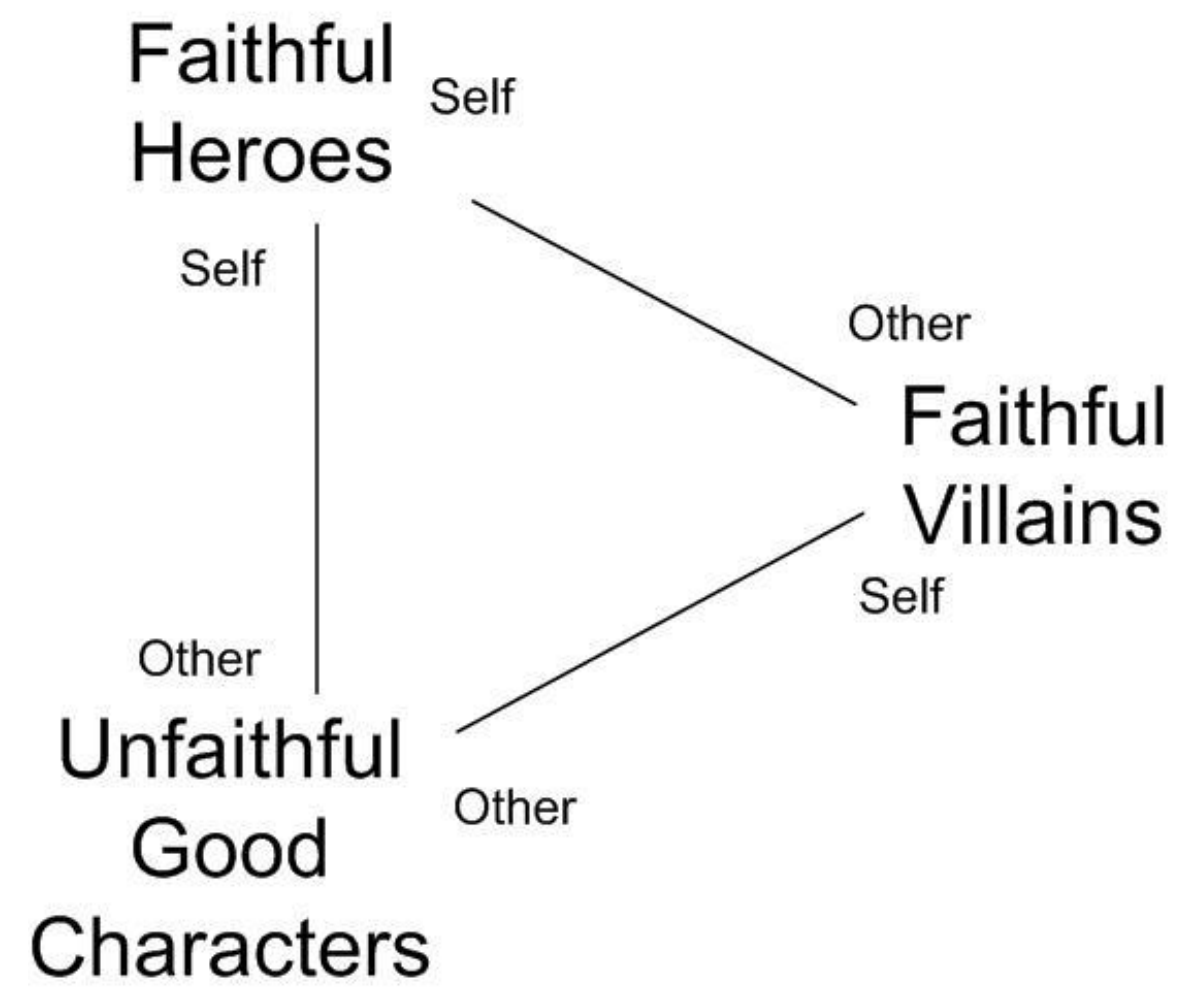

Figure 14 - The Secondary Other in The Phantom Menace

As mentioned above, the religion in The Phantom Menace is not a uniform one despite the fact that it all stems from the single divine power of the Force. Apart from the major division between the light and the dark sides of the Force, which are essentially sects, there is a further division shown within the light side with one character, a Jedi named Qui Gon Jinn (Liam Neeson), encouraging a belief in what he calls the "living Force," a concept not readily explained in the film, though others 
discourage this. The textures of the religion revealed by these sectarian divisions once again parallel real-world anxieties with feuding religions representing the tensions which had come to the fore in a post-Cold War era, not just through debates over family values, but also through deployments of direct violence in events such as the 1993 World Trade Center bombing. It would be easy to read these religious tensions in relation of the events of $9 / 11$, but given the time difference between the two there is not a concrete connection. It is worth noting, however, that while the film does contain a Self/Other binary based upon the sectarian divisions within the religion, the characters all ultimately believe in a single divine force. This connects with the Taoist notion of good and evil which posits that the oppositional sides are part of a larger unified whole rather than separately existing entities.

In the film, of course, this manifests itself in the already discussed faithfulness that both the heroes and the villains maintain. At this larger level, then, the film offers a view of a world where there is a single divine power. Despite the intense sectarian violence in the film, an alternate reading suggests it not as a reflection of premillennial religious anxieties, but as a response to them. Accordingly, The Phantom Menace becomes a film which shows a world at war, but it also shows a world which has a single theism. There is only one divinity in The Phantom Menace and it defines the world of the film. Again, since the film draws on various religions in a way that opens it up to diverse readings, different audiences were potentially able to watch it at the time of its release and see a world wherein their own religion was represented. Thus the film can be seen as a sort of religious paradise where the Self is aligned with the faith of the viewer. Interestingly this even applies to atheistic and agnostic viewers as the claim above by Lucas about his mythological inspiration suggests. However, as previously discussed, the nostalgia for this religious panacea is only superficial to the film. The religion used to define the primary Self/Other relationship of the film carries with it structures of violence that function to further texture both the Self and Other. Specifically, they solidify the connections between the film and its non-religious historical context. Thus by examining the violence inherent in the construction of religion in the film, secular 
structures of violence become clear such as racism and sexism, both major issues in the United States in the late-1990s. These structures of violence become visible through an analysis of the mythic construction of the film.

\section{Mythic Divisions: Defining the Self and Other in The Phantom Menace}

The Star Wars films are often referred to as modern myths. In his analysis of the presence of alien messiahs in science fiction film, Hugh Ruppersberg observes that the original films shared much with other science fiction films that showcased messiah-like characters (33). While Star Wars did not feature an alien messiah, a lack which Ruppersberg argues is not typical of science fiction films, there remains a strong messianic subtext throughout the trilogy. Ruppersberg contends that the "messianic theme lent these films a governing mythology" even though "the primary emphasis falls on action and character" (33). While this emphasis remains in The Phantom Menace, the centrality of the mythological elements to the plot enhances the importance of the "governing mythology." For Ruppersberg, though, "The struggle of good and evil [in the original films] never develops beyond an amorphously defined abstraction" (33). However, by analysing the mythic construction of The Phantom Menace in greater detail, particularly in light of the Self/Other binary discussed above, it becomes clear that the apparent emptiness of the mythological elements and binaries in the film actually conceal a nuanced series of relationships. A closer examination of these relations reveals the presence of implicit inequalities -in other words, structural violence.

The mythology of the Star Wars films grew substantially between the release of Return of the Jedi and The Phantom Menace, and became a key aspect of the marketing for the film. This is clear in the initial trailer for the latter which claimed: “Every generation has a legend...Every journey has a first step...Every saga has a beginning..." ("Star Wars The Phantom Menace"). The remainder of the trailer then highlights specific elements of the mythology regarding the character Anakin who later becomes Darth Vader from the original trilogy of films. As previously mentioned, Lucas has acknowledged he drew on the myth theories of Campbell in devising the plot to the films, and this is alluded to through the mention of the 
"journey" in the trailer. Wetmore, though, argues that the Star Wars saga is "not truly myth" (101) in the sense Campbell defines it. ${ }^{18}$ He does, though, observe that the integration of mythic structures into the films results in pervasive "Manichaeisms" (96). By their very nature, these mythic binaries segment groups in such a way that they become Self and Other to one another, often representing oppositional ideologies. In order to sustain these oppositions, structures of violence are needed. As discussed above, The Phantom Menace does not segment good and evil-Self and Other-along the broad division of faithfulness so much as it does across a constructed moral system, which is predicated upon the mythic elements of the film.

When discussing myth, Wetmore engages with the work of Roland Barthes. At a general level, Barthes asserts that "myth is a type of speech" which "is not defined by the object of its message, but by the way in which it utters this message" (107). If myth was to support structural violence, then it would be evidenced in the construction of the message rather than the message itself. To examine the violence of the film, particularly with regard to the mythological binaries it presents, it is necessary to explore the ways in which the Self and Other in the film, the good and evil believers respectively, are characterised. A starting point to this investigation is provided by an argument Wetmore makes when he writes, "If we cannot understand other people on our own terms, myth allows us to remove their humanity and make them something other than people" (96). What Wetmore suggests, then, is that it is the notion of humanity-and often the lack of it - which is a key factor in The Phantom Menace in terms of identifying the Self. More importantly, since both the good and evil characters of the film are faithful, humanity, in a very literal sense, becomes one of the primary axes upon which the Other of the film is defined.

At the purely visual level, the Self, composed of the good characters in the film, is primarily represented by humans while the Other, made up of the villains, is comprised primarily of non-human characters. As shown in Table 3, although there

\footnotetext{
${ }^{18}$ See Wetmore The Empire 100-101 for his complete argument.
} 
are some good characters which are either aliens or robots, almost none of the villains are human.

However, this is not to suggest that the good aliens and robots are heroes, as they are secondary characters in the film. For instance, although Yoda is a key figure in the mythology of the saga, his role in The Phantom Menace is minor, essentially acting only as an advisor to the heroes. Additionally, following the narrative model established by Vladimir Propp and applied by Graeme Turner to the original Star Wars, the good non-human characters fulfil traditional secondary roles (Turner 82). So while R2-D2, a Droid, and Jar Jar Binks, a Gungan, both perform heroically at points in the film, they fit better into the other character categories Propp establishes such as the donor, the helper, and the dispatcher (79-80). ${ }^{19}$

\begin{tabular}{|l|l|l|}
\hline Human & Good & Bad \\
\hline & $\begin{array}{l}\text { Qui-Gon Jinn } \\
\text { Obi-Wan Kenobi } \\
\text { Anakin Skywalker } \\
\text { Queen Amidala } \\
\text { Shmi Skywalker } \\
\text { Captain Panaka }\end{array}$ & Darth Sidious \\
\hline Alien & $\begin{array}{l}\text { Jar Jar Binks } \\
\text { R2-D2 } \\
\text { C-3PO }\end{array}$ & $\begin{array}{l}\text { Darth Maul } \\
\text { Sebulba } \\
\text { Watto }\end{array}$ \\
\hline & Yoda & $\begin{array}{l}\text { Nute Gunray } \\
\text { Rune Haako }\end{array}$ \\
\hline
\end{tabular}

Table 3 - Humans and Aliens sorted in Good/Bad alignments

The only human among the villains is Darth Sidious (Ian MacDiarmid). Despite the fact that he is the primary villain in the story, he makes only minor appearances in

${ }^{19}$ See Chapter 4 in Turner 1999 for more. 
the plot itself. When he is shown, he is a cloaked figure with a face shrouded by a black hood. While this conceals his face, making him appear less human, he is also often presented via holographic communication technology which reduces him to a flickering blue image. By mediating his image in this way, he ceases to be a human figure. Much like the representation of the Nazis in Saving Private Ryan, this fusion of human and technological is a pervasive element of The Phantom Menace, and again suggests a connection between the film and the underlying technophobia of the era through another binary of the film: technological mastery versus technological reliance.

While the villains in the film are sometimes presented as fused with their technology, the above example of Darth Sidious as a hologram being the prime example, more often they appear separate from it. For instance, although the Neimoidians, one of the villainous races in the film, control the Droid army, they are physically distanced from it such that when they are confronted by the weaponwielding heroes, they are forced to submit. What is more, the Droid army itself is entirely dependent on a single spaceship which controls them all. When the ship is destroyed, the entire army immediately deactivates in a scenario akin to the $\mathrm{Y} 2 \mathrm{~K}$ bug predictions. Conversely, the heroes, though heavily dependent on technology, prize natural qualities instead, as is evidenced in the repeated statements made by Qui Gon Jinn to "be mindful of the living Force." This is also evident in a comparison between the villainous Droid army, composed entirely of virtually identical robots - some have different paint schemes - and the noble Gungan army which is a homoethnic, but has individual fighters such as Binks.

It is useful here to draw again on the work of Michael Ryan and Douglas Kellner, who observe that "fantasy films concerning fears of machines or of technology usually negatively affirm such social values as freedom, individualism, and the family" (245). In response, they suggest, "conservative values associated with nature" were posited as "antidotes to that threat" (245). The Phantom Menace operates very much within that paradigm with the technologically-oriented Trade Federation supporting structures of violence which privilege them in a variety of ways, legitimising direct violence in terms of race, species, and more. Since 
technology is the means by which the Neimoidians are able to deploy direct violence, technology becomes something to be feared. However, as Ryan and Kellner observe, technology itself is not always "ontologically evil" but is "subject to changes in meaning according to context and use" (251), a fact that is clear in the deployment of technology by the heroes that stands in opposition to the use of it by the villains. Thus the deployment of technology reinforces the divide between human and inhuman, even when the characters being represented are other species. For Galtung, this dehumanisation of the Other is a key tactic in legitimising structural violence through ideology ("Cultural" 298). As he remarks, "When Other is not only dehumanized but has been successfully converted into an 'it', deprived of humanhood, the stage is set for any type of direct violence" (298). Thus by making the non-human villains so reliant upon a technology which has been framed as extremely threatening, they become that 'it' and direct violence becomes legitimised. This evokes the work of Robert L. Ivie on "images of savagery" (279) and enemies of the United States. Given the prolific use of tactics during the Cold War which sought to dehumanise enemies, the fact that the Neimoidians are reduced to genocidal non-humans subtly aligns them with the vilified Soviets from the Cold War. Potential connections to the Soviet Other are not the only real world corollaries found in the film, however.

In designing the various alien races of The Phantom Menace, the filmmakers prided themselves on the fact that they created numerous unique amalgamations of real world cultures. While this could have functioned similarly to the combination of religious elements discussed above by potentially unifying a fragmented society under a multicultural banner, the filmmakers instead essentialised non-white cultures and reproduced various stereotypical elements. Along these lines, Wetmore writes:

"When using real world material, including mythic structure, real languages, recognizable environments, and characters rooted in actual ethnicities, to construct an imaginative geography and history and then posit a simple duality as the method for defining 
what everything is...the narrative can be used to define the real world equivalents" (96).

Thus, although the alien races are visually different from human races, they are culturally similar, and in those similarities exist structures of violence.

\section{Intergalactic Stereotypes: Race and The Phantom Menace}

One of the major alien races of the film is the Neimoidians. The Neimoidians run the Trade Federation, the evil organisation attempting to exploit the inhabitants of the central planet of the film, Naboo. As many have observed, the Neimoidians are clear stereotypes of Asian cultures. For instance, John Leo draws parallels with cinematic antecedents describing the characters as

"stock Asian villains out of black-and-white B movies of the 1930s and 1940s, complete with Hollywood oriental accents, sinister speech patterns, and a space-age version of stock Fu Manchu clothing" (14).

Wetmore takes these connections further, focusing specifically on the negative Asian stereotypes evoked by the depiction of the Neimoidians (162-168). Specifically, he draws a connection between the stereotypical Asian qualities of the characters and the depictions of Japanese villains found in many World War II films such as The Bridge on the River Kwai (163). Wetmore argues that similarities such as the sneak attack on Naboo and the subsequent establishment of (off-screen) prison camps establishes direct parallels between the Neimoidian Leader, Nute Gunray (Silas Carson), in The Phantom Menace and Colonel Saito (Sessue Hayakawa), the Japanese Colonel tasked with building the titular bridge in The Bridge on the River Kwai. This positioning, as Wetmore observes, is so pervasive that "there is not a single Neimoidian presented in a positive light in either [The Phantom Menace] or [its sequel Attack of the Clones]" (163). The result is that the Neimoidians are consistently shown to be weaker than their adversaries. Since the Nemoidians are so strongly depicted using negative Asian stereotypes, the inferiority of their characters becomes an issue of ethnicity. This connection 
effectively privileges whiteness and Western culture over non-White Eastern peoples. It is worth noting that the post-9/11 racial profiling of Arabs extended to Asian persons as well. As Edith Wen-Chu Chen and Grace J. Yoo observe, after the passage of the USA PATRIOT Act "South Asians throughout the United States have experienced increased racial and religious profiling that has taken the forms of harassment, hate crimes, and profiling in airline and travel security" (xx). The Other, then, is not limited to the Arab in the post-9/11 United States, but is instead tied more fully to a non-white ethnicity. Returning to The Phantom Menace, though, it is important to emphasise that the preference the film exhibits towards whiteness is not just evident in the depiction of the villains, but of the heroic sidekicks as well.

Binks, an alien creature encountered by the Jedi, quickly establishes himself as a good character albeit one whose primary function is to be a comic sidekick. While the behaviour and mannerisms of the Neimoidians clearly draw on Asian stereotypes, those of Binks are drawn from stereotypical traits of Caribbean cultures. At the same time, though, Binks also reactivates racial stereotypes ascribed to black characters in America, specifically the "Coon." Donald Bogle defines the pure Coon stereotype as "unreliable, crazy, lazy, subhuman creatures good for nothing more than eating watermelons, stealing chickens, shooting crap, or butchering the English language" (8). Jar Jar Binks fits this description well; in one scene he even attempts to steal a chicken-like creature from a market stall he passes, as shown in Figure 15. 


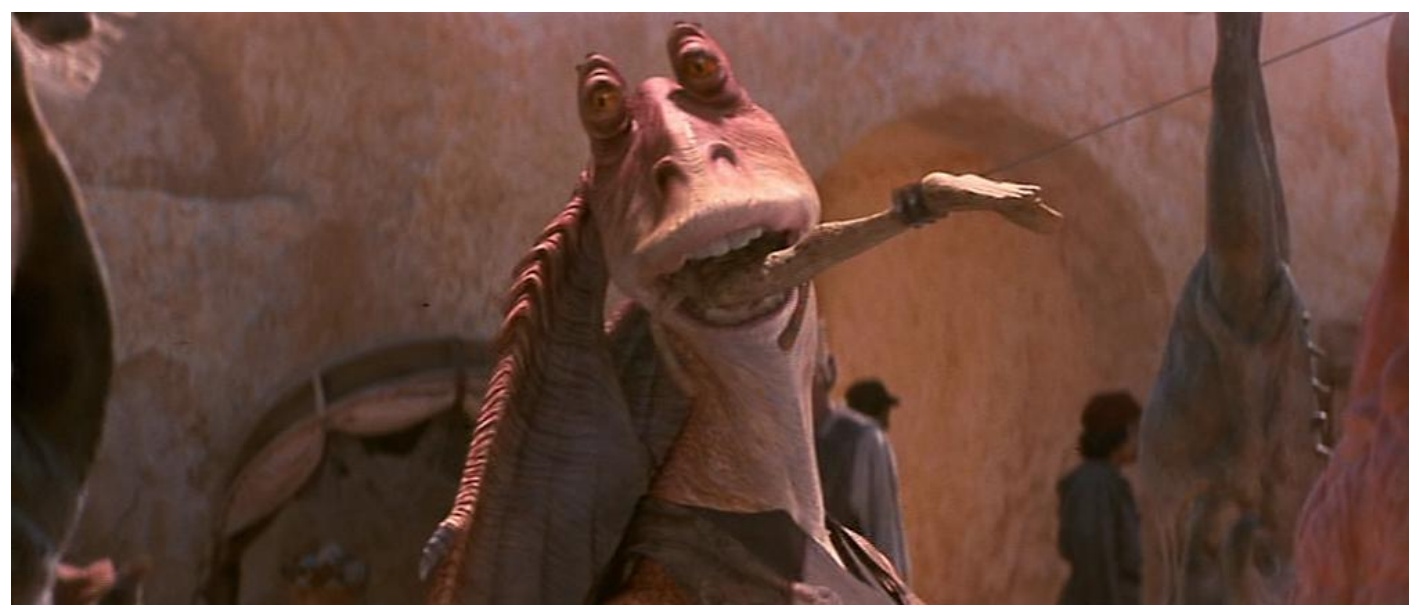

Figure 15 - Stereotype reactivated with Binks stealing "chicken" in The Phantom

Menace

Esther Godfrey, writing on The Phantom Menace, argues that the film "speaks volumes about society's love affair with blackface" (n. pag.), and observes that "Binks puts on what is indeed a 'new millennium minstrel show,' pushing the burnt cork and lipstick of traditional blackface into a computer-generated construction that masks the entire black male body" (n. pag.). Her remarks here evokes the historical context of the film, and can be interpreted as a suggestion that Binks functions as a response to the questioning of the structural violence in the United States that reasserts the privileging of whiteness over non-whiteness. However, it is worth considering the fact that Binks is indeed a "computer-generated construction," as it complicates his position as a strictly racial figure since he is also a special effect. Dan North, for instance, suggests the hate directed at Binks from fans is less perhaps because of the racial elements and more because Binks exists simultaneously as a character, an effect, and a commodity (156-157). ${ }^{20}$ This is not to say that Binks should not be considered in terms of the pre-millennial anxieties centred on the cinematic black body, as he should, but for now the salient point remains that The Phantom Menace constructs a Self/Other relationship which is very much fuelled by race-based structural violence. ${ }^{21}$ So while Binks, the "Coon,"

\footnotetext{
${ }^{20}$ See North 155-162 for a discussion of how Binks is positioned at the focal point of a number of different cultural trends surrounding both race and technology.

${ }^{21}$ For more on the raced body and the millennium, see the following chapter which analyses The Grinch.
} 
is allowed to accompany the representatives of the Self because he does not challenge the authority of whiteness, the Neimoidians, representing a stereotypical Asian menace, are villains because they threaten the position of the white heroes as "top dogs" in the film world. After all, despite the racial diversity, the Supreme Chancellor (Terrence Stamp) and his replacement, Senator Palpatine (Ian MacDiarmid), are both elderly white men. However, there are some counterpoints to these structurally violent stereotypes, specifically in the figures of Queen Amidala and her head of security, Captain Panaka (Hugh Quarshie), who is black.

Throughout the first two acts of the film, Queen Amidala is a passive figure. She is captured by the army of Droids controlled by the Neimoidians, accompanies the Jedi on their exploits, and is used as a pawn in the political manoeuvrings of Imperial senators. Similarly, Captain Panaka is unable to protect the queen from the Droid army and spends the rest of the second act of the film inactive. During the first two thirds of the film, then, both the queen and Panaka adhere to gender and racial stereotypes respectively. For Amidala, this is evident in the way that she always defers to male authority. Additionally, in all scenes involving political discourse, her speech is stilted and mechanical, suggesting she is nothing more than a puppet giving a patriarchal regime a matriarchal face, something reflected in the narrative itself. As for Panaka, he specifically resembles some aspects of the black stereotype of the Tom.

Bogle describes the Tom as a constantly "chased, harassed, hounded, flogged, enslaved, and insulted" (4-6) character, none of which applies to Panaka. However, he also identifies the Tom as a character who will "keep the faith, ne'er turn against their white massas, and remain hearty, submissive, stoic, generous, selfless, and ohso-very kind," (4-6). All of these traits, Bogle argues, allow white audiences to embrace the Tom. Panaka fits this latter description closely, serving as the loyal guardian of the white queen. This reverence for the white queen is additionally important since it means that despite his military position, Panaka is not what Bogle calls a "Brutal Black Buck," a stereotypical savage who is driven by base, often sexual, desires. Rather than lusting for the white queen, though, he protects her. This of course emphasises the dominance of white authority by having a black 
character sanction it. Thus the film represents gender-and race-based structures of violence for much of the first two acts. There are some exceptions to this. Mace Windu, for instance, is a key Jedi figure played by black actor Samuel L Jackson. Although Windu is an obstacle for the heroes, he is not a villain. Further, although his antagonism towards the heroes could be read as a subtle activation of the threatening Buck stereotype, it does not develop in that way as he always presents clearly articulated rationales for his opposition; he offers the audience a positive non-white character that challenges the structures of violence in the film even if it does not entirely overcome them. However, even without a character like Windu, the final act of the film reverses the structural violence which surrounds the queen and Panaka in the first two acts.

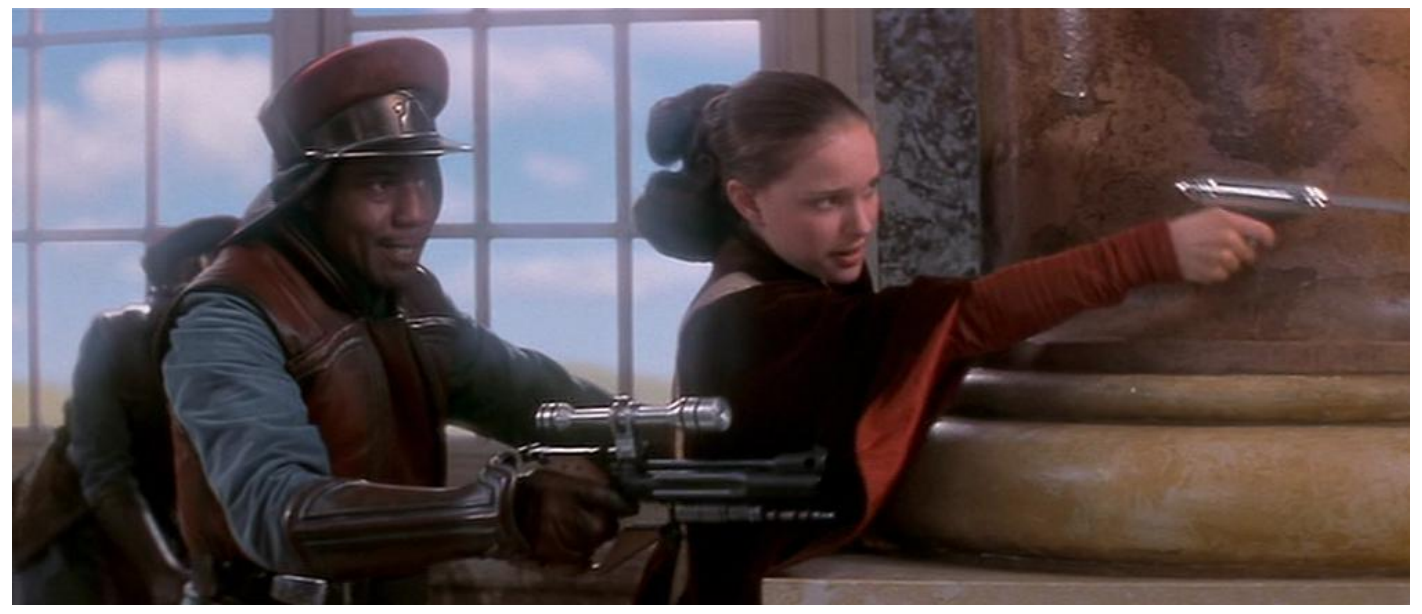

Figure 16 - Fighting stereotypes with direct violence in The Phantom Menace

At the climax of the film, the main characters split off as the film develops four sequences of direct violence simultaneously. In one of these, the queen and Panaka deploy direct violence to retake control of the planetary government from which the queen had been forcibly deposed, as shown in Figure 16. In this sequence, both of the characters break free from the stereotypes that they had previously inhabited. Although it requires direct violence for them to do so, the fact that they do transform subverts the structures of violence such that a social equity - an equal right to deploy direct violence-is achieved for both women and non-white characters. Given the dominance of the white patriarchy in the rest of the film as well as in countless others, this could be viewed as a step away from 
structural violence as it expands the notion of the Self. However, since it is so heavily predicated upon direct violence, it cannot truly be considered structural peace. Also of importance here is the consideration of whiteness itself.

Anakin, the messiah of the film, is presented as the image of pure whiteness; he is blond-haired and blue-eyed. This positioning evokes other science-fiction messiahs, such as Roy Batty (Rutger Hauer) in Blade Runner. Of Batty, Richard Dyer writes that his "unmistakably Teutonic appearance" positions him "at the top of the Caucasian tree" (214), a statement which can also be applied to Anakin. Thus, even as the film both traffics in and challenges racial stereotypes, it reinforces the notion of pristine and dominant whiteness. Interestingly, the fact that Darth Sidious is also an extreme white suggests that only whiteness can truly pose a threat to whiteness, an idea which is not substantively developed in this film, but one which hold strong parallels to the already discussed position of the Nazis in Saving Private Ryan. In both, a place upon the spectrum of whiteness exists that ultimately seeks to obliterate all that is not itself. That the Self of both films essentially seeks the same, but in a less extreme fashion is not acknowledged. Ultimately, then, the dream of a Self unified by religion that The Phantom Menace articulates is a dream which is undermined by structural violence. However, by elevating the stakes of the religion-based conflict to extremes of direct violence-survive or perish-the film manages to conceal those structures. This same process can be seen in the post9/11 era.

\section{Faith and Terrorism: Fighting The Phantom Menace after 9/11}

On the eve of the millennium, the post-Cold War identity crisis in the United States was joined by apocalyptic anxieties. Between the two, the national Self seemed to fragment as Kaplan had predicted, with people indeed taking "psychological refuge in their insulate communities and cultures" (76). There was not a clear national Self. This was exacerbated by such events as the Clinton impeachment and the Columbine High School shootings; the fabric of the nation seemed to be unravelling. The central dream of The Phantom Menace, however, is one of unity. As discussed above, it is heavily predicated upon religion, and interfaces with 
multiple real-world corollaries. Returning to the expanded notion of "wishing" 9/11 drawn from the work of Jean Baudrillard (5), what The Phantom Menace seemed to provide the viewing public with was indeed, to borrow from Card, a return to world grounded by "a Deep Story that gives meaning to suffering and makes sense of the randomness of life" (n. pag.). Thus the film deferred anxieties by dreaming of domestic unity against a common enemy again, a common Other. Interestingly, although Baudrillard based his ideas upon the ruined cityscapes of the disaster films of the mid- to late-1990s, The Phantom Menace, despite depicting an empire in decline, does not actually show the empire in ruin. So despite the titular menace, the film remains quite optimistic, even with the final shot, a victorious celebration, serving as a mirror of the final shot in the original film, with good having triumphed over evil. This is a key detail as it suggests that in a morally justified struggle, particularly when the good side is properly aligned with a divine power, there can be a definitive victor. The moral certainty afforded by a religiously-grounded worldview was overtly articulated by the Bush administration in its response to the attacks of September 11, 2001.

In the days following 9/11, George W. Bush framed the conflict with the perpetrators of the attacks in religious terms when he remarked

"This is a new kind of - a new kind of evil. And we understand. And the American people are beginning to understand. This crusade, this war on terrorism is going to take a while" ("Remarks" n. pag.).

While the larger implications of the use of the word "crusade" will be explored in Chapters Six, Seven, and Eight, the importance of the term to the current discussion is that it overtly frames the "war on terrorism" within a religious context, specifically the historical war between Christians and Muslims.

Analysing the rhetoric of Bush in the immediate post-9/11 period, Debra Merskin concludes that his words were often "ground in universal notions of enmity" (172), but when joined with historical and cultural stereotypes ultimately were able "to revivify, reinforce, and ratify the Arab as terrorist stereotype" (172). Of course stereotypes also framed the terrorists as Muslims as well. The result was the 
creation of a religion-based conflict wherein the Self and Other were not just implied to be Christian and Islamic respectively, but were overtly Christian and Islamic. In other words, the Self and Other were constructed based on displays of faith. Accordingly, Muslims practicing their faith in the wake of 9/11 were suspected of being part of the terrorist Other as numerous hate crimes from that period show. The roles of Bush as president and a man of faith became blurred through his repeated invocation of the Christian God in his speeches. This led some, such as journalist Ron Suskind, to describe Bush as having "created the faithbased presidency" (47). While there is much more to that claim than religion, the fact that the national Self was increasingly positioned within a religious binary meant that it was aligned with the notion of a Chosen People. This is not a new conceit for the US Self as previous policies, such as Manifest Destiny, have privileged the nation in similar ways. However, as with those previous policies, the elevation of the US above an Other legitimised the use of direct violence. In the post-9/11 era, however, the fact that the Other was given a very specific faceArab Muslims - meant that direct violence would become legitimised against that particular population. It is unsurprising, then, that the Iraq invasion, which had no real connection to the events of $9 / 11$, was not met with outright protest by the American people as a whole since the Other was defined in such a broad way that it could be adapted to include Iraq and its leader, Saddam Hussein. However, opponents of the Self were not limited to Arabs or Muslims. This is because inherent in the definition of the Other were structures of violence which could be applied to numerous different demographics.

For instance, those that decried the policies enacted by the Bush administration, such as the invasion of Iraq, were viewed as supporters of the Other. This was certainly the case with the music trio The Dixie Chicks when they spoke out against Bush and experienced vociferous criticism as a result. This particular example also raises the question of other attending structures of violence in the post-9/11 period, such as sexism, many examples of which can be found in The Terror Dream by Susan Faludi. The positioning of Bush as the religious patriarch of the national Self is an example of this, but just as the film challenged sexism to some degree 
with the warrior figure of Amidala, so too were such gender-based structures of violence countered by Condoleezza Rice. The similarities, both positive and negative, between the response to 9/11 and The Phantom Menace once again suggest a process of dreaming. The film dreamt of a resolution to the identity crisis which the post-Cold War United States suffered through, and the Bush administration made those dreams a reality. 


\section{Chapter Five Insidious Acceptance in the New Millennium: Dr. Seuss' How the Grinch Stole Christmas (2000)}

The passing of the millennium without catastrophe assuaged many anxieties, but at the same time it underscored the lack of coherent national identity in the United States. As was the case with the pre-millennial period, many turned to the past to determine the future identity of the country. For instance, on October 3, 2000, during the first presidential debate, George W. Bush, then governor of Texas, made the following critique of his opponent Vice President Al Gore. He said:

\footnotetext{
"The vice president and I have a disagreement about the use of troops. He believes in nation-building. I would be very careful about using our troops as nation-builders. I believe the role of the military is to fight and win war and, therefore, prevent war from happening in the first place" (Bush et al, "First" n. pag.).
}

Despite the dubious logic of that statement, Bush saw the identity of the country in its militaristic past. While this was not an overt support of the concept of "victory culture" discussed previously, it certainly drew on past notions of military glory. This was underscored when he specifically remarked that "I want to rebuild the military power" (Bush et al, "First" n. pag.). While the fact that Bush ultimately lost the popular vote of the 2000 presidential election despite being named the winner, the way in which he looked backward to the US past was indicative of a nostalgic trend in the country at that time. This historical gaze is important as cinema is a primary location of nostalgia. It is useful, then, to explore the idea of the "nostalgia film" advanced by Fredric Jameson.

For Jameson, a nostalgia film is one which is "about the past and about specific generational moments of that past" ("Postmodernism"18). He argued that Star Wars was a nostalgia film which offered younger viewers a novel experience while older viewers were able to pacify a nostalgic desire for a previous era 
("Postmodernism" 19). Though Jameson was writing about films from decades earlier, his description of Star Wars provides an explanation for the appeal of Dr. Seuss' How the Grinch Stole Christmas, and for the phenomenal box-office success it experienced, grossing US260 million dollars and becoming the most successful film of the year (Box Office Mojo).

At the turn of the millennium, The Grinch was already well established in popular US culture through its previous iterations. The book, How the Grinch Stole Christmas!, by Dr. Seuss was one of the top 40 all-time bestselling books for children at the time the film was released, having sold over 3 million copies (Roback et al 25), and the 1966 adaptation into an animated television special became a holiday staple after its original airing. Following the argument Jameson makes about nostalgia films, the movie version of this American experience allowed children to enjoy the story for the first time while adults were afforded the opportunity to return to an earlier period in their lives, specifically the period of the early Cold War.

On the visual level, the film definitely evokes an America from the 1950s. In the production notes of the film, this is made explicit through details about how the props for the film were simply modified versions of "1950s style appliances" (Universal 16). The evocation of that era goes far beyond the set, as even the families and businesses are from a time long past. The costume designer, Rita Ryack, says that a primary source of inspiration for her work was cookbooks from the 1950s. She is quoted in the production notes saying that the main family of the film "was sort of a cockeyed version of the perfect '50s TV family" (Universal 19), which is reflected in their attire. The result is that Whoville, the central location of the film, is brought to life as an American town out of a Norman Rockwell painting seen through the lens of Dr. Seuss; the American pieces are all there-a town square, a post office, cozy homes - but their Seussian geometry relocates them all within an imaginary past which attempts to recreate the experience of either reading the Grinch story or watching the previous adaptation. Thus the historical details of that period are elided, leaving the audience with only the nostalgia-based memory of the period. This is in keeping with the notion of the nostalgia film as 
Jameson notes that they are "historicist rather than historical" (The Cultural 130), in that they reuse the visual motifs and styles of the era. Pertinent to the discussion of violence, Jameson adds that

"since [the nostalgia film] is necessarily based on the recognition by the viewer of pre-existing historical stereotypes, including the various styles of the period, it is thereby reduced to the mere narrative confirmation of those same stereotypes" (The Cultural 130).

Accordingly, the recreation of an older America reactivates many stereotypical elements from the American past-as well as the violence associated with them. However, The Grinch expands the narrative far beyond both the original story and the television adaptation, adding violence which is grounded in American anxieties at the turn of the millennium. At the same time, and likely because of the millennial concerns, the film remains firmly grounded in a Christian tradition. Thus the veneer of nostalgia functions to conceal and communicate violence from multiple eras of American history.

In this chapter I will argue that The Grinch subtly defines the Self along religious lines, covertly positioning the Other in terms of race and class. While the presence of religious themes create an affinity between this film and the previous film, Star Wars: Episode I-The Phantom Menace, the engagement with religion changes as the heterogeneous faith of The Phantom Menace is replaced by a homogeneous construct in The Grinch; there is only one religion in The Grinch. The result is a framework which supports a more binary worldview which, drawing on the work of Galtung, divides the Chosen and the Unchosen ("Cultural" 297). It is my contention that the film does indeed build a binary diegetic world that contains structures of violence. More importantly, these structures do not display an expansion of the Self, but reinforce violence against the Other. This same process is again found in the response to the attacks of September 11, 2001, carried out by the Bush administration. I will begin by looking at the conception of family in the postmillennial period, suggesting that a desire could be seen for a return to a mythic 
American definition of a traditional family structure, and how that return is mediated by religion. Next I will show how The Grinch also conflates family values with religious values, specifically those of Christianity, by using materialism as a seemingly secular device. With the Self defined upon religious lines, I will then explore the articulation of the Self, demonstrating how it adheres to numerous structures of violence including those based upon class, gender, and ethnicity. With the Self/Other binary made clear, I will then show the ways in which that binary allows the conversion of the Grinch (Jim Carrey), an ostensibly peaceful ending, as one of violence where the Grinch is not converted, but tamed. Connecting these ideas to the response to $9 / 11$, I will argue that The Grinch dreams of a future return to a nostalgic past where the United States is driven by both whiteness and religion toward a future where the non-white, non-Christian Other is defeated and potentially tamed, which is one possible future offered by US government in the post-9/11 period.

\section{Religion and Family in the Millennial United States}

Kirsten Moana Thompson argues that in the 1990s "apocalyptic dread" "took explicit form in American cinema" (1). For her, apocalyptic dread is a syndrome that includes the "social anxieties, fears, and ambivalence about global catastrophe" (1). She also identifies what she refers to as the "twin" of apocalyptic dread, "millennial dread." She defines millennial dread in terms of Judeo-Christian eschatological beliefs. Specifically she deals with millennialism, the Christian belief that there will be one thousand years of peace before the end of times. Although Thompson observes that both of these dreads are evident beyond the millennium, she acknowledges that the year 2000 was a key year in terms of pre-apocalyptic imagery, especially for millennialism. The anxieties about the millennium found in film, Thompson argues, were driven by a widely perceived social crisis which found its base with "an increased cultural conservatism and (re)turn to fundamentalist religions" (7) in the late-twentieth century United States. Therefore millennial anxieties grew along with the search for a post-Cold War identity in the United States, a parallel development which links the two. This linkage is even clearer in 
the fact that eschatological beliefs offered a solution to the lack of a national Self for many in the United States as apocalyptic scenarios conferred the status of Self onto the faithful. Despite the lack of an actual apocalypse at the turn of the millennium, the cultural conservatism and revitalised religion that Thompson argues returned in the pre-millennial period remained in the post-millennium. This was evidenced at the national level in the 2000 election, in which both candidates, George W Bush and Al Gore, espoused strong Christian rhetoric in their bids for election. In terms of violence, then, what the presidential candidates in 2000 evidenced was the existence of a strong Self-Other binary which was based upon a Christian, or in broader terms, religious world view.

As discussed previously in regard to Star Wars: Episode I - The Phantom Menace, religion is one of the major cultural domains within which Johan Galtung sees cultural violence existing ("Cultural" 296). Specifically, the Judeo-Christian-Islamic traditions permit the construction of a violent binary between Chosen and Unchosen people. As he frames it, the "Occidental tradition of not only dualism but Manicheism [sic], with sharp dichotomies between good and evil" ("Cultural" 296) informs that split. Of course this division is treated differently by different religions, but it is not uncommon for the structural violence to lead to direct violence.

Despite the religious diversity of the United States, the post-millennial period, particularly with the victory of Bush in the 2000 election, was one dominated by a notion of Self based largely on Christian values. However, as Thompson suggests, these religious beliefs were not new to pre-millennial America, but instead were something that the United States had returned to (7). Specifically, the Self-Other dynamic they established was derived from the historical period between World War II and the Vietnam War. The importance of this era to the religious return in the 1990s is best understood through the apparent crisis of the family that permeated 1990s discourses.

Some of the key proponents of family values in the 1980s and 1990s in the United States were religious groups such as the Moral Majority and the Christian Coalition. For them, the disappearance of the so-called traditional family was tied to the 
belief that religious values were no longer regarded as part of a dominant Self in the United States. While this can be explained in terms of the fragmentation of the Self in the post-Cold War identity crisis the United States experienced, which Robert Kaplan predicted, the perceived crisis of the family was cited as the source of many problems from that period (76). As Stephanie Coontz has argued, it became "the key to explaining the paradox of poverty amid plenty, alienation in the midst of abundance" (256). The apparent dissolution of family values, then, coupled with the return of certain religious beliefs at the end of the millennium resulted in a large push for a redefinition of the Self in terms of a family founded on religious values if not beliefs. Therefore the proponents of the family values movement in the 1990 s sought a return to the nuclear ideal, which was the television family of the 1950s. As Coontz notes, this family is best represented by the "Ozzie and Harriet or Leave it to Beaver model" (23). However, as Coontz also observes, a return to that television type was not actually possible since it was never reflective of the American family in the first place. One reason is that the depiction of the idealised nuclear family in the 1950s elided many socio-economic factors such as racism and sexism. For instance, Coontz observes that "minorities were almost entirely excluded from the gains and privileges accorded white middle-class families" (30) in the 1950s and 1960s. Ruth Westheimer and Ben Yagoda concur on this point, noting that while " 25 percent of American people...were poor in the fifties" (46) that same statistic among black families was fifty percent, a difference that suggests a distinct inequality. Coontz also argues, though, that the complaints about the contemporary "collapse of traditional family commitments and values...almost invariably mean the uniquely female duties associated with the doctrine of separate spheres for men and women" (41). ${ }^{22}$ However, according to popular television programs, the family was white, upper-middle class, and strongly patriarchal. Thus, the desire in the 1990s for a redefining of the Self according to the mythical televisual family of the 1950s incorporates structures of violence which place the Self in an even more privileged position as it defined Others based upon values systems which are closely aligned with religion, specifically Christianity,

\footnotetext{
${ }^{22}$ See Westheimer and Yagoda, especially Chapter III, for a more statistic-based approach to the inaccuracy of the represented family in the 1950s.
} 
and race. It is within these boundaries that The Grinch defines the family, yet it is only religion, not race, that is dealt with overtly.

\section{"Where is Christmas": Faith and Materialism in The Grinch}

At the beginning of the film, it is clear that the Whos, the inhabitants of the central location of the film, Whoville, are suffering from a crisis. Specifically, the family structures which would normally be associated with the Norman Rockwell-esque environments are in jeopardy due to the impending arrival of Christmas. As shown at the beginning of the film, Christmas is not an event which brings people together. Instead, it is an orgy of consumption wherein family structures are acknowledged, but not supported. This is evident in multiple shopping scenes where hordes of people writhe in lines trying to buy numerous gifts, but it is made clearer in the scenes involving the central character of the film, Cindy Lou Who (Taylor Momsen), the clear representative of the Self in the film. Cindy Lou continually attempts to get others to realise that Christmas is about unity, but the other Whos, including her father, fail to fully grasp this. At one point she is so upset that she sings a song called "Where is Christmas?" The song questions the changing nature of Christmas from a holy day to a holiday, and ultimately suggests that the transformation has disrupted familial bonds. In other words, the disappearance of Christmas has broken the family. While this does reflect anxieties active in the United States in the post-millennial period, a more developed understanding of how Christmas is deployed as a religious concept in the film is needed to fully grasp the implications.

The fact that The Grinch is a Christmas movie grounds it in a religion-based Self/Other binary. What is more, the Chosen/Unchosen binary indicates a high potential for violence-cultural, structural, and direct. However, it is important to consider that Christmas in The Grinch, despite the ties of the holiday to religion, is not solely a religious event. As Paul V.M. Flesher and Robert Torry argue of the original story, the focus is "on the Santa Claus Christmas rather than the Christian Christmas" (31). This is true of the film as well, as is readily apparent in the advertising materials for the film which often show the Grinch dressed as Santa 
Claus, something he does in the final act of the film. This "Santa Claus Christmas" is in keeping with the trend observed by Rowana Agajanian who argues that contemporary Hollywood films show a secular Christmas. However, she also notes that they may "contain a degree of religious symbolism" (147). This is made clearer in the discussion of the original Grinch story by Flesher and Torry who identify the use of the key Christian trope of conversion, which is also present in the film (31). They write that "Christian doctrine requires people to convert in order to become members of the church" (31). The fact that the conversion of the Grinch from nonbeliever to believer is the pivotal moment of the film shows that even though the Christmas of the film might be secularised, the larger relationship between the Self and the Other in the film remains firmly grounded in Christian values. Accordingly, the Self/Other binary of the film is indeed based upon a structure of violence which privileges the Chosen People of the Self over the Unchosen People of the Other. However, the fact that the Other is seemingly able to join the Self via conversion introduces a new dynamic to the Self/Other binary in that it makes the boundary between the two permeable.

In The Grinch, then, one is defined as Self or Other by choice. One can change (convert) from Other to Self if one so desires. This is something that is not evident in the films analysed thus far. For instance, in Titanic, although Rose is able to transcend class boundaries, this is only because Self in the film is defined independently of class. Rose is never shown to be a happy member of the aristocracy, and her interactions with the lower classes in the film simply provide an outlet for her hidden self to emerge. In short, she is always part of the Self even though at the start of the film she seemingly belongs to a class which is primarily defined in the film as Other. The Grinch, on the other hand, genuinely does not believe in Christmas, and spends almost the entire film actively trying to hurt those identified as Self, particularly Cindy Lou. This results in the Grinch being the primary deployer of direct violence in the film. It should be noted, however, that the direct violence does not seriously harm anybody. If he killed somebody, for instance, his conversion might not be as easy as it ultimately is. In fact, the Grinch is made a character even more likely to be converted through flashbacks to his 
childhood, new additions to the story, which reveal he was the target of direct violence in the form of childhood bullying. Interestingly, although the bullying of the Grinch is definitely presented as negative, the film does not explore this direct violence in a substantive fashion. Regardless, the Grinch, positioned as a secretly vulnerable character, ultimately changes his ways, and he does so when he has an epiphany.

The epiphany of the Grinch comes just after the Whos have recuperated Christmas as a holy day. In so doing, the family structures which were previously broken are healed, and, so moved by the unity of Self, the hateful Grinch has his heart literally grow such that he realises the Self is actually the side he should be on. This choice is immediately validated by the Whos who allow the Grinch to join them. As Greg Metcalf observes the "reintegration of the outsider into a community or social consensus" (100) is a key trope, the trope of American Christmas films in the 1980s, and draws heavily from the seminal A Christmas Carol by Charles Dickens. Although the novel was originally a nostalgic look at Christmas in England, it was readily adopted into American culture. This is clear in many texts, including The Grinch, where the Grinch is a thinly veiled Ebenezer Scrooge, but also in the way that the film showcases Christian conversion connections. What is more important, though, particularly in terms of the anxieties of the post-millennial era, is the reuniting of the Grinch with his lost childhood love. Thus a religious return does not only mend broken families, but also forges new ones. The need for a return, though, reinforces the difference between Cindy Lou and the remaining Whos that runs throughout most of the film.

Most of the Whos seem to worship materialism. They are seen glorifying objects of wealth, and Christmas decorations-golden calves, as it were-throughout much of the film. However, materialism does not represent a complete fall from grace. Instead it shows that they have lost their way. They still celebrate Christmas, but they have forgotten its meaning. The ritual is carried out, but the meaning is gone, which is again underscored in the song, "Where are you Christmas?" Thus while the Whos are all part of the Self, they are not as ideally positioned as Cindy Lou. The film makes it very clear that she is the model that everybody should emulate. 
Conversely, the mayor of Whoville, Augustus May Who (Jeffrey Tambor) is positioned as the counterpoint to Cindy since he thrives in the materialistic nature of the holiday. While this might make him a villain in another film, the fact that he still respects the holiday ensures that he remains part of the Self. It does, however, suggest that the Self is not uniform throughout much of the film, fragmented by various levels of belief in materialism, and only healed through a return to religion by a symbolic rejection of consumerism. Interestingly the sole Other of the film, the Grinch, also opposes materialism. In that regard, he and Cindy Lou have much in common. However, the primary difference between the two characters is that unlike Cindy, the Grinch does not believe in Christmas, a thinly veiled representation of his disregard for religion. In this way the film overtly presents the Self and Other as factors of religion. However, the film subtly reinforces further divisions between Self and Other that actively engage with notions of structural violence, privileging upper and middle class characters as well as white characters.

\section{The "Choice" of Poverty: The Grinch as Other}

As discussed above, the film is critical of materialism. The scenes of rampant consumption are paired with shots of Cindy Lou looking disappointed. What is more, when the Grinch finally steals Christmas, the absence of gifts allows the Whos to realise that they are all part of the same Self. While the film posits that the religious awakening of the people in town allows them to now accept the Grinch, factors of class seem also to play a role. This is made clear in the fact that throughout the film the Grinch is the only citizen of Whoville who is clearly a member of the lower class, something which is evident in the contrast between the pristine cleanliness of Whoville and the squalor of the cave in which the Grinch lives. 


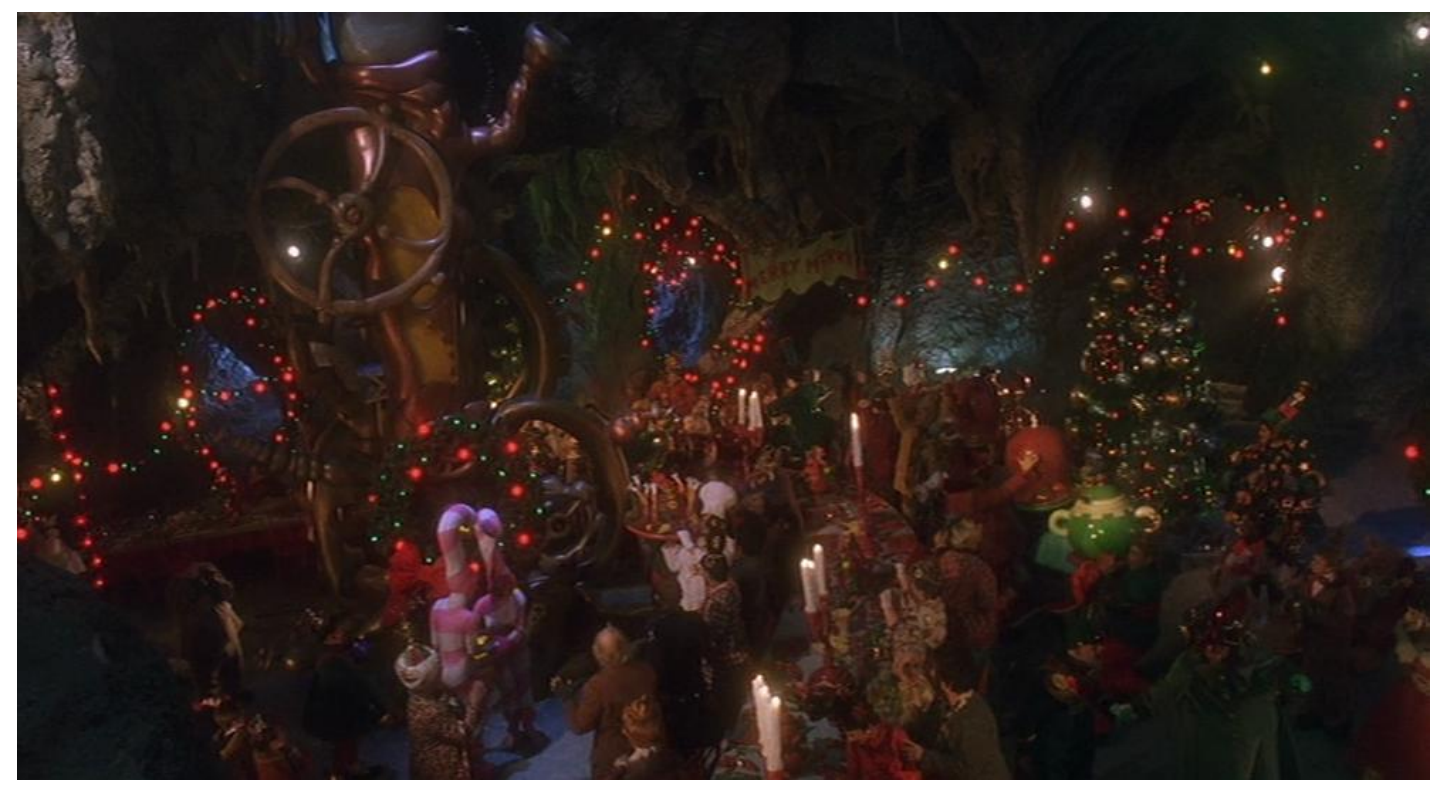

Figure 17 - Superficial normalisation of the Grinch through redecoration of his cave in The Grinch

In Whoville, everything is blanketed by clean, white snow, and everything is meticulously designed. In addition, everybody seems to be quite wealthy in some way, the reason, perhaps, why materialism is such an easy temptation for the Whos. The only sign that there are really any negatives to this wealthy lifestyle are the numerous trash receptacles in the town. They function by taking the trash and physically relocating it to the top of the mountain. In fact the receptacles would not even garner attention in the film were it not for the fact that they are the primary means of transportation for the Grinch. This is because his home is literally the garbage dump. Everything he owns and eats comes from the waste of the pristine Whoville. While this does not prevent him from owning things-though he is not entirely materialistic-it does position him as the only character in the film that lives in abject poverty. This is made repeatedly clear in the film, but perhaps never as forcefully as when the Grinch is eating a meal of trash, including glass. While the film could use the contrast between the wealthy Whoville and the impoverished Grinch as a means of mounting a critique of class-based violence, it instead uses the disparity as a platform for comedy. For instance, when Cindy Lou travels via the garbage disposal system the Grinch uses as a transit system, she laughs and smiles the entire time, making the trip look like an amusement ride, 
which was likely intentional given the ride-aesthetics that are so crucial to contemporary blockbusters. In addition, when the town ultimately joins the Grinch in his cave for a feast in the final scene of the film, the cave has been made over with ornate decorations so that it resembles the town proper, as shown in Figure 17.

The implication being that by realising the Self was superior, he could automatically rise from poverty; the power-and choice-was his all along. In short, it validates the idea that the upper middle class is superior to the lower class. Even though materialism is ostensibly condemned by the film - a message many critics have noted the irony of given the ostentatious production design of the film - the feast at the end of the film stands as a monument to consumption and the film presents it as happy since the Grinch has now been permitted to take part in it. What is more, the scene is evocative once again of a Rockwell-esque gathering where the Self is bound by homogeneity, this time of class. However, the permission is a guarded one. The Grinch is not the same at the end of the film as he is at the beginning. The Self of the film did not learn to accept him on his terms, but finally accepted him on their terms. To understand the transformation of the Grinch, particularly in relation to structural violence, it is useful to once again, following bell hooks, look at gender and ethnicity as well (7-8). While both racism and sexism are evident in The Grinch, it is ethnicity that the film puts on vibrant display even as it attempts to hide the fact that it does.

\section{"Greenface": Ethnicity-based violence in The Grinch}

It is not uncommon for Hollywood films to obliquely engage with racial issues in the United States. For instance, Andrew Ross observed of the 1989 version of Batman that "the Joker [the villain of the film] plays his role in whiteface" (emphasis in original, 31). Ross suggests that the film then deals with race, particularly issues facing blacks in the United States, by substituting an equivalent white figure and reducing actual racial elements to invisibility (33). The performance of Jim Carrey in 
The Grinch functions in a similar fashion. ${ }^{23}$ As Joe Morgenstern wrote in his review of the film, Jim Carrey was "Stuck behind a prosthesis that's part 'Planet of the Apes' and part Chewbacca as a minstrel in greenface" ("A 'Grinch'” n. pag.) While the references to Planet of the Apes and Star Wars connect The Grinch to a tradition of cultural violence in the United States where the Other is depicted as inhuman in some way, the use of the words "minstrel" and "greenface" connect The Grinch with a much larger tradition of ethnicity-based violence in the United States without actually representing the ethnicities that the violence targets. Such obtuse connections with race-using green instead of an actual skin tone-are not unfamiliar in Hollywood. For instance, in The Boy with the Green Hair, green hair on a white boy is used as a marker of Otherness. Similarly in The Grinch, the otherness is more problematic since while the Grinch himself is green, the actor playing him, Carrey, is white. Despite this removal of any racial representations, the "greenface" label of the performance accurately describes the ways in which the character activates pre-existing racial stereotypes. To understand how those stereotypes function within the film, it is useful to first consider the way in which the articulation of the faith-based Self of the film relates to the ethnicity-based Self.

As discussed above, the overt Self/Other relationship of the film is predicated upon a religion-based structure of violence. The Grinch does not believe so he is the Other. Those who do believe are positioned as part of the Self, but their relationship to materialism textures that Self to some degree. That same division between the Whos and the Grinch is visible when dealing with race, but the nuances within the Self vanish. Instead there is a plain binary, and the division is entirely race-based, as shown in Table 4, where the green Grinch is the only character relegated to the position of Other.

\footnotetext{
${ }^{23}$ For a more detailed exploration of Carrey and his bodily performances, see Sobchack "Thinking." She does not deal explicitly with his performance in The Grinch, but her discussion can certainly help to inform the ethnic stereotypes at play in it.
} 


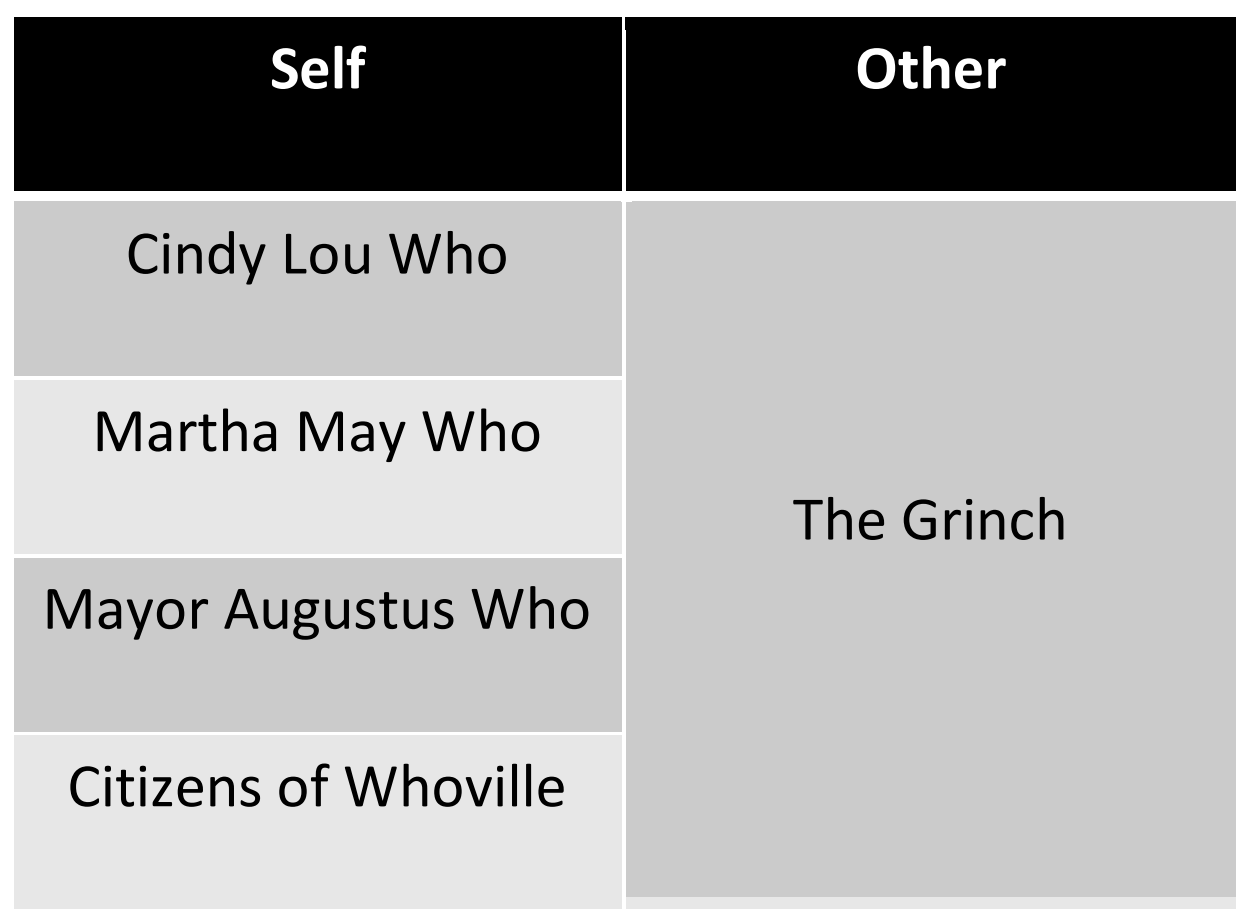

Table 4 - The race-based Self and Other

Although the Whos are not uniformly white, the only non-white Whos appear briefly, and even then usually just in the background. The most prominent nonwhite Who seen in the film is the proprietor of one of the shops who speaks as he operates his cash register, but is not involved in any proper dialogue with other characters after that. Beyond that, the Whos are overpoweringly white with Cindy Lou once again presented as the ideal Self as she is pristinely white and blond. Thus, even as the Grinch is positioned as Other through his lack of faith, that division is reinforced by his lack of whiteness, articulating a strong ethnicity-based structure of violence. This violence is made even clearer when considered in relation to theories surrounding representations of ethnicity in film.

Drawing on critical race theory and science fiction films, Ed Guerrero observes that 'the 'monster' always constitutes the return of the socially or politically repressed society, those energies, memories and issues that a society refuses to deal openly with" (43). The result, he argues, is that "cinematic expressions of slavery have become sedimented into a range of contemporary film narratives and genres, and, specifically, into the symbolic or latent content of many films depicting African Americans" (43). What Guerrero is describing is essentially cultural violence. A 
comparison with the work of Galtung makes this connection explicit as Galtung not only describes slavery when defining cultural violence, but he uses the same language Guerrero does. For example, of slavery Galtung says that

"This massive direct violence over centuries seeps down and sediments as massive structural violence, with whites as the master topdogs and blacks as the slave underdogs, producing and reproducing massive cultural violence with racist ideas everywhere" (295).

For Galtung, racism is a structure of violence which perpetuates and propagates a systemic inequality between two or more races ("Cultural" 294-295). In the slavery example above, whites are privileged over blacks through an unequal exchange which denies the blacks certain needs including identity, well-being, survival, and of course freedom. While the Grinch is not denied all of these-he is neither killed nor exploited-his ethnicity is definitely a key factor, as it functions to deny him identity as a Self, instead relegating him to his position as Other. This is clear in one of the main subplots of the film, which involves a love triangle between the Grinch, Augustus May, and a female Who, Martha May Whovier (Christine Baranski).

According to the flashbacks in the film, the Grinch arrived in town and was a mischievous child. Although his adopted parents - two women-took care of him, he is shown to be unfit for family life; he threatens the family structure. This is of course reflected in the failure of the two-mother family, something that can easily be read as violence against non-hetero sexuality, or at least a reaffirmation of the need for patriarchal family units. As for the hostility of the Grinch, it was only in school that he was finally pacified to some degree through his attraction to Martha May. So while it is suggested by the film that a coupling with Martha May could ultimately tame his Otherness, the prospect of miscegenation is not something with which the film engages. Instead the Grinch is segregated from Whoville with the implicit understanding that the pristine whiteness of the Whos, embodied to some degree in Martha May and aligned with the Self, needs to be protected from his green and corrupting touch, the grasp of the Other. This relationship evokes the 
discussion Guerrero engages in around the film Gremlins, writing, "...the white woman as the essence of whiteness, the most prized possession of the white man and the object of desire of all other races, is a powerful representational current running through Western literature and cinema" (64). This is clearly seen in The Grinch in the way Augustus May feels entitled to Martha May since he is the mayor of Whoville, but also how he is threatened by the Grinch and the more animal-like sexuality. This is evident since even as adolescents what Martha May is explicitly attracted to is the different colouration of the Grinch and his muscularity. For instance, when recounting the moment when the child Grinch ran amok in school after being mocked by the other children, Augustus May and another Who, Whobris (Clint Howard) remark "the anger" and "the fury," respectively while Martha May says in a lusty voice, "the muscles." This also points towards the sexualised presentation of Martha May, something the film overtly does when she is shown as an adult through revealing costumes, as shown in Figure 18.

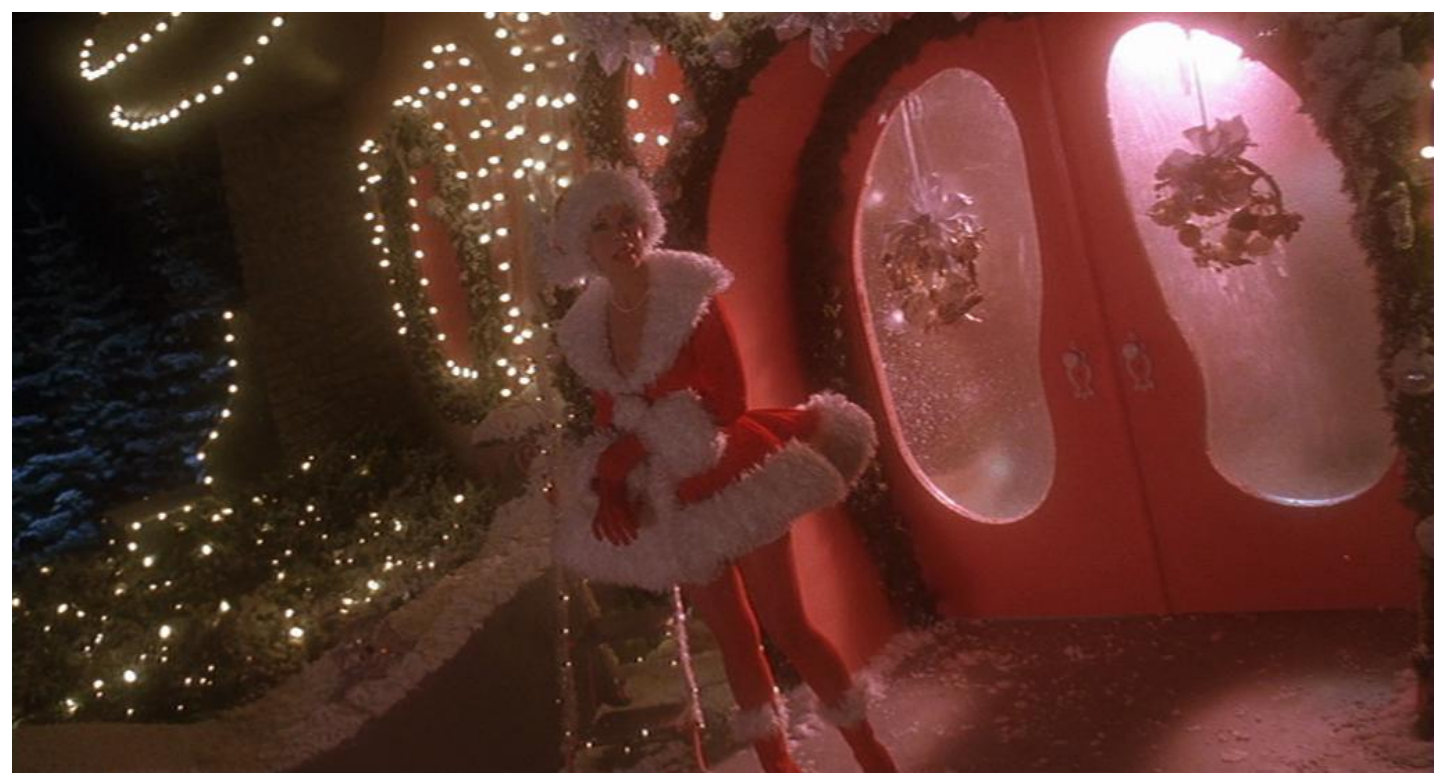

Figure 18 - The sexualised Martha May in The Grinch

In so doing, it makes her ultimate coupling with the non-white Grinch even more problematic in terms of violence as it suggests only sexual (i.e. "bad") women would do something like that, as opposed to the nicer more conservative Whos. At the same time, however, the coupling with the Grinch tames her sexuality in the 
same way it tames the Grinch. However, the Grinch is reduced to a sexual being as well since, even as a child, he desires Martha May. As Guerrero also noted, "It is the threat of white woman's rape by the monstrous, black other that gives whiteblack contrasts much of their social charge and meaning" (emphasis in original) (64). The fact that the vibrantly green Grinch lusts after the pure white Martha May, and vice versa, absolutely draws on the threatening stereotypes of ethnic Others, specifically the one Donald Bogle identifies as the brutal black buck in his seminal volume Toms, Coons, Mulattoes, Mammies, and Bucks (13).

Bogle argues that the brutal black buck stereotype has cinematic roots as far back as The Birth of a Nation where the animalistic Gus (Walter Long) pursued the virginal Flora (Mae Marsh) (10). Bogle sees the brutal black buck as divisible into the black brute and the black buck. While the black brute "was a barbaric black out to raise havoc" (13), the black buck is a "psychopath" who is "oversexed and savage, violent and frenzied" and constantly thirsts for white women in a way that confirms the assumption that the "white woman was the ultimate in female desirability, herself a symbol of white pride, power, and beauty" (13-14). Addison Gayle frames the stereotype in even more dire terms, observing that the "'brute Negro' who, out of lust and hatred, presents a clear and present danger to the purity and sanctity of white womanhood and civilized America as well" (qtd. in Guerrero Framing 13). Both of these descriptions point towards traits of the Grinch, particularly the notion that he is a violent and frenzied savage. However, given the family nature of the film, his sexuality is more repressed than would be with a more traditional version of the stereotype. In action, though, the Grinch as Other very closely parallels an Other like Gus, since both share a desire to destroy whiteness even as they lust after it and are drawn towards it. Gus manifests his hatred by pursuing the white woman who is the symbol of "civilized America," and the Grinch directs his hatred towards the idealised whiteness of Whoville, which is also the symbol of contemporary America. Thus the Grinch becomes an ethnic Other who is attempting to destroy the white self of the proxy United States. Within this Self-Other paradigm, the stealing of Christmas becomes racially charged as a Black buck figure has robbed white America of its cultural traditions. A 
connection can clearly be drawn here to the anxieties surrounding the postmillennial family discussed above. Further, given the "sedimentation" of issues surrounding slavery, the Self-Other construction of non-whites assaulting white America not only evokes images of historical groups such as the Black Panthers, but also foreshadows conflicts to come with the obvious connection to the ethnicallybased violence in the post-9/11 period, particularly the War on Terror.

However, if the Grinch were only the stereotypical brutal black buck, the conversion/assimilation narrative would not function because that stereotype could be neither assimilated nor tamed. According to its cinematic precedents, that stereotype can only properly be controlled in death. One of the key cinematic examples of this would be the black body of the eponymous character in King Kong which, overcome with lust for the white woman, must be killed. It is worth noting that in 2005, while the War on Terror and its attending structures of ethnicitybased violence raged on, King Kong was remade and met with considerable although not overwhelming success. Unlike Kong, though, the Grinch does not die, but is instead converted. Therefore, the most threatening aspect of his character, his lust for the white Martha May and the metaphoric danger that he represents is coupled with a buffoonish likeability, which emerges from the fact that the Grinch is assaulting the materialism of the holiday in a way that is threatening but largely benign. The Grinch is therefore a menace, but simultaneously an idiot. This bears a noteworthy parallel to the assessment Guerrero makes of another film that subtly deals with racism, Little Shop of Horrors, wherein he argues that a large, and again green, plant is representative of symbolic threats to whiteness (59). The plant, Audrey II (Levi Stubbs), is "dangerous but simultaneously entertaining and likeable" (59), which is exactly how the Grinch is presented. The Grinch, therefore, as Guerrero suggests of Audrey II, is both "Sambo and brute" (59).

The Sambo figure is the same as the racist coon figure that Bogle identifies (8), and which was discussed in the previous chapter in relation to Jar Jar Binks. For Bogle, the coon stereotype has multiple variations including the pickanniny, the pure coon, and the uncle remus. The Grinch is most closely aligned with the pure coon, which Bogle describes as "unreliable, crazy, lazy, subhuman creatures good for 
eating watermelons, stealing chicken, shooting crap, or butchering the English language" (8). While the Grinch definitely does not have some of these traits-his use of English, for instance, is often quite witty-he still strongly resembles this stereotype as he is often seen lazing about in his filthy home speaking to himself like a buffoon. While this characterisation is certainly included for comic relief, it also functions to make his ultimate acceptance into white culture possible. However, as noted above it is the Grinch who must change so that the white Whoville will bring him in. This change comes not through assimilation, but through a transformation from the buck and coon to the tom.

\section{Taming as Conversion: Structural Violence in The Grinch}

As was also discussed previously, the tom stereotype describes a black character that is willingly and eternally subservient to a white master. As Bogle describes it, the tom character will "keep the faith, ne'er turn against their white massas, and remain hearty, submissive, stoic, generous, selfless, and oh-so-very kind" (6) all of which helps to "endear themselves to white audiences and emerge as heroes of sorts" (6). The transformation for the Grinch from rejected Other to accepted Other, as shown in Table 5, comes when he hears that the Whos celebrate Christmas even without the presents he has stolen. As Table 5 also shows, the rejected Grinch has the qualities of the brutal black buck, with some elements of the coon stereotype. The accepted Grinch, however, shares qualities almost entirely with the tom figure. 


\section{Grinch as Rejected Other Grinch as Accepted Other}

Lazy

Crazy/Psychotic

Sexualised

Angry

Unpredictable

Animalistic

Buffoonish
Selfless

Submissive

Tamed

Friendly

Generous

Table 5- Traits of the Grinch as Rejected Other versus the Grinch as Accepted Other

When the Grinch does begin to change, writhing about in pain, he finally articulates to his dog that he is "feeling," which indicates his conversion. His first act is then to try to keep the giant sleigh of presents he has stolen from sliding off the mountaintop he lives upon. He is failing in this, and is about to give up when he realises that Cindy Lou is sitting on top of the presents. In essence, his theft of Christmas has not imperilled the white woman, but the even purer white girl. He redoubles his efforts to keep the sleigh from falling in a demonstration that shows he now also believes, as Bogle describes, that the white woman/girl stands as "a symbol of white pride, power, and beauty" (13-14) that must be protected. Through a miraculous feat of strength, the Grinch not only stops the sleigh, but lifts it over his head in a computer generated "money shot" which shows him triumphant at the top of the mountain. Of course the ideological implications of the Other literally elevating the Self reinforce the race-based structural violence which informs the Self/Other binary of the film. In terms of stereotypes, at this moment the uncontrolled strength associated with the brutal black buck is not only reined in, but is deployed in service of the whiteness that the brutal black buck is shown to endanger. The Grinch is thus tamed. Moreover, he realises that the traditions of the whites are of the utmost importance so, along with Cindy Lou, he returns Christmas to Whoville. He even goes so far as to offer himself up to a police officer in town, shown in Figure 19, further displaying his newfound subservience to 
the white system. That act endears him both to the Whos, who forgive him, and to the audience as well since the threat the Grinch represents has been sterilised.

As a reward he finally wins the hand of Martha May. At first this seems to suggest growth beyond the standard structural violence of the racial stereotypes which define the Grinch, but the coupling is not entirely normal. For instance, the coupling is not sealed with physical contact-a kiss or even a hug - but instead by Martha May returning to Augustus May the engagement ring he had earlier given her. She then proclaims her love of the Grinch. So while the coupling of the two still suggests the threat of miscegenation, this tom Grinch cannot even kiss her. In fact, the only kiss he receives is one of respect from Cindy Lou. The implicit message is that this tom Grinch has been desexualised, neutered in a way, which thus allows him to coexist with the Self, and, not taint the Self by reproducing. This is, of course, coupled with the notion that Martha May has been tamed as well, ensuring that she will not reproduce either. This arrangement, however, is contingent upon the fact that the Grinch continually acknowledges his subservience to the Self.

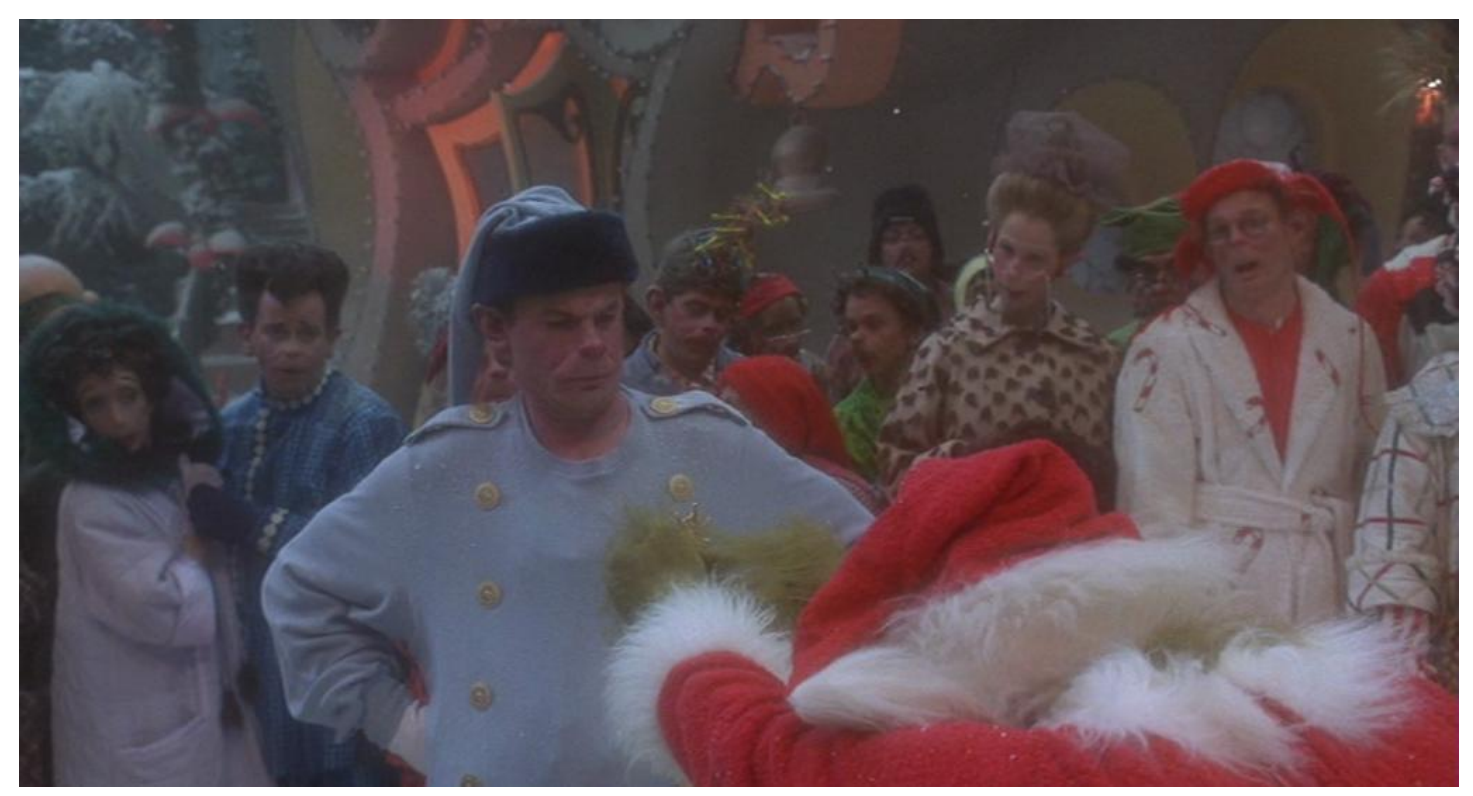

Figure 19 - The Grinch throwing himself before the law, and the Self in The Grinch

While this situation resembles the anxieties felt about racial tensions in the United States in the pre-9/11 era, especially between blacks and whites, it is worth 
exploring the fact that the stereotypes that inform the structural violence of the film and frame the Grinch as Other are not isolated to blacks, but apply also to Arabs. In his examination of Arab stereotypes in Hollywood films, Jack Shaheen identifies multiple stereotypes of Arabic people which are used repeatedly (15). These include the villain and the sheik, and include traits such as bumbling fools, dangerous threats to American values, animals. What is more, he observes that "in the mid-1980s, studios presented notable African-American actors facing off against, and ultimately destroying, reel Arabs" (15). In these films, the black characters were thus allowed to "defeat" the stereotypes which were (and often still are) associated with them, but this victory came by way of remapping many of those stereotypical traits onto the Arab characters. What makes the correlation between the black and Arab stereotypes so important is that although The Grinch could be read as structurally violent in the way it creates a coded black Other, the Other in the film could easily be read as Arab as well. Reconfigured in that way, the Self-Other paradigm of The Grinch becomes defined as a conflict between white America and Arabs, which perfectly presages the $9 / 11$ conflict.

\section{The Ethnic Other after 9/11}

The coming of the millennium was surrounded by anxiety, but by hope as well. The fears were largely grounded in apocalyptic scenarios which suggested the world would catastrophically end while the hopes saw the twenty-first century as a symbol of a new age, one perhaps free from the post-Cold War identity crisis which had plagued the United States. The passing of the millennium without incident left the identity crisis untouched. What is more, its persistence was clearly seen in the turmoil surrounding the 2000 presidential election. In that election, faulty procedures led to what many have subsequently considered a stolen presidency. What is relevant to this discussion is the fact that the election and its controversy seemed to highlight both the division of the nation and the desire for a unity at the national level. Both candidates, Al Gore and George W. Bush, offered a version of Self which their supporters saw as mending the lost national identity. With Gore, this was through his liberal social policies such as those which supported gay rights. 
For Bush, this was by way of his "compassionate conservatism," which articulated a desire to resolve social issues, but absolved the government from any responsibility. While the precise implementation of the policies Gore proposed will never fully be known since he was not named victor of the election, what is clear is that his policies seemed founded on the notion of an expansion of the Self to define marginalised groups that many might describe as Other, such as the homosexual population in the United States. Conversely, Bush, using compassionate conservatism as a means of avoiding certain issues, seemed to articulate a much more traditional concept of Self, one grounded in mythic ideals, such as the idealised American family. Of the two, it is the latter of which The Grinch dreams.

The Grinch is a story not of progress, but of regress. As discussed above, it is suffused with nostalgia for a mythic American past, and the ultimate resolution of the film - a reformed family structure-suggests it is a past which is drawn largely from media which propagated those myths. However, when the relationship between the Self and Other is articulated, it is clear that only through an assault by the Other, the literal theft of Christmas, is the Self able to heal itself. The Grinch once again shows that the notion of wishing that Baudrillard articulates is useful, but only when reappropriated. This is because The Grinch, like the films previously analysed, ends with the affirmation of the United States as a dominant Self. In particular, The Grinch dreams of a unification of the Self in a traditional fashion in the wake of a traumatic event, and that is precisely the dream the Bush administration attempted to realise.

In the aftermath of the attacks of September 11, 2001, Bush scored the highest approval rating in recorded history for a president in the United States at $90 \%$ ("President Bush's Approval" n. pag.). Although this would continually drop throughout his two terms in office, it reflected a remarkable amount of unity in support of the president. This was bolstered by his rhetoric which, again, directly connected him with Franklin Delano Roosevelt via the Four Freedoms. While the support Bush garnered was for his response to the attacks of 9/11, it applied to both the peaceful and violent aspects of the response to 9/11. This meant that in addition to engendering a sense of Self on a national scale, it also fostered a strict 
Self/Other binary based on multiple structures of violence. This is most evident in the characterisation of the Other along ethnic and religious lines, particularly through the rhetorical framing of the War on Terror as a "crusade." In that regard, the Self becomes defined as white and Christian while the Other is non-white and non-Christian, a definition which comes from the mythic past of the United States, a past dominated by the whiteness of the founding fathers and the violent expansionist policies that Othered populations such as indigenous American people. This return to a nostalgic past, one which is "historicist rather than historical," to borrow from Jameson (The Cultural 130), functions in the same way as the dreams of The Grinch. At the same time, however, implicit in the idea of a crusade is the notion that ultimate victory will defeat and potentially even tame that Other. In that way, The Grinch could be said to articulate a vision of that future. Thus, even though Bush may have lost the popular vote in the election, his post-9/11 policies, which were different from his campaign platform, won him broad acclaim as it repositioned the United States as the Chosen Nation, so to speak, while the Arab and Islamic nations were reinforced as the Other. Indeed, it was of such a national unity that The Grinch dreamed. 


\section{Chapter Six}

\section{A Paranoid Turn for a New Crusade:}

\section{Harry Potter and the Sorcerer's Stone (2001)}

In the aftermath of the events of $9 / 11$, the post-Cold War identity crisis that the US faced as the sole superpower disappeared almost entirely. The Soviet Other was forgotten in the face of a new conflict with a new Other. Despite the shift from the Cold War paradigms, the United States found itself in a binary opposition again, one which was defined by the Bush administration as a struggle against terror. The United States was now a Self defined against the Other of the nebulous terrorists. However, the initial framing of the conflict was more textured than the eventual use of the War on Terror moniker suggests. As noted in Chapter Four, in the days after the attacks that took place on September 11, 2001, President Bush described this new paradigm as a "crusade" ("Remarks" n. pag.). Although Bush would not use the word "crusade" in later speeches, the religious connotations of his use of the word are clear given the fact that the perpetrators of the attacks of 9/11 were Islamic. Following Johan Galtung ("Cultural” 296-298), the Self/Other paradigm, grounded as it was in religion, became very clear. The United States became a Chosen Self tasked with scouring the planet of the Unchosen Other, using whatever violence was necessary. However, the activation of the term "crusade" adds a new dimension to this relationship. James Carroll observes, one of the "key pillars of the Western mind that put the Crusade in place" (24) is the fact that, "mobilization against an enemy outside inevitably led to a paranoid fear of enemies within" (25). This meant that "The war against Islam abroad became a war against dissent at home" (25). In short, the crusade mentality disrupts the boundaries between the Self and Other.

In the films already analysed in the pre-9/11 era, there is a very clear distinction made that the enemy is an external force. The films show a definite demarcation between the Self and the Other. While there are nuances to this, the crisis of 
involvement Private Upham faces in Saving Private Ryan being a prime example, there is no actual questioning of allegiance in any of the films. What is more, in some films, such as Dr. Seuss' How the Grinch Stole Christmas, the Other submits to the Self. In the post-9/11 era, there is a shift in the Self/Other dynamic away from concrete divisions to a more nebulous separation. In this new era, the Other might be hidden within the Self. This is evident in the first blockbuster in the post-9/11 period, Harry Potter and the Sorcerer's Stone, the highest grossing film of 2001 in the United States.

At one level, The Sorcerer's Stone presents a very standard Self/Other relationship. Like the pre-9/11 films analysed so far, the Self is mindful of others, particularly those who are marginalised, but it is also able to deploy direct violence when needed. Conversely, the Other is quickly established through a hierarchical order based on various structures of violence including ethnicity. What differentiates the relationship in The Sorcerer's Stone from that found in pre-9/11 cinema is that the ultimate Other is revealed to (literally) be part of somebody who was thought to belong to the Self. This unveiling relocates the standard fantasy paradigm within the realm of paranoia. Screen paranoia, of course, was not unique to the post-9/11 era. Not only was it prevalent in Hollywood cinema during the Cold War, film noir being a key example, but, as Wheeler Winston Dixon (2009) observes, it was also present in the 1990s "in such films as The Usual Suspects, Bound, and Red Rock West" (iv). What makes the post-9/11 paranoia different is that it played out on screen in ways that paralleled its socio-political development in the United States during the first years of the War on Terror.

My analysis will aim to show the ways in which The Sorcerer's Stone operates within a paradigm of paranoia that is predicated upon traditional structures of violence such that a familiar Self/Other relationship is ultimately articulated despite the way in which the plot of the film diverges from trends seen in the pre-9/11 films already analysed. Accordingly I will begin by looking at the tradition of paranoia in the United States with specific attention paid to its resurgence in the 1990s and the applicability of the concept to post-9/11 culture. While my analysis will ultimately read The Sorcerer's Stone in term of paranoia, it is necessary to understand the 
mythic qualities of the film first. Therefore my analysis will next read the mythic and folkloric qualities of the film drawing on the works of both Roland Barthes and Vladimir Propp respectively. It is my contention that the film utilises mythic villains in conjunction with a narrative device I term the "false villain" in a way that creates an atmosphere of paranoia within the film, particularly for those already familiar with the narrative either through previous viewings of the film or through foreknowledge from reading the books. I will explore the ways in which this paranoia breaks down the traditional Self/Other relationship by making the formerly discrete boundary permeable. The result of this process is that it makes structures of violence which privilege the white male less conspicuous. Lastly, I will connect that discussion of The Sorcerer's Stone with the rhetoric and politics of the Bush administration in regard to 9/11. Specifically I will show the ways in which the film dreams, to once again build on the work of Jean Baudrillard (7), the deployment of the Bush doctrine in the post-9/11 culture of paranoia.

\section{Paranoia, USA: The Post-9/11 Crusade}

Throughout the $20^{\text {th }}$ century, paranoia has been a consistent theme in US media. Wheeler Winston Dixon (Film Noir 90) notes that the post-World War II period was a time of paranoia in domestic culture. As American society recovered from the war, and the Cold War began, noir echoed that transition. Dixon argues that foundations of noir were "to trust no one, to believe nothing as truth, to expect the worst in all possible situations, [and] to realise that deception was an integral feature of social discourse" (Film Noir 90). In short, one had to suspect everybody because the Other could be anywhere, attempting to infiltrate the Self. As Dixon questions, "Weren't the Russians our allies in World War II" (Film Noir 90). Thus cinema at that time reflected the anxieties of the period with paranoia being the central concern. This is unsurprising given the climate of US politics during that period, which Richard Hofstadter described as having a "paranoid style" (77). Interestingly, in his discussion of this style, Hofstadter contends that the enemy, the Other, is akin to a "projection of the self" (85). As he argues, despite the clear Otherness of the enemy, there is an affinity between the Self and Other. Although 
Hofstadter does not take his thinking to the level of an irrational fear of the Other passing as the Self, it can be inferred from his closing statement:

"We are all sufferers from history, but the paranoid is a double sufferer, since he is afflicted not only by the real world, with the rest of us, but by his fantasies as well" (86).

In short, the "fantasies" of the paranoiac could explain developments such as McCarthyism and the Red Scare of the 1950s. While paranoia remained prevalent throughout the Cold War, it also persisted in the post-Cold War era. Dixon observes that films in the 1990s which fall into the category of neo-noir, examples he gives being The Usual Suspects and Bound, preserve the core of noir cinema, but do so by responding to a new set of fears. His analysis of noir films during the 1990 s and 2000s shows that paranoia was a key part of US culture in this period. Douglas Kellner expands upon the concept of paranoia in the 1990s by distinguishing between critical paranoia and populist paranoia ("The X-Files" 205). As he describes it, the former "is rationally suspicious of hegemonic institutions like the state, the military or corporations," while the latter "demonises irrationally dominant institutions and often projects evil onto occult and supernatural figures" ("The X-Files" 205). While this distinction is developed further in the analysis Kellner conducts, it highlights the fact that paranoia is a multi-faceted concept. More importantly, it shows that paranoia is tied very closely to power relations. Since violence is largely predicated upon those same connections, it can be argued that paranoia is similarly aligned as well. In his analysis of The X-Files, Kellner constructs an argument relevant to paranoia in the post-9/11 era when he remarks that the show "combines rational social critique and mistrust with occultist projection onto the supernatural that deflects attention from the real sources of social oppression" (205). Combining this with the work of Johan Galtung on cultural violence where Galtung argues that cultural violence legitimises and conceals structural violence ("Cultural" 294-296), it can be argued that screen paranoia obfuscates structures of violence. This is because, like cultural violence, screen paranoia legitimises violence, both structural and direct, against an Other. 
Patrick O'Donnell views paranoia in the 1990s in a similar way, suggesting that "it is a symptom of cultural identities negotiated within and in apposition to "history"' (viii). He clarifies by remarking

$$
\begin{aligned}
& \text { "the manifestations of paranoia in contemporary literature and } \\
& \text { culture are inextricably bound up with the conceptions of identity } \\
& \text { and history that are being lived out within the epistemic conditions } \\
& \text { of-to use the epochal shorthand-late capitalism" (x). }
\end{aligned}
$$

The link O'Donnell makes between paranoia and late capitalism is an important one since it shows, as he writes, that "paranoia did not die with the fall of the wall and the liberation of Bucharest" (viii), but it is also a statement which reflects the time period in which O'Donnell was writing, which was before 9/11. This is evident in the fact that his work is only able to consider the "epistemic conditions" of pre-9/11 late capitalism; the events of 9/11 provided a new set of "conditions" within which paranoia was grounded.

As mentioned above, five days after $9 / 11$ Bush referred to the struggle against the terrorists who staged the attacks on the United States as a "crusade." The word crusade immediately situated the Self and the Other in an ideologically fuelled binary; one is either part of the Self, the crusader, or the Other, the infidel. While the religious connotations are clear, the deployment of the term by Bush in the political arena of the United States gives it a secular grounding too since the Chosen and Unchosen labels apply not just to religious groups, but to US and its allies, and those who are either openly opposed to the United States or have not made their allegiance clear. This position was made explicit by Bush nine days after September 11,2001 , when he remarked, "Either you are with us or you are with the terrorists" ("Address" n. pag.). While this does potentially ground the opposition in nationalist terms-enemies of the state-the historic context of crusades prevents it from being divorced entirely from a religious reading. Thus, with the rhetoric of the crusade mobilised in such a way, one is either Self or Other. Despite this clear division, actually identifying the Self and the Other is a problematic endeavour. 
The most obvious - and obviously flawed-means of identifying the Self from the Other relies upon differences, usually those which are based upon structures of violence. In the post-9/11 world, these structures were both race-based and religion-based. Thus, as Michael Welch repeatedly details in Scapegoats of September $11^{\text {th }}$, the Other was superficially defined by many US citizens as both Arabic and Islamic. This was evidenced by the rise in hate crimes against Muslims and Arabs. ${ }^{24}$ Again, the use of the word "crusade" by Bush supports this notion as it draws upon the historical conflict between Christianity and Islam. What makes paranoia relevant here, though, is the obvious fact that not all Arabs and Muslims are terrorists and not all terrorists are Arabs and Muslims; the Oklahoma City bombing in 1995 stands as testament to the latter of the two points while the former is self evident. Accordingly a paranoid search for the enemy began in the immediate post-9/11 era. As noted above, Carroll observes that the "mobilization against an enemy outside inevitably led to a paranoid fear of enemies within" (25) and this was indeed the case in the United States as everybody eventually fell under the gaze of suspicion, not just those who adhered to the racial or religious stereotypes. Of course it is absolutely the case that those who did match racial and religious stereotypes were under far more suspicion than those who did not, but as noted above, the paranoia which targeted the Other-that the Other could be anybody-concealed the presence of similar structures of violence so that the illusion of equal treatment was put forth despite the existence of discriminatory practices, racial profiling for instance. Fear of the Self becoming Other, though, was exacerbated by events such as the capture of John Walker Lindh, an American fighting for the Taliban, during the Afghanistan invasion in 2001.

Carroll also notes of the original crusades, "The war against Islam abroad became a war against dissent at home" (25), and the widespread paranoia of a hidden Other led the United States to become a battleground of patriotism wherein questioning the country or its leadership became tantamount to treason. As mentioned earlier, this was evident in 2003 when the country music trio, The Dixie Chicks, openly criticised Bush for the impending Iraq invasion and suffered critical and popular

\footnotetext{
${ }^{24}$ See Welch, especially Chapter Five, for more on post-9/11 hate crimes.
} 
backlash, including a boycott, as a result. Accordingly violence became increasingly based upon a rigid Self/Other binary that was defined by the Bush administration and abstracted from reality. This is clear in the idealised version of the Self Bush offered when he evoked the Four Freedoms to define the Other, saying that "They hate our freedoms - our freedom of religion, our freedom of speech, our freedom to vote and assemble and disagree with each other" ("Address" n. pag.). Thus, those who support terrorists hate a nebulously defined freedom, and, by extension, the United States as well. However, the domestic response to 9/11 was actually to actively curtail freedoms in the United States. This was evidenced by the signing of the USA PATRIOT Act into law on October 26, 2001, an act whose stated objective was "To deter and punish terrorist acts in the United States and around the world, to enhance law enforcement investigatory tools, and for other purposes" (n. pag.) and aims to meet that goal through a variety of ways, some of which have been challenged as unconstitutional. ${ }^{25}$ Yet the complexity of the USA PATRIOT Act and the multitude of tactics employed to locate and attack the Other suggest that the terrorists were not as easily categorised as Bush indicated in his rhetoric. In fact, it reveals the ways in which the enemies Bush identified were mythic constructions.

The rhetorical terrorists were not real terrorists. The mythic terrorists Bush described hated the freedom of America. That was their sole motivation for mounting attacks against the United States. Those terrorists were not responding to decades of US foreign policies particularly those which directly and indirectly affected the Middle East. Of course many, including Chalmers Johnson who popularised the term "blowback" in the post-9/11 era, argue that this is the precise reason why the terrorists attacked the United States on September 11 (vii-xvii). The divorcing of the terrorists from history once again evokes the work of Barthes on myth, particularly in his remarks that myth is the "privation of history" (151). Thus the terrorists imagined by Bush in his rhetoric are ahistorical; they are the bogeymen which haunt the post-9/11 United States. Of course the construction of the United States as a beacon of freedom is itself a mythic conceptualisation that

\footnotetext{
${ }^{25}$ The acronym USA PATRIOT Act stands for: Uniting and Strengthening America by Providing Appropriate Tools Required to Intercept and Obstruct Terrorism. See Whitehead and Aden for a comprehensive analysis of the constitutionality of the USA PATRIOT Act.
} 
relies heavily on disregarding domestic history. This is clear in the fact that the 1990s were rife with major instances of inequities, as evidenced by the race-based violence-cultural, structural, and direct-which events such as the trial of OJ Simpson made clear. However, this notion of the United States as the "City on a Hill" perpetuated by Bush, but also by the pre-9/11 films already discussed, suggests a culture receptive to a revitalised notion of American Exceptionalism, but also one that was vigilant against threats to that aspect of the United States. It is unsurprising, then, that in the post-9/11 world Bush redefined the world in terms of a Self and Other relationship based upon notions of good and evil. This was the case in his State of the Union Address on January 29, 2002, when he labelled Iraq, Iran, and North Korea as the Axis of Evil ("President" n. pag.). It is this same mythic approach to good and evil, the Self and the Other, that has already been discussed with the pre-9/11 films, and it is the same approach used in The Sorcerer's Stone.

\section{Mythic Beginnings: The Violence of Plot in The Sorcerer's Stone}

At one level, The Sorcerer's Stone seems an unlikely candidate for an American blockbuster. To begin, it is set in the United Kingdom, starting in the fictitious town of Little Whinging. Most of the action then takes place in an English boarding school for young wizards and witches called Hogwart's. All of the actors in the film are British, and while most of the adult cast are well-known British actors, including Richard Harris, Maggie Smith, Alan Rickman, and Robbie Coltrane, the feature players are unknown British child actors. While the producer and co-producer of the film, David Heyman and Tanya Seghatchian respectively, are both English, the director and screenwriter, Chris Columbus and Steve Kloves respectively, are from the United States. Of course the resounding success of the stories with US consumers long before the film was released cannot be discounted entirely, yet other popular adaptations, such as The Chronicles of Narnia: The Lion, the Witch, and the Wardrobe, were not as successful as The Sorcerer's Stone. I contend that this is because The Sorcerer's Stone, which was released in November 2001, resonated with the immediate post-9/11 need of the American people for a mythic story which simplified notions of good and evil in the same way that Bush did with 
his rhetoric. Accordingly, part of the success of the film can be seen as a response to the very traditional formula the original story followed, and which the film adaptation preserved and presented on screen.

As with Star Wars: Episode I-The Phantom Menace, The Sorcerer's Stone is a fable of sorts. It tells the story of a young orphan boy who is told he has unexpected abilities and then uses those abilities to fight against evil in the world. Also like The Phantom Menace, The Sorcerer's Stone is easily mapped into the framework established by Propp which identifies the key tropes of fairy tales, specifically the seven spheres of action he delineates: the villain, the donor, the helper, the princess and her father, the dispatcher, the hero, and the false hero (79-80). ${ }^{26}$ Propp makes it clear that these spheres are not discrete, and that multiple characters can share the various roles identified by each (80). This is evident in The Sorcerer's Stone. For instance Albus Dumbledore (Richard Harris), the headmaster of the school, operates within the sphere of the donor, helper, and arguably the dispatcher as well. Of course some characters are located more firmly in a single sphere. Harry Potter (Daniel Radcliff) clearly functions within the sphere of the hero and his friends Ron Weasley (Rupert Grint) and Hermione Granger (Emma Watson) act as helpers. While the fact that the film is so traditional in this regard can offer an explanation as to why it was so readily received by American audiences, and indeed audiences worldwide, which had previously made hits out of movies which followed similar folktale formulae, it is the particular deviations from the Proppian model that bear closer scrutiny in the paranoia of the post-9/11 era.

As previously mentioned, Bush split the world into a binary structure with his remark that "Either you are with us or you are with the terrorists" ("Address" n. pag.). It is important to note, though, that this was not a sentiment restricted to the Bush administration as days earlier Hillary Clinton made similar remarks during an interview with Dan Rather on the CBS Evening News. In both cases the binary worldview is reinforced. This same logic applies to the Proppian morphology as the spheres of action break down into those which support the hero and those which stand in opposition. This is not to suggest that the US response to $9 / 11$ is akin to a

\footnotetext{
${ }^{26}$ For more details on the spheres of action in folktales see Propp, Chapter VI.
} 
fairy tale, although such an investigation might prove illuminating. Instead it is to suggest that characters in fairy tales, the film included, are often grouped into a Self/Other binary with the Self being Us, the hero, and the Other being Them, those opposed. As seen in Table 6, the character roles segment into those which benefit the hero (including the hero) and those which hinder the hero. While exploring the structures of violence utilised to define the Other in the film is crucial, first the effects of this binary logic on the plot must be understood. Specifically, it is necessary to understand the way in which the film plays on expectations of villainy.

\begin{tabular}{|c|c|}
\hline Self & Other \\
\hline Donor & Villain \\
\hline Helper & False Hero \\
\hline Princess/Her Father & \\
\hline Dispatcher & \\
\hline Hero & \\
\hline
\end{tabular}

Table 6 - Division of Proppian character spheres along Self/Other boundary

In the film, the ultimate villain is Lord Voldemort. He is an evil wizard who the audience is informed killed many wizards and witches including the parents of Harry Potter. He was somehow defeated by the infant Harry and has returned to exact his revenge. Voldemort, however, only appears in a single scene at the end of the film when Harry confronts him, and even then he lacks full corporeality, existing merely as a face on the back of the head of another villain, Professor Quirinus Quirrell (Ian Hart). However, Quirrell is not revealed as a villain until this scene either. Before this point, the main characters believe the real villain is Professor Severus Snape (Alan Rickman). The film intentionally misleads the viewer to believe the same thing, showing various encounters that support that conclusion, such as Snape presumably casting a hex on Harry during a sporting event. The hex is ultimately discovered to be Snape protecting Harry, but again this is not revealed 
until the end of the film. Thus what emerges is, to use the same terminology as Propp, a false villain, a character who appears to be a villain but is not.

It is important to make immediately clear that the false villain is not a sphere of action in the Proppian sense. Also, despite the similar nomenclature it is not an analogue of the false hero that Propp identifies. The difference is that while the false hero is a sphere of action that certain characters operate within-Draco Malfoy (Tom Felton) is a false hero in The Sorcerer's Stone as he wants to reap the success of the victory won by Harry-the false villain is simply a plot device; at the end of the story the false hero remains while the false villain disappears, having been revealed to belong to another sphere of action. In the case of Snape, he is shown to be a helper. The false villain, then, has to do with how the story is told rather than the story itself. For The Sorcerer's Stone, the false villain encourages the audience to suspect Snape.

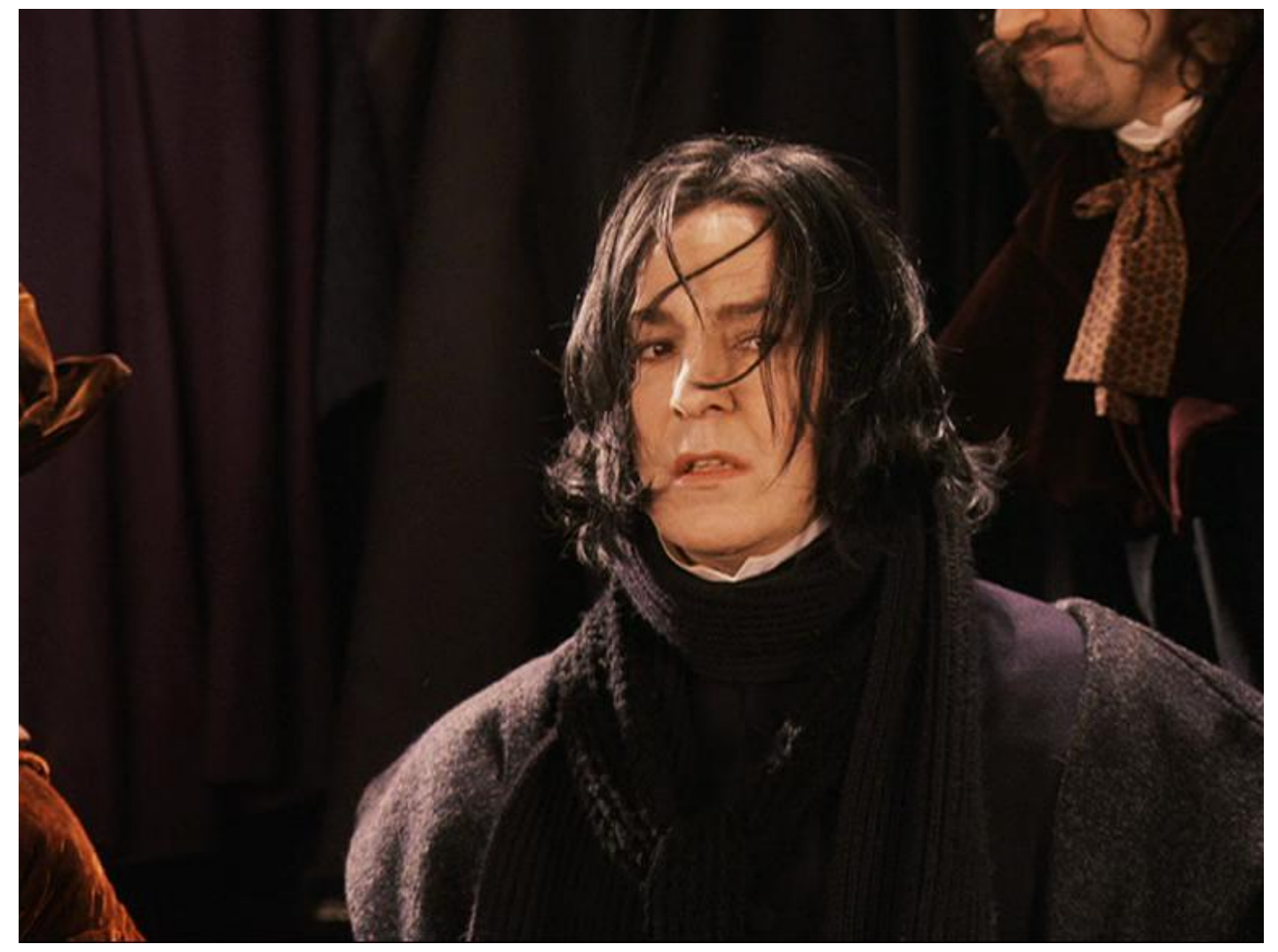

Figure 20 - Severus Snape under suspicion in The Sorcerer's Stone 
From the moment Snape, shown in Figure 20, is introduced in the film, he adheres to traditional codes of cinematic villainy. His costume is entirely black, his complexion is pale, and his flowing robes suggest a certain ambiguity to his sexuality. It is worth noting that these elements, the dark black and pale white, both draw upon existing structures of violence which marginalise characters based on ethnicity and sexual orientation. The marginality of Snape is underscored when contrasted with the more fatherly Dumbledore, who wears warm colours, and the uncle-like Rubeus Hagrid (Robbie Coltrane), who wears earthen tones. What is more, the way Snape behaves suggests villainy as well. Not only is he the head of the Slytherin House at the school, the house the characters note is notorious for producing evil wizards and witches including Voldemort, but he actively hates the hero. Through his overt opposition to Harry, then, he seems to be part of the Other. As already mentioned, despite his appearance he is actually part of the Self, actively protecting Harry from the unrevealed villains. Initially this seems like it combats structural violence. Looking like a villain, the film suggests, does not make one a villain. It indicates that persons should not be judged based on preconceived notions and that others should be receptive to new people and ideas, seemingly supporting a system of structural peace wherein equity is maintained between all members of society. Of course, the fact that characters marginalised by structures of violence are allowed to be part of the Self is not new. In The Phantom Menace, for instance, Jar-Jar Binks (Ahmed Best) was part of the Self despite being a racial and ethnic stereotype. That being said, inclusion into the Self does not make one a hero, and neither Binks nor Snape are truly heroic figures. The major difference between The Sorcerer's Stone and pre-9/11 films, then, is not the fact that the seemingly evil Snape is actually good, but that the false villain device calls into question the entire Self/Other binary.

\section{The False Villain: Structural violence in The Sorcerer's Stone}

In the pre-9/11 films discussed, the Self/Other was not compromised. As mentioned above, there were some moments that showed weakness in the Self, 
but the Self was never actually questioned. For instance, in Saving Private Ryan the failure of Upham to save Mellish from his death at the hands of the Nazi SS officer questions the fortitude-physical and emotional-of the men fighting for the Self, but it never casts doubt on their underlying allegiances. There were even moments when the line between the Self and the Other blurred, as was the case in The Grinch when the Grinch shifted from Other to Self. However, as I have discussed, that transition was not so transgressive at it seemed since the Grinch was only allowed to join the Self on its terms rather than gain acceptance on his own terms. In The Phantom Menace, where the audience knows Anakin Skywalker will ultimately become a villain, there is not any overt indication that will happen. Even when the film reduced the heroes to micro-selves, as was the case with the religion in The Phantom Menace, the film maintained a core sense of Self and Other. In those films, the villains are villains and the heroes are heroes. At a broader level, then, the Self and the Other are clear. None of the pre-9/11 films analysed thus far contained a false villain device. What is more, the inclusion of it in The Sorcerer's Stone creates an atmosphere of paranoia that functions retroactively on the plot.

Professor Quirrell, the true villain, bears many of the same traits as Professor Snape, the false villain. Like Snape, Quirrell is characterised as an effeminate character, so much so that he periodically resembles the stereotype of the sissy. This is clearest when he faints upon the arrival of a troll in the dungeon of the school, but it is also evident in his constant cowardice and fearfulness when teaching the students. By having Quirrell adhere to such stereotypes, it challenges the apparent structural peace engendered by having Snape be a part of the Self. However, Quirrell bears additional markers which marginalise him ethnically. Most noteworthy is the fact that his wardrobe includes a purple turban. The inclusion of this item of clothing may seem easy to dismiss as an important point to analyse in terms of $9 / 11$ because the book, and even the movie, were completed before the events of September $11^{\text {th }}$. What is more, the turban as presented in the film is likely analogous to those worn by Sikhs rather than Arabs, something which would seem to distance the representation from 9/11 even further. However, even though the film was planned and completed well before $9 / 11$ and the turban might 
not be directly connected with Arab attire, the film was released after that date and it is in that post-9/11 paradigm that the audience received it. The turban, then, becomes enmeshed in a larger cultural trend that existed before 9/11 of vilifying Arab characters, a trend explored by authors such as Jack Shaheen (28-33). This means that it becomes a very important signifier of structural violence. That signification, however, shifts dramatically after the betrayal is revealed at the end of the film.

Throughout almost the entire film, Professor Quirrell is presumably part of the Self. He is seemingly an active member of the magic community. He holds a prestigious position at the school, and is trusted by the well-respected headmaster, Dumbledore. Although he is not shown to be the nicest of teachers, he offers neither the children nor the audience any reason to suspect him through his behaviour. As a villain he is virtually invisible. This invisibility achieves the effect of normalising his markings of the Other, specifically his turban. To point, if Quirrell were not ultimately a villain he would be an example of structural peace since he was a non-villain character that bore traits often associated with a marginalised population. However, because he is revealed as a villain, the audience is essentially chastised by the narrative for ignoring the signs of marginalisation with the conclusion of the film suggesting that the Self must be probed to see if it is really the Self or if it is the Other passing as the Self. While the film does not have any form of investigation into the loyalties of other members of the Self after the betrayal and death of Quirrell, its conclusion does nothing to suggest that there could not be further Others concealed within the Self. The probing, then, comes not from the text itself, but from a re-examination of the text through repeated viewings. As Barbara Klinger notes, "When a film becomes a blockbuster, a large part of its success is generated by audience members who return to see it again in theatres" (135). Accordingly, The Sorcerer's Stone likely had a number of repeat viewers not only in the theatre, but on DVD and video as well. In addition, a large number of viewers will have watched the film the first time with foreknowledge about the plot from reading the book. Thus the audience watches or re-watches 
the film with suspicion since they are aware from the beginning that Quirrell, shown in Figure 20, is the Other disguised as the Self.

In such a viewing, with close scrutiny being paid to Quirrell, his actions, which might seem innocent when viewed without knowledge of his ultimate betrayal, suddenly gain a sinister quality. When he is seen in a chance appearance at a popular shopping destination, watching a sporting event, or being accosted by the false villain, Snape, the audience is able to look beyond the façade of innocence and see Quirrell as the concealed Other, masquerading as the Self. They are effectively asked to adopt a paranoid approach to viewing, to look beyond the surface and to see the enemy within. With paranoia as a guiding ethos, signs of betrayal are looked for and it is at this point that the markers of Otherness that Quirrell gains greater importance. Thus, his marginalised masculinity might be important to some viewers while his turban would stand out to others particularly due to the fact that the turban literally conceals the face of evil that Quirrell bears. What is more, the turban would have additional ideological meaning to audiences at the time in light of the events of 9/11 and the subsequent popular rhetoric which activated antiArab and anti-Islamic sentiment. In this way, the film validates structural violence in multiple ways since Quirrell is marginalised for his gender performance as well as his attire, the latter of which carries both ethnic and religious meanings. 


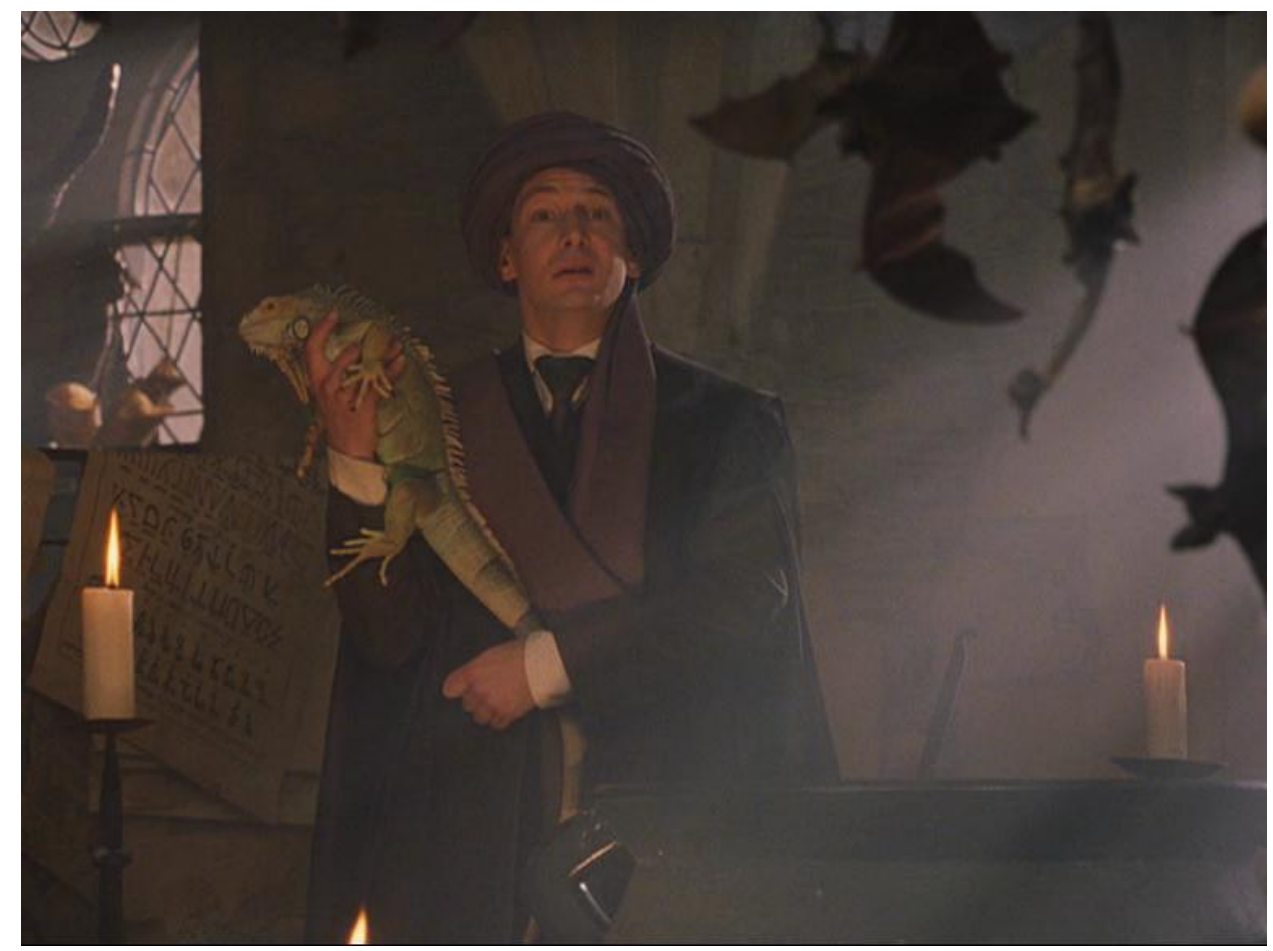

Figure 21 - Quirinus Quirrell, the actual villain of The Sorcerer's Stone

As mentioned above, paranoia has the ability to obfuscate violence. In this case it is specifically accomplished by marking Quirrell as the Other, effectively guiding the attention of the viewer towards him. The result is that the other characters in the film, and the structures of violence which define them, go unmarked, which implicitly condones them. This is very clear with gender-based structures of violence in the film which privilege traditional notions of masculinity.

Harry proves his worth repeatedly through masculine deeds, including both defeating a troll and becoming a star athlete. Characters that are less able than Harry, such as his classmate Neville Longbottom (Matthew Lewis), are often presented as comic relief as is the case when Neville mounts his broom and, unable to control it, is carried away. As for the female characters, although some of the professors are women, they all generally fit into existing stereotypes. For instance, Professor McGonagall (Maggie Smith) is always fretting over the children in a motherly way while Madame Hooch, the broomstick instructor, is characterised as butch and adheres to the stereotype of the masculine, potentially lesbian, female physical education teacher. As for the main characters, Hermione is repeatedly 
demonstrated to be very smart, but physically inept and dependent upon Harry for protection as is clear in the aforementioned troll sequence where she is reduced to a damsel in distress. Lastly, the father figure Dumbledore, who talks to Harry about his deceased parents, essentially passes on the patriarchal authority to Harry. In this way, there is a structure of violence in the film which privileges men over women. There is a similar privileging of whiteness in the film.

There are non-white characters in the film, but they are generally reduced to nonnarrative token parts. For instance there is a black student who works as the announcer during the quidditch match, a full-contact sport for witches and wizards. There are, however, white characters that are clearly marked as others, most notably Hagrid, who is a human/giant hybrid. His position of Other is additionally marked by his affinity for and communion with other marginalised creatures such as centaurs and dragons. While his job as groundskeeper of the school would logically have him reside outside of the school, the fact that this ethnically different figure lives beyond the walls of the school itself is quite telling of the racial elements of the film as Hagrid is essentially Uncle Tom living in his cabin, perpetually faithful to his white master Dumbledore. In the same way patriarchal authority is passed from Dumbledore to Harry, so too is the authority of whiteness. As for Quirrell, his whiteness is called into question through his concealment of a monstrous face. In this way, the film subtly supports structures of violence in much the same way as pre-9/11 films which also tended to privilege the white male. However, unlike pre-9/11 films, The Sorcerer's Stone ultimately directs the viewer away from the normalised characters - those that adhere to the structures of violence-and towards the deviant characters, such as Snape and Quirrell, through its deployment of the false villain device and the resultant paranoia. The structures of violence within the film are thus concealed even further. It must be noted here that readers of the books would have brought an additional layer of knowledge to the film as racial discourses are developed much further in them, as they are in the subsequent Harry Potter films; in Harry Potter and the Chamber of Secrets, for instance, the term "mudblood" is introduced as a racial slur. However, these issues are not developed in any substantive way in The Sorcerer's Stone. Regardless, the 
film still articulates multiple structures of violence which are essentially concealed. What makes this process even more problematic is its relation to direct violence.

Throughout the film, direct violence is shown to be a viable means of success for the Self. For instance, when Harry is playing quidditch, he succeeds not just by outwitting his opponents and displaying exceptional athleticism, but also by periodically fighting the players on the other team. An even clearer instance of the deployment of direct violence is when a troll invades the school and Harry manages to defeat it by attacking it with his wand. His actions here seem justified in the fact that the troll is trying to kill his friend, Hermione. Although Harry is scolded afterwards by teachers at the school for doing something so dangerous, he is also rewarded for his deeds, an action which ultimately condones the use of direct violence against those identified as the Unchosen Others. Given the paranoid atmosphere of the film, the probing of the Self to find the Other becomes a search for a target of direct violence. The fact that such a response is merited is reinforced by the way the film characterises the villain.

Before Quirrell is revealed as the villain, he is a cowardly figure. Once he is unmasked-or "unturbaned" - he becomes a bloodthirsty madman intent on killing anybody to achieve his goals, even children, as the climax of the film demonstrates when he tries to kill Harry and his friends. Thus, through Quirrell, the film positions the Other as one who can only be defeated through death. Interestingly, when Harry ultimately kills Quirrell, he does so simply by placing his hands on him. Despite the fact that the franchise has been plagued by criticisms that argue it supports evil through witchcraft and wizardry, a claim originating from religious communities long before the release of the film (Blume n. pag.), the laying on of hands in this scene is an act suffused with Judeo-Christian traditions as it is the act which appears in multiple Biblical passages. While the connections are not developed in a substantive way in this film, there are potential messianic connections that could be made. Unlike the benevolent laying on of hands associated with religion, though, it is clear that Harry does so to kill Quirrell. Despite this important difference, though, and regardless of whether Harry is read as a messiah figure or not, the laying on of hands functions to identify the Chosen 
and the Unchosen. In short, it supports a structure of violence. In this case, that structure is fused with direct violence as it results in the immediate death of the Unchosen. The fact that Harry is highly lauded for his actions suggests that the film sanctions both structural and direct violence when it targets the Other. What makes this process additionally problematic is that it is predicated upon a system which condones scrutiny of the Self, particularly by way of profiling people in order to flush out, as it were, the hidden Other before that Other can harm the self. More telling is the fact that Harry commits all of this violence in direct opposition to the school rules because he believes he is right. The film of course bears out that he is indeed right; by following his instinct, he saved the school. This approach towards violence holds strong parallels to the Bush response to 9/11.

\section{The Unilateral Wizard: The Bush Doctrine and The Sorcerer's Stone}

Even in his first few months in office, the Bush administration was driven by what commentator Charles Krauthammer identified as a policy of unilateralism.

According to Krauthammer, the administration had begun a process of "reversing the premises of Clinton foreign policy and adopting policies that recognize the new unipolarity and the unilateralism necessary to maintain it" (n. pag.). In short, while the Clinton administration attempted to downplay the position of the United States as the sole superpower in the wake of the Cold War, the Bush administration embraced it by beginning to act unilaterally "to maintain [US] pre-eminence" (n. pag.). Additionally, Krauthammer argued that according to Bush administration policies, the US might eventually need to adopt a policy of "pre-emption." However, there is no substantive engagement with the concept. Writing in June of 2001, Krauthammer could not have guessed the application these principles of what he termed "the Bush doctrine" would have.

After 9/11, unilateralism and pre-emption became hallmarks of the Bush foreign policy as wars were launched in both Afghanistan and Iraq without approval from the United Nations. In the case of the Iraq invasion, it was primarily justified by arguing the United States was under imminent threat from Saddam Hussein who, it was claimed, possessed and would use Weapons of Mass Destruction (WMDs) 
against the United States. The fact that key evidence which supported the notion that Iraq had WMDs has come under considerable questioning - the Downing Street Memo and the Plame/Wilson scandal being key instances of doubt-as well as the lack of any exit strategy from Iraq suggest ulterior motives for the invasion, specifically occupation of the country for oil. Interestingly, Krauthammer states that the United States has "no particular desire...to conquer for the extraction of natural resources" (n. pag.). Regardless, the salient points of this discussion are that the Bush doctrine essentially revitalised the concept of victory culture that Tom Engelhardt claimed died with the Cold War (x-xi). Engelhardt of course revised his position after $9 / 11$ since the United States once again played the role of a noble defender even as it was the aggressor and instigator of multiple conflicts including the Second Iraq War. This image is embodied in the figure of George W Bush who, in his construction of his own image as a cowboy, attempted to play the role of a world sheriff, ostensibly protecting smaller nations from "rogue" nations. This is important because it is ultimately that role that Harry Potter himself assumes as he essentially adheres to the Bush doctrine, in letter if not entirely in action.

As discussed in Chapter Three, the primary principles of the Bush doctrine as laid out by Krauthammer are that the United States acts as enforcer of the peace, maintainer of the peace, and extender of the peace (n. pag.). Despite the proliferation of the word peace here, it is important to acknowledged that the policy is predicated on much violence-direct, structural, and cultural--as the policies are designed around overt and implicit assertion that the United States is the "top dog," to use the language Galtung does ("Cultural" 295), in relation to all other nations. In The Sorcerer's Stone, Harry enforces the peace, doing so at one point by openly confronting classmate, Draco, who is harassing other students. The most striking similarity between the actions Harry takes and the Bush doctrine, however, is when Harry eschews the rules and regulations of the school, and even the authorities of the school, to unilaterally and pre-emptively break into a forbidden part of the school to defeat the villain. The rationale is that if he does not do this the enemy Other will obtain an object of immeasurable importance, the titular sorcerer's stone, which can be used to mount a campaign of direct violence. 
This cavalier approach to crisis, of course, succeeds wildly in the film and in so doing it validates it as the approach towards maintaining peace suggested by the Bush doctrine. It is worth returning then to the idea of "wishing for" 9/11 advanced by Baudrillard (7), wherein he argued the disaster films of the 1990s articulated a dream for the end of the hegemony of the United States.

As I have asserted in previous chapters, the popularity of certain films outside the disaster genre, and even those within it, showed that those which resolved the post-Cold War identity crisis of the United States resonated with domestic audiences. In that same way, I contend that the attacks of September 11 created a desire for a simplified Self/Other relationship that the Bush administration addressed by creating a binary world of good and evil. Along those lines, The Sorcerer's Stone resonated with viewers not simply because of the represented struggle between good and evil, but because good triumphs. What is more, the process by which evil was defeated in the film - pre-emptively and unilaterallystrongly resembled the policies of the Bush administration even before September 11. With that dream, however, comes its nightmarish underside, which is paranoia. Accordingly, it is necessary to return to the concept of the crusade here.

As mentioned above, the notion of $9 / 11$ being the start of a crusade against evil began just days after the events of September 11 with remarks made by Bush. With the nebulous identifications of the enemies, the Other, subsequently made, a domestic search started for the Other within the Self, thus showing how a discrete Self/Other relationship was no longer viable. The USA PATRIOT Act once again demonstrates how this is the case as it provided the legislative groundwork from which constitutionally questionable tactics, such as domestic-wiretapping, were facilitated. The justification for this paranoia was the threat of harm; the Other could strike at any moment. In The Sorcerer's Stone, this same paranoid logic was at work, with the Other hiding within the Self, ultimately striking and nearly killing the hero. When Harry kills Quirrell with his touch, the explanation given for this miraculous moment is not magic, but instead it is love. Quirrell, apparently, was so evil that love killed him. As fantastic as that sounds, it is virtually the same as saying it was because of freedom that the terrorists attacked the United States. In 
both instances, the mythic nature of the conflicts draws attention away from accompanying structures of violence, ultimately supporting white patriarchal authority. 


\section{Chapter Seven}

\section{Atoning for Sins Past: Spider-Man (2002)}

In 2002, the "crusade" that George W. Bush led against terrorists transitioned from Afghanistan to Iraq. Although many have subsequently argued that Iraq was the target even before the attacks of 9/11-Joyce Battle (2010) asserts that "September 11 was not the motivation for the U.S. invasion of Iraq - it was a distraction from it" (n. pag.) - Iraq became a formal target in early 2002. As I have already noted, this was evident in the 2002 State of the Union Address where Bush identified Iraq, along with Iran and North Korea, as the "axis of evil" ("President" n. pag.) and claimed that they were "arming to threaten the peace of the world" ("President" n. pag.). Additionally, he argued that given the threats these states posed to the United States, "the price of indifference would be catastrophic" ("President" n. pag.). He also added that "The United States of America will not permit the world's most dangerous regimes to threaten us with the world's most destructive weapons" ("President" n. pag.). In essence, he reiterated the principles of the Bush Doctrine, suggesting that the United States had an obligation to depose the leadership of those countries, and alluded to the potential for pre-emption. What all of this rhetoric hinges upon is a Self/Other paradigm that positions the United States as a victimised Self, and the nations which support and harbour terrorists as part of a monolithic evil Other. However, as discussed in the previous chapter, the nature of the crusade and its binary worldview engenders a shift in the actual shape of the relationship between the Self and the Other.

Harry Potter and the Sorcerer's Stone was predicated upon paranoia. The Other, the film warned, could be hidden within the Self. To convey this message, the film utilised the false villain device. This device concealed the identity of the true villain until the end of the film. The revelation of the villain encouraged the audience to look upon the Self with suspicion to find a potentially concealed Other. In May of 2002, seven months after the premiere of The Sorcerer's Stone in the United States, Spider-Man was released, and it solidified that shift. Unlike The Sorcerer's Stone, 
Spider-Man dispensed with the false villain device and openly presented the Self as having been infiltrated by the Other. Since that device was key to concealing major structures of violence within the film, its lack in Spider-Man opened the film up to more diverse readings, particularly with regard to the events of 9/11.

In a blatant effort to capitalise on the sympathies of post-9/11 audiences, SpiderMan flaunts its patriotism, and overtly and covertly plays to the reawakened national pride found in that population. This is evident not only in something as simple as the colouration of Spider-Man, a red and blue which is directly connected to that of the American flag in the film (as it has been in the comic), but it is also clear in the self-censorship of the film. Specifically, an early teaser trailer, which prominently featured the World Trade Center buildings, was re-edited to omit them. Similarly, the World Trade Center buildings are absent from the numerous skyline shots found in the final film. The result is that even though the film never directly references the attacks of $9 / 11$ and the destruction they caused in New York City, the traces of the event of $9 / 11$ are felt throughout the film regardless. This is particularly true of the story itself, which tells how Spider-Man gained his powers and ultimately uses them for good, after suffering a harsh loss for failing to use them. This lesson is driven home through the repeated utterance of the key line in the film: "With great power comes great responsibility."

My analysis in this chapter will focus on the ways in which the refined articulation of Self and Other ultimately can be read as condoning the 2003 invasion of Iraq while simultaneously condemning its critics as Others within the Self. The key to understanding how Spider-Man positions its Self/Other relationship in that fashion is the historical context of its release. Accordingly, the first element of my analysis will be an examination of how the events of $9 / 11$ and the subsequent wars responded to the policies of the pre-9/11 United States. Specifically, I will look at how the "end of victory culture," as Tom Engelhardt labels it in his book of the same name, engendered a sense of shame which plagued the US military, something often associated with the Vietnam syndrome as well (10-15). This discussion suggests that the events of 9/11 transformed the shame over military 
intervention into shame over military non-intervention. That argument, which is developed further at the conclusion of the chapter, serves as a means of understanding how Spider-Man defines its Self and Other. This is important because it is the articulation of Self and Other which normalises the internalisation the Other; the Self may contain a hidden Other. What is more, it shows how the standard structures of violence utilised to mark the Others in films thus far are not precisely the same structures that define the Self and the Other in this film. Instead, both are defined by their relationship to the central theme of the film, which is power necessitating responsibility. To understand how this relationship connects to the historical moment of its release, my analysis will approach the concept of atonement, which the film deals with extensively. I will then draw that discussion into a broader context by comparing the process of atonement in the film to both the Clinton and Bush Doctrines with my analysis here fully developing the argument that the pre-9/11 shame was transformed by the events of $9 / 11$ while at the same time depicting a shift from the Clinton Doctrine to the Bush Doctrine. My analysis will then conclude by showing how this transformation is dramatised in Spider-Man in such a way that it essentially articulates the "dream" of a situation where a noble invasion serves as a means of atonement for a shamed nation.

\section{Sins of the US Father}

When discussing the victory in the first Gulf War, President George H. W. Bush remarked that, "It's a proud day for America. And, by God, we've kicked the Vietnam syndrome once and for all" ("Remarks" n. pag.). As mentioned previously, Douglas Kellner describes the Vietnam syndrome as "the shame concerning the loss of the war and overcoming the reluctance to again use U.S. military power" (Media 28). The words of Bush Sr., then, seem to present the First Gulf War as a noble act which served to atone for the Vietnam War such that the stature of the US military would return to the glory it won in World War II. However, the record of military interventions during the 1990s shows that US military power had not been fully recuperated. For instance, the American involvement in the Kosovo War in 1999 was criticised despite the supposedly noble intentions President Clinton argued for, 
including preventing genocide. The opposition to US involvement in Kosovo supports the argument made by Engelhardt (10-15) that the Vietnam syndrome and the avoidance of using military power was part of a larger movement away from "victory culture." As the failed bid for re-election Bush Sr. made in the wake of the First Gulf War shows, the war did not bathe all of his acts in the "purifying glow" Engelhardt argues accompanied militaristic endeavours in victory culture (4). Thus, the atonement of the US military for Vietnam and other post-World War II interventions was incomplete. As Engelhardt observes, though, in the wake of 9/11 victory culture returned.

After the Cold War ended, Engelhardt noted that the United States was plagued by being the only superpower in a world built by the struggle between two superpowers. Without the Soviet Other, the US did not have an enemy against which to define itself. This began to change even in the pre-9/11 period of the presidency of Bush Jr. As Charles Krauthammer observed when he defined the Bush Doctrine in 2001, stating that the major difference between the Clinton and Bush administrations was that the Clinton administration sought to placate the other major players in the world despite the fact that they were all inferior to the United States (n. pag.). The Bush administration, Krauthammer claims, finally accepted the role the United States had as the most powerful nation on the planet (n. pag.). Based on that suggestion, it can be argued that the Clinton era was associated with further shame for being the victor of the Cold War given the high costs needed to reach that level, such as the Vietnam War. The Bush administration, according to Krauthammer, cast off the shame of being the sole super power in a number of ways, most notably by acting unilaterally. What began to take shape, then, was a binary world which was divided between the United States and all other nations - which were implied to be inferior. According to Johan Galtung, this is a form of ideologically-driven cultural violence ("Cultural" 298-299). Specifically, the nation becomes the Chosen one while that which is not the nation becomes the Unchosen one. The result is that the Chosen nation, in this case the United States, is seen to be more worthy of everything, a position which creates a global inequity which favours the United States. While the ideology behind the 
violence in the Bush presidency both pre- and post- $9 / 11$ is the same, the exact formulation is different.

Before 9/11, Bush attempted to define a national imaginary. He constructed a cowboy/rancher persona, but in terms of the mythological nature of that figure, he lacked an evil Other. He was a cowboy without purpose. What is more, despite the fact that his government acted unilaterally in its responses to 9/11, he did not have full public support in the United States. This is primarily due to the highly contested nature of the 2000 election which brought him to office. In that election, disputes surrounding the votes in the state of Florida led to a delayed election result that cast a pall over the victory Bush ultimately claimed. This was underscored by the fact that Al Gore, the Democratic candidate, actually won the popular vote. Thus during the first months in which Bush was in office, the nation was divided as the enemy was not foreign, but domestic. Although the red state/blue state paradigm would truly take hold during the 2004 election cycle, divisiveness was present throughout the country. In terms of the state system described by Galtung, the United States was essentially a multi-national system where the national sphere would be stratified along various lines such as race and class. Thus, the capacity for violence in the domestic sphere-cultural, structural, and direct-was high (Galtung Peace 66). For the nationalistic cultural violence to take hold, a unified domestic space is required, and for that a common Other is needed, which is exactly what the attacks of $9 / 11$ provided.

Although Bush only referred to the conflict as a "crusade" once, the label established a conflict wherein the United States and its allies were in diametric opposition to the terrorists and those who would harbour and support them. As discussed in the previous chapter, the conflict carried with it obvious religious connotations, but it also bore a nationalist quality as Bush claimed that the reason the United States was a target was because of its democratic ways, as evidenced in definition of the Other via the Four Freedoms. That comment served the double purpose of identifying the Other as well as the Self in mythic terms. However, the 
attacks provided more than just a redefinition of Self as they also redefined shame for the nation.

As discussed above, the Vietnam syndrome refers to a pervasive sense of shame felt by many in the United States in the wake of the Vietnam War. Again as Kellner observes, that shame led to a "reluctance to again use US military power" (Media 28). What the attacks of $9 / 11$ suggested was that the post-Cold War era had been one of leniency and complacency. Bush Sr. did not depose Saddam Hussein and Clinton, despite urging a regime change in Iraq and noting the significance of Osama bin Laden as a threat to the United States, did not properly safeguard the nation through military action. What is more, the World Trade Center bombing that took place in 1993 indicated the value of the target to terrorists, yet no counterterrorism precautions were maintained (Lipton "Giuliani" n. pag.). Thus, it is my contention that $9 / 11$ took the shame over military power and transformed it into shame over not using military power. It is no surprise, then, that the War in Afghanistan began on October 9, 2001, less than a month after September 11.

It is important to note again that just before the war in Afghanistan Bush held an approval rating of $90 \%$ ("President Bush's Approval" n. pag.). Similarly, the policies being pushed through the US government were well received. The USA PATRIOT Act, for instance, which is constitutionally questionable (Whitehead \& Aden "Forfeiting" 1083-1086), passed on October 25 in the Senate with a margin of 98 to 1 with 1 abstention. Thus in the immediate wake of the events of 9/11, the United States was largely unified, in the early stages of a crusade where, as Bush remarked on September 20, 2001, "Either you are with us, or you are with the terrorists" ("Address" n. pag.). However, such a strict division between Self and Other led to the realisation of what James Carroll argues is a peril of a crusade, which is that "mobilization against an enemy outside inevitably led to a paranoid fear of enemies within" such that "The war against Islam abroad became a war against dissent at home" (25). Accordingly, the Other within the Self served as a reminder of the shame the nation felt, and was as threatening as the external Other. It is this same 
articulation of the Other as both a foreign and domestic threat that Spider-Man utilises.

\section{Old Glory: Patriotism, Self, and Other in Spider-Man}

With Spider-Man, it is clear from the promotional materials alone that Spider-Man (Tobey Maguire) is the hero and that the Green Goblin (Willem Dafoe) is the villain. Despite that clarity, it is not as easy to define the Self and the Other. This is because both Spider-Man and the Green Goblin have alter-egos. Spider-Man is also the average lower-class kid, Peter Parker, and the Green Goblin is also the ultrawealthy military manufacturing magnate, Norman Osborne. While Parker and Spider-Man are both part of the Self, and the Goblin is Other, Osborne straddles the line between the two. This is mainly due to the fact that he is not initially entirely aware that he is the Green Goblin. Accordingly, he is both Self and Other. However, unlike The Sorcerer's Stone which conceals the penetration of the Self by the Other using a false villain device, Spider-Man makes this configuration clear from the outset, opting instead for simple dramatic irony; the audience knows that Osborne is also the villainous Green Goblin even though Spider-Man does not until the end of the film. Thus, instead of the plot revealing to the audience that the Other might be hiding within the Self, the film shows that the Other is expected to be within the Self. A cultural paranoia, which was reliant upon surprise in The Sorcerer's Stone is thus normalised in Spider-Man. While that continues to suggest that the Self should be probed, it also directs the suspicions of the audience, focusing them directly on the characterisations of both Spider-Man and the Green Goblin. In more specific terms, the viewer is guided by the film to observe the ways in which these characters are aligned, for both good and evil. One of the most overt connections made between both characters is their connection with the United States.

Patriotism is a key factor in the identity of both the hero and the villain. For the hero this is clear from the opening and closing shots which feature the flag of the United States. The first shot identifies the neighbourhood that Peter Parker comes 
from as being a generic, all-American place-one of the boroughs of New York City-which has the US flag prominently hanging from the front of a local business. The final shot shows a triumphant Spider-Man swinging around the city until he finally lands atop a building where he poses for a moment on a flag pole with his red and blue costume harmonising with the flag. He then leaps away, leaving the US flag waving in the wind, as seen in Figure 22. Spider-Man is thus equated with heroic America, and with all that the flag represents. Interestingly, these shots are very similar to the literal flag waving found in the opening and closing shots of Saving Private Ryan (1998) as well as the opening shot of Independence Day. Unlike those films, however, where the flag is in peril-from Nazis and aliens respectively-in Spider-Man it is a valiant symbol suggesting that the prediction made by Robert Kaplan, that "the traditional symbols of American patriotism" (76) would wane, had expressly not come to pass. The connection between Spider-Man and the United States is made even more explicit when Spider-Man is fighting the Green Goblin near the end of the film. He is trying to save both the girl he loves and a cable car full of children while the Goblin is attempting to kill them all. Citizens of the city intervene at the last moment, stopping the Goblin and allowing Spider-man to save everybody. As they do this, one of the people shouts "Mess with Spidey and you mess with New York!" Given the position of New York City in the wake of 9/11 as "America's City," the equation between Spider-Man and New York makes the connection between him and the United States is even stronger. Thus, the United States is positioned as a heroic entity, embodied in Spider-Man, which will defend its citizens at all costs as its citizens will defend it. Yet even as Spider-Man is so forcefully paired with the United States, so too is the Green Goblin. 


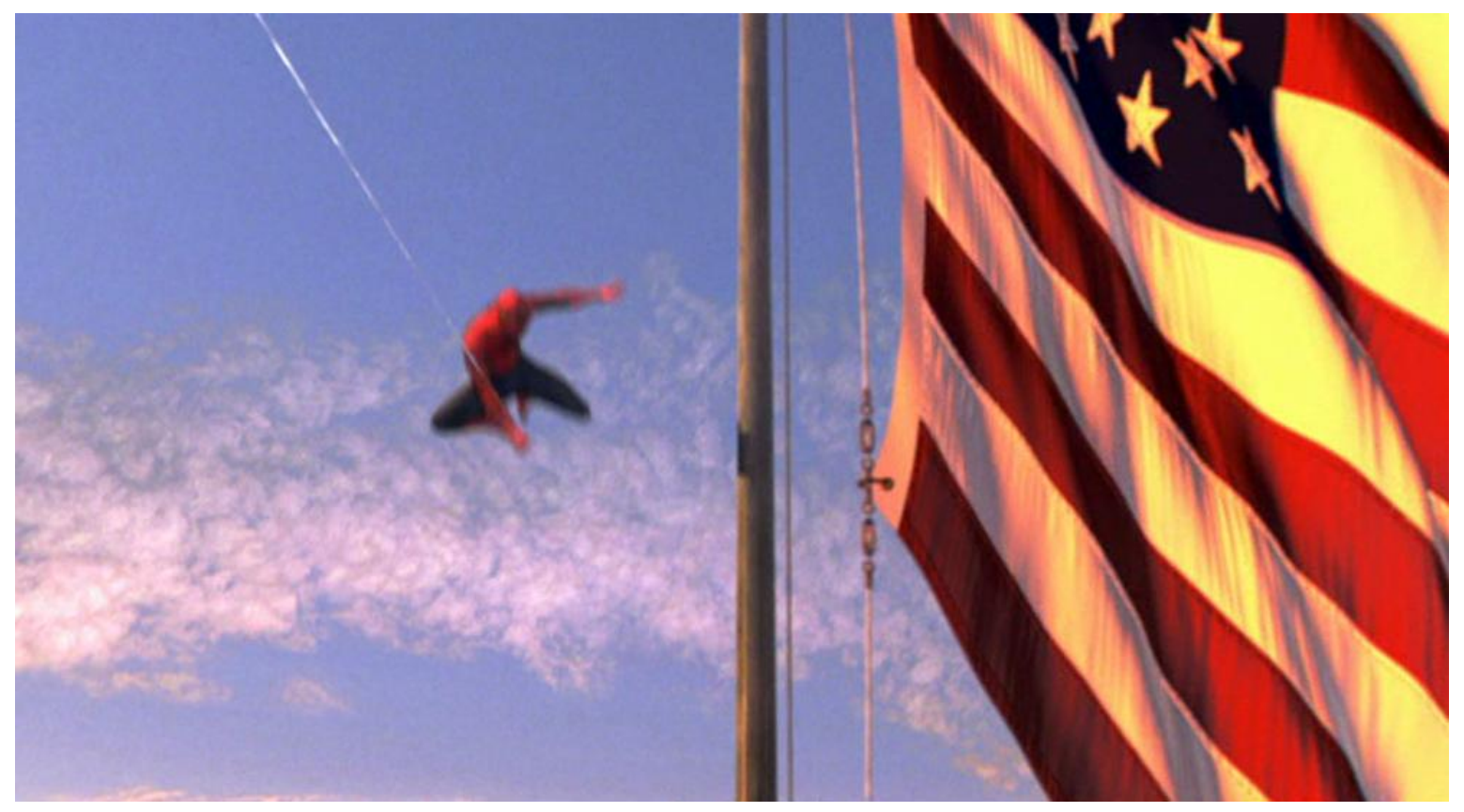

Figure 22 - New glory and Old Glory: the final moments of Spider-Man

Norman Osborne is a prime example of capitalism. According to the film, he founded the company, Oscorp, and grew it into a powerful government contractor that is the number one supplier for the US military. While this could be framed in a positive way, the film uses his position to mount a mild critique of capitalism. For instance, Oscorp is developing a super-soldier serum which is not working as planned so Osborne tests it on himself in an effort to expedite research and secure funding. This goes predictably awry and turns Osborne into a homicidal madman. While it could be said that Osborne is a victim of his own ambition, it is equally the case that he is driven by the strictures of society. In a psychoanalytic reading of the film, Robert Peaslee suggests that the Green Goblin "is a clear representation of the unbridled ego" (n. pag.) which serves as a counterpoint to the "Protestant values" held by Osborne "such as a rigid work ethic, advancement and accumulation through wisdom and frugality, and responsibility" ("With" n. pag.). This analysis from Peaslee largely supports the notion that the system is what has driven Osborne mad, not his aspirations. 
However, it should be noted that in testing the product on himself, Osborne perfectly plays the role of the mad scientist defined by Susan Sontag in her discussion of science fiction disaster films of the 1950s, since he uses science to create something which could ultimately threaten humanity itself (45). While the attacks of the Goblin are not shown to be threatening on a global level, the fact that the US military is interested in acquiring the technology suggests a darker underside to it all. The US military is of course saved from being demonised as they search for another more responsible supplier - one that Sontag would describe as being able to "administer the same scientific discovery better and more safely" (46) - and in so doing become victims of the Green Goblin. Thus the Goblin essentially represents the military-industrial complex and capitalism having (literally) gone mad. This is underscored even further when the board of directors votes to sell the company and to oust Osborne as CEO, thereby provoking the Goblin again, who kills them. In terms of Self and Other, the Goblin is clearly the Other as he is attempting to destroy not just an American city, but what was at that time the American city. Norman Osborne, however, is caught between Self and Other since he is a victim of corporate capitalism. Even so, being a blockbuster film heavily dependent upon corporate support, it does not critique corporations too thoroughly. The salient point of the critique remains the double position of Norman Osborne as victim and perpetrator. This is important not only because it normalises suspicion and paranoia, but also because it makes the identification of the Other more challenging. This is on account of many of the traditional structures of violence that would mark one as an Other not being present in Osborne.

The villain of Spider-Man, Norman Osborne, stands in stark contrast to both the villain and the false villain in The Sorcerer's Stone, who were effeminate, with the villain additionally being marked as an ethnic Other by way of various stereotypical traits including his turban; Osborne is a virile white male. While this is by no means a sign of goodness - white men are often villains as evidenced in Titanic with Caledon Hockley (Billy Zane)-the whiteness and masculinity displayed by Osborne are not dramatically different from the whiteness and masculinity which SpiderMan possesses. The prominence of men in the story, of course, reasserts the 
power of patriarchal authority. The result is a privileging of men over women. Mary Jane Watson (Kirsten Dunst) is the girl that Peter Parker loves. However, his relationship with her is one of silent yearning and, to Spider-Man, Mary Jane is simply a woman that needs to be rescued from a man by a man; her fate is not her own. The fact that masculinity is privileged, however, is not mobilised against the Green Goblin as his masculinity is not challenged in standard ways such as by making him effeminate, despite the fact that he poses as an injured woman in one scene to lure Spider-Man into a trap. Instead, the major differences between Spider-Man and the Green Goblin can be found in the oft-repeated line in the film, "With great power comes great responsibility," which is first uttered by Uncle Ben (Cliff Robertson), the uncle and surrogate father of Peter Parker, just before he dies. Interestingly, Norman Osborne is presented as a potential surrogate father after Uncle Ben dies. Koh observes further that the Green Goblin, in offering Spider-Man "a Faustian apprenticeship" (743), reinforces a larger structures of Oedipal themes in the film. While the issues of fatherhood certainly merit closer scrutiny, which Koh gives them, the larger point here is that what differentiates the hero and the villain in the film is their stance on the statement of responsibility: Spider-Man heeds it and the Green Goblin does not. This is most evident in the way they are defined in relation to both class and technology, which will be explored in turn.

Norman Osborne is a wealthy man. As stated above, he is the head of a major corporation, and lives a lifestyle filled with mansions, chauffeurs, and apparently limitless wealth. It seems in the film that his wealth, again like the villainous Hockley in Titanic, is only spent on himself and his immediate family. Although his wealth is scorned by his son, Harry Osborne (James Franco), Harry makes use of the wealth for his own benefit throughout the film and ultimately replaces his father, who dies at the climax. What makes this a particularly negative quality is that he uses the wealth to win over Mary Jane, the girl Peter Parker loves, though he is too shy to admit his feelings. Again, this patriarchal situation denies Mary Jane any agency. In terms of class, though, Peter Parker is just the opposite of the Osbornes. He is shown to come from meagre, but hardly impoverished beginnings. Initially he sees power as a means of gaining personal wealth. This is evident when he enters a 
wrestling contest to win money so he can buy a car to impress Mary Jane.

However, when his lack of respect for his power results in the death of his uncle, he understands that class mobility is inconsequential and that his duty to society, which might relegate him to a permanent life of poverty, is of the utmost importance. Thus, the film does not criticise the accumulation of wealth or power, but it does assert that the Self is selfless while the Other is selfish. A similar paradigm emerges when the positioning of technology is examined in the film.

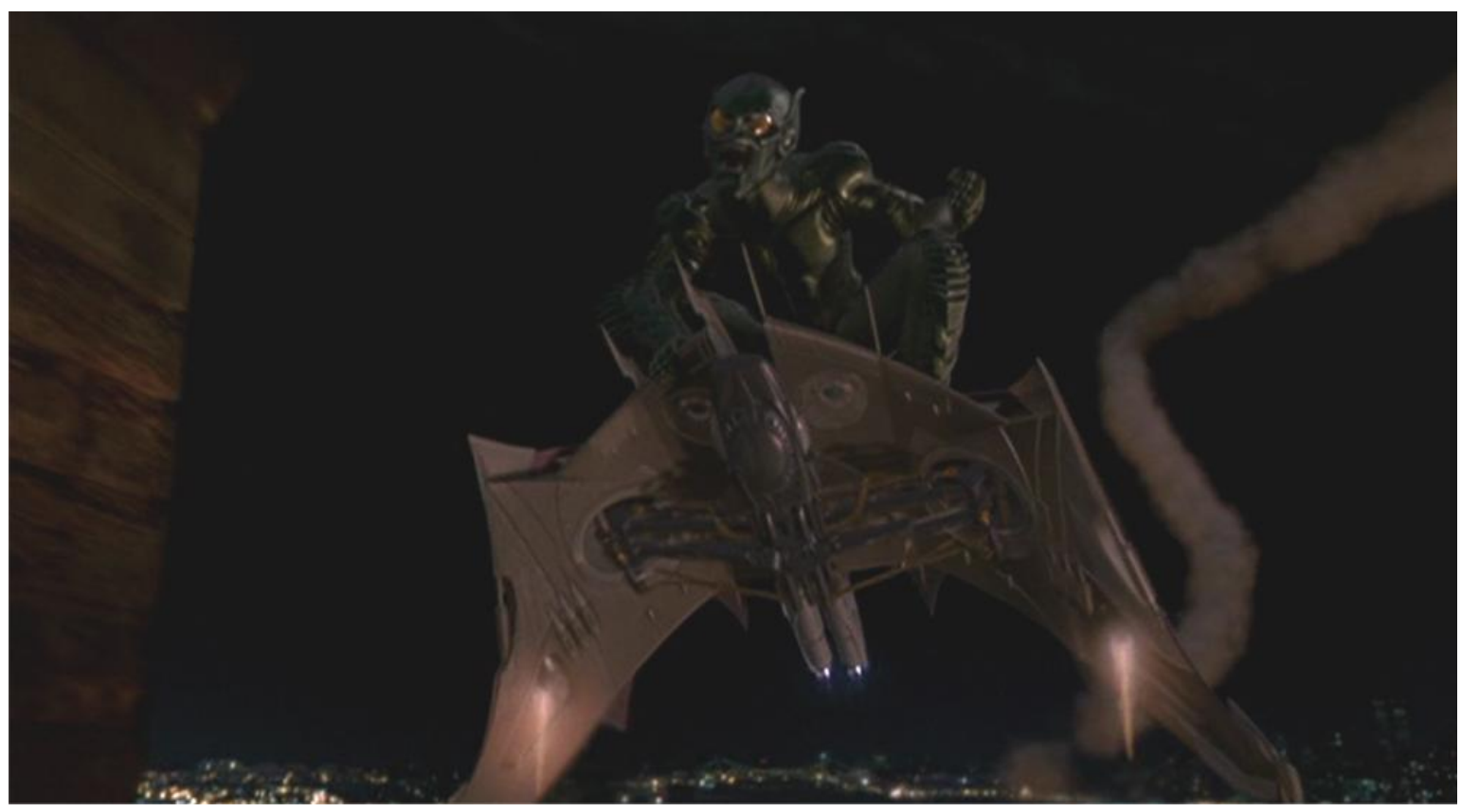

Figure 23 - The techno-terror of Spider-Man

As with many of the films analysed thus far, Spider-Man exhibits both technophobia and technophilia, although it displays these traits in a covert fashion. In terms of technophobia, the film shows particular wariness toward military technology. This is evident in the fact that the Green Goblin, his glider, and his weaponry, are all the product of military research, and explicitly exhibit a machine aesthetic, as shown in Figure 23. It is, the film suggests, research for the armed forces which drives the Green Goblin mad. However, Spider-Man himself is the product of technology as well. Peter Parker gets his super powers from the bite of a genetically-modified spider. Unlike the technology which produces the Goblin, however, the spider is 
produced at a university. Furthermore, while the technology Spider-Man uses is internalised and becomes a part of his body, the internal transformation of the Goblin becomes externalised in the form of an armoured flight suit. In this way, the more natural technology of Spider-Man emphasises his humanity while the mechanical technology of the Goblin diminishes his own. This double position of technophilia and technophobia is summed up by Wilson Koh, who remarks that the technology "is presented as miraculous and monstrous by turns" (737). Given the fear of technology, it is useful here to engage again with the position on technology which is articulated by Michael Ryan and Douglas Kellner in their discussion of technophobic science fiction films. The argument they make is that technophobia is often a conservative position and that films which exhibit it suggest that

"technology represents artifice as opposed to nature, the mechanical as opposed to spontaneous, the regulated as opposed to the free, an equalizer as opposed to a promoter of individual distinction, equality triumphant as opposed to liberty, democratic living as opposed to hierarchy derived from individual superiority" (245).

While first half of the argument accurately captures the anxieties surrounding the Green Goblin and his lack of regard for humanity, the second half does not suit the film. This lack of parity suggests that the film articulates a technophobia which is not conservative in that way. Instead, the technophobia seems to be driven by patriotic ideals. Accordingly, the film echoes the individualistic principles of the United States which suggest that things such as technology and wealth are not inherently evil, and instead it is up to each person to decide whether they will use them for good or for evil. Interestingly, for both the Self and Other, power is equated with direct violence. Granted Spider-Man responds to direct violence rather than initiating it, the result is still that direct violence is praised as heroic even as it is condemned as villainous. To again cite the key line of the film, "With great power comes great responsibility," and Spider-Man, the Self, ultimately heeds these words in all aspects of his being while the Green Goblin, the Other, respects 
them in none. As for Osborne, it is when the concept of Self and Other is approached in this way that he clearly becomes the Other since he lacks concern for the greater good. Thus when Spider-Man ultimately defeats the Green Goblin/Norman Osborne, it is actually a purging of American society of those elements which take the position of America for granted. Spider-Man, then, effectively purifies the nation.

\section{Eternal Vigilance: Spider-Man, Atonement, and Presidential Doctrines}

Atonement is a key trope in cinema. As Christopher Robert Deacy observes, "While not all films which are produced by Hollywood may be carriers of religious significance, it is in the medium of film that prominent expressions of religiousness and fertile models and exemplars of redemptive activity can be seen to abound" ("Redemption" n. pag.). ${ }^{27}$ That having been said, Spider-Man is a film very concerned with atonement. The central plotline sees high-school nerd Peter Parker gaining super-powers after being bitten by a genetically engineered spider. Later, when he fails to use them to stop a criminal, his uncle is killed as a result. His subsequent actions, fighting crime at all levels from petty theft to grand larceny, are undertaken in an effort to atone for his failure to use his great power responsibly. Niall Richardson argues that the film is "on various levels, a Biblical allegory" (694). Apart from overt religious references, Richardson finds this allegorical reading of the film in the way it deals with guilt and shame. Drawing on the separate theoretical works of Eve Kosofsky Sedgwick and Steve Connor, Richardson defines guilt as an objective quality attached "to specific deeds or actions" (698) such that a person can be guilty of having done something. Shame is an internal quality. Richardson remarks that "a subject cannot be separated from his shame; he is his shame" (698). This leads him to conclude that "Christianity is such a popular and convenient religion because it offers the opportunity of transcribing shame into guilt and temporarily expunging it" (698). Whether or not one agrees with that assessment of Christianity, the ultimate conclusion Richardson reaches is that "Spider-Man is constantly atoning for his guilt for the death of Uncle Ben" (699).

\footnotetext{
${ }^{27}$ For a more comprehensive look at redemptive themes in Hollywood cinema, see Deacy Faith in Film.
} 
Thus, the film can be seen to exist in two parts with the death of Uncle Ben serving as the point of demarcation between the two. Before that point, Spider-Man is selfish, and after that point he is selfless. In the second half, his selflessness is driven by a need to "expunge" his shame for his behaviour in the first half and its consequences.

Wilson Koh argues that the film is a nostalgic film in the sense articulated by Fredric Jameson, which is that it is "historicist rather than historical" (The Cultural 130). In other words, Koh sees the mise-en-scène of the film actively creating "idealized interpretations of the past" (737) such that the film ultimately avoids identification with the post-9/11 trauma the city-and indeed the nation-suffered, such that the film "provides its audiences with an appealing better-than-real illusion to escape into" (738). While there is certainly a nostalgic feel throughout much of the film, even Koh acknowledges that there are still overt connections to the events of 9/11 and the aftermath. For him these connections are limited, yet his citation of a comment which establishes connections between the film and 9/11 shows that audiences did indeed notice such parallels (744). It is arguable, however, that the film bears pervasive traces of the events of $9 / 11$, and it is precisely because it does that it resonated so strongly with US audiences. In order to understand why audiences responded to the film, it is necessary to consider the narrative split with regard to the United States during the 1990s, particularly with regard to the Clinton Doctrine.

On February 26, 1999, President Bill Clinton delivered a speech that has been interpreted as signposting the key principles of his presidency. In that speech, Clinton made the following remarks:

"The question we must ask is, what are the consequences to our security of letting conflicts fester and spread. We cannot, indeed, we should not, do everything or be everywhere. But where our values and our interests are at stake, and where we can make a difference, we must be prepared to do so. And we must remember 
that the real challenge of foreign policy is to deal with problems

before they harm our national interests" ("Remarks" n. pag.).

While it does have some similarities to the Bush Doctrine, it does not position the United States as a guardian of the world; the United States is not the Chosen nation, to use the language of cultural violence. Instead, it suggests that the United States will absolutely intervene in foreign affairs - with military force even-provided there is a clear benefit for the nation. This is not a selfish position, so to speak, especially when considering that at the time of the speech the United States was comprised of almost 300 million people. However, when treated as a single entity-the United States - the Clinton Doctrine can be seen as self-serving. The US will do only that which threatens its "national interests," which are nebulously defined. In terms of Spider-Man, then, the selfish first half of the film is the equivalent of the Clinton Doctrine.

The US emerged from the Cold War as the sole super-power, and Clinton, according to Krauthammer who chastised him for it, sought to appease lesser nations rather than act unilaterally and bear the mantle of power proudly (n. pag). The Clinton Doctrine bears this out, as rather than asserting the (super) power of the United States onto the nations of the world, ostensibly to defend them, it guards its power. This is, of course, in direct contrast to the Bush Doctrine which, as defined by Krauthammer, overtly seeks "to extend peace by spreading democracy and free institutions" (n. pag.). It is necessary, though, to note the links between the two. For instance, the Clinton Doctrine essentially legitimises military interventions, a stark shift from the positions informed by the Vietnam syndrome which made warfare shameful. In fact, the Clinton Doctrine so clearly advocated the strategic use of the US military that commentators such as Michael T. Klare, defense correspondent for The Nation, cautioned of the ultimate end it might lead to. As Klare wrote in 1999, in the wake of the bombings during the Kosovo War,

"If the newly hatched Clinton Doctrine is not repudiated, the bombing of Yugoslavia may be only the first in a series of recurring 
overseas interventions - a prospect that should galvanize peace and disarmament groups across America" (n. pag.).

While the Bush Doctrine has ultimately proven those concerns to be quite valid, the military aspect of the Bush Doctrine only began in earnest in the wake of $9 / 11$, and it was primarily motivated by shame.

While many have attempted to place blame for the attacks of $9 / 11$ on people on both sides of the political spectrum, there is no definitive locus for blame; the attacks happened due to any number of interrelated issues. However, the ambiguity of the rationale is not sufficient to appease the immediacy of the feelings awakened by the images of destruction the attacks produced-fear, anger, hate, and more. These feelings were exacerbated by suggestions that the attacks may have been preventable. For instance, in 2005 the United States, via the Justice Department Office of the Inspector General, released a report that assessed the pre-9/11 performance of the FBI and concluded that "[their] review found significant deficiencies in the FBI's handling of intelligence information relating to the September 11 attacks" (A Review Chapter 6, n. pag.). From this, it can be argued, a sense of shame arose. While that shame includes regret over not using military force more proactively-or pre-emptively to use the language of the Bush Doctrine-it is not predicated upon military involvement. Instead, the shame, much like the Bush Doctrine, is predicated upon the notion that the United States has both great power and great responsibility. Being the bearer of that power, then, the United States is obligated to work in any capacity it can to prevent events like the attacks of $9 / 11$ no matter where they might happen on the globe, in order to atone for the shame of $9 / 11$. The response to $9 / 11$, then, particularly the invasion of Iraq in 2003, was a response to that shame, and Spider-Man, released in mid2002 , represents an articulation of those dreams before they came to pass. One major difference between the Bush Doctrine and Spider-Man that must be addressed is the concept of pre-emptive direct violence. Spider-Man fights crime, but he only uses his powers in response to direct violence, as is seen in a montage where he stops robberies and other crimes. Even when he is being bullied in school, 
he only attacks after he has been attacked. Conversely, as spelled out in the Bush Doctrine, it is expected that the United States will sometimes need to strike first, particularly if the stakes are high enough. Despite that difference, the film still dreams of the application of the Bush Doctrine.

\section{Spider-Man and Iraq: Guilt After 9/11}

As noted above, Richardson argues that Spider-Man is able to "expunge" shame by turning it into guilt (698-699). To do this he claims that Spider-Man "must therefore continuously protect the innocent from the thugs and criminals of the city" since he has "pleaded guilty to the death of his Uncle Ben" (699). Richardson builds a larger argument, then, that the shame that led to the death of Uncle Ben was his shame over pursuing his selfish (and base) desire for Mary Jane (699). In terms of the two halves of the plot, then, the first half is retroactively one of shame, while the second is one of guilt, with a sense of atonement as well. The pre-9/11 period of the Clinton Doctrine was a time of shame, which was largely an extension of the Vietnam syndrome. During this time the US monitored its own well-being and, as discussed above with the Clinton Doctrine, acted selfishly, so to speak. This shame was largely retroactive since what it failed to do was to prevent 9/11. Whether or not $9 / 11$ was actually preventable is not important here since there has been sufficient doubt cast on the argument that it was unpreventable. It is important, however, that the doubts surrounding the preventability of $9 / 11$ are focused on the military. Thus, the shame of the Vietnam syndrome and "victory culture" as a whole became a major factor in considering the events of 9/11. This was particularly the case in the rhetoric utilised by the Bush administration which brought military intervention to the fore. Engelhardt ties this directly together with victory culture when Bush said he wanted bin Laden "'Dead or Alive'" (313). In terms of deeds, the almost immediate invasion of Afghanistan in October of 2001 showed that rhetoric and action were quickly joined. As with Spider-Man, the violence in Afghanistan could be interpreted as a transcription of shame into guilt. The United States felt shame for not securing its borders. However, as with the crime-fighting Spider-Man performs, invading Afghanistan allowed the shame to 
become an admission of guilt. Yet as with Spider-Man, the protection must be continuous and explicit. Thus the war in Afghanistan, which is still being waged a decade later, was not sufficient since the visibility of the protection ebbed.

Accordingly a new target needed to be named, which is to say a new threat had to be offered to the public. Along those lines, Bush remarked in his 2002 State of the Union Address that in the new world of us versus them, "the price of indifference would be catastrophic" ("President" n. pag.). Iraq was presented as the next major threat, and for much of 2002 the Bush administration pushed for war. However, as Carroll writes, "The war against Islam abroad became a war against dissent at home" (25). While many debates have taken place which ask whether the Iraq invasion was a "war against Islam" -indeed many of the anxieties that Spider-Man addresses are about targeting a foreign Other-the duality of Norman Osborne as both Self and Other suggests that the anxieties in the film are simultaneously about the fear of an internal Other. Specifically, through the defeat of the Green Goblin/Norman Osborne, the audiences of the film were able to "dream" of a United States where dissent against the mythic United States, both foreign and domestic, was quashed.

As discussed above, the true Other of Spider-Man is not a figure who would traditionally be positioned as an Other, but instead has nearly all the same qualities of the hero. The key difference is with regard to their positions on power. Peter Parker/Spider-Man chooses to use his responsibly for the good of society while Norman Osborne/Green Goblin wants to use his for his own gain. While the Self and Other in the film are not directly analogous to the Bush and Clinton Doctrines respectively, there are strong similarities. For instance, the Self, Spider-Man, seeks to impose his ideology upon the citizens of New York City. Those citizens are roughly divided into upstanding citizens and criminals. Due to this binary opposition then, those who would not support Spider-Man would essentially be the same as those who oppose him, an echo of the us-or-them statement made by Bush on September 20, 2001. Of course the ideology Spider-Man advocates is the central tenet of the film, that power demands responsibility, and it is quite different from the three principles of the Bush Doctrine which position the United States as 
enforcer of peace, maintainer of peace, and extender of democracy and free institutions (Krauthammer "The Bush Doctrine" n. pag.). However, the key connection remains that both Spider-Man and the Bush Doctrine aim to use their power, ostensibly, for good. Again, this connection is based upon a mythic version of the Bush administration rather than a realistic assessment, but it is the mythic version that was often dealt with in mainstream media, media which perpetuated myths such as the image of Bush as a cowboy. As for the Other, the Green Goblin, his agenda is the accumulation of power for personal gain. This frame was similar to the one used to position Saddam Hussein as a mad tyrant. However, the internal threat was not a power mad tyrant. Instead, the Other within the Self would be those that opposed military action in Iraq. In terms of atonement, they would effectively prevent the shame of non-intervention from being transcribed into guilt. This would theoretically leave the country doubly shamed as it would feel shame for non-intervention, but it would also, paradoxically, still feel the shame for intervention. Thus, those who opposed the war would be treated as Others, and indeed this was the case.

This was made clear in the 2002 controversy surrounding the director of the National Economic Council, Lawrence B Lindsey. After initial estimates of the cost of the Iraq War were announced, Lindsey, speaking with the Wall Street Journal, estimated that the 50 billion USD estimate was far below what the actual cost would be, which he calculated would be at least 100 to 200 billion USD (Davis "Bush Economic Aide" n. pag.). Although other reasons were given for his resignation just a few months after his criticism of the budget, the Christian Science Monitor observed that "the White House was certainly displeased with his comments" ("West Wing Loyalty" n. pag.). However, given the binary world that Bush defined in his rhetoric after $9 / 11$, it is reasonable to suggest that the comments made by Lindsey about the budget of the invasion of Iraq essentially established him as an opponent of the nation, an impediment to the continuous process of expunging shame. Whether or not his resignation was motivated by that particular statement, the fact that other members of administration criticised his statements suggests 
that his dissenting voice needed to be quelled. History has, of course, proven Lindsey to be correct in his criticism of the budget.

What ultimately emerged, then, was a system that attempted to be a unitary state system in which Galtung argues the cultural violence of nationalism was combined with "steep Self-Other gradients" which resulted in "the ugly ideology of the nationstate" ("Cultural" 299) where "killing in war is now done in the name of the "nation"" ("Cultural" 299), something very clearly evidenced in the official rationale behind the wars in Afghanistan and Iraq. In terms of the state system articulated by Galtung (60-69), despite the overt patriotism that led many to see the United States as the type of unitary system Galtung describes, this apparent unification was the result of the Bush administration defining the Self. As noted previously, a key aspect of that definition was its mobilisation of the crusader mindset. Accordingly, although the crusade was a war abroad, it engendered a sense of paranoia at home. Again, as Spider-Man shows, that paranoia had been normalised by mid-2002 as, unbeknownst to the hero, the villain was both Self and Other. Since the country was not actually unified in its support of Bush and the Iraq invasion, violencelargely cultural and structural-was the result, as predicted by the state system model Galtung builds. Beneath that violence, though, remained the struggle with shame and guilt that Spider-Man depicted and, more importantly, showed audiences a dream of resolving. 


\section{Chapter Eight \\ The Failure of the King:}

The Lord of the Rings: The Return of the King

(2003)

In 2002, Spider-Man articulated the dreams of a nation embroiled in a worldwide conflict that President George W. Bush had labelled a "crusade." The film showed the hero triumphant and the glory of the United States was restored through the defeat of external enemies who were simultaneously internal. The double-victory of Spider-Man pointed towards a recuperation of nationalism such that the United States was once again a noble Self defined in opposition to an evil Other. As discussed in the previous chapter, however, the film did not end in a world free of violence. At the conclusion, Spider-Man is perched high above the streets of New York City vigilantly waiting for an Other to assault the city once again and to possibly infiltrate the Self. For him to be in that position, though, it was crucial that he had first defeated the Green Goblin. Even if only temporary, it showed that a war against evil could actually be waged. Thus Spider-Man ended with a sense of vigilance and suspicion; the Other could strike at any moment, and in countless devious ways in this new world order. Yet there is no sense that the war against evil would ever be won. The watchful eye of Spider-Man-or one like him - it is suggested, always will be needed. However, this seemed to stand in contrast to the rhetoric that framed the War on Terror as a long, but ultimately finite struggle. On May 1, 2003, it seemed that the first major battle against terror had been won.

On that day, Bush landed on the aircraft carrier, the USS Abraham Lincoln, and made a speech in which he announced that "Major combat operations in Iraq have ended. In the Battle of Iraq, the United States and our allies have prevailed" ("President Bush" n. pag.). Praising the US military, he said to them that "Because 
of you, our nation is more secure. Because of you, the tyrant has fallen, and Iraq is free" (“President Bush" n. pag.). However, Bush added that:

"The war on terror is not over, yet it is not endless. We do not know the day of final victory, but we have seen the turning of the tide. No act of the terrorists will change our purpose, or weaken our resolve, or alter their fate. Their cause is lost. Free nations will press on to victory" ("President Bush" n. pag.).

Thus, unlike the narrative of Spider-Man, which presented a dream of eternal vigilance, Bush argued that a long period of vigilance would ultimately end, a fact reinforced by the allusions in this speech - "the turning of the tide" - that Engelhardt argues proves it "had World War II on the brain" (311). That World War II had such a victorious end in Europe-eliding, of course, the atomic bombing of Japan-suggests that the speech articulated a desire for total victory. This is the same dream that The Lord of the Rings films presented.

The Lord of the Rings trilogy was finally unveiled in December of 2001 when the first film, The Fellowship of the Ring, premiered. A year later, The Two Towers was released, and in December of 2003, the final film, The Lord of the Rings: The Return of the King, opened theatrically. ${ }^{28}$ While the initial two films were the secondhighest domestic grossing films in 2001 and 2002 respectively, the franchise would only take the highest spot with the final instalment. In that film, the dream of a state of peace was shown to be earned after a crusade against evil. The conflict in the film followed the trends established by the films already discussed, namely the shift of the Other towards, and within the Self. However, The Return of the King changed the landscape even further by making the Self a multi-faceted entity. It is this element which forms the foundation of both the dreams and nightmares articulated by the film.

\footnotetext{
${ }^{28}$ Extended editions of all three films were subsequently released on DVD. Since the scope of this analysis is the theatrical release of various films, the extended editions and all supplementary footage will not be the direct focus of analysis.
} 
Despite the escapist nature of The Return of the King, it has been noted that the film bears strong connections to the War on Terror (Gelder 105-109; Kellner "The Lord" 19). The analyses which draw those parallels, however, do not take into consideration the ways in which the film dreams of a world that a victory in the War on Terror promised to deliver. Accordingly, my analysis of The Return of the King will discuss the ways in which the dream of peace articulated by the film resembles a Pax Americana which was presumed to be the goal of the War on Terror, the "crusade" Bush saw himself as leading. I will begin, then, by examining the concept of Pax Americana as it informed the War on Terror as well as the Bush Doctrine. The focus will be on determining how the notion of a Pax Americana relates to the tripartite concept of violence established by Johan Galtung, particularly cultural violence ("Cultural", Peace). With that relationship explored, the concept of Self and Other in The Return of the King will be studied using the work of Vladimir Propp on folktales. Given the fact that this conception deviates from the trends established by both pre- and post-9/11 films in terms of the definition of the Self, particular attention will be given to that divergence. To emphasise the importance of that change, it is useful to understand how typical the film otherwise is in terms of violence. Accordingly, my analysis will then focus on the violence of the film itself. This will primarily involve an exploration of direct and structural violence, showing how the redefinition of Self does not noticeably affect those representations. Instead it implies a new avenue of violence. Lastly, I will show how the different path of violence suggested in The Return of the King is one which the Bush administration had already utilised in the post-9/11 wars. Unlike the film, though, which is largely sanitised in this regard, censoring of the War on Terror would only succeed for a limited period of time. What is more, since that war lacked the truly definitive victory of which the film dreamed, it was one which could not be perpetually sustained. Accordingly, this chapter will conclude by arguing that the War on Terror ultimately broke from the dreams articulated in the film. 


\section{Pax Americana: Planning for a New World Order}

In 1997, several prominent conservatives including William Kristol, formed The Project for the New American Century. The Project is very closely related to the Bush Doctrine in its goals, emphasising military strength and interventionist foreign policy. The similarities between the two are unsurprising given the fact that future Vice-President Dick Cheney was one of the signatories on the 1997 Statement of Principles issued by the Project. In that document, the Project articulates its aspirations for the American government as follows:

\footnotetext{
"America has a vital role in maintaining peace and security in Europe, Asia, and the Middle East. If we shirk our responsibilities, we invite challenges to our fundamental interests. The history of the 20th century should have taught us that it is important to shape circumstances before crises emerge, and to meet threats before they become dire. The history of this century should have taught us to embrace the cause of American leadership" ("Statement" $n$. pag.).
}

In short, the Project argues that because the United States was the sole superpower in the post-Cold War era-making it the sole super-power of the world-it essentially has a claim to that world. Accordingly, the United States is defined as a Self to all other nations in the world in an unequal relationship. Other nations may join that Self, but only in submissive positions where they concede to US authority. Those that do not make that concession remain the Other. This stance is made even clearer in a report released by the Project in 2000 titled Rebuilding America's Defenses.

In that document, four missions are established for the United States, all designed to assert the military prowess of the United States. They are defending the homeland, maintaining a standing army prepared to "win multiple simultaneous large-scale wars" (Rebuilding 6), conducting "constabulary duties" (Rebuilding 6) in foreign nations, and "[transforming] U.S. armed forces" (Rebuilding 6) by 
integrating new technologies into the military. These missions are explicitly driven by the geo-political landscape of the post-Cold War era, which the report defines as unipolar, reasserting the dominance of the US Self. Most important, all of these goals fall under a single "strategic goal," which is to "preserve Pax Americana" (Rebuilding 2). Of course the very notion of a Pax Americana is one which is underpinned by violence.

As discussed in previous chapters, Johan Galtung defines some cultural violence as being ideologically driven ("Cultural" 298-299). In describing the United States as the only super-power in opposition to the rest of the world, the ideology of that claim is one of nationalism. The United States is the Chosen Nation, so to speak, while all others are Unchosen. In this configuration, they may choose to align themselves, in a subservient fashion, with the United States, but until they do so they are the Other and not the Self. If they do not, and if they remain the Other, then they risk being defined as a threat by the United States and structures of violence against them might ultimately legitimise direct violence. This conceptualisation of the world is very similar to the one argued by Noam Chomsky where he asserts that US foreign policy only makes sense when paired with the notion that the United States owns the world ("We Own" n. pag.). The result in that case resembles violence founded in the concept of the "nation-state" that Galtung ("Cultural" 299) articulates. As the list of missions compiled by the Project for the New American Century suggests, particularly with regard to their predication upon foreign military interventions, the nation-based violence described by Galtung is sanctioned by the Project. It is important to consider, though, that this violence is not just direct. As the Project warns in Rebuilding America's Defenses, "the failure to prepare for tomorrow's challenges will ensure that the current Pax Americana comes to an early end" (13). Preparing for those challenges does not simply entail military involvement, but an information campaign that these same reports show the Project itself conducted. Thus, the violence encouraged by the Project encompasses the direct, structural, and cultural aspects of violence, all designed to assert and protect the global inequities which maintain the United States as a worldwide Self. Given the fact that cultural and 
structural violence are also necessary, it is unsurprising that connections have been made between Pax Americana and US hegemony.

Hegemony itself is a multifaceted concept. As David Grondin notes, "the term 'hegemony'...has the capacity to encompass both the Gramscian concept of consensus and persuasion as well as the classical view that highlights the role of military power and coercion in the evolution of US foreign policy" (1-2). While the former framing of the term is important to this thesis as it heavily informs the diagnostic critique of Douglas Kellner (1995), it is the latter conception of hegemony that is most useful here as the Pax Americana is heavily predicated upon militarism. As Grondin also observes, September 11 provided the justification for policies aimed at expanding the American empire. Of the attacks of 9/11 he writes, "neoconservative analysts could now trumpet a new-found political will intended to translate the vision of global dominance into reality" (15). What is more, he argues that

"With the obvious evidence of American vulnerability, it became easy to legitimize a course of action that, absent the terrorist attacks on the country, would have smacked of old-fashioned imperialism" (15-16).

Thus 9/11 served as a gateway toward a global Pax Americana. Grondin directly connects the push towards that goal to the 2002 document, The National Security Strategy of the United States of America, which echoes many of the same ideas which had been put forward previously by the Project for the New American Century.

Like the earlier Rebuilding America's Defenses, the 2002 National Security Strategy report defined the United States as the sole Self in the world. However, rather than protecting the interests of the United States, the report focuses on the idea of freedom, an angle which had more public appeal. This is evident early in the report through the following statement: 
"People everywhere want to be able to speak freely; choose who will govern them; worship as they please; educate their childrenmale and female; own property; and enjoy the benefits of their labor. These values of freedom are right and true for every person, in every society-and the duty of protecting these values against their enemies is the common calling of freedom-loving people across the globe and across the ages" (The National Security iv).

In short, the document presents the mythic US Self, one of unbridled liberty, as the appropriate model for the world to follow. The means by which the expansion of this model will be accomplished are suggested in the statement which immediately follows the previous one:

"Today, the United States enjoys a position of unparalleled military strength and great economic and political influence. In keeping with our heritage and principles, we do not use our strength to press for unilateral advantage. We seek instead to create a balance of power that favors human freedom: conditions in which all nations and all societies can choose for themselves the rewards and challenges of political and economic liberty" (The National Security iv).

The mention of the strengths of the United States, particularly its military prowess, points toward multiple forms of violence. The most prominent, though, remains the reiteration of the United States as a global Self despite the apparent advocacy of a "balance of power that favors human freedom" (The National Security iv). Given the push for a Pax Americana, it would seem that unbalanced power is what is desired. Accordingly, the nation-based structures of violence discussed above, such as the privileging of the United States, are maintained despite their reframing within an apparent context of structural peace. This rhetorical hypocrisy is even more apparent considering the passage of the USA PATRIOT Act in 2001 as it actively curtailed the freedoms of the citizens of the United States, significantly challenging key elements of the Bill of Rights, including those protecting citizens from illegal search and seizure as provided by the Fourth Amendment to the US 
Constitution. This would ultimately manifest itself in debate over illegal wiretapping authorised by the Department of Justice. What these issues suggest, however, is that the binary Self/Other relationship established by the Bush administration in its rhetoric was not as transparent as it seemed.

In his rhetoric, Bush positioned the enemy Other in binary opposition to the United States by casting them as haters of freedom. However, the USA PATRIOT Act suggests that to effectively fight the Other the government must restrict the freedoms of the Self. Logically this would mean that the Self is engaging in the same behaviour which it uses to define the Other. Furthermore, the imposition of American military authority around the globe indicates that the United States is curtailing international freedoms by forcing other nations into positions of subservience in acknowledgement of the US as Self. It is important to note that in both instances, the differences between the Self and the Other are diminished. This is a position reinforced by some commentators such as John Milbank who observed that the War on Terror is "a new sort of war without aim or a foreseeable end, often to be fought in secret" (310). While the "endless" nature of the war merits further discussion below, the key point here is the idea that a "secret" aspect of the war suggests that some behaviour must be hidden from the Self. Thus, to preserve a Pax Americana, it is suggested that the Self may need to engage in tactics that are not befitting of the Self. This is clear in the legislation signed into law by Bush, such as, but not limited to, the USA PATRIOT Act, which brought the Self and Other into close alignment by way of violence. The increasing parity between Self and Other that such laws created were justified by the fact that, as Bush said on the USS Abraham Lincoln, the "war on terror... is not endless" ("President Bush" n. pag.), meaning that sacrifices must be made to reach the ultimate state where the mythic US Self stands alone. While the question of whether the war to achieve that end can ever actually be won is highly debated, the fact that the Self was overtly becoming like the Other was clear, and it is that same movement of Self toward Other through violence that is dramatised in The Return of the King. 


\section{Becoming like "them": Heroes, Villains, and the Self and Other}

The Return of the King is a very traditional story. This was intentional as its original author, J.R.R. Tolkien, drew heavily upon mythological and folkloric constructs. While the film has changed some of the elements of the books-the character Arwen (Liv Tyler) plays a minor role in the book, but is a featured player in the film - the structure of the film maintains the roots the story holds in traditional storytelling. Specifically, the seven spheres of action identified by Vladimir Propp (79-83) and discussed earlier in Chapter Six, can all be found in various guises in The Return of the King. Some of the protagonists of the film, Aragorn (Viggo Mortensen) and Frodo Baggins (Elijah Wood), for instance, are both heroes, while others, Samwise "Sam" Gamgee (Sean Astin) and Gandalf the White (Ian McKellan), though heroic, are primarily helpers. Again, though, Propp makes clear that these categories are not discrete, so there is often overlap between characters and functions (80-83). This is the case in The Return of the King, particularly given the fact that the film tells two concurrent and interrelated narratives.

It should be noted first, though, that the film is not an "American" film per se. Tolkien, the original author, was English, while the film production itself was located in New Zealand and was helmed by New Zealand director Peter Jackson. Although the production crew was populated with talent from around the world, these factors are not as important as they might seem. This is because The Return of the King, like Harry Potter and the Sorcerer's Stone, holds such strong ties to the universal elements of folktales and mythology that it was something US audiences had embraced again and again; it was not foreign. What is more, it fit into the blockbuster format, and as the domestic box office grosses for The Return of the King have showed, it worked with the form admirably. Thus, despite its international pedigree, audiences in the US were familiar with the journey the heroes in the film undertake, and how they face severe trials which test their mettle each step of the way. However, even as the key narrative elements of the film are preserved, certain other aspects have changed, namely the articulation of the Self and Other. To understand those changes, it is useful to re-examine the spheres of action defined by Propp. 
The Return of the King finishes the saga of The Lord of the Rings, concluding its two major narratives. One is a story of military glory; the other is about the destruction of the enemy by way of the central focus of the film, a ring. The first details the journey of Aragorn (Viggo Mortensen) as he returns from the wilderness to assume his rightful position as king of Gondor, also called the White City, the capital of the free nations. To do so, he must lead the armies of those nations to victory against the forces of Sauron, an evil sorcerer and warlord. The latter story tells of the quest of Frodo and Sam as they attempt to destroy the One Ring, which Sauron wants back as it will give him ultimate power. While both strands of the plot serve the same goal of defeating the Other, the ways in which they articulate the relationship between the Self and the Other are very different. In the story of the return of Aragorn, the Self is very traditional: a warrior, masterful with direct violence, but careful in its use. Conversely the Other is less adept at direct violence, but more numerous and more willing to use it to defeat the Self. This relationship is similar to that seen in many of the films already analysed, particularly those in the pre9/11 era, such as Saving Private Ryan, Star Wars: Episode I - The Phantom Menace, and in particular Independence Day, whose president returns to power in much the same way as Aragorn does. Like those films where the Other is decisively defeated by the end, so too is the Other vanquished in The Return of the King. However, the direct violence which achieves that end is only partially responsible for the final victory in this film. The triumph is found primarily through the other narrative and it is there that the Self and Other come together.

In their quest to destroy the One Ring, Frodo and Sam join up with Gollum (Andy Serkis), a character suffering from multiple personality disorder. In terms of his Self/Other dynamic, Gollum strongly resembles the Green Goblin from Spider-Man. Sméagol, the other personality, is conflicted about his position regarding the Self while Gollum is clearly constructed as evil. In Proppian terms, Gollum and Sméagol are both villains since they, like the Green Goblin, ultimately join the side of the Other. This is not the case in the previous film as Sméagol has moments where he genuinely attempts to help Frodo. In The Return of the King, though, the evil nature of Gollum/Sméagol is clear when they lead Frodo into a cave inhabited by a giant 
female spider in the hope that Frodo will be killed so that Gollum can have the Ring. Additionally, while the audience and Sam are both aware that Gollum is planning to betray Frodo, Frodo is not aware of this until it is almost too late. Again, this does engender a sense of paranoia, but given the overt markings of Gollum, who is a shrivelled monstrous figure, he is clearly distanced from the good protagonists. The reasoning behind the trust Frodo places in Gollum, then, is that Frodo has ceased to be able to recognise those signs. This is because Frodo, in effect, is a Self that begins to behave like an Other.

Throughout the film, Frodo increasingly becomes aligned with Gollum. At one point Sam attacks Gollum, accusing him of treachery, but Frodo intervenes. Sam remarks that Gollum "is a villain," and Frodo responds by chastising Sam, telling him that they need Gollum because "We can't do this by ourselves." This need increases as Frodo begins to become more like Gollum, coveting the ring and distrusting Sam. At one point he even goes so far as forcing Sam to leave their group. Ultimately Frodo is so much like Gollum that he chooses to keep the ring instead of destroying it. Despite that choice, Frodo lives while Gollum dies. This happens because Gollum, driven by greed, steals the ring from Frodo and, in careless celebration, falls to his death destroying the ring in the process. Frodo, though, because he is still part of the Self despite his proximity to the Other, is saved by Sam. Accordingly it is important to note that Frodo never reached the same level of Otherness that Gollum did. As a sequence at the beginning of the film revealed, Gollum murdered his best friend to get the One Ring from him. For Frodo to truly be like Gollum he would have had to kill Sam, but of course he does not, and that is who saves him. Even so, by choosing to keep the ring, he betrays the Self in a way that aligns him with the Other even if he does not fully become the Other.

In all of the films analysed so far, pre- and post-9/11, there have been no instances of the Self aligning with the Other in this way. There have been moments where the Self was weak and caused harm as a result-Private Upham (Jeremy Davies) in Saving Private Ryan is the key example of this. There have been instances of the opposite, as discussed in the chapters on the post-9/11 films where the Other masqueraded as Self, but in both The Sorcerer's Stone and Spider-Man the Other 
was found out and purged from the Self by a noble agent of the Self. That discovery re-established the division between Self and Other, but the very fact that such a passing was possible created an atmosphere of paranoia. This related directly to the concept of the crusading mindset detailed by James Carroll (24-25). That paranoia, though, was not directed at the hero, but the ancillary characters of the Self, such as Gollum. While the positioning of Gollum in the film in an alliance with the Self suggests suspicion is still crucial, the fact that the hero himself is like the Other points not to an increased paranoia, but to a completely new perspective on the relationship between the Self and the Other.

The Self in the Return of the King is not uniform. While all elements of the Self are devoutly opposed to the Other, they exist in various positions and proximities to the Other. These variations are largely defined by the tactics the characters choose to employ in combating the Other. For example, Aragorn wages a just war against the evil armies of Sauron, always remaining a beacon of hope for the free people. While he does enlist the help of the Army of the Dead, a group of spirits who abandoned a king in a previous battle and were cursed as a result, his allegiance with them is one of duty and oath such that his own Self is not compromised. Further, when the Army of the Dead fulfils their obligation to him, he releases them from their servitude, maintaining his honour. Gandalf is more of a marginal figure. While he is clearly aligned with the good Self, helping to lead the armies of the free peoples, his knowledge of the enemy brings him closer to the Other, but, as a result, makes him a more potent foe. At the same time, though, it distances him from the pure Self. Frodo, of course, is very close to the Other, almost becoming the Other at the climax of the film. Thus, a spectrum of Self emerges that sees the protagonists at various distances from the Other even as they remain identified with the Self, as shown in Figure 24. Otherwise stated, the Self/Other paradigm becomes detached from the Hero/Villain paradigm detailed by the Proppian spheres of action. 


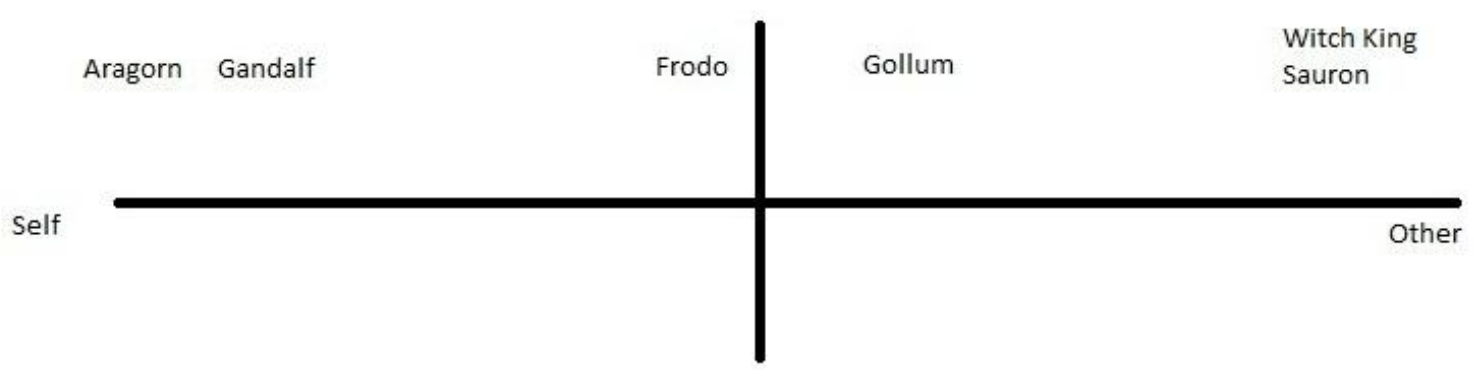

Figure 24 - Main characters on Self/Other spectrum

According to Propp, the Hero is the one who "[departs] on a search" (80) and "[reacts] to the demands of the donor" (80), who in turn is the one that prepares the hero for a journey or gives him or her a magical item, in this case the Ring; the hero may also be involved in a wedding. The villain is the one who fights or struggles with the hero (79). In the case of Frodo, he is a hero for every moment of the film even when he attempts to keep the ring. It should be noted that while some, such as Christine Brooke-Rose, argue Frodo is on an anti-quest, she also argues that this "does not affect the quest structure" (235), and subsequently maintains the status of Frodo as a hero. Thus the Proppian model still applies. So even when Frodo puts on the ring and is not acting in the best interests of the Self, by drawing on the larger concept of functions in the fairytale that Propp details (79$80)$, it is clear that the decision to keep the Ring could be seen as a struggle between the hero and the villain, with the Ring representing the villain. What is more, it is through this struggle that Frodo is branded, another key function, when Gollum bites off one of his fingers. ${ }^{29}$ This marking ultimately leads to the defeat of those characters who inhabit the sphere of the villain-Gollum and Sauron-as it is through that process that Gollum gains the ring and destroys it. This construction suggests a binary division between heroes and villains, as seen in Figure 25.

${ }^{29}$ See Propp, Chapter III for more on the functions of characters within fairytales. 


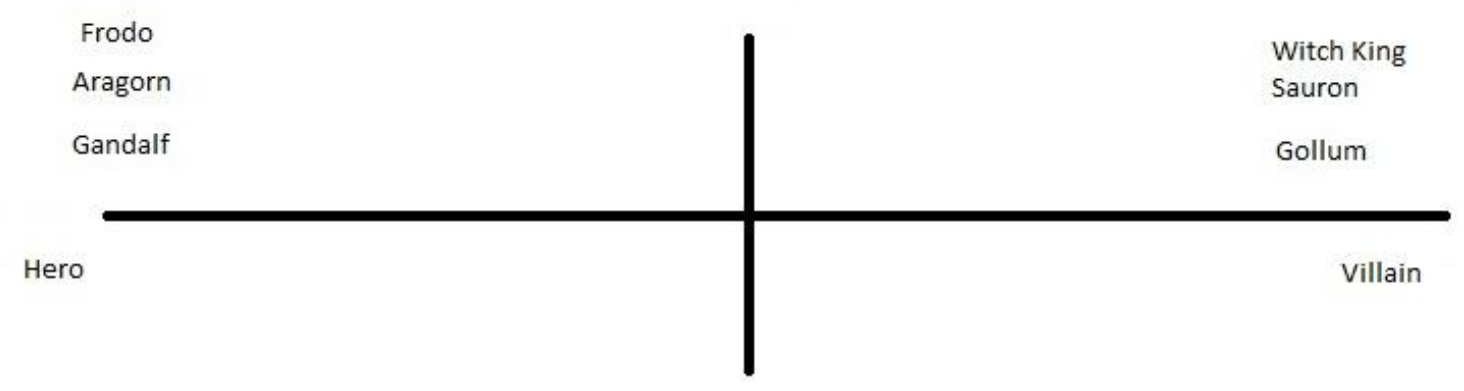

Figure 25 - Main characters on Hero/Villain spectrum

What this dissociation between Self/Other and Hero/Villain indicates is a validation of behaviour that would not normally be associated with the noble Self. Again, in the film itself none of the characters who are identified with the Self do anything that would truly locate them within the realm of the Other-Frodo does not murder Sam and Aragorn always remains noble-yet the mobility of the Self along a spectrum toward the Other suggests a dramatic difference in the way the Self is defined. Specifically, Frodo, one of the heroes, behaves in a way that the film itself condemns, but the film maintains his position as hero regardless; his transgression is permitted as it serves the greater good. Thus, the film establishes an ethic wherein the ends-a peace dominated by the Self-justify the means even if the means cause the Self to be like the Other. It is important to be mindful of the fact that the film condones violence in a variety of ways already, structural in particular, but the redefinition of Self in this way expands the range of that support to forms of violence which are condemned. That having been said, it is necessary to understand that within the film, violence remains bound within the standard lines already present in the films previously analysed. To understand the significance of this expansion, it is useful to first examine the structures of violence the film condones as they reinforce the resemblance of the film to those that preceded it.

\section{"The Days of the Kings": Structural Violence as victory in The Return of the King}

When the One Ring is destroyed and the heroes triumph over the villains, the bifurcated plot is unified. All of the characters come together and slowly they bid 
farewell to one another. That point of narrative unification marks another key juncture for the film, which is the point at which direct violence disappears from the film. Before that point, the characters thrive on combat and are even defined by it. Both Meriadoc "Merry" Brandybuck (Dominic Monaghan) and Peregrin "Pippin" Took (Billy Boyd), two of the hobbits, become heroic through their deeds on the battlefield, with Merry helping to slay the Witch King. Furthermore, as noted above, Aragorn is only able to reclaim the throne of Gondor by raising and leading an army. Although Sam and Frodo do not participate in any of the major battles of the film, they still often engage in direct violence; they must do so to escape from a giant spider and a tower full of orcs, as well as to overcome Gollum at the climax of the film. After the ring is destroyed, though, an image of apparent peace, albeit a peace haunted by the spectre of militarism, is pervasive. This is clearest in the coronation ceremony of Aragorn, shown in Figure 26.

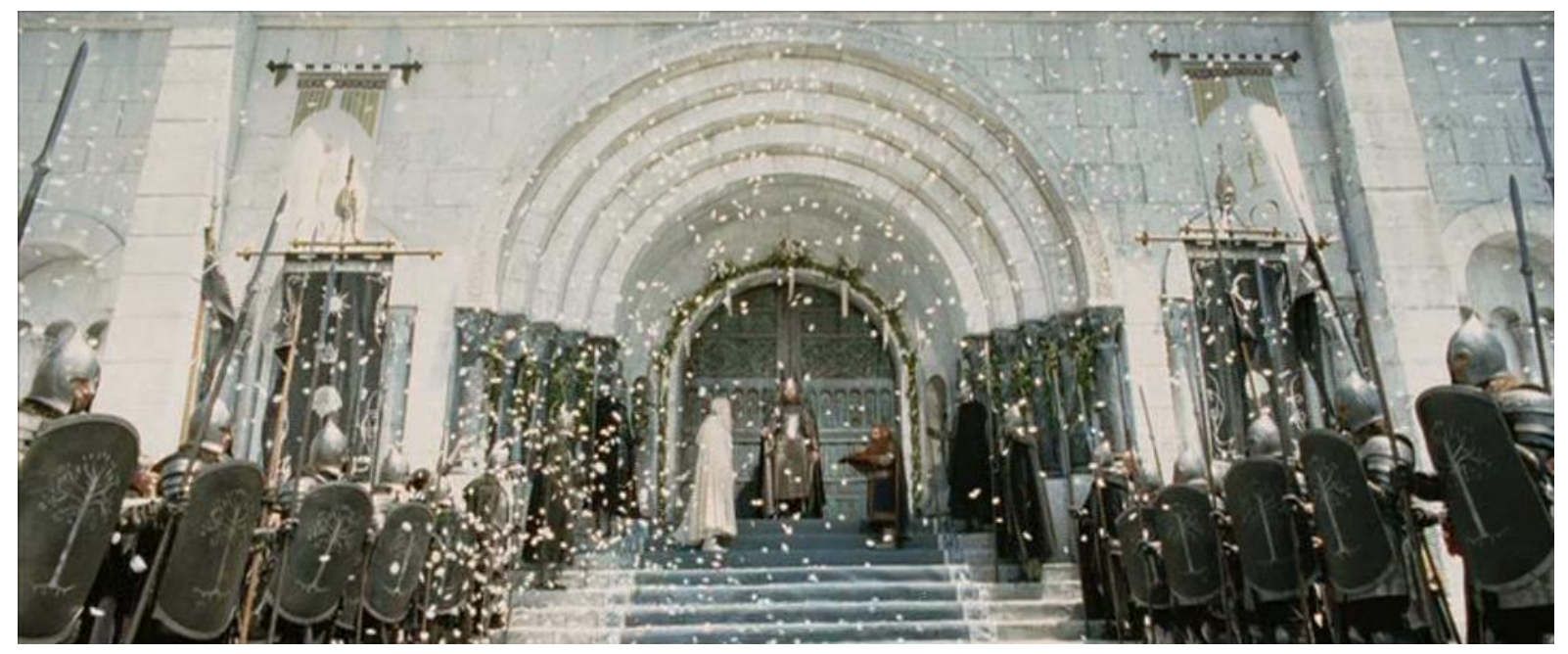

Figure 26 - "The Days of the King" in Return of the King

At the ceremony, Aragorn, now king of the free peoples, is crowned by Gandalf. At this point Aragorn speaks to the gathered crowds, saying, "This day does not belong to one man but to all. Let us together rebuild this world that we may share in the days of peace." This remark clearly signals the shift in the film, something also marked by the change in its visual palette from dark colours to bright whites. After singing a song in Elvish, Aragorn is reunited with his Elven lover, Arwen. Then he approaches the hobbits, who begin to bow, but he stops them, insisting instead 
that everybody bows to them. The hobbits are left standing as all the people around them bow. This sequence can be read in terms of structural peace as it suggests that in these "days of the king," as they are called in the film, inequities between races have been abolished, and that everybody, regardless of race, is equal. However, this apparent peace, much like the rest of the film, is filled with structures of violence, particularly those based upon gender, ethnicity, and class. Throughout the film, the character of Eowyn (Miranda Otto) stands as a figure of resistance against patriarchal oppression. She wants to fight with the men of her nation, but is repeatedly denied. She is told by her father and brother that direct violence is for men and not women. She defies the patriarchal order and fights in the major battle of the film, ultimately killing one of the chief villains, the Witch King. When she does so, she asserts her femininity by removing her helmet and proclaiming her gender. Kellner argues that in this moment she "[achieves] phallic power" ("The Lord" 35). Although direct violence is the means by which she overcomes the inequity of patriarchal order, which is problematic in terms of establishing peace, she does manage to establish gender equity. In fact, this points to a further issue of the film which is that direct violence is sign of power. Kellner articulates a similar notion when he writes that in the film "militarism is the privileged route to manhood and virtue," and that "the manly character takes up the sword" ("The Lord" 36). The equality Eowyn thus achieves is predicated upon performing in a stereotypically "manly" fashion, which entails performing acts of direct violence, something seen in previous films such as The Phantom Menace. As problematic as that might be in terms of direct peace, it is nonetheless a situation which supports structural peace, which is to say equality. However, the earned equity is thrown into question at the coronation of Aragorn where she is paired with warrior male, Faramir (David Wenham), as part of a traditional heterosexual couple. While there certainly could be nuances to the relationship that are not expressed in the brief shot of the couple, the image of Eowyn, no longer a warrior, but essentially subdued and domesticated through the relationship with Faramir is one which challenges structural peace even if it does not overtly support the structural violence of a patriarchal system. 
Interestingly, Lianne McLarty suggests that the film does not advocate a unified masculinity. She argues that "patriarchy is destroyed and replaced by male characters who do not seek power as a means of controlling others" (182), ultimately producing "anti-patriarchal heroes" (182). While some characters can indeed be read that way, Frodo in particular, it does not change the fact that their ascent to heroism is accomplished through direct violence, something strongly linked with traditional masculinity. As Kellner observes, "the trilogy on the whole is a celebration of military valor and heroism linked with valorizations of patriarchy, whiteness and hierarchy" ("The Lord" 31-32). This point is crystallised in the moment that Aragorn is coronated as leader of the free people. Whether he sought to have that power or not, the film suggests that he is the only rightful heir to the throne, thus reinforcing notions of patriarchal authority. This violence, which is again problematic, is not atypical of blockbuster cinema, as previous chapters have shown.

In terms of ethnicity, the film points towards a resolution of racial and ethnic tensions via the hobbits because they are presented as ethnic Others even though they are clearly included as part of the Self. The praise and acceptance they receive at the end of the film, then, suggests an overcoming of ethnic boundaries and a new age of ethnicity-based structural peace. However, a deeper analysis of the sequence reveals that it actually reinforces structural violence. Although the original stories do not indicate any particular ethnicity for the hobbits, the film presents them all as white. In fact, the only difference between them and the good humans in the film is their height. Thus a spectrum of whiteness is established, again similar to that articulated by Sander L. Gilman when discussing the painting by Edwin Long (221). Lianne McLarty connects the racial formations in the film to class observing that:

"the more a Middle Earth race is associated with the privileges accrued through learning and knowledge and with the refined cultural production, the whiter they are, almost whiter than white in the ethereal light of the Elves" (176). 
Conversely, she notes that "the lower levels of this hierarchy of whiteness are invoked through working class imagery (the Dwarves are miners)" (176).

Embedded within racial issues, then, are those of class, which is precisely one of the connections bell hooks suggests (7-8). While privileging whiteness in this way is problematic, it is made even more so in the way the film presents the inequity between the humans and non-humans as representative of all racial inequities, comparable, for instance, to the tensions between whites and blacks in the United States. By making a substitution in this way-a spectrum of whiteness in place of actual racial diversity-the film reinforces rather than challenges racism. As many, including McLarty (176), have observed, this is because the film maintains ethnic divisions.

In his assessment of the racial depictions in the film, Kellner emphatically comments, "Never before has Whiteness had such extravagant visual apotheosis, nor has it triumphed so completely in cinematic spectacle" ("The Lord" 34). This is evident in the fact that not only are all the heroic characters white, but whiteness is highly privileged by them. For instance, Gandalf the Gray dies in the first film and is reborn in a stronger and purer form as Gandalf the White, or the White Rider, as he is sometimes called, shown in Figure 27 . Later, he is tasked with defending the White City.

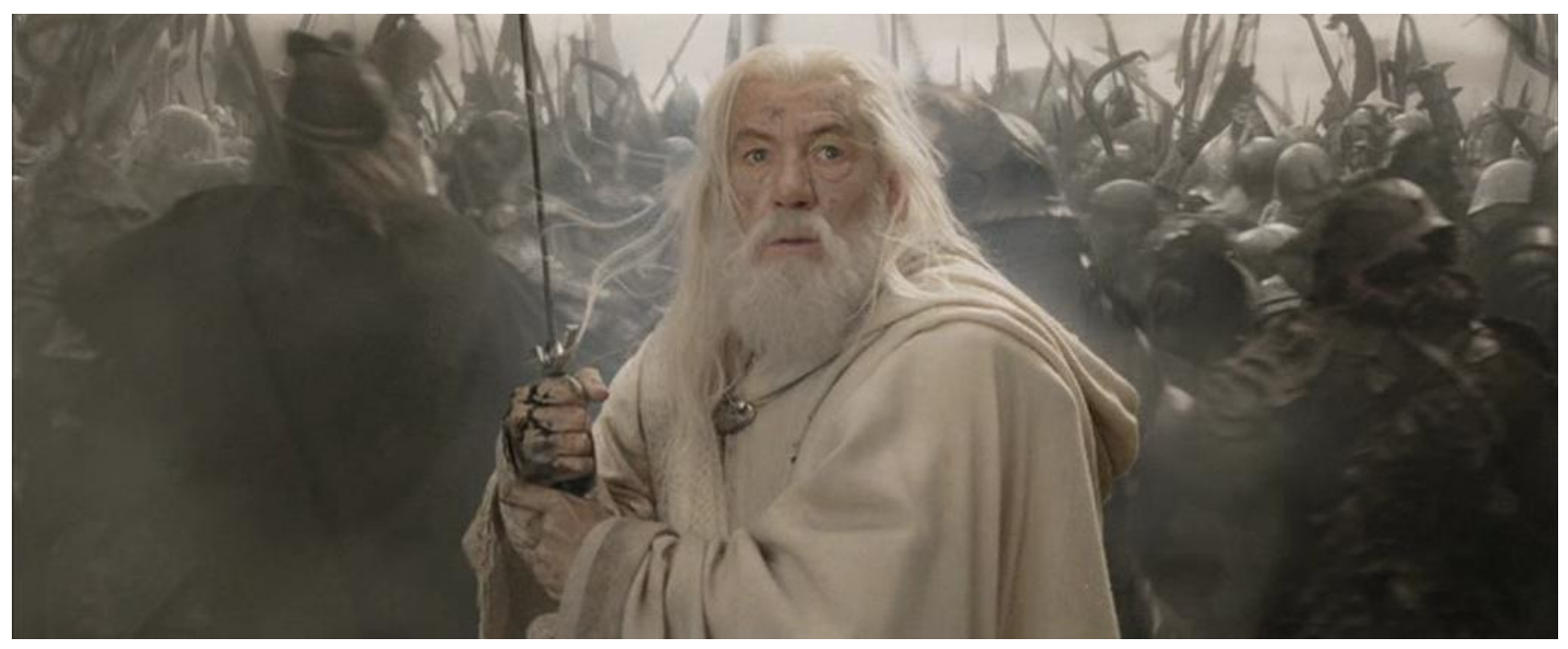

Figure 27 - The White Rider in battle in Return of the King 
Similarly, Kellner notes that Sauron is "described as a Dark Lord who lives in a Black Land and unleashes Black Riders, including a faceless Witch King dressed in black, possessor of a black flying dragon" ("The Lord" 34). In addition to these overtly black figures, the soldiers of Sauron include the black-skinned orcs, who are primitive and bestial, as well as the Southrons and Easterlings, characters who appear to be Middle Eastern that arrive riding olyphaunts, giant elephant-like creatures. While the characterisation of the orcs makes them resemble stereotypes of black characters, specifically the Black Buck figure articulated by Donald Bogle (13-14), the depiction of the Southrons and Easterlings is similar to stereotypes of Arab characters, such as those discussed by Jack Shaheen (15). As discussed in Chapter Five, those stereotypes are closely related. These dark characters are absent almost entirely from the denouement of the film, suggesting that they were only evil Others who have no place in the peaceful time dominated by the Self. The result is a strengthening of the structural violence which privileges a white Self over a non-white Other. As Kellner remarks of the film, "Whiteness is affirmed as the sign of good and virtue while black is the color of evil and villainy in a passion play between the forces of Light and Darkness" ("The Lord" 34). An interesting extension of this is the "dirtying" of Frodo as he behaves like the Other, as shown in Figure 28. Many characters of course have their whiteness sullied in combat, but for Frodo it carries additional implications, as discussed above. However, the whitest character of the film, Gollum, functions much the same way as the Nazis in Saving Private Ryan and Darth Sidious in The Phantom Menace, which is again as whiteness having gone too far. As with the gender-based structural violence of the film, this implicit racism is not atypical for the films analysed thus far. Similar to some of the films analysed previously, The Return of the King even makes some efforts to establish structural peace. 


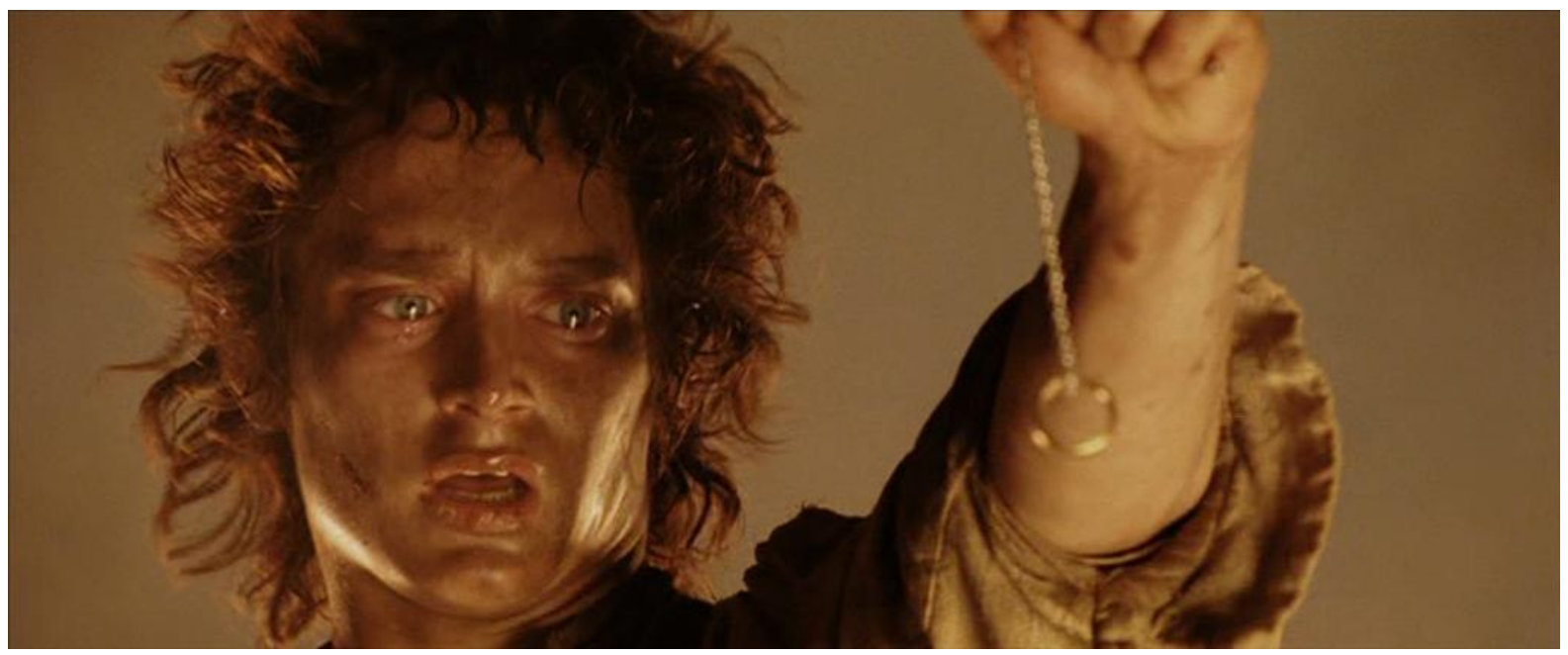

Figure 28 - Frodo darkened as corruption nears in Return of the King

Although the film reinforces heteronormativity through the multiple couplings at the end of the film-Aragorn with Arwen, Eowyn with Faramir, Samwise with Rosie - the sexual orientation of some characters is left largely ambiguous. ${ }^{30}$ This is particularly the case with Frodo, as well as with Merry and Pippin. For Frodo, many of his scenes with Sam suggest an underlying affinity between the two. For instance, after the ring is destroyed Frodo and Sam share a moment where they reflect on their home and the time they spent together. Had the scene remained the same, but one of them were female, they would likely have kissed. As for Merry and Pippin, they can easily be read as lovers, particularly when they have to part ways before the major battle of the film. At that parting they lament that they might not see one another again. While the film does not develop these potential readings in any explicit way, it is possible to see it as an effort to include non-hetero sexualities into the film. However, the film only ever engages with these issues implicitly. While that does indicate some level of structural peace, the lack of a more developed-or even consistent-message restricts its efficacy.

The larger point to be made by this discussion of structural violence and peace is that the film is similar in many respects to the pre- and post-9/11 films that came before it. Structural violence driven by gender and ethnicity-based inequities were

\footnotetext{
${ }^{30}$ See Ruth Goldberg and Krin Gabbard for a more detailed reading of the sexuality in the film, particularly the homosexual elements.
} 
found in nearly every film analysed. Although the hints at a challenge to heteronomativity are unusual, they are not forceful enough to mark a major difference. This violence, then, is not unusual for a blockbuster film. This is true for Frodo as well, who commits direct violence almost entirely out of self-preservation. Even his actions which position him close to the Other, such as the casting out of Sam, involve minimal direct violence. The film itself, then, does not dramatise the violence of the Self acting as Other. Instead, the transformation of the Self shows very little indication of violence, yet that transformation is what ultimately produces the "peaceful" world that is seen at the end of the film. To justify the transformation, then, the film needed to position the characters in a supreme peril where the stakes were either the domination or destruction of the Self. Thus, the presentation of that dream in the film was realised by the all or nothing approach that was presented in the build-up to the Iraq War.

\section{Quagmire: Self and Other Disjunction in Iraq}

The 2003 invasion of Iraq was sold to the American people through techniques which played on the fears and anxieties of the nation. The attacks of 9/11 were presented as a harbinger of violence to come, of the imminent peril the Self was in if it did not respond. That response, however, was not predicated upon an evaluation of facts. Writing about the relationship between the response to 9/11 and previous US reactions to attacks, Christopher Sharrett observes that media in the United States did not scrutinise potential factors that might have led to the events of $9 / 11$, such as the funding of the mujahideen (129). Rather than interrogating the Self, Sharrett notes that "Ignoring historical processes, the media [concentrated] instead on fomenting rage against a supernatural villain" (129). While Sharrett specifically refers to Osama bin Laden and al-Qaeda, the building up of Iraq as a similar threat, particularly in the shape of its leader, Saddam Hussein, was also part of the rhetorical strategy of the Bush administration. For instance, on September 8, 2002, National Security Advisor, Condoleezza Rice, spoke about the potential for Hussein to acquire or build nuclear weapons. At one point she said "there will always be some uncertainty about how quickly he can acquire nuclear 
weapons. But we don't want the smoking gun to be a mushroom cloud" ("CNN Late" n. pag.). This statement became a key point in the case for war, and was reinforced by similar remarks, particularly those made on February 5,2003 , to the United Nations Security Council by Secretary of State Colin Powell. Again the thrust of the argument was that Iraq presented an imminent threat to the world due to its possession of Weapons of Mass Destruction (WMDs). Interestingly, the threat of attack was reinforced in various entertainment media. Dennis Broe, for instance, observes that the show 24 engages in a process of "promoting and rationalising the endless war," and that it "keeps the audience afraid of terrorists, nuclear bombs, and viruses" (101). Furthermore, the hero becomes justified in "[ignoring] legal rights...in his battle to save humanity (with humanity here reduced to the United States only)" (101). In short, 24 exhibited movement of the Self towards the Other. Again, though, that transition was justified through the protection of the Self.

In a similar fashion, the questionable nature of a pre-emptive strike became justified by the dual goal of protecting the "homeland" (i.e. the Self), and spreading the ideology of the United States. It is unsurprising, then, that in the speech Bush delivered aboard the USS Abraham Lincoln to announce the end of major combat in Iraq, he again reiterated the importance of WMDs to the mission and stated the expanded importance of the mission. Both of these elements are similar to The Return of the King. In the film, the homelands of all the free peoples of Middle Earth are in peril and must be saved. At the same time, the means of saving them is by uniting them all under the banner of the king. Returning once again to the notion of "wishing" 9/11 that theorist Jean Baudrillard advances (7), the film very much dreams the equivalent of a Pax Americana. This is evident at the conclusion when Aragorn is crowned king, and all the free people implicitly swear allegiance to him. With Aragorn serving as the corollary of US leadership, he now controls all the lands of the free people, a nebulously defined entity. The dream, then, is that the period of war functions as a crucible which eradicates the impurities of the Other, leaving only the Self, the Chosen Ones, to rule. While the speech aboard the USS Abraham Lincoln seems to have made that dream a reality seven months before the film was even released, the fact that the war in Iraq was still being fought by the 
time the film premiered at the end of the year suggests that the failure of Bush to deliver a golden age of peace only intensified the desire for it. At the same time the dreams of the deliverance of that peace, though approving of the Self being like the Other, did not sanction the Self actually being the Other.

As discussed, the transformation of Frodo from Self into Other in The Return of the King was sanitised. Frodo temporarily hurt Sam by asking him to leave, but no major violations of the Self occurred even when Frodo tried to keep the ring; everybody remained part of the Self. The larger implication, again, is that the Self will need to do things that it would not normally do if it is meant to triumph. The sanitised version of this presented in the film, however, gave no indication as to how far this could be taken. As the USA PATRIOT Act shows, there was initially great support placed behind acts which restricted freedoms of US citizens. However, as time progressed the tolerance of people for displays of the Self becoming the Other decreased significantly, even if that process was in the name of eventual liberty. This is clear in the response to the Abu Ghraib prison scandal in 2004. Early in that year, reports began to appear regarding prisoner abuse at the Abu Ghraib detention facility in Iraq. These reports persisted until April of that same year when photographs appeared which graphically depicted the dehumanisation of the prisoners by US soldiers. The acts of direct violence towards the prisoners included rape, physical beatings, and humiliations both sexual and otherwise, and were legitimised by structures of violence which positioned the prisoners as sub-human. These images, which showed the Self as Other, provoked much dissent. While the reason for this is apparent given the fact that basic human rights were being violated, the important factor to consider is that the Abu Ghraib scandal did not veer far from the dream of The Return of the King.

In the film, the dream was that an age of peace would follow a period of sacrifice. Part of the sacrifice would be the Self necessarily behaving like the Other. As noted above, that behaviour did not involve explicit acts of becoming the Other, instead it simply required resembling the Other. The Abu Ghraib scandal, however, showed the process going much further. For the Bush administration, though, the failure was not so much deviating from the dreams of the film, but it was the inability to 
censor the war. To draw on the words of John Milbank, the government could not keep the secret fighting secret (310). The failed attempts at censorship extended beyond outright atrocities, though, as the government sought to prevent photographs of American caskets being published as well. As Engelhardt observes, these "near biblical injunctions" even led to the lack of "body counts" (320). In short, the image of a war being won could not be maintained. The further away victory seemed, the further away the arrival of an age of peace became. The dreams of the people, as identified via cinema, no longer harmonised with the dreams of Bush and his supporters, a disjunction that rattled the entire agenda of the administration. While it was not sufficient to prevent Bush from being reelected in November, 2004, it did ultimately build up to the Republicans losing control of both the House of Representatives and the Senate in the mid-term elections in 2006 as the American people grew tired of the continually rising death toll in Iraq. Thus, the dream found in The Return of the King of a pristine Pax Americana, one forged by clean and noble deeds, did not come to pass. 


\section{Conclusion}

\section{Blockbuster Cinematic Violence and 9/11}

Although film theory throughout the twentieth and twenty-first centuries has revealed the complexity and depth present when a film is projected onto a screen in a darkened room, the theoretical models and frameworks cannot take away the magic of the screen. Films still carry with them a sense of wonder, and for many audience members, that wonder is like a dream. The images on the screen entertain, excite, terrify, worry, depress, and elate viewers, who are bathed in the ethereal glow of flickering light. While many theoretical approaches have been taken which apply psychoanalytic theories to the screen-Christian Metz, Laura Mulvey, and Kaja Silverman, for instance, have all made seminal contributions to the field-such theories often focus more on spectatorship than the historical context. Douglas Kellner eloquently sums up the relationship between the images on screen and that context in front of it by arguing that, "popular media culture taps into existing fears, hopes, fantasies, and other concerns of the day" (Media 105). Mike Chopra-Gant makes a similar point, arguing that popular cinema best responds to the general trends in society due to the large number of viewers such cinema attracts (11-12). Following from these statements, then, it is reasonable to assume that when a film is successful at the box-office, it is because it is relevant in some way to the audience. In that way, the cinema screen becomes a site of dreams. When the American blockbuster inhabits that space, as it pervasively did in the late twentieth and early twenty-first centuries, it dreams of violence. It dreams of direct violence; it dreams of structural violence, and, in so doing, it is cultural violence. Yet not all films have dreams that are collectively embraced. Some films fade into oblivion; the dreams they present are similar to most others, yet they lack something essential to the violent imagination. Other films, however, articulate dreams that resonate with large numbers of people. Audiences go again and again to see the film and its dreams. Such films capture something in their dreaming - a need, a hope, a fear-and audiences choose to participate in that dream again and again. 
This thesis has had two tasks. The first was to expand upon the idea suggested by Baudrillard of a relationship between blockbuster cinematic violence and its historical moment, specifically that of films surrounding 9/11. The second was to establish a larger methodological framework that can reliably link history and blockbuster cinematic violence. While the latter is the larger goal of the thesis, it is the former that has been the primary objective of this work. As this thesis has repeatedly shown via the violence-calibrated diagnostic critique, the films that were most successful in the 1990s repeatedly "tapped into" the anxieties of the postCold War United States. Films continually dreamed of a world wherein the Self was no longer without opposition, and had a definite identity. To that end the violence of American blockbuster cinema in the pre-9/11 period was deployed to first identify an external Other, which simultaneously defined the Self. This same approach was taken in the US response to 9/11 when the Bush administration articulated an Other through terrorism, albeit vaguely, against which direct, structural, and cultural violence were directed so that the United States once again had a distinct Self; peaceful means were not utilised. The pre-9/11 films dreamed of a return to a binary world, and the response to $9 / 11$ did just that. However, the War on Terror, despite having clear sides - the United States versus the terroristsdid not actually exist in a binary world; the Other could pass as the Self. Thus as the post-9/11 films also tapped into the zeitgeist of the period, anxieties that were very different from those found in pre-9/11 cinema emerged. The post-9/11 films dreamed paranoid dreams where the Other had penetrated the Self, and was always potentially concealed as the Self. Despite this distinct shift, violence is legitimised in all the films analysed through the oppositional positioning of a Self and an Other along traditional sites of violence in society, including gender, ethnicity, and class. Throughout this thesis, then, the answer to the first task-the relationship between 9/11 and dreams of blockbuster cinematic violence-has been charted.

In Chapter One, the creation of an alien Other in Independence Day dreamed of a return to a binary, Cold War-style conflict that would permit the United States to achieve a military victory, bringing the Cold War to the never-realised state of a Hot 
War. In Chapter Two, which looks at Titanic, the resilience of the United States via the American Dream is presented, and the analysis shows how the identity of the nation remained steadfast in the face of the external Other composed of the Edwardian Era supporters who sought to uphold class-bed structural inequality. In Chapter Three, Saving Private Ryan dreams of a return to a hot war in which the Self is clearly defined through the US military in opposition to the Nazi Other. In Chapter Four, Star Wars: Episode I - The Phantom Menace pits the Self in opposition to an external Other that is attempting to commit genocide. Lastly, in the final film analysed from the pre-9/11 period, The Grinch, an external Other, is attempting to destroy the Self. That the Other is ultimately accepted into the Self suggests the previously static Self/Other binary has become dynamic. What this change suggests is that the dream of a return to a Cold War binary of Self versus external Other seen in the previous four films gave way to a changing sense of acceptance where the Other is not so villainous as it might seem. Of course the change in The Grinch is one which only occurs alongside structural violence that continually marginalises the Grinch, it remains one which potentially moves towards peace rather than violence. The event of $9 / 11$, however, seems to have disrupted this shift, as the dynamism of The Grinch appears in post-9/11 films, but it "taps into" the post-9/11 anxieties and inscribes the dynamic Self and Other within the paranoia of the post-9/11 period. The highest grossing films of 2001,2002 , and 2003, explored the permeability of the border between the Self and Other.

In Chapter Six, a false villain device is used in Harry Potter and the Sorcerer's Stone to engender a sense of paranoia throughout the entire film. In so doing, the Self and Other are once again pitted in a struggle of direct violence where the Other is ultimately uncovered within the Self and defeated. In Chapter Seven, the false villain device was replaced by simple dramatic irony in Spider-Man with the audience aware of the infiltration of the Other, but the cinematic Self dangerously unaware. Of course when the Self finally realises this penetration, the Other is defeated, leaving the Self vigilant against future incursions. Finally, in Chapter Eight, the relationship between Self and Other is transformed to such a degree in The Lord of the Rings: Return of the King that the Self was able to emulate the 
behaviour of the Other without losing its status as Self. In so doing, the dire struggle between Self and Other was resolved with not only the total elimination of the Other, but also of the elements of the Self which resembled the Other. In short, the film dreamed of cataclysmic violence which would purify the Self. This struggle against a hidden Other was both realised and unrealised in the response to 9/11. In all three post-9/11 films the binary between Self and Other was destabilised. However, even as they tapped into the anxieties of the period, but dreamed of solutions that could not come to pass; the mission was not accomplished in the Iraq War, and terrorism - an idea rather than an opponent-could not be eliminated.

By applying the violence-calibrated diagnostic critique to the films within the range, the first task of this thesis has been completed. The blockbuster cinematic violence of pre-9/11 films dreamed not of the event of $9 / 11$, but of the revitalisation of the US Self that occurred through the response to 9/11, and the post-9/11 film violence, drawing on the anxieties of the period, wished for an end to terrorism, but no such end could be reached. The second task of this thesis, which is to create a reliable methodology that, to borrow from Kellner (Media 116), allows history to read blockbuster cinematic violence, and blockbuster cinematic violence to read history, has been implicitly explored throughout this work. In order to process the findings, though, it is necessary to revisit the methodology used to complete the first task, particularly the concept of violence articulated by Johan Galtung which underpins it all.

\section{The Violence-Calibrated Diagnostic Critique}

In each chapter, the thesis has articulated the ways in which the Self/Other binaries are firmly supported by multiple structures of violence that produce eruptions of direct violence; the films legitimise both forms of violence. In other words, these chapters have repeatedly shown that blockbuster American cinema is culturally violent. This is not a surprising conclusion, though, given the proliferation of studies both inside and outside of film theory which focus on violence in that cinema. However, rather than focusing on the ways in which direct violence might prompt some viewers to emulate it, this thesis has deployed a methodology which 
focused on the broader scope of violence as articulated by Galtung to provide an historical perspective. From this vantage, what is most noteworthy is the fact that the cultural violence on display in these films so strongly resembles the violenceboth direct and structural-that was centrally located in the response to 9/11 articulated by the Bush administration. The explanation for this is simple, however. The pre-9/11 films dreamed of a resolution to the post-Cold War identity crisis, and the Bush administration enacted policies that effectively realised those dreams. This is not, however, to suggest causality: the films which played before did not cause the official response to those events, but instead legitimised such violence (and ultimately de-legitimised it as well). This is the function of cultural violence as defined by Galtung, and it is a key to broadening the scope of the methodology to address the second task of this thesis.

\section{Direct Violence}

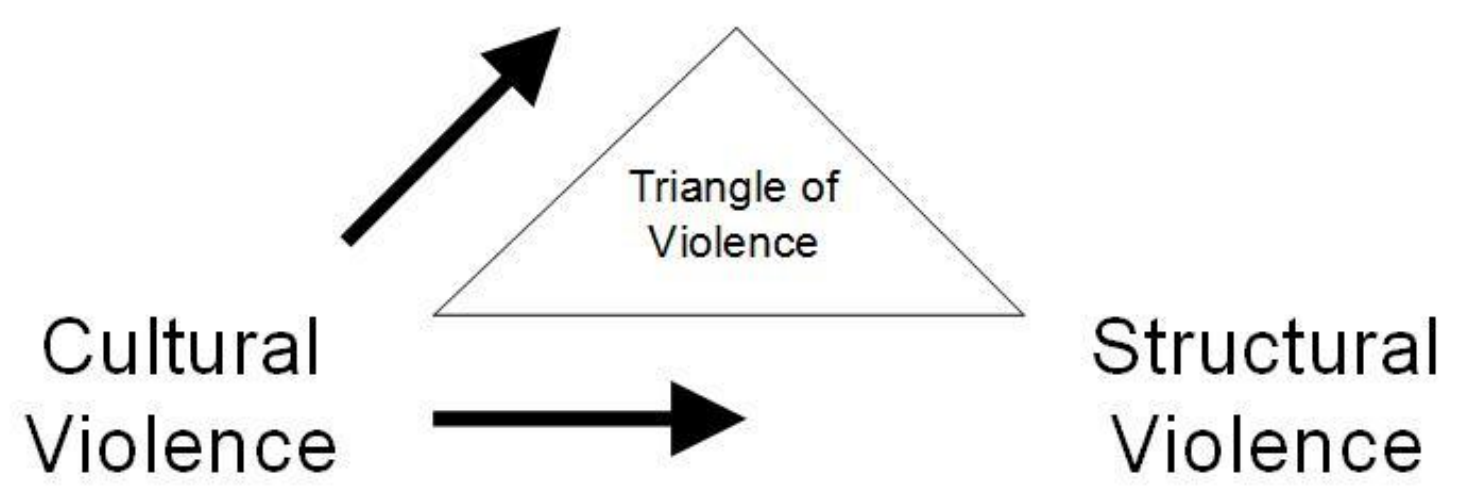

Figure 29 - Tripartite Violence redux

Galtung argues that tripartite violence essentially regenerates itself. If a system lacks one or two forms of violence, the presence of at least one other form of violence will eventually cause the absent forms to remanifest themselves. For example, if direct violence and structural violence are not present, but cultural violence is, Galtung claims that eventually direct and/or structural violence will 
emerge, as shown in Figure 29. This is important because in the wake of the Cold War, there was an apparent absence of violence that had been previously pervasive in the United States, specifically violence directed toward the Soviet Other. The disappearance of the macro-level violence that helped to define the US Self resulted in the dissolution of unity. As Galtung observes of state systems, the less unified the national Self is, the weaker its capacity to build internal peace (Peace 65). The result was increasing attention paid to violence within the United States itself. Yet even as these domestic anxieties were "tapped into" by popular mediaIndependence Day, for instance, addresses issues of ethnicity-the films themselves had grander dreams, and continually articulated violence on the macro-level that had once existed between the United States and the Soviet Union. Although there were numerous changes to the way in which the Other was represented, it always manifested itself as a force that rivalled the Self, but never defeated it. In this way, although the broad-scale structural and direct violence that defined the Cold War had disappeared in the 1990s, it persisted in the cultural sphere. Otherwise stated, even though a global superpower that could be defined as an Other against the United States no longer existed, since the United States was the only superpower, films continued to dream of such an enemy.

Returning to the notion of violence remanifesting itself, then, the persistence of cultural violence in this fashion legitimises its structural and direct counterparts, and, Galtung would contend, will ultimately "breed violence." By aligning the viewers with the Self, then, the films also manage to align them with a network of representations that effectively legitimise-explicitly or otherwise-structural and even direct violence. Although many of these legitimisations do not necessarily deal with realistic situations - the aliens of Independence Day and The Phantom Menace, for instance, are clearly fictional-the violence that informs such aspects of the films under investigation adheres to generic practices of prejudice and discrimination. Thus, it is in keeping with the theories of peace and violence advanced by Galtung that the legitimisation of violence at the cultural level manifested itself within a different sphere of society with the films essentially "dreaming" of the violence that was ultimately carried out by the Bush 
administration in the post-9/11 period. If the methodology were to work beyond the realm of 9/11, then, it would reveal similar connections. It would show how blockbuster cinematic violence routinely "taps into" the anxieties of any period (Kellner Media 105). To that end, it is useful to briefly explore the period of US history that exists after the Iraq invasion.

The events of $9 / 11$ greatly affected the domestic landscape, and opened the door to a return to the past, which was clear in the ways the Bush administration sought to align itself with a mythic American history. However, with the domestic landscape changed and the United States increasingly embroiled in a "crusade," the dreams of the films changed from dreaming for a return to the past and a unified Self to seeing the ultimate victory of the Self through the purging of the Other. As Jim A. Kuypers argues, "it is clear that no metanarrative on the War on Terror evolved" (152). The result was "a fractured and confused" understanding of the War on Terror in the media (152). As a result, the frame of the War on Terror was not one which could be supported for a long period of time. The appearance of Bush on the USS Abraham Lincoln with the "Mission Accomplished" banner behind him became emblematic of this failure to meet the dreams articulated by the films from 2001 to 2003. This post-"mission accomplished" period, then, is different from the immediate response to $9 / 11$. An application of the methodology to this period should provide an indication of its functionality outside of the scope of this thesis. While a new study would need to be conducted to fully analyse the blockbuster cinema after 2003, even a brief investigation produces interesting findings. Specifically, it shows that the dreams in pre-9/11 films were following a trajectory that, like many things, was disrupted by $9 / 11$. While that disruption was essentially a dream come true given the fact that it enabled the Bush administration to rearticulate the national Self in a way that closely paralleled the dreams of those films, the fact that there were signs of a move towards peace in blockbuster cinematic violence in 2000 cannot be discounted. 


\section{Blockbuster Cinematic Violence Beyond 9/11}

At the turn of the millennium, the precise nature of the relationship between Self and Other seemed to change with The Grinch. While the relationship remained a negative one in terms of violence, the film incorporated a sense of mobility in the Self and Other that the previously analysed films did not. Again, both sides of the binary were heavily grounded by structural violence, particularly in the form of class- and ethnicity-based stereotypes and prejudices, but the fact that there was a shift at all suggests a change that may ultimately have led towards the development of a Self/Other binary that in turn ultimately legitimised structural peace rather than violence. This is suggested by the fact that the highest grossing film of 2001 that debuted and earned the majority of its total box-office take before 9/11, was Shrek. Shrek told the story of an ogre who interacts with the human world, ultimately rescuing a human princess who, in a happy ending, becomes an ogre. In other words, the Other is positioned as the Self, and the apparent Self becomes the Other. Of course there are a number of factors which mitigate the radical nature of this plot. For one, the film once again uses green as a coded ethnicity such that the characters of Shrek, and (eventually) his ogre-bride, Fiona, do not have direct real-world corollaries. Additionally, Shrek and Fiona are both voiced by prominent white actors, Mike Myers and Cameron Diaz respectively. Thus, like Jim Carrey in The Grinch, Shrek and Fiona can be read as animated characters in "greenface." What is more, much of the film is predicated upon Shrek excelling at direct violence. Even so, the very fact that Fiona turns into an ogre at the end of the film shows that the changes suggested by the violence of The Grinch may very well have developed into a more peaceful series of dreams. Ultimately Shrek became the third highest-grossing film of the year, behind The Sorcerer's Stone and The Lord of the Rings: The Fellowship of the Ring, both of which were released after the events of 9/11, and both of which "tapped into" the anxieties of that period. While it is not unusual for films that do not become the highestgrossing film of the year to articulate more diverse relationships between the Self and the Other-which are also potentially more peaceful-what makes Shrek noteworthy is that in 2004 , as the dreaming of victory in the War on Terror was 
turning into a nightmare with the mission continually going "unaccomplished," the highest grossing film of the year was the sequel to Shrek.

Unlike the first Shrek film, which tells the story of the transformation of the Self into Other, Shrek 2 begins with the Self as Other. What is more, the central plot of the film involves attempting to have a traditional Self-represented here as a white, upper class, heterosexual couple, the king and queen of Far Far Away-to accept them as they are. Again, the film is predicated upon a resolution of direct violence, and there are still overt structures of violence implied through the articulation of both the Self and the Other. The most obvious, for instance, involves the central plot of the film where Shrek embarks on a quest to become white in an effort to be the man he thinks Fiona wants. What is more, he succeeds in becoming white before ultimately realising that being white will make neither him nor Fiona happy. Amongst other issues with the storyline is the implication that in his true form, Shrek is white, a fact which serves as an impediment to his positioning as a nonwhite character. Despite such problematic racial depictions, though, it is clear that the film seems not only to continue the development of the Self and Other found in the post-9/11 films analysed in this thesis, but also appears to refocus that change within the pre-9/11, post-millennial context of the first Shrek film. Thus the more overt structures of violence found in a film like The Return of the King, which privileged whiteness and masculinity over all while denigrating non-white ethnicities, were suggested to be faulty by Shrek 2 . For instance, the conflict in the film erupts because Shrek believes he needs to adhere to an ideal of whiteness for Fiona. In that way, the film engages with issues of race in a way that is not seen in the films analysed thus far. The end of the film does present some problematic racial issues-Shrek and Fiona return to live in the swamp, effectively the poor part of the kingdom-but again the contention that the Self might not be a privileged upper-middle class person remains present throughout the film. Ultimately, though, the Self/Other binary of the film destabilises the boundary between the two.

While Return of the King presented a Self that emulated the behaviour of an Other, the Self of Shrek 2 broke down the traditional Self/Other binary by effectively- 
albeit guardedly-integrating the traditional Self and Other. The result is that the actual Other of the film is one that reinforces structures of violence and deploys direct violence to do so. This again plays into the concept of reactive violence that Tom Engelhardt argues is crucial to the "American war story" (5). It is also necessary to note that the Other is even further marked via stereotypes as one of the primary villains of the film, Prince Charming, is depicted as an effeminate if not homosexual figure, so much so that he is even voiced by Rupert Everett, who is openly gay. Despite that regressive side of Shrek 2, I contend that the film is not entirely without progressive elements since those which would normally be privileged-whiteness - are ultimately dissociated from the Self, with other qualities - non-white ethnicities - being used to visually define the characters. While this still does place a strong emphasis on the visual qualities, especially since, as noted above, both characters are voiced by white actors, it still represents a dramatic shift from the white-dominated films analysed. What is more, the shift away from traditional protagonists and a critique of the traditional qualities associated with the Self continues in subsequent years.

In 2005, the highest grossing film of the year was Star Wars: Episode V-Revenge of the Sith. The film was the second sequel to The Phantom Menace, and represents a dramatically different type of Self/Other binary than the first film. While The Phantom Menace presented a discrete boundary between the Self and the Other, Revenge of the Sith breaks down that distinction with the primary Self of the film not simply emulating the behaviour of the Other, as was the case in Return of the King, but becoming the Other through acts of violence. The film, of course, still maintained structures of violence-the previously warrior-like Padme (Natalie Portman) is domesticated via pregnancy, essentially losing all narrative agency. However, it also provided a thinly veiled critique of the contemporary historical moment into which it was released. For instance, at one point in the film a character remarks, "If you're not with me, then you're my enemy," a clear allusion to the divisive rhetoric of Bush and others such as Hillary Clinton. While the versions uttered in the immediate aftermath of the attacks of $9 / 11$ were met with great praise, the Revenge of the Sith iteration was presented after the Iraq invasion 
with death tolls rising, and increasing public outcry against the invasion-cumoccupation. Accordingly, it was framed as a critique of the Bush administration. The ideology that defined the Self in 2001 , then, and indeed in nearly all of the pre9/11 films analysed, was that which identified the Other in 2005.

This formation illustrates two clear points. The first is that the violence in the films after 2003 suggests another change in the dreams of the films. Specifically, they develop the movement of the Self into a full-fledged crisis of the Self. A more detailed study would be needed to determine if this crisis is a delayed manifestation of the identity issues which plagued the United States in the 1990s after the Cold War or if it is the logical extension of the crusader mindset. Yet regardless of the motivation, the boundary between the Self and the Other is no longer discrete. That having been said, there still remain clear cases of good behaviour and bad behaviour which are definitely informed by structures of violence. For instance, in Revenge of the Sith it is acceptable for Anakin Skywalker (Hayden Christiansen) to kill certain characters at the beginning of the film, but as he transforms from Self to Other it becomes unacceptable. Killing, then, is sometimes legitimate for the characters in the film, but without a detailed analysis of the violence, the precise structures that determine that cannot be accurately determined. The second point the post-Iraq invasion films support, and something which is evidenced throughout this thesis, is that the construction of the Self and Other in films is continually changing, but that continuous process seems to also form larger phases. Most importantly, though, even the observations from this cursory analysis suggest that the violence-calibrated diagnostic critique functions as a general methodology for analysing the relationship between blockbuster cinematic violence and its historical moment.

\section{Past \& Future}

The analysis in this thesis has dealt explicitly with two periods in American history, the span from 1996 to 2001 which involved the second term of President Clinton and the first year in office of President Bush, and the period from 2001 to 2003, which began with the attacks on September 11, 2001, and lasted beyond the end of 
major combat operations in Iraq. Although there could certainly be further subdivisions, it was within those time frames that the major trends in cinematic violence emerged, trends which informed the trajectory of the Self and Other as discussed throughout this thesis. As briefly detailed above, 2004 seemed to mark a new phase in the development of cinematic violence. It continued the transformation of the Self and Other that had begun in earnest after the events of $9 / 11$, but it included a framing of the relationship between the two that suggested a move beyond the diametric opposition that was dominant in pre-9/11 cinema and, to a lesser extent, post-9/11 cinema. What these shifts indicate is a need to more closely examine the violence in films using the methodology synthesised for this thesis. There are two primary ways that the work could be extended, in terms of the length of the period being studied, and in terms of the number of films per year. In the first case, as I have shown above, new trends can be found, and even a brief look beyond 2005 reveals a further change in the nature of the violence in the highest-grossing cinema in the United States.

The top movies in the three years after Revenge of the Sith were Pirates of the Caribbean: Dead Man's Chest (2006), Spider-Man 3 (2007), and The Dark Knight (2008). In Dead Man's Chest, the plot focuses heavily on Captain Jack Sparrow (Johnny Depp), a character which thrives on its ambiguous sexuality-some commentators labelled the pirate Sparrow a "swishbuckler" as a result. Additionally, the plot involves gender passing, with Elizabeth Swann (Keira Knightly) pretending to be a man for much of the film. Additionally, one of the primary villains of the film, Lord Cutler Beckett (Tom Hollander), seems to be characterised in terms of a homosexual stereotype. At the same time, the minorities presented onscreen, particularly Tia Dalma (Naomie Harris), adhere to gross stereotypes that activate structures of violence which privilege whiteness. While this is indeed a step backward, the film represents a much more progressive view of sexuality and sexual orientation than the films which preceded it did. Spider-Man 3 also explored the nature of the Self by having Peter Parker/Spider-Man (Tobey Maguire) become corrupted by an alien life form. The fact that the creature is black and Parker is white raises any number of issues regarding ethnicity-based structural violence, but 
again the Self is destabilised. However, the return to prominence of Spider-Man suggests a desire for a return to more traditional masculinities. Indeed, the return to hard-bodied masculinity can clearly be seen in The Dark Knight, in which the vigilante justice that Batman/Bruce Wayne (Christian Bale) embodies is denigrated even as it is ultimately praised. While a more detailed analysis of the film is needed to reach any substantive conclusion, even a cursory look at the film reveals a heavy endorsement of vigilante justice, something which is ultimately in line with the Bush Doctrine as defined by Charles Krauthammer, particularly in terms of its unilateralism (n. pag.). What is more, that trend seems to have been continued in the top film of 2010, and indeed of all-time at the US box-office, Avatar. It is worth considering that this shift roughly adheres to the major political changes going on in the United States, and the world, at that time. For instance, in 2004 and 2005, the dissent against the Iraq War intensified to such a level that in 2006 the Republicans lost control of the US Congress, and in 2008, Barack Obama was elected as President of the United States. At the same time, the bubble economy that had been growing in the US burst, and a major crash ensued. The point of this discussion is not to analyse these films in any great detail, nor is it to suggest definite connections between the social horizon outlined above and the violence of the film, particularly in the way it articulates the relationship between the Self and the Other. Instead it is to contend that, based on the analysis conducted in this thesis, the methodology could in fact be expanded to look in greater detail at blockbuster cinematic violence beyond the $9 / 11$ period. This could be accomplished by expanding the scope of this research to include a more longitudinal study sample could reveal much about the expansive relationship between cinema in the United States and the contemporary historical moments into which they were released. As mentioned above, though, a deeper sample could also be useful.

In 2010, the top five films were Toy Story 3, Alice in Wonderland, Iron Man 2, The Twilight Saga: Eclipse, and Harry Potter and the Deathly Hallows, Part I. A full analysis of the violence in each of these films will reveal the diverse ways in which cinema, to borrow from Kellner in his discussion of the diagnostic critique, "[taps] 
into existing fears, hopes, fantasies, and other concerns of the day" (Media 105). For instance, Alice in Wonderland articulates, very broadly, a story of nostalgia and coming of age, while Iron Man 2, is about wealth, and masculinity. These films all came out during the same time conservative parties retook the House of Representatives in a mid-term election, largely driven by the rise of the Tea Party movement. By extending the sample selection in each year, a more complete picture of the United States and the violence that cultural artefacts legitimise could be determined. While this would offer a much greater sense of the textures the phases of cultural violence contain, the actual phases would be harder to determine given the lack of broad time frame. Ideally, then, future studies would find a way to marry length with depth. In both approaches, however, there are limitations, and they must be made clear.

In the analysis conducted in this thesis, violence is continually read in terms of the historical developments in the United States. However, there is again no clear causal link between cinema and history in terms of violence. For example, although audiences flocked to The Sorcerer's Stone after the events of 9/11, the film was planned, marketed, and virtually completed well before that point. Additionally, the conclusion that the pre-9/11 films which "dreamed" of 9/11 does not imply that such films brought the event to pass. What it does instead is suggest that the types of violence that will be accepted by a certain population - the US population in this case-can be inferred from its popular cinema. Thus, the fact that US audiences embraced not only The Sorcerer's Stone in the wake of 9/11, but also all of the films discussed in the pre-9/11 period, helps to explain why the American people did not immediately react negatively to paranoia-driven violence in the United States, such as the domestic wiretapping, in the wake of 9/11. In short, the violence in cinema indicates types of violence that audiences will accept, which is precisely the theory that underpins tripartite violence. As the attacks of $9 / 11$ show, although seemingly shocking changes can result from historical events, a closer examination of cultural artefacts, particularly from the vantage point of the violence articulated therein, reveals that such changes are not at all surprising. 
American blockbuster cinema is culturally violent. It legitimises direct violence, but it does so by presenting structures of violence. While some of these structures are explicitly detailed by the films, others are implicit. The end result is that the dreams of the film continually involve the resolution of all conflicts with violence. Thus, what this thesis ultimately reveals is the fact that, in terms of cultural consumption, the United States embraces violence, particularly when it privileges a noble Self. As a result, peace is hard to find. This is not to say that peace is absent from cinema, even from blockbuster cinema. Toy Story 3, for instance, the highest grossing film of 2010 , does have messages of inclusiveness and acceptance, but it is haunted by structures of violence, particularly surrounding ethnicity. Peace, then, only seems to be accepted when integrated into a larger framework of violence. Part of this has to do with the blockbuster aesthetic, which engenders violence and conflict, but it also evokes the question posed by title of the second album released by the heavy metal band, Megadeth, "Peace sells...but who's buying?" Certainly not the American cinema-goer and that is cause for concern. 


\section{Appendix}

Below are the box office figures for the top five films in each year from 1996 to 2003. All figures from Box Office Mojo.

\begin{tabular}{|c|c|c|}
\hline Rank & Title & Gross \\
(in millions USD)
\end{tabular}

Table 7 - Highest grossing films in the US in 1996

\begin{tabular}{|c|c|c|}
\hline Rank & Title & $\begin{array}{c}\text { Gross } \\
\text { (in millions USD) }\end{array}$ \\
\hline 1 & Titanic & 600 \\
\hline 2 & Men in Black & 250 \\
\hline 3 & The Lost World: Jurassic Park & 229 \\
\hline 4 & Liar Liar & 181 \\
\hline 5 & Air Force One & 172 \\
\hline
\end{tabular}

Table 8 - Highest grossing films in the US in 1997 


\begin{tabular}{|c|c|c|}
\hline Rank & Title & Gross \\
\hline 1 & Saving Private Ryan & 216 \\
\hline 2 & Armageddon & 201 \\
\hline 3 & There's Something About \\
\hline 4 & Mary & 176 \\
\hline 5 & A Bug's Life & 162 \\
\hline & The Waterboy & 161 \\
\hline
\end{tabular}

Table 9 - Highest grossing films in the US in 1998

\begin{tabular}{|c|c|c|}
\hline Rank & Title & $\begin{array}{c}\text { Gross } \\
\text { (in millions USD) }\end{array}$ \\
\hline 1 & $\begin{array}{c}\text { Star Wars: Episode I - The } \\
\text { Phantom Menace }\end{array}$ & 431 \\
\hline 2 & The Sixth Sense & 293 \\
\hline 3 & Toy Story 2 & 245 \\
\hline 4 & $\begin{array}{c}\text { Austin Powers: The Spy Who } \\
\text { Shagged Me }\end{array}$ & 206 \\
\hline 5 & The Matrix & 171 \\
\hline
\end{tabular}

Table 10 - Highest grossing films in the US in 1999 


\begin{tabular}{|c|c|c|}
\hline Rank & Title & $\begin{array}{c}\text { Gross } \\
\text { (in millions USD) }\end{array}$ \\
\hline 1 & $\begin{array}{c}\text { Dr. Seuss' How the Grinch Stole } \\
\text { Christmas }\end{array}$ & 260 \\
\hline 2 & Cast Away & 233 \\
\hline 3 & Mission: Impossible II \\
\hline 4 & Gladiator & 215 \\
\hline 5 & What Women Want & 187 \\
\hline
\end{tabular}

Table 11 - Highest grossing films in the US in 2000

\begin{tabular}{|c|c|c|}
\hline Rank & Title & $\begin{array}{c}\text { Gross } \\
\text { (in millions USD) }\end{array}$ \\
\hline 1 & $\begin{array}{c}\text { Harry Potter and the Sorcerer's } \\
\text { Stone }\end{array}$ & 317 \\
\hline 2 & $\begin{array}{c}\text { The Lord of the Rings: The } \\
\text { Fellowship of the Ring }\end{array}$ & 313 \\
\hline 3 & Shrek & 267 \\
\hline 4 & Monsters, Inc. \\
\hline 5 & Rush Hour 2 & 255 \\
\hline
\end{tabular}

Table 12 - Highest grossing films in the US in 2001 


\begin{tabular}{|c|c|c|}
\hline Rank & Title & $\begin{array}{c}\text { Gross } \\
\text { (in millions USD) }\end{array}$ \\
\hline 1 & Spider-Man & 403 \\
\hline 2 & $\begin{array}{c}\text { The Lord of the Rings: The Two } \\
\text { Towers }\end{array}$ & 339 \\
\hline 3 & $\begin{array}{c}\text { Star Wars: Episode II - Attack } \\
\text { of the Clones }\end{array}$ & 302 \\
\hline 4 & $\begin{array}{l}\text { Harry Potter and the Chamber } \\
\text { of Secrets }\end{array}$ & 261 \\
\hline 5 & My Big Fat Greek Wedding & 241 \\
\hline
\end{tabular}

Table 13 - Highest grossing films in the US in 2002

\begin{tabular}{|c|c|c|}
\hline Rank & Title & $\begin{array}{c}\text { Gross } \\
\text { (in millions USD) }\end{array}$ \\
\hline 1 & $\begin{array}{c}\text { The Lord of the Rings: The } \\
\text { Return of the King }\end{array}$ & 377 \\
\hline 2 & Finding Nemo & 339 \\
\hline 3 & $\begin{array}{c}\text { Pirates of the Caribbean: The } \\
\text { Curse of the Black Pearl }\end{array}$ & 305 \\
\hline 4 & The Matrix Reloaded & 281 \\
\hline 5 & Bruce Almighty & 242 \\
\hline
\end{tabular}

Table 14 - Highest grossing films in the US in 2003 


\section{Works Cited}

Adams, James Truslow. The Epic of America. 1931. New York, NY: Triangle Books, 1941. Print.

Agajanian, Rowana. "'Peace on Earth, Goodwill to All Men': The Depiction of Christmas in Modern Hollywood Films." Christmas at the Movies: Images of Christmas in American, British and European Cinema. Ed. Mark Connelly. London, UK: I.B. Tauris \& Co Ltd, 2000. 143-164. Print.

Agamben, Giorgio. Homo Sacer: Sovereign Power and Bare Life. Trans. Daniel Heller-Roazen. Palo Alto, CA: Stanford University Press, 1998.

---. State of Exception. Trans. Kevin Attell. Chicago, IL: University of Chicago Press, 2005.

Althusser, Louis. "Ideology and Ideological State Apparatuses (Notes Towards an Investigation)." Media and Cultural Studies: Keyworks. Rev ed. Eds. Meenakshi Gigi Durham and Douglas Kellner. Malden, MA: Blackwell Publishing Ltd, 2006. 79-87. Print.

Ambrose, Stephen. Citizen Soldiers: The U.S. Army from the Normandy beaches to the Bulge to the surrender of Germany, June 7, 1944-May 7, 1945. New York, NY: Simon \& Schuster, 1997. Print.

Arendt, Hannah. On Violence. London, UK: Alan Lane The Penguin Press, 1970. Print.

Baard, Erik. "George W. Bush Ain't No Cowboy." Villagevoice.com. The Village Voice, 21 Sep. 2004. Web. 1 Mar. 2011. <http://www.villagevoice.com/2004-0921/news/george-w-bush-ain-t-no-cowboy/1/>

Balides, Constance. "Jurassic Post-Fordism: Tall Tales of Economics in the Theme Park." Screen 41.2 (2000): 139-160. Print.

Bandura, Albert. Aggression: A Social Learning Analysis. Englewood Cliffs, New Jersey. Prentice-Hall, 1973. Print.

Barthes, Roland. Mythologies. Trans. Annette Lavers. New York, NY: Hill and Wang, 1972. Print.

Bartol, Curt R. \& Anne M. Bartol. Criminal Behavior: A Psychological Approach. $8^{\text {th }}$ ed. Upper Saddle River, NJ: Prentice Hall, 2007. Print. 
Basinger, Jeanine. The World War II Combat Film: Anatomy of a Genre. New York, NY: Columbia University Press, 1986. Print.

---. "Translating War: The Combat Film Genre and Saving Private Ryan." The Newsmagazine of the American Historical Society. American Historical Association, Oct. 1998. Web. 11 May 2010. <http://www.historians.org/perspectives/issues/1998/9810/9810FIL.CFM>.

Battle, Joyce. "The Iraq War - Part I: The US Prepares for Conflict, 2001." The National Security Archive. The George Washington University, 22 Sep. 2010. Web. 1 Jan. 2011 <http://www.gwu.edu/ nsarchiv/NSAEBB/NSAEBB326/print.htm>

Baudrillard, Jean. The Spirit of Terrorism and Requiem for the Twin Towers. Trans. Chris Turner. London, UK: Verso, 2002. Print.

Bell-Metereau, Rebecca. "The How-To Manual, the Prequel, and the Sequel in Post9/11 Cinema." Film and Television After 9/11. Ed. Wheeler Winston Dixon. Carbondale, IL: Southern Illinois University Press, 2004. 142-162. Print.

Benjamin, Walter. "Critique of Violence (Reflections)." On Violence: A Reader. Eds. Bruce B. Lawrence and Aisha Karim. Durham, NC: Duke University Press, 2007. 268-285. Print.

Blume, Judy. "Is Harry Potter Evil?" The New York Times 22 Oct. 1999: 27A. LexisNexis. Web. 1 Apr. 2011.

Bodnar, John. "Saving Private Ryan and Postwar Memory in America." The American Historical Review 106.3 (June 2001): 805-817. Print.

Bogle, Donald. Toms, Coons, Mulattoes, Mammies, \& Bucks: An Interpretive History of Blacks in American Films. Expanded Ed. New York, NY: The Continuum Publishing Company, 1989. Print.

Bordwell, David. The Way Hollywood Tells It: Story and Style in Modern Movies. Los Angeles, CA: University of California Press, 2006. Print.

Bourdieu, Pierre. Outline of a Theory of Practice. Trans. Richard Nice. Cambridge, UK: Cambridge University Press, 1977. Print.

Box Office Mojo. IMDb.com, Inc., 2010. Web. 20 Aug. 2010.

Broe, Dennis. "Fox and Its Friends: Global Commodification and the New Cold War." Cinema Studies. 43.4 (2004): 97-102. Print.

Brokaw, Tom. The Greatest Generation. New York, NY: Random House, 1998. Print. 
Brooke-Rose, Christine. A Rhetoric of the Unreal: Studies in Narrative \& Structure, Especially of the Fantastic. Cambridge, UK: Cambridge University Press, 1981. Print.

Browne, Nick, Theresa Webb, Kevin Fisher, Bernard Cook, David McArthur, Corinne Peek-Asa, and Jess Krauss. "American Film Violence: An Analytic Portrait." Journal of Interpersonal Violence 17.4 (April 2002): 351-370. Print.

Buckland, Warren. Direct by Steven Spielberg: Poetics of the Contemporary Hollywood Blockbuster. New York, NY: Continuum, 2006. Print.

Bukatman, Scott. Terminal Identity: The Virtual Subject in Postmodern Science Fiction. London, UK: Duke University Press, 1993. Print.

Burns, Lisa M. First Ladies and the Fourth Estate: Press Framing of Presidential Wives. Dekalb, IL: Northern Illinois University Press, 2008. Print.

Bush, George H W. "Remarks to the American Legislative Executive Council." George Bush Presidential Library and Museum. 1 Mar. 1991. Web. 1 Jan. 2011 $<$ http://bushlibrary.tamu.edu/research/public_papers.php?id=2754\&year=1991 \&month $=3>$

Bush, George W. "Remarks by the President Upon Arrival." The White House: President George W. Bush. The White House, 16 Sep. 2001. Web. 26 Oct. 2010 $<$ http://georgewbushwhitehouse.archives.gov/news/releases/2001/09/20010916-2.html>

---. "Guard and Reserves 'Define Spirit of America.'” The White House: President George W. Bush. The White House, 17 Sep. 2001. Web. 1 Jan. $2011<$ http://georgewbushwhitehouse.archives.gov/news/releases/2001/09/20010917-3.html>

---. "Address to a Joint Session of Congress and the American People." The White House: President George W. Bush. The White House, 20 Sep. 2001. Web. 1 Jan. $2011<$ http://georgewbushwhitehouse.archives.gov/news/releases/2001/09/20010920-8.html>

---. "President Delivers State of the Union Address." The White House: President George W. Bush. The White House, 29 Jan. 2002. Web. 1 Jan. $2011<$ http://georgewbushwhitehouse.archives.gov/news/releases/2002/01/20020129-11.html>

---. "Bush: Don't wait for mushroom cloud." CNN.com. Time Warner. 8 Oct. 2002. Web. 15 Mar. 2010. <http://archives.cnn.com/2002/ALLPOLITICS/10/07/bush.transcript/> 
---. "President Bush's Statement." Pbs.org PBS NewsHour, 19 Mar. 2003. Web. 1 Mar. $2011<$ http://www.pbs.org/newshour/bb/middle_east/iraq/bush_319.html>

---. "President Bush Announces Major Combat Operations in Iraq Have Ended." The White House: President George W. Bush. The White House, 1 May 2003. Web. 1 Jan. 2011 <http://georgewbushwhitehouse.archives.gov/news/releases/2003/05/20030501-15.html>

Bush, George W., Al Gore \& Jim Lehrer. "First Presidential Debate." Pbs.org PBS NewsHour, 3 Oct. 2000. Web. 1 Mar. 2011. <http://www.pbs.org/newshour/bb/election/2000debates/1stdebate2.html>

Caplow, Theodore, Howard M. Bahr, John Modell, Bruce A. Chadwick. Recent Social Trends in the United States: 1960-1990. Montreal, QC: McGill-Queen's-University Press, 1991. Print.

Card, Orson Scott. "'Star Wars' Our Public Religion." USA Today 17 Mar. 1997: 13A. LexisNexis. Web. 1 Apr. 2011.

Carroll, James. Crusade: Chronicles of an Unjust War. New York, NY: Metropolitan Books, 2004. Print.

Chen, Edith Wen-Chu and Grace J. Yoo. "Introduction." Encyclopedia of Asian American Issues Today. 2 vols. Eds. Edith Wen-Chu Chen and Grace J. Yoo. Santa Barbara, CA: ABC-CLIO, LLC, 2010. xvii-xxi. Print.

Chomsky, Noam. Hegemony or Survival: America's Quest for Global Dominance. New York, NY: Henry Holt and Company, LLC, 2004.

---. "We Own the World: Adapted from a Z Media Institute talk, June 2007." Z Magazine. 21.1 (2008): n. pag. Web. 31 Jan 2011. <http://www.zcommunications.org/we-own-the-world-by-noam-chomsky>

Chopra-Gant, Mike. Hollywood Genres and Postwar America: Masculinity, Family and Nation in Popular Movies and Film Noir. London, UK: I.B. Tauris \& Co Ltd, 2006.

Clinton, William J. "Inaugural Address, January 20, 1997." The American Presidency Project. The American Presidency Project, 20 Jan. 1997. Web. 1 Feb. 2011 <http://www.presidency.ucsb.edu/ws/index.php?pid=54183>

---. "Remarks by the President on Foreign Policy." Clinton Materials Project, Virtual Library Publications. Office of the Press Secretary, 26 Feb. 1999. Web. 1 Jan. $2011<$ http://clinton6.nara.gov/1999/02/1999-02-26-foreign-policyspeech.html> 
Connor, Steve. "The Shame of Being a Man." Textual Practice 15.2 (2000): 211-219. Print.

Coontz, Stephanie. The Way We Never Were: American Families and the Nostalgia Trap. 2000 ed. New York, NY: Basic Books, 2000. Print.

Davis, Bob. "Bush Economic Aide Says Cost Of Iraq War May Top \$100 Billion." Wall Street Journal. 16 Sep. 2002: A1 (18 par.). Factiva. Online. 14 Jan. 2011.

Deacy, Christopher. Faith in Film. Hampshire, UK: Ashgate Publishing Limited, 2005. Print.

---. "Redemption and film: Cinema as a contemporary site of religious activity." Media Development 1(2000). Online. 14 Jan. 2011. $<$ http://waccglobal.org/en/component/content/article/76-2000-1/795Redemption-and-film-Cinema-as-a-contemporary-site-of-religious-activity.html>

Dixon, Wheeler Winston. "Introduction: Something Lost-Film after 9/11." Film and Television After 9/11. Ed. Wheeler Winston Dixon. Carbondale, IL: Southern Illinois University Press, 2004. 1-28. Print.

---. Film Noir and the Cinema of Paranoia. New Brunswick, NJ: Rutgers University Press, 2009. Print.

Domhoff, G. William. "Power in America: Wealth, Income, and Power." Who Rules America?. N.p. Jan. 2011. Web. 1 Mar. 2011. <http://sociology.ucsc.edu/whorulesamerica/power/wealth.html>

Donnelly, KJ "Riverdancing as the Ship Goes Down." The Titanic in Myth and Memory. Ed. Tim Bergfelder and Sarah Street. London, UK: I.B. Tauris \& Co Ltd, 2004. 205-214. Print.

Dyer, Richard. White. London, UK: Routledge, 1997. Print.

Early, Gerald. "American Skin." Nytimes.com. The New York Times, 1 Feb. 2004. Web. 1 Mar. 2011. <http://www.nytimes.com/2004/02/01/books/americanskin.html?src=pm>

Edsall, Thomas Byrne. "The Return of Inequality." The Atlantic Monthly. Jun. 1988: 86-94. Print.

Ehrenhaus, Peter. "Why We Fought: Holocaust memory in Spielberg's Saving Private Ryan." Critical Studies in Media Communication 18.3 (Sep. 2001): 321337. Print. 
Engelhardt, Tom. The End of Victory Culture: Cold War America and the Disillusioning of a Generation. $2^{\text {nd }} \mathrm{ed}$. Amherst, MA: University of Massachusetts Press, 2007. Print.

"Extra! America Attacked / the World Trade Center Attack, War and Anthrax Terror, all seen here, Dominated the News in 2001. for Other Big Stories, Turn the Page.: [all Editions]." Newsday: A.02. ProQuest Central. 2001. Web. 10 Apr. 2011 <http://search.proquest.com/docview/279544695?accountid=14782>.

Faludi, Susan. The Terror Dream: Fear and Fantasy in Post-9/11 America. Carlton North, Victoria, Austral.: Scribe Publications Pty Ltd, 2008. Print.

Flesher, Paul V.M. and Robert Torry. Film \& Religion: An Introduction. Nashville, TN: Abigndon Press, 2007. Print.

Foucault, Michel. The History of Sexuality, Vol 1: The Will to Knowledge. 1978. Trans. Robert Hurley. New York, NY: Random House, Inc., 1990. Print.

---."The Subject and Power." 1994. Power. Ed. James D. Faubion. Trans. Robert Hurley. New York, NY: The New Press, 2000. 111-133. Print.

---."Truth and Power." 1994. Power. Ed. James D. Faubion. Trans. Robert Hurley \& C. Lazzeri. New York, NY: The New Press, 2000. 111-133. Print.

---. Archaeology of Knowledge. Trans. A. M. Sheridan Smith. 1972. Abingdon, Oxon: Routledge Classics, 2002. Print.

Gabbard, Krin. "Saving Private Ryan Too Late." The End of Cinema As We Know It: American Film in the Nineties. Ed. Jon Lewis. London, UK: Pluto Press, 2001. 131-138. Print.

Galtung, Johan. Interview by Sohail Inayatullah. Civilization, Peace and the Future: An Interview with Johan Galtung. Feb. 1988. Web. 1 Mar. 2011. <http://www.metafuture.org/Civilization\%20peace\%20and\%20the\%20future\%2 Olnterview\%20with\%20Galtung\%201988\%20by\%20Inayatullah.pdf>

---. "Cultural Violence." Journal of Peace Research 27.3 (Aug 1990): 291-305. Print.

---. Peace by Peaceful Means: Peace and Conflict, Development and Civilization. Thousand Oaks, CA: Sage Publications Inc, 1996. Print.

Galtung, Johan Vincent, \& Richard C. Vincent. U.S. Glasnost: Missing Political Themes in U.S. Media Discourse. Cresskill, NJ: Hampton Pres, Inc., 2004. Print. 
Gelder, Ken. "Epic Fantasy and Global Terrorism." From Hobbits to Hollywood: Essays on Peter Jackson's Lord of the Rings. Ed. Ernest Mathijs and Murray Pomerance. New York, NY: Rodopi, 2006. 101-118. Print.

Gerbner, George, Michael Morgan, and Nancy Signorielli. "Television Violence Profile 16: The Turning Point from Research to Action." George Gerbner Archive. Annenberg School for Communication at University of Pennsylvania, December 1993. 38 pages. Web. 1 Apr 2011.

$<$ http://www.asc.upenn.edu/gerbner/archive.aspx?sectionID=155\&packagelD=6 23>

Gilman, Sander L. "Black Bodies, White Bodies: Toward an Iconography of Female Sexuality in Late Nineteenth-Century Art, Medicine, and Literature." Critical Inquiry 12.1 (1985): 204-242. Print.

Godfrey, Esther. "'To Be Real': Drag, Minstrelsy and Identity in the New Millennium." Genders 41 (2005): n. pag. Web. 1 Mar. 2011. <http://www.genders.org/g41/g41_godfrey.html>

Goldberg, Ruth, and Krin Gabbard. "'What does the Eye Demand': Sexuality, Forbidden Vision and Embodiment in The Lord of the Rings." From Hobbits to Hollywood: Essays on Peter Jackson's Lord of the Rings. Ed. Ernest Mathijs \& Murray Pomerance. New York, NY: Rodopi, 2006. 267-281. Print.

The Grinch Production Notes. Universal City, CA: Universal Pictures, 2000. Print.

Grondin, David. "Introduction: Coming to Terms with America's Liberal Hegemony/Empire." Hegemony or Empire? The Redefinition of US Power under George W. Bush. Eds. Charles-Philippe David \& David Grondin. Hampshire, UK: Ashgate Publishing Limited, 2006.

Guerrero, Ed. Framing Blackness: The African American Image in Film. Philadelphia, PA: Temple University Press, 1993. Print.

Hadaway, C Kirk, and Penny Long Marler, and Mark Chaves. "What the Polls Don't Show: A Closer Look at U.S. Church Attendance." American Sociological Review, 58.6 (1993): 741-752. Print.

Hall, Sheldon, and Steve Neale. Epics, Spectacles, and Blockbusters: A Hollywood History. Detroit, MI. Wayne State University Press, 2010. Print.

Hammond, Michael. "Some Smothering Dreams: The Combat Film in Contemporary Hollywood." Genre and Contemporary Hollywood. Ed. Steve Neale. London, UK: British Film Institute, 2002. 62-76. Print. 
Harris, Hilary. "Failing 'White Woman': Interrogating the Performance of Respectability." Theatre Journal 52.2 (2000): 183-209. Print.

Hasian, Jr., Marouf. "Nostalgic Longings, Memories of the "Good War," and Cinematic Representations in Saving Private Ryan." Criticial Studies in Media Communication 18.3 (2001): 338-358. Print.

Hegel, Georg Wilhelm Friedrich. Lectures on the Philosophy of World History. Ed. Johannes Hoffmeister. Trans. H. B. Nisbet. Cambridge, UK: Cambridge University Press, 1975. Print.

Hobbes, Thomas. Leviathan. Rev. Student ed. Ed. Richard Tuck. Cambridge, UK: Cambridge University Press, 1996. Print.

Hobby, Teresa Santerre. "Independence Day: Reinforcing Patriarchal Myths about Gender and Power." The Journal of Popular Culture 34.2 (2000): 39-55. Print.

Hofstadter, Richard. "The Paranoid Style in American Politics." Harper's Magazine Nov. 1964: 77-86. Print.

hooks, bell. Where We Stand: Class Matters. New York, NY: Routledge, 2000. Print. Imbusch, Peter. "The Concept of Violence." International Handbook of Violence Research. Eds. Wilhelm Heitmeyer \& John Hagan. AH Dordrecht, Neth.: Kluwer Academic Publishers, 2003. 13-40. Print.

Ivie, Robert L. "Images of Savagery in American Justifications for War." Communication Monographs 47 (Nov 1980): 279-291. Print.

Jameson, Fredric. "Postmodernism and Consumer Society." Postmodernism and its Discontents: Theories, Practices. Ed. E. Ann Kaplan. London, UK: Verso, 1988. 13-29. Print.

---. The Cultural Turn: Selected Writings on the Postmodern 1983-1998. London, UK: Verso, 1998. Print.

Jancovich, Mark. Rational Fears: American Horror in the 1950s. Manchester, UK: Manchester University Press, 1996. Print.

Jeffords, Susan. Hard Bodies: Hollywood Masculinity in the Reagan Era. New Brunswick, NJ: Rutgers University Press, 1994. Print.

Johnson, Chalmers. Blowback. New York, NY: Time Warner, 2002.

Kakoudaki, Despina. "Spectacles of History: Race Relations." Camera Obscura 17.2 (2002): 108-153. Print. 
Kaplan, Robert. "The Coming Anarchy." The Atlantic Monthly. Feb. 1994: 44-76. Print.

Keane, Stephen. Disaster Movies: The Cinema of Catastrophe. $2^{\text {nd }}$ ed. London, UK: Wallflower Press, 2006. Print.

Kendrick, James. Film Violence: History, Ideology, Genre. London, UK: Wallflower Press, 2009. Print.

Kellner, Douglas. Media Culture. New York, NY: Routledge, 1995. Print.

---. "The X-Files and Conspiracy." Conspiracy Nation: The Politics of Paranoia in Postwar America. Ed. Peter Knight. New York, NY: New York University Press, 2002. 205-232. Print.

---. "The Lord of the Rings as Allegory: A Multiperspectivist Reading." From Hobbits to Hollywood: Essays on Peter Jackson's Lord of the Rings. Ed. Ernest Mathijs \& Murray Pomerance. Amsterdam: Rodopi, 2006. 17-39. Print.

Kennedy, John F. "Rice University, 12 September 1962." John F. Kennedy Presidential Library and Museum. John F. Kennedy Presidential Library and Museum, 12 Sep. 1962. Web. 1 Feb. 2011. <http://www.jfklibrary.org/AssetViewer/Archives/USG-15-r29.aspx>

King, Geoff. Spectacular Narratives: Hollywood in the Age of the Blockbuster. London, UK: I.B. Tauris \& Co Ltd, 2000. Print.

---. "Spectacle, narrative, and the spectacular Hollywood blockbuster." Movie Blockbusters. Ed. Julian Stringer. London, UK: Routledge, 2003. 114-127. Print.

Klare, Michael T. "The Clinton Doctrine." The Nation. The Nation, 19 Apr. 1999. Online. 1 Jan. 2011. <http://www.thenation.com/article/clinton-doctrine>

Klinger, Barbara. Beyond the Multiplex: Cinema, New Technologies, and the Home. Berkeley, CA: University of California Press, 2006. Print.

Kodat, Catherine Gunther. "Saving Private Property: Steven Spielberg's American DreamWorks." Representations 71 (2000): 77-105. Print.

Koh, Wilson. "Everything old is good again: Myth and nostalgia in Spider-Man." Continuum 23.5 (2009): 735-747. Print.

Krämer, Peter. "'Want to take a ride?': reflections on the blockbuster experience of Contact (1997)." Movie Blockbusters. Ed. Julian Stringer. London, UK: Routledge, 2003. PAGES. Print. 
Krauthammer, Charles. "The Bush Doctrine: ABM, Kyoto, and the New American Unilateralism." The Weekly Standard 6.36 (2001): 21 (46 par.). LexisNexis Acadmeic. Online. 14 Jan. 2011.

Kunkel, Dale, Barbara Wilson, Edward Donnerstein, Daniel Linz, Stacy Smith, Timothy Gray, Eva Blumenthal, and W. James Potter. "Measuring Television Violence: The Importance of Context." Journal of Broadcasting \& Electronic Media. 39.2 (1995): 284-291. Print.

Kuypers, Jim A. Bush's War: Media Bias and Justifications for War in a Terrorist Age. Lanham, MD: Rowman \& Littlefield Publishers, Inc., 2006. Print.

Lefeber, Walter. "The Bush Doctrine." Diplomatic History 26.4 (Dec 2002): 543-558. Print. <http://onlinelibrary.wiley.com/doi/10.1111/1467-7709.00326/pdf>

Leo, John. "Fu Manchu on Naboo." U.S. News and World Report. 12 Jul. 1999: 14. Print.

Lipton, Eric. "Giuliani Says City Was Prepared on 9/11." The New York Times. The New York Times Company. 29 Sep. 2002. Web. 14 Jan. 2011. <http://www.nytimes.com/2002/09/29/nyregion/giuliani-says-city-wasprepared-on-9-11.html?src=pm>

Lubin, David M. Titanic. London, UK: British Film Institute, 1999. Print.

Lucas, George, and Bill Moyers. "Of Myth and Men." Time, 18 Apr. 1999. Web. 26 Nov. 2010. <http://www.time.com/time/magazine/article/0,9171,232982,00.html>

Machiavelli, Niccolò. The Prince. $2^{\text {nd }}$ Ed. Trans. Harvey C. Mansfield. Chicago, IL: University of Chicago Press, 1998. Print.

Mair, Jan. "Rewriting the 'American Dream': Postmodernism and Otherness in Independence Day." Aliens R Us: The Other in Science Fiction Cinema. Ed. Ziauddin Sardar and Sean Cubitt. London, UK: Pluto Press, 2002. 34-50. Print.

Mattina, Anne F. "Hillary Rodham Clinton: Using Her Vital Voice." Inventing a Voice: The Rhetoric of American First Ladies of the Twentieth Century. Ed. Molly Meijer Wertheimer. Lanham, MD: Rowman \& Littlefield, 2004. 417-434. Print.

McDowell, John C. The Gospel According to Star Wars: Faith, Hope, and the Force. Louisville, KY: Westminster John Knox Press, 2007. Print.

McLarty, Lianne. "Masculinity, Whiteness, and Social Class in The Lord of the Rings." From Hobbits to Hollywood: Essays on Peter Jackson's Lord of the Rings. 
Eds. Ernest Mathijs \& Murray Pomerance. New York, NY: Rodopi, 2006. 173-188. Print.

McQuillan, Laurence. "White House to move to Texas for a while." USA Today.com. USA TODAY, 3 Aug. 2001. Web. 1 Feb. 2011.

<http://www.usatoday.com/news/washington/august01/2001-08-03-bushvacation.htm>

Megadeth. Peace Sells... but Who's Buying? Capital Records, 1986. CD.

Merskin, Deborah. "The Construction of Arabs as Enemies: Post-September 11 Discourse of George W. Bush." Mass Communication \& Society 7(2): 157-175. Print.

Metcalf, Greg. "'It's (Christmas) Morning in America:' Christmas Conventions of American Films in the 1980s." Beyond the Stars: Studies in American Popular Film. Eds. Paul Loukides \& Linda K. Fuller. Vol 2. Bowling Green, OH: Bowling Green State University Popular Press, 1991. 100-113. Print.

Metz, Christian. The Imaginary Signifier. Trans. Ben Brewster, Celia Britton, Annwyl Williams, Alfred Guzzetti. Bloomington, IN: Indiana University Press, 1982. Print.

Milbank, John. "Sovereignty, Empire, Capital, and Terror." The South Atlantic Quarterly. 101.2 (2002): 305-323. Print.

Morgenstern, Joe. "The Plot Limps Behind in 'Saving Private Ryan'." The Wall Street Journal, July 24, 1998.

---. "A 'Grinch' That's Two Sizes Too Tall Is No Fun at All." The Wall Street Journal. Dow Jones \& Company, Inc., 18 Nov. 2000. Web. 20 Aug. 2010. <http://online.wsj.com/article/NA_WSJ_PUB:SB974427903973290764.html>

Mulvey, Laura. Visual and Other Pleasures. 2nd ed. New York, NY: Palgrave Macmillan, 2009. Print.

Murray, Gabrielle. "Post-9/11 and Screen Violence." Understanding Violence: Contexts and Portrayals. Eds. Marika Guggisberg and David Weir. Oxford, UK: Interdisciplinary Press, 2009. 3-13. Print.

North, Dan. "Kill Binks: Why the World Hated Its First Digital Actor." In Culture, Identities and Technology in the Star Wars Films: Essays on the Two Trilogies. Ed. Carl Silvio and Tony M Vinci. Jefferson, NC: McFarlane \& Company, Inc., Publishers, 2007. 155-174. Print.

O'Donnell, Patrick. Latent Destinies: Cultural Paranoia and Contemporary U.S. Narrative. Durham, NC: Duke University Press, 2000. Print. 
Owen, A Susan. "Memory, War and American Identity: Saving Private Ryan as American Jeremiad." Critical Studies in Media Communication 19.3 (September 2002): 249-282. Print.

Paramount Pictures. "Handbook of Production Information: Titanic." Paramount Pictures \& Twentieth Century Fox, 1997. Print.

Parekh, Bhikhu. "Marxism and the Problem of Violence." Development and Change 23.3 (July 1992): 103-120. Print.

Peaslee, Robert. "'With Great Power Comes Great Responsibility': Central psychoanalytic motifs in Spider-Man and Spider-Man 2." PSYART: An Online Journal for the Psychological Study of the Arts. Article 050720 (12 May 2005). Online. 14 Jan. 2011. <http://www.clas.ufl.edu/ipsa/journal/2005_peaslee01.shtml>

"President Bush's Approval Ratings." Chart. Washingtonpost.com. The Washington Post Company, 20 Jan. 2009. Web. 14 Jan. 2011.

$<$ http://www.washingtonpost.com/wpdyn/content/custom/2006/02/02/CU2006020201345.html>

Prince, Stephen. "Graphic Violence in the Cinema; Origins, Aesthetic Design, and Social Effects." Screening Violence. Ed. Stephen Prince. New Brunswick, NJ: Rutgers University Press, 2000. 1-44. Print.

---. "Why Do Film Scholars Ignore Movie Violence?" The Chronicle of Higher Education, 10 Aug. 2001 Web. 1 Apr 2011. <http://chronicle.com/article/WhyDo-Film-Scholars-Ignore/14075>

The Project for the New American Century. Statement of Principles. 3 Jun. 1997. Web. 1 Apr. 2011. <http://www.newamericancentury.org/statementofprinciples.htm>

---. Rebuilding America's Defenses: Strategy, Forces and Resources For a New Century. Sep. 2000. Web. 31 Jan. 2011. <http://www.newamericancentury.org/RebuildingAmericasDefenses.pdf>

Propp, Vladimir. Morphology of the Folktale. Trans. Laurence Scott. Second ed. London, UK: University of Texas Press, 1968. Print.

Redmond, Sean. "Titanic: Whiteness on the High Seas of Meaning." The Titanic in Myth and Memory. Ed. Tim Bergfelder and Sarah Street. London, UK: I.B. Tauris \& Co Ltd, 2004. 197-204. Print.

Rice, Condoleezza, and Wolf Blitzer. "CNN Late Edition with Wolf Blitzer: Interview With Condoleezza Rice; Pataki Talks About 9-11; Graham, Shelby Discuss War on 
Terrorism." CNN.com. Time Warner. 8 Sep. 2002. Web. 1 Mar. 2011.

<http://transcripts.cnn.com/TRANSCRIPTS/0209/08/le.00.html>

Richardson, Niall. "The Gospel According to Spider-Man." The Journal of Popular Culture 37.4 (2004): 694-703. Print.

Roback, Diane, and Jason Britton, and Debbie Hochman Turvey. "All-Time Bestselling Children's Books." Publishers Weekly 17 Dec. 2001: 24-32. Print.

Robinson, Walter [Ritoku]. "The Far East of Star Wars." Star Wars and Philosophy: More Powerful than you Can Possibly Imagine. Eds. Kevin S. Decker \& Jason T. Eberl. Peru, IL: Open Court Publishing Company, 2005. Print.

Rogin, Michael. Independence Day, or How I Learned to Stop Worrying and Love the Enola Gay. London, UK: British Film Institute, 1998. Print.

Roosevelt, Franklin D. "Our Documents: Franklin Roosevelt's Annual Address to Congress - The "Four Freedoms." Fdrlibrary.marist.edu. Franklin D. Roosevelt Presidential Library and Museum. 6 Jan. 1941. Web. 1 Mar. 2011. <http://docs.fdrlibrary.marist.edu/od4frees.html>

Ross, Andrew. "Ballots, bullets, or Batmen: can cultural studies do the right thing?" Screen 31.1 (1990): 26-44. Print.

Ruppersberg, Hugh. "The Alien Messiah." Alien Zone: Cultural Theory and Contemporary Science Fiction Cinema. Ed. Annette Kuhn. London, UK: Verso, 1990. 32-38. Print.

Ryan, Michael, and Douglas Kellner. Camera Politica: The Politics and Ideology of Contemporary Hollywood Film. Bloomington, IN: Indiana University Press, 1988. Print.

Sardar, Ziauddin. "Introduction." Aliens R Us: The Other in Science Fiction Cinema. Ed. Ziauddin Sardar and Sean Cubitt. London, UK: Pluto Press, 2002. 1-17. Print.

Sartre, Jean-Paul. "Preface to Frantz Fanon's Wretched of the Earth." Violence in War and Peace: An Anthology. Eds. Nancy Scheper-Hughes and Philippe Bourgois. Malden, MA: Blackwell Publishing Ltd, 2004. 229-235. Print.

Schaefer, Nancy A. "Y2K as an Endtime Sign: Apocalypticism in America the finde-millenium." The Journal of Popular Culture, 38.1 (2004): 82-105. Print.

Schaffer, Bill. "Just Like a Movie: September 11 and the Terror of Moving Images." Senses of Cinema 17 (2001): n. pag. Web. 1 Apr. 2011. <http://archive.sensesofcinema.com/contents/01/17/symposium/schaffer.html $>$ 
Schultz, Rick. "James Cameron tells the astonishing story of Titanic, his breathtaking labor of love." IndustryCentral. IndustryCentral.net. n.d. Web. 15 Mar. 2010. <http://www.industrycentral.net/director_interviews/JC01.HTM>

Sedgwick, Eve Kosofky. "Queer Performativity: Henry James's 'The Art of the Novel."' GLQ: A Journal of Lesbian and Gay Studies 1.1 (1993): 1-18. Print.

Shaheen, Jack G. Reel Bad Arabs: How Hollywood Vilifies a People. New York, NY: Olive Branch Press, 2001. Print.

Sharrett, Christopher. " $9 / 11$, the Useful Incident, and the Legacy of the Creel Committee." Cinema Studies. 43.4 (2004): 125-131. Print.

Silverman, Kaja. The Acoustic Mirror: The Female Voice in Psychoanalysis and Cinema. Bloomington, IN: Indiana University Press, 1988. Print.

Slocum, J. David. "Introduction: Violence and American Cinema: Notes for an Investigation." Violence and American Cinema. Ed. J. David Slocum. New York, NY: Routledge, 2001. 1-34. Print.

---. 'The 'film violence' trope: New Hollywood, 'the Sixties,' and the politics of history." New Hollywood Violence. Ed. Steven Jay Schneider. Manchester, UK: Manchester University Press, 2004. 13-33. Print.

Slotkin, Richard. Gunfighter Nation: The Myth of the Frontier in Twentieth-Century America. New York, NY: HarperPerennial, 1993. Print.

Sobchack, Vivian. "The Violent Dance: A Personal Memoir of Death in the Movies." Screening Violence. Ed. Stephen Prince. New Brunswick, NJ: Rutgers University Press, 2000. 110-124. Print.

---. "Thinking through Jim Carrey." More Than a Method: Trends and Traditions in Contemporary Film Performance. Eds. Cynthia Baron, Diane Carson \& Frank P. Tomasulo. Detroit, MI: Wayne State University Press, 2004. 275-296. Print.

Sontag, Susan. "The Imagination of Disaster." Commentary (Oct 1965): 42-48. Print.

"Star Wars The Phantom Menace Teaser HD." YouTube. Aug 10, 2009. Web. 26 Nov 2010. < http://www.youtube.com/watch?v=sYkHD9y8Eql>

Stevenson, Richard W. "Iraq Illicit arms gone before the war, inspector states." Nytimes.com. The New York Times, 24, Jan. 2004. Web. 31 Jan 2011. <http://www.nytimes.com/2004/01/24/world/iraq-illicit-arms-gone-before-warinspector-states.html> 
Stringer, Julian. "Introduction." Movie Blockbusters. Ed. Julian Stringer. London, UK: Routledge, 2003. 1-14. Print.

Suskind, Ron. "Without a Doubt." New York Times Magazine 17 Oct. 2004: 44-106. Print.

Taubin, Amy. "Playing it Straight." Sight \& Sound VI.8 (1996): 6-8. Print.

Thompson, Kirsten Moana. Apocalyptic Dread: American film at the turn of the millennium. Albany, NY: State University of New York Press, Albany, 2007. Print.

Tomasulo, Frank P. "Empire of the Gun: Steven Spielberg's Saving Private Ryan and American Chauvinism." The End of Cinema As We Know It: American Film in the Nineties. Ed. Jon Lewis. London, UK: Pluto Press, 2001. 115-130. Print.

Turner, Graeme. Film as Social Practice. $3^{\text {rd }}$ ed. London, UK: Routledge, 1999. Print.

United States. Office of the Inspector General. A Review of the FBI's Handling of Intelligence Information Prior to the September 11 Attacks. Jun. 2005. Web. 1 Mar 2011. <http://www.justice.gov/oig/special/0506/index.htm>

---. The White House. The National Security Strategy of the United States of America. Sep. 2002. Web. 1 Mar. 2011.

<http://www.au.af.mil/au/awc/awcgate/nss/nss_sep2002.pdf>

Uniting and Strengthening America by Providing Appropriate Tools Required to Intercept and Obstruct Terrorism (USA PATRIOT ACT) Act of 2001. HR 3162 RDS. 24 Oct. 2001. Web. 1 Jan. 2011

<http://epic.org/privacy/terrorism/hr3162.html>

Universal Pictures. The Grinch. Universal City, CA: Universal Pictures, 2000. Print.

"War Against America: [EDITION: PM =]." San Francisco Chronicle: A.12. ProQuest Central. 2001. Web. 10 Apr. 2011 <http://search.proquest.com/docview/411520336?accountid=14782>.

Welch, Michael. Scapegoats of September $11^{\text {th }}$ : Hate Crimes \& State Crimes in the War on Terror. Piscataway, NJ: Rutgers University Press, 2006. Print.

Wetmore Jr., Kevin J. The Empire Triumphant: Race, Religion and Rebellion in the Star Wars Films. Jefferson, NC: McFarland \& Company, Inc. Publishers, 2005. Print.

"West Wing Loyalty: A Fine Line." Editorial. Christian Science Monitor. 17 Dec. 2002: 8 (10 par.). LexisNexis Academic. Online. 14 Jan. 2011. 
Westheimer, Ruth, \& Ben Yagoda. The Value of Family: A Blueprint for the $21^{\text {st }}$ Century. New York, NY: Warner Books, 1996. Print.

Westwell, Guy. War Cinema: Hollywood on the Front Line. London, UK: Wallflower Press, 2006. Print.

Whitehead, John W., and Steven H. Aden. “Forfeiting 'Enduring Freedom' for 'Homeland Security': A Constitutional Analysis of the USA PATRIOT Act and the Justice Department's Anti-Terrorism Initiatives." American University Law Review 51.6 (2002): 1081-1133. Print.

Windolf, Jim. "Star Wars: The Last Battle." Vanity Fair Feb. 2005: 108-121. Print.

Winn, J Emmett. The American Dream and Contemporary Hollywood Cinema. London, UK: The Continuum International Publishing Group Ltd, 2007. Print.

Wolff, Edward N. "Recent Trends in Household Wealth in the United States:Rising Debt and the Middle-Class Squeeze-an Update to 2007 (Working Paper No. 589)." Levy Economics Institute of Bard College. Mar. 2010. Web. 1 Mar. 2011. <http://www.levyinstitute.org/publications/?docid=1235>

Wolfowitz, Paul. "Standup of U.S. Northern Command." Defense.gov. U.S. Department of Defense, 1 Oct. 2002. Web. 1 Apr 2011. <http://www.defense.gov/speeches/speech.aspx?speechid=292>

Wojcik, Daniel. The End of the World as We Know It: Faith, Fatalism, and Apocalypse in America. New York, NY: New York University Press, 1997. Print.

Wuthnow, Robert. Communities of Discourse: Ideology and Social Structure in the Reformation, the Enlightenment, and European Socialism. Cambridge, MA: Harvard University Press, 1989. Print.

Wyatt, Justin. High Concept: Movies and Marketing in Hollywood. Austin, TX: University of Texas Press, 1994. Print.

Ẑiżek, Slavoj. Violence: Six Sideways Reflections. London, UK: Profile Books LTD, 2008. Print.

Zuckoff, Mitchell, and Matthew Brelis. "Thousands Feared Dead After Planes Hit Towers, Pentagon: [Third Edition]." Boston Globe: A.1. ProQuest Central. 2001. Web. 10 Apr. 2011 <http://search.proquest.com/docview/405407169?accountid=14782>. 


\section{Films Cited}

Alice in Wonderland. Dir. Tim Burton. Walt Disney Studios Motion Pictures, 2010. Film.

American Graffiti. Dir. George Lucas. Universal Pictures, 1973. Film Armageddon. Dir. Michael Bay. Buena Vista Pictures, 1998. Film.

Avatar. Dir. James Cameron. Twentieth Century Fox, 2009. Film.

Beach Red. Dir. Cornel Wilde. United Artists, 1967. Film.

The Birth of a Nation. Dir. D.W. Griffith. David W. Griffith Corp., 1915. Film

Bound. Dir. The Wachowski Brothers. Gramercy Pictures, 1996. Film.

The Boy with the Green Hair. Dir. Joseph Losey. RKO Pictures, 1948. Film.

The Bridge on the River Kwai. Dir. David Lean. Columbia Pictures, 1957. Film.

Charlie's Angels. Dir. McG. Columbia Pictures, 2000. Film.

The Chronicles of Narnia: The Lion, the Witch, and the Wardrobe. Dir. Andrew Adamson. Buena Vista Pictures, 2005.

Courage Under Fire. Dir. Edward Zwick. Twentieth Century Fox, 1996. Film.

Do the Right Thing. Dir. Spike Lee. Universal Pictures, 1989. Film.

Dr. Seuss' How the Grinch Stole Christmas. Dir. Ron Howard. Imagine Entertainment, 2000. Film.

First Blood. Dir. Ted Kotcheff. Orion Pictures Corporation, 1982. Film.

Gremlins. Dir. Joe Dante. Warner Brothers Pictures, 1984. Film.

The English Patient. Dir. Anthony Minghella. Miramax Films, 1996. Film.

Harry Potter and the Chamber of Secrets. Dir. Chris Columbus. Warner Bros. Pictures, 2002. Film.

Harry Potter and the Deathly Hallows Part I. Dir. David Yates. Warner Bros. Pictures, 2010. Film.

Harry Potter and the Sorcerer's Stone. Dir. Chris Columbus. Warner Bros. Pictures, 2001. Film. 
Independence Day. Dir. Roland Emmerich. Twentieth Century Fox, 1996. Film. Iron Man 2. Dir. Jon Favreau. Paramount Pictures, 2010. Film.

King Kong. Dirs. Cooper, Merian C. \& Ernest B. Schoedsack. RKO Radio Pictures, 1933. Film.

King Kong. Dir. Peter Jackson. Universal Pictures, 2005. Film.

Little Shop of Horrors. Dir. Franz Oz. The Geffen Company, 1986. Film.

Lord of the Rings: The Fellowship of the Ring. Dir. Peter Jackson. New Line Cinema, 2001. Film.

Lord of the Rings: The Return of the King. Dir. Peter Jackson. New Line Cinema, 2003. Film.

Lord of the Rings: The Two Towers. Dir. Peter Jackson. New Line Cinema, 2002. Film. A Night to Remember. Dir. Roy Ward Baker. Rank Film Distributors, 1958. Film. Poltergeist. Dir. Tobe Hooper. MGM/UA Entertainment Company, 1982. Film Rambo: First Blood Part II. Dir. George P. Cosmatos. TriStar Pictures, 1985. Film. Red Ball Express. Dir. Budd Boetticher. Universal Pictures, 1952. Film. Red Dawn. Dir. John Milius. MGM/UA Entertainment Company, 1984. Film. The Sands of Iwo Jima. Dir. Allan Dwan. Republic Pictures, 1949. Film. Saving Private Ryan. Dir. Steven Spielberg. DreamWorks Distribution, 1998. Film. Schindler's List. Dir. Steven Spielberg. Universal Pictures, 1993. Film.

Shrek. Dir. Andrew Adamson \& Vicky Jenson. DreamWorks Distribution, 2001. Film. Shrek 2. Dir. Andrew Adamson, Kelly Asbury \& Conrad Vernon. DreamWorks Distribution. Film.

Spider-Man. Dir. Sam Raimi. Columbia Pictures, 2002. Film.

Star Wars. Dir. George Lucas. Twentieth Century Fox, 1977. Film.

Star Wars: Episode 1 - The Phantom Menace. Dir. George Lucas. Twentieth Century Fox, 1999. Film.

Star Wars: Episode 2 - Attack of the Clones. Dir. George Lucas. Twentieth Century Fox, 2002. Film. 
Starship Troopers. Dir. Paul Verhoeven. TriStar Pictures \& Touchstone Pictures, 1997. Film.

Top Gun. Dir. Tony Scott. Paramount Pictures, 1986. Film.

Titanic. Dir. Robert Lieberman. Columbia Broadcasting System, 1996. Film.

Titanic. Dir. James Cameron. Paramount Pictures, 1997. Film.

Top Gun. Dir. Tony Scott. Paramount Pictures, 1986. Film.

Toy Story 3. Dir. Lee Unkrich. Walt Disney Studios Motion Pictures, 2010. Film.

The Twilight Saga: Eclipse. Dir. David Slade. Summit Entertainment, 2010. Film.

Twister. Dir. Jan de Bont. Warner Bros. Pictures, 1996. Film.

The Usual Suspects. Dir. Bryan Singer. Gramercy Pictures, 1995. Film.

Volcano. Dir. Mick Jackson. Twentieth Century Fox Film Corporation, 1997. Film. 